\title{
Insider Threat Mitigation Workshop Instructional Materials
}

Philip Gibbs/Brookhaven National Laboratory Robert Larsen/Los Alamos National Laboratory Mike O’Brien/Lawrence Livermore National Laboratory Jose Rodriguez/Sandia National Laboratory

January 2008 


\title{
BROOKHGWEN \\ NATIONAL LABORATORY
}

BNL-106059-2008-IR

Insider Threat Mitigation Workshop Instructional Materials

\author{
Philip Gibbs \\ Brookhaven National Laboratory \\ Robert Larsen \\ Los Alamos National Laboratory \\ Mike O’Brien \\ Lawrence Livermore National Laboratory \\ Jose Rodriguez \\ Sandia National Laboratory
}

January 2008

Nonproliferation and National Security Department

Brookhaven National Laboratory

U.S. Department of Energy

National Nuclear Security Administration

Office of International Material Protection and Cooperation 


\section{DISCLAIMER}

This report was prepared as an account of work sponsored by an agency of the United States Government. Neither the United States Government nor any agency thereof, nor any of their employees, nor any of their contractors, subcontractors, or their employees, makes any warranty, express or implied, or assumes any legal liability or responsibility for the accuracy, completeness, or any third party's use or the results of such use of any information, apparatus, product, or process disclosed, or represents that its use would not infringe privately owned rights. Reference herein to any specific commercial product, process, or service by trade name, trademark, manufacturer, or otherwise, does not necessarily constitute or imply its endorsement, recommendation, or favoring by the United States Government or any agency thereof or its contractors or subcontractors. The views and opinions of authors expressed herein do not necessarily state or reflect those of the United States Government or any agency thereof.

Notice: This manuscript has been authored by employees of Brookhaven Science Associates, LLC under Contract No. DE-AC02-98CH10886 with the U.S. Department of Energy. The publisher by accepting the manuscript for publication acknowledges that the United States Government retains a non-exclusive, paid-up, irrevocable, worldwide license to publish or reproduce the published form of this manuscript, or allow others to do so, for United States Government purposes. 


\section{Executive Summary}

Insiders represent a formidable threat to nuclear facilities. This set of workshop materials covers methodologies to analyze and approaches to mitigate the threat of an insider attempting abrupt theft of nuclear materials.

This report is a compilation of workshop materials consisting of lectures on technical and administrative measures used in Physical Protection (PP) and Material Control and Accounting (MC\&A) and methods for analyzing their effectiveness against a postulated insider threat.

Presentation is envisioned to be through classroom instruction and discussion. Several practical and group exercises are included for demonstration and application of the analysis approach contained in the lecture/discussion sessions as applied to a hypothetical nuclear facility.

\section{Mode of Instruction}

The suggested mode of instruction for these materials is lecture, demonstrations, and small group exercises.

\section{Participants}

Participants attending this workshop should currently, or in the near future, be responsible for designing and/or analyzing PP or MC\&A systems. It is suggested that the ideal participant pool consist of a mix of PP, MC\&A, and vulnerability assessment (VA) professionals.

Workshop length - 5 training days 


\section{January (Monday)}

0900-0930 Introduction (Dr. Lui Daming and Mr. Dave Huizenga)

0930-1015 Lecture 1: Overview/Course Mechanics

1015-1030 Break

1030-1\$00 Lecture 2a: Insider Threat Administrative Measures .

[Exercise] Administrative Measures

1200-1300 Lunch

1300-1430 Lecture 2b: Insider Threat Technical Measures

[Exercise] Technical Measures

1430-1445 Break

1445-1630 Lecture 3: Introduce hypothetical facilities

\section{January (Tuesday)}

0900-1045 Lecture 4: Target Analysis

[Exercise] Identify Targets

1045-1100 Break

1100-1200 Lecture 5a: Insider Threat Overview

1200-1300 Lunch

1300-1430 Lecture 5b: Insider Characterization

[Exercise] Identify Insiders

1430-1445 Break

1445-1630 Lecture 6a: Path Analysis - Sequence of Actions

[Exercise] Development of path analyses 


\section{January (Wednesday)}

0900-1045 Lecture 6b: Path Analysis - Characterize Protection Measures

[Exercise] Development of path analyses

1045-1100 Break

1100-1200～Lecture 7: Scenario Development

1200-1300 Lunch

1300-1430 [Exercise] Scenario Development

1430-1445 Break

1445-1630 Lecture 8: Analyze or evaluate scenarios

[Exercise] Evaluate Scenarios

\section{January (Thursday)}

0900-1045 Lecture 9: Upgrade Analysis

1045-1100 Break

1100-1200 Lecture 10: Upgrade exercise and presentation

[Exercise] Upgrade Exercise and presentations

1200-1300 Lunch

1300-1600 [Exercise] Upgrade Exercise and presentations (continued from morning)

\section{January (Friday)}

0900-1045 Lecture 11: Maintaining system effectiveness

1045-1100 Break

1100-1200Ｌecture 12: Facilitated closing discussion 


\section{Insider Workshop Primer}

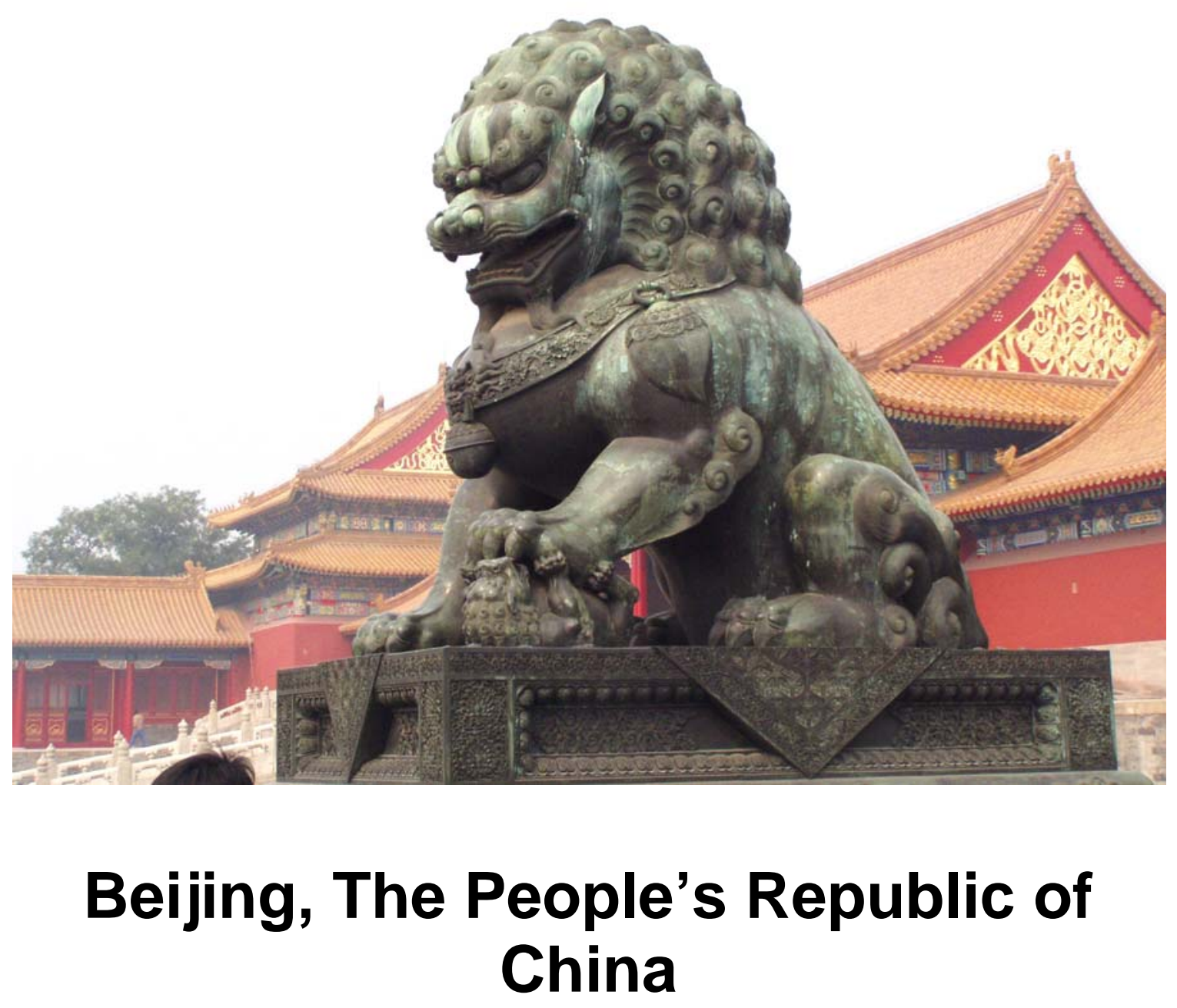

January XX, 2008 


\title{
PRIMER FOR THE INSIDER TRAINING COURSE \\ January XX, 2008
}

\author{
Basic Physical Protection Systems (PPS)
}

May 212007

\begin{abstract}
Background
Physical protection systems at different sites are seldom identical because of the differences in facilities, targets, and threats. The basic design for physical protection systems is quite well established but considerable engineering and design tailoring is usually required for each site. DOE and NNSA sites use DOE Order 470.4-2. This Manual establishes requirements for the physical protection of safeguards and security (S\&S) interests.
\end{abstract}

\section{Objectives}

The objectives of the physical protections system should be:

a. To establish conditions which would minimize the possibilities for unauthorized removal of nuclear material and/or for sabotage ; and

b. To provide information and technical assistance in support of rapid and comprehensive measures to locate and recover missing nuclear material and to cooperate with safety authorities in minimizing the radiological consequences of sabotage.

\section{PPS Functions: Detection, Delay, and Response}

An effective physical protection system integrates people, equipment, and procedures for the protection of assets or facilities against theft, sabotage, or other malevolent human attacks. Depending on the assets and possible targets in the facility, a probable type of adversary may be identified. Adversaries can be categorized into three main groups: outsiders, insiders, and outsiders working in collusion with insiders. Outsiders include terrorists, criminals, extremists, and hackers. An insider is considered anyone with knowledge of operations in the facility and who has unescorted access to security areas and sensitive information. An outsider that operates with insider assistance represents a great challenge for the security system since the insider can move around the facility without raising suspicion and can choose the best time to act. Regardless of these possibilities, the PPS must respond to the challenge and prevent an attack by bringing into effect its three main functions: detection, delay, and response.

\section{The Detection Function}

Detection is the discovery of an adversary action. It includes sensing of covert or overt intrusion activities. The following is a typical detection sequence:

1. A sensor reacts to a stimulus and initiates an alarm.

2. The information from the sensor is reported and displayed.

3. A person assesses the information and judges the alarm to be valid or invalid. (Note: detection without assessment is not considered detection.) 


\section{PRIMER FOR THE INSIDER TRAINING COURSE January XX, 2008}

An increasing number of exterior and interior sensors for intrusion detection are in the market today. They are designed to respond to specific stimuli and are classified according to whether they are active or passive, covert or visible, volumetric or line detection, line-of-sight or terrain following, and according to application modes. Some are associated with fences, others are buried, and others are freestanding such as infrared sensors and video motion detectors. All sensors are susceptible of generating invalid alarms, called nuisance alarms, which are caused by anything other than an intrusion. Invalid alarms caused by faulty equipment are called false alarms. Some sensors are of the type called dual technology because they respond to two different stimuli thereby reducing the probability of generating nuisance alarms. In interior environments, detection of moving objects or persons plays a very important role in physical security. Most common types are infrared and microwave sensors. For detection of entry through doors or windows, the most common types are electromechanical sensors such as magnetic switches and vibration detectors. Protection of large metallic objects is commonly done through proximity sensors where the metallic object itself becomes part of the detection system. Assessment of alarms is normally done with video cameras strategically located around the facility and aimed to probable targets. Additionally, video cameras can also be effectively used as motion sensors, in which case they are called video motion detectors, or VMDs. They can only be used as sensors, however, in places where there is no movement of objects or persons, such as in storage rooms or vaults. Entry control is also included in the detection function. It allows the entry and movement of authorized persons and materials and detects any attempt of unauthorized entry. There are many different technologies for entry control of personnel, but in essence, an entry control system verifies if the person trying to gain access into a facility is in reality who they claim they are. This is based on whether the person has a valid credential, or knows a valid personal identification number, or possesses the proper unique physical characteristic that matches the one on record. In other words, verification is done based on what you have, what you know, or what you are. Examples of credentials include photo ID badge, magnetic card, bar code card, and proximity card, with the last one being among the most secure credential systems these days. In increasing use recently, biometric identification systems make use of unique physical characteristics such as fingerprints, hand geometry, retinal pattern, speech recognition, and handwriting. Fingerprinting has been in use for many years and is considered one of the most reliable means of distinguishing one individual from another. With modern technology based on image processing and pattern recognition, automatic fingerprinting is now a common means for entry control. Another example of advanced technology is the retinal scan device, which recognizes the unique pattern of blood vessels in the retina of the eye. 


\section{PRIMER FOR THE INSIDER TRAINING COURSE January XX, 2008}

\section{The Delay Function}

This function provides elements of delay that slow down adversary progress. Delaying an adversary is an effective means of giving the response force adequate time to respond and interrupt the adversary. Delay elements are normally barriers in the form of fences, barbed concertina tape, reinforced walls and doors, cages around storage bins, heavy duty roll-up doors, to mention a few. Overall PPS effectiveness can be increased by placing sensors at delay points, preferably in a way that delay takes place right after detection to improve the assessment function. Delay before detection can only be a deterrent and not an effective measure because it does not provide additional time to respond to the adversary. Delay elements outside the facility, such as big boulders, trees and shrubbery, could force adversaries to change or abandon their tactic. Conventional construction is relatively weak for a highly motivated and welltrained attacker. Chain-link fences can only stop small vehicles but are totally ineffective against medium and large trucks. However, if an adversary encounters a series of progressively more difficult barriers, he will be forced to carry heavier equipment and tools that will contribute to increase the delay time. In any event, the most cost-effective means of improving the delay provided by a chain-link fence against climbing is to add a roll of BTC to the outriggers. Other forms of delay elements include reinforced concrete walls, special doors and windows, reinforced roofs and floors, and dispensable barriers. Dispensable barriers are those that are deployed only when necessary, that is, during an attack. They are normally foams or other chemical products that can delay or even totally immobilize an intruder. Due to their high cost, they are more appropriate to use near the asset to be protected, preferably in a closed area to contain the collateral contamination and reduce the clean up task.

\section{The Response Function}

The response function consists of the actions taken by the response force to prevent adversary success and includes: responding personnel, contingency planning, communication, and interruption. Responding personnel may include proprietary or contract guards, local and state police, and in some cases federal agencies such as the FBI, DEA, or Customs. Contingency planning is the development of well-documented procedures for identifying potential targets, respond to different threats, interact with outside agencies, and determine what level of force guards can use in different situations. Once potential targets are identified, security personnel can evaluate likely adversary routes and develop tactical plans to address various threats to the facility and to determine guard patrol routes and schedules. Procedures and plans for guard actions in the event of an adversary attack should be well established and practiced through periodic training exercises. If outside agencies are likely to participate in the response, joint training exercises should be planned and executed. Communication is a vital component of the response function since all other system functions depend heavily on proper communication between all responding personnel. Information must be transferred through this network with speed and accuracy. 


\section{PRIMER FOR THE INSIDER TRAINING COURSE January XX, 2008}

Communication to the response force must contain information about adversary actions and instructions for deployment. The most common means of communication to the response force is through clear-voice radios, normally of the FM (frequency modulation) type. Clear voice means that the signal has not been encrypted or encoded. As a result, however, eavesdropping on the part of adversaries is possible through the use of standard receivers or scanners. If an adversary can monitor a conventional radio transmission, they can also transmit deceptive messages with a conventional transmitter tuned to the same channel frequency. Another form of disturbing a radio transmission, known as jamming, can be done by inserting an unwanted signal into the channel that can mask a desired signal. If the jamming signal is of sufficient power, it can totally destroy the true signal making it unusable. Periodic jamming exercises should be established to practice procedures to counteract a jamming attack. Alternate means of communication, such as intercoms, public address, or cellular phones must be available at all times and everybody in the response force must know what to do in case of a jamming attack. One modern technology for counteracting eavesdropping, deception and jamming is the spreadspectrum or frequencyhopping communication system. In this system, the master transmitter makes the other receivers to follow it automatically from channel to channel as the message is transmitted. For any particular receiver in the system, the message is received like any other continuous message. For an intruder, however, the transmission is going to sound like bits and pieces making impossible the intelligibility of the message. The last segment of the response function is interruption, which is defined as the successful arrival in sufficient number of the response force at an appropriate location to confront the adversary. The probability of successful interruption can be enhanced by the use of deployment through known, protected paths. To measure the effectiveness of a PPS, a procedure called timely detection can be performed to obtain the probability of interruption based on cumulative delays and probabilities of detection along adversary paths. Timely detection consists in obtaining a cumulative probability of detection at a point in time and place where the remaining adversary time just exceeds the guard response time. In other words, at a point where there is still enough time left for the response force to interrupt the adversaries before their goal is completed. 
PRIMER FOR THE INSIDER TRAINING COURSE January XX, 2008

Integrated Physical Protection System

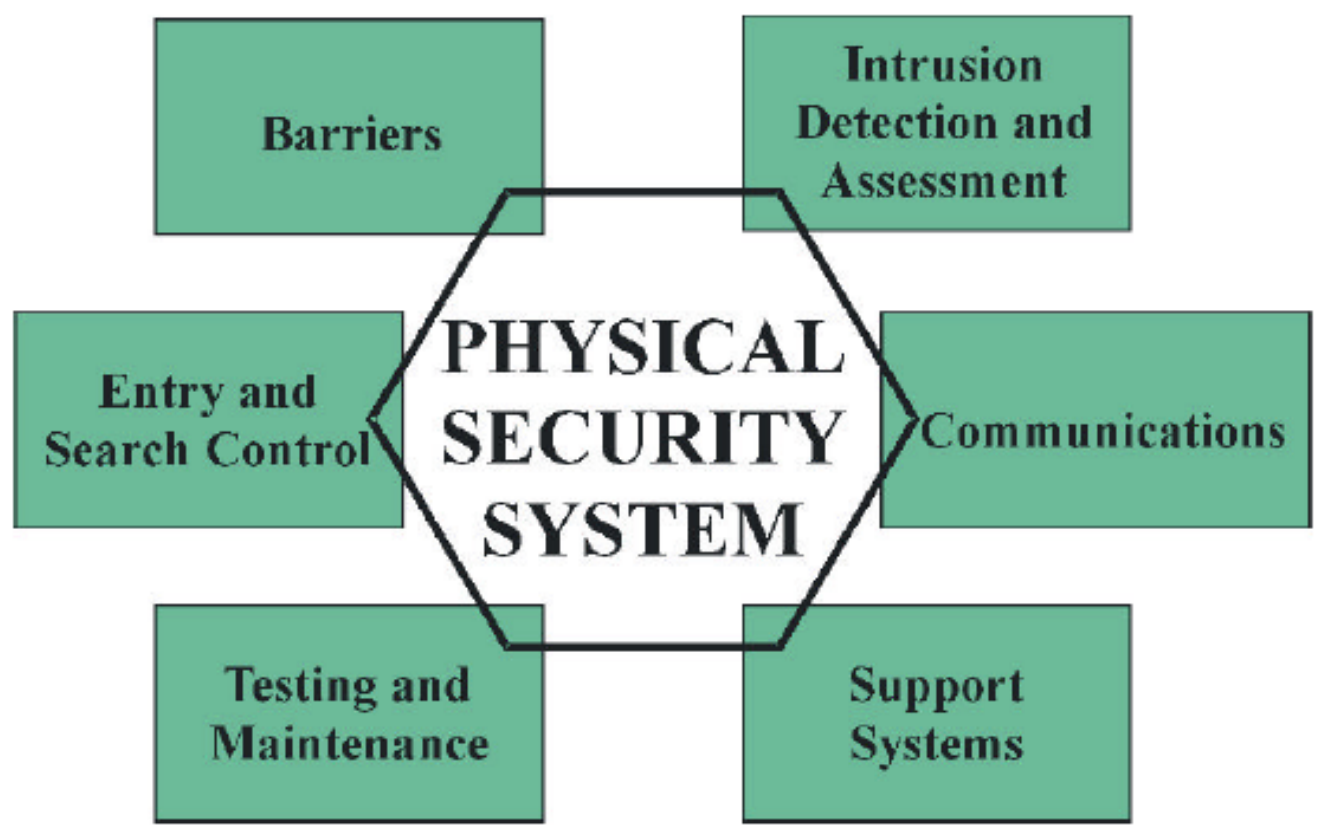




\section{PRIMER FOR THE INSIDER TRAINING COURSE January XX, 2008}

Schematic Adversary Path to an SNM Asset

Adversary

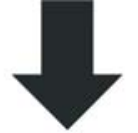

Outside

BARRIER (demarcation)

ECS

IDS (exterior)

LAYER 1

BARRIER (delay, assessment)

\section{BARRIER (demarcation)}

\section{ECS}

IDS (interior)

LAYER 2

\section{BARRIER (delay, assessment)}




\section{PRIMER FOR THE INSIDER TRAINING COURSE \\ January XX, 2008}

\section{DEFINITIONS:}

\section{ASSESSMENT:}

The determination by a guard or an electronic system of the cause of an alarm and the extent of the threat.

CENTRAL ALARM STATION:

An installation which provides for the complete and continuous alarm monitoring, assessment and communications with guards, facility management and the response force.

\section{DEFENCE IN DEPTH:}

A concept used to design physical protection systems that requires an adversary to overcome or circumvent multiple obstacles, either similar or diverse, in order to achieve his objective.

\section{DESIGN BASIS THREAT:}

The attributes and characteristics of potential insider and/or external adversaries, who might attempt unauthorized removal of nuclear material or sabotage, against which a physical protection system is designed and evaluated.

\section{GUARD:}

A person who is entrusted with responsibility for patrolling, monitoring, assessing, escorting individuals or transport, controlling access and/or providing initial response.

\section{INNER AREA:}

An area inside a protected area where Category I nuclear material is used and/or stored.

INTRUSION DETECTION:

Detection of an intruder by a guard or by a system comprising of a

\section{PATROL:} sensor(s), transmission medium and control panel to annunciate an alarm.

A function carried out by guards to inspect elements of physical protection at regular or irregular intervals.

\section{PHYSICAL BARRIER:}

A fence or wall or a similar impediment which provides penetration delay and complements access control.

PROTECTED AREA:

An area under surveillance, containing Category I or II nuclear material, and/or vital areas surrounded by a physical barrier.

\section{RESPONSE FORCES:}

Persons, on-site or off-site who are armed and appropriately equipped and trained to counter an attempted unauthorized removal of nuclear material or an act of sabotage.

\section{SABOTAGE:}

Any deliberate act directed against a nuclear facility or nuclear material in use, storage or transport which could directly or indirectly endanger the 


\section{PRIMER FOR THE INSIDER TRAINING COURSE January XX, 2008}

health and safety of personnel, the public and the environment by exposure to radiation or release of radioactive substances.

SECURITY SURVEY:

A detailed examination, made by the State s competent authority, of proposed physical protection measures in order to evaluate them for approval.

TRANSPORT:

International or domestic carriage of nuclear material by any means of transportation beginning with the departure from a facility of the shipper and ending with the arrival at a facility of the receiver.

TRANSPORT CONTROL CENTRE:

An installation which provides for the continuous monitoring of vehicle location and security status and for communication with the transport vehicle, its guards, the response forces and the shipper/receiver.

UNAUTHORIZED REMOVAL:

The theft or other unlawful taking of nuclear material.

VITAL AREA:

An area inside a protected area containing equipment, systems or devices, or nuclear material, the sabotage of which could directly or indirectly lead to unacceptable radiological consequences. 


\title{
PRIMER FOR THE INSIDER TRAINING COURSE \\ January XX, 2008
}

\author{
Basic Material Control and Accounting (MC\&A) Program
}

\section{GENERAL INFORMATION}

\section{A. PURPOSE}

The MC\&A program at a facility contain the MC\&A elements of a graded safeguards program. While every MC\&A program has as its objective the protection of nuclear materials (NM) assets, the program must also meet specific requirements defined by national and international agreements. A graded approach should be used to provide varying degrees of physical protection, materials accounting, and materials control to different types, quantities, physical forms, and chemical or isotopic compositions of nuclear material with the risks and consequences associated with the threat scenario. Specifically, the more attractive special nuclear materials (SNM) are to malevolent acts, the more stringent the controls are established.

\section{B. INTRODUCTION TO NUCLEAR ACCOUNTING AND CONTROL}

\section{Material Control}

Material control means the use of control and monitoring measures to prevent or detect loss when it occurs or soon afterward.

\section{Material Accounting}

Material accounting is defined as the use of statistical and accounting measures to maintain knowledge of the quantities of SNM present in each area of a facility. It includes the use of physical inventories and material balances to verify the presence of material or to detect the loss of material after it occurs, in particular, through theft by one or more insiders.

\section{OBJECTIVES OF MATERIAL ACCOUNTING AND CONTROL}

The primary objectives of the MC\&A system are to demonstrate that materials are present, to provide timely detection of material loss, and to define the locations of loss, should they ever occur. This is achieved through a MC\&A design the enables the facility to provide effective accounting and control for nuclear materials. 


\section{PRIMER FOR THE INSIDER TRAINING COURSE \\ January XX, 2008}

\section{BASIC CONCEPTS IN ACCOUNTING AND CONTROL}

Accounting for the nuclear material inventory involves performing:

Nuclear material measurements

Tracking and verifying the location and quantities of nuclear materials

Maintaining records and reports

Performing data analysis to account for and detect loss of nuclear material Investigate and resolve apparent loss of nuclear material

\section{E. DEFINITIONS}

\section{Protected Area (PA)}

A Security Area encompassed by physical barriers, surrounded by intrusion detection and assessment systems, and having access controls for the protection of Category II quantities of special nuclear material and/or to provide a concentric security zone surrounding a Material Access Area or Vital Area

Limited Area (LA)

A Security Area defined by physical barriers, used for the protection of classified matter and/or Category III quantities of special nuclear material, where protective personnel or other internal controls can prevent access by unauthorized persons to classified matter or special nuclear material.

Material Access Area (MAA)

A Security Area defined by physical barriers and subject to access control, used for the protection of Category I quantities of special nuclear material or Category II quantities of special nuclear material with credible rollup to Category I quantity. A Material Access Area shall be contained within a Protected Area and shall have separately defined physical barriers constructed to provide sufficient delay time to control, impede, or deter unauthorized access. Area boundaries shall conform to the layered protection concept with a separate Material Access Area located within a separate and distinct Protected Area. Material Access Areas shall direct the flow of personnel and vehicles through designated portals.

Material Balance Area (MBA)

Is an area with physical boundaries in which:

The quantity of nuclear material in transfers can be determined, A physical inventory can be determined, and

A Material Balance can be established and evaluated for.

Key Measurement Points (KMP)

Strategic locations at which measurements are made for loss detection analysis 


\section{PRIMER FOR THE INSIDER TRAINING COURSE \\ January XX, 2008}

Category I

Vault or process area (e.g., glovebox line), MBA, MAA, and Protected Area

U235 HEU > 5000g

$\mathrm{U} 233 / \mathrm{Pu}>2000 \mathrm{~g}$

Category II

Vault-type room or authorized process area, MBA, and Protected area

U235 HEU < 5000g and $>1000 \mathrm{~g}$

$\mathrm{U} 233 / \mathrm{Pu}<2000 \mathrm{~g}$ and $>500 \mathrm{~g}$

Category III

Locked alarmed storage location or patrolled at intervals not to exceed 8 hours, MBA, and Limited security area

U235 HEU $<1000 \mathrm{~g}$ and $>15 \mathrm{~g}$

$\mathrm{U} 233 / \mathrm{Pu}<500 \mathrm{~g}$ and $>15 \mathrm{~g}$

Category IV

Locked storage location, Material balance area, and Limited security area

and/or property protection

U235 HEU $<15 \mathrm{~g}$

$\mathrm{U} 233 / \mathrm{Pu}<15 \mathrm{~g}$

Note! US Nuclear Material Categorization

Human Reliability Program (HRP)

A Human Reliability Program (HRP), is designed to meet the objective of protecting the national security through a system of continuous evaluation of individuals working in positions affording unescorted access to certain materials, facilities, Information, and programs. The purpose of this continuous evaluation is to identify in a timely manner individuals whose judgment may be impaired by physical and/or emotional disorders, the use of illegal drugs or the abuse of legal drugs or other substances, the abuse of alcohol, or any other condition or circumstance that may represent a reliability, safety, and/or security concern.

\section{SECTION 1 - MATERIALS ACCOUNTING}

\section{ACCOUNTING SYSTEM}

a. The nuclear accounting system tracks the nuclear material inventories, accurately documents all transactions, and issues periodic reports. The system provides a complete audit trail on all accountable nuclear material from receipt through disposition. 


\section{PRIMER FOR THE INSIDER TRAINING COURSE January XX, 2008}

\section{PHYSICAL INVENTORY PROGRAM}

a. The physical inventory program provides a performance test that validates the accuracy of the book values with a statistical result and may establish values to determine book closure. The book values may be updated on a continual basis, and the constant monitoring of other MC\&A elements provides for accurate book values in a near real-time fashion. On some approved interval a shutdown and cleanout is performed in all processing areas to ensure all material is accounted for. The physical inventory is used to correct inventory records if an error is found.

\section{MEASUREMENT AND MEASUREMENT CONTROL PROGRAM}

a. The measurement and measurement control program ensures that all nuclear material (NM) measurement methods that support declared inventory values have a metrological basis. Inventory values should be traceable to recognized international standards. Programs should be place to assure that measurement systems used to determine values are in control prior to use. Measurements provide assurance that the NM values have been properly established and in conjunction with materials accounting provide a means to detect material that may have been lost, stolen, or diverted.

\section{MATERIAL TRANSFERS}

a. The accountability process for nuclear material transfers covers internal and external transfer activities. The MC\&A objectives for material transfers are to deter and/or detect theft or diversion, by ensuring that all authorizations are in place, and provide an audit trail of transfers. In addition transfer checks and measurements and response to abnormal conditions ensure immediate detection.

\section{MATERIAL CONTROL INDICATORS PROGRAM}

a. Material Control Indicators program assesses key indicators to provide assurance that losses and unauthorized removals of nuclear material (NM) are detected in a timely fashion. Each indicator has an associated action limit. Some key indicators:

i. Administrative Inventory Adjustments reviews

ii. Normal Operating losses reviews

iii. Propagation of Variance reviews

\section{SHIPPER/RECEIVER DIFFERENCE PROGRAM}

a. A shipper/receiver difference evaluation is preformed for all external transfers of accountable nuclear materials between the shipping facility and the receiving facilities. For those transfers covered by a 


\section{PRIMER FOR THE INSIDER TRAINING COURSE January XX, 2008}

shipper/receiver agreement, the shipper/receiver difference is evaluated and resolved as described by the agreement. A shipper/receiver agreement will allow safeguards closure of the transaction and provide protocols for resolving any subsequent shipper/receiver difference resulting from later accountability measurements.

\section{SECTION 2 - MATERIALS CONTROL}

\section{ACCESS CONTROLS}

a. The nuclear material (NM) access control program limits access to NM, NM data, MC\&A system hardware, software, and other equipment and/or data to authorized individuals. .

b. Category I - Individuals must be Q-cleared and Human Reliability Program (HRP)-approved; they must be trained in safeguards procedures and security regulations and have a need to know and a need to access to the material. Security police officers control access to Category I MBAs. Visitors and other personnel must enter and exit by defined paths that have special nuclear material (SNM) detectors and metal detectors, either stationary or handheld.

c. Category II - If the MBA is credible for "roll-up", all the access controls for Category I MBAs apply. If the MBA is not credible for rollup, all the access controls for Category I apply with one exception: personnel can have unescorted access when they meet all the following criteria:

i. personnel are either Q-or L-cleared,

ii. personnel know the MBA and the safeguards and security (S\&S) regulations, and

iii. personnel have a need to know and a need to access.

d. Category III - Access controls for Category III MBAs are similar to those for Category II MBAs. The difference is that Category III MBAs can use locked doors with key control or combination locks on the doors and administrative controls for the combinations. MBA personnel or the security police officer checks badge and maintains control logs for access.

e. Category IV - Access controls for Category IV MBAs must have locked doors, requiring either keys or combinations. The MBA custodian controls the distribution of keys and combinations administratively. A person with unescorted- access authorization must escort visitors. Personnel who have access to Category IV material must know the MBA and the $S \& S$ regulations and have a need to know and a need to access the material. 


\section{PRIMER FOR THE INSIDER TRAINING COURSE January XX, 2008}

\section{MATERIAL SURVEILLANCE}

a. Using a graded safeguards concept to establish a Materials Surveillance program (MSP) to detect unauthorized activities or anomalous conditions during normal operations and emergency conditions. The program is designed in combination with other safeguards elements to ensure that all reportable nuclear material is in authorized locations and the unauthorized material flows or transfers are detected in time to prevent unauthorized removal of material from the facility. The facilities implementation of the material surveillance program establishes MSPs to monitor and control NM, consistent with the material's quantity, attractiveness level, and accessibility.

i. Two-Person Rule - The safeguards two-person rule helps to ensure that no unauthorized activities occur in Category I or II MBAs.

ii. Daily Administrative Checks

\section{MATERIAL CONTAINMENT}

a. The objective of the facility materials containment program is to ensure that nuclear materials controls are used in accordance with graded safeguards principles. Material containment measures are multilayered and provide defense-in-depth safeguards assurance against diversion, theft, or other compromises to the nuclear material inventory. In an effort to minimize the potential for unauthorized access to nuclear materials, the amount of material in use is limited to operational needs and by safety factors.

Whenever practical it should be located in physical areas and administrative locations based on a graded safeguards approach.

b. If an emergency or abnormal situation results in the evacuation of a Category I or II MBA, personnel not associated with the emergency recovery activities are not allowed to re-enter the Material Access Area until the following 3 conditions are met:

i. Evacuated personnel have been searched,

ii. The Material Access Area has been declared safe for reentry, and

iii. A Daily Administrative Check has been performed if necessary.

\section{DAILY ADMINISTRATIVE CHECKS}

a. The purpose of the Daily Administrative Check (DAC) program is to provide timely detection of obvious anomalies in Category I and II areas where roll-up to a Category I is credible. 


\section{PRIMER FOR THE INSIDER TRAINING COURSE January XX, 2008}

\section{TAMPER INDICATING DEVICES PROGRAM}

a. The TID-Indicating Device (TID) program provides a time-limited deterrent mechanism that will help detect any attempts to access the object being TID'd. Tampering is defined as the unauthorized opening of a container, package, door, or object to which a TID has been affixed or that is intrinsically sealed to provide the same type of deterrence as a TID. Intrinsically sealed items have physical characteristics that should their integrity be violated would immediately indicate tampering.

i. As part of the TID program individuals must complete training and continue to receive regular refresher training before they are authorized to apply, void, or remove TIDs. TIDs are a benefit only if they have been properly applied so that it is easy to detect when then have been compromised. TIDS are only considered a reliable safeguards element when they are used in conjunction with an effective material surveillance program.

ii. A TID program also includes a management element to track the disposition of all TIDs at a facility.

\section{SNM PORTAL MONITORING}

a. THE SNM Portal Monitoring Program provides detection of SNM at the Material Access Area boundary and Protected Area access points. This detection assures that in combination with other detection elements (Metal Detector, X-Ray), undetected unauthorized removal of nuclear materials is not credible. All personnel and vehicles entering or leaving a Protected Area of Material Access Area are subjected to SNM monitoring. The ingress check is preformed to create a baseline on the person, item, or vehicle, thus easing the assessment upon egress. Random metal shielding monitoring is performed at the Protected Area, while the Material Access Area is subject to $100 \%$ monitoring.

\section{WASTE MONITORING}

a. The purpose of a facilities material control and accountability waste monitoring program is provide monitoring that will detect the theft or diversion of SNM by "piggy backing" on liquid, solid, and gaseous waste streams leaving a Material Access Area in time to prevent the removal of goal quantity. Waste monitoring equipment is maintained and controlled to ensure that the equipment is capable of detecting specified amounts of SNM. A response plan should be established for evaluating and resolving situations involving discharges exceeding facility specific limits if the situation is not satisfactorily resolved or if there is an indication of malevolent action. 


\section{Hypothetical Facility Data Book \\ The Uranium Research Facility (URF)}

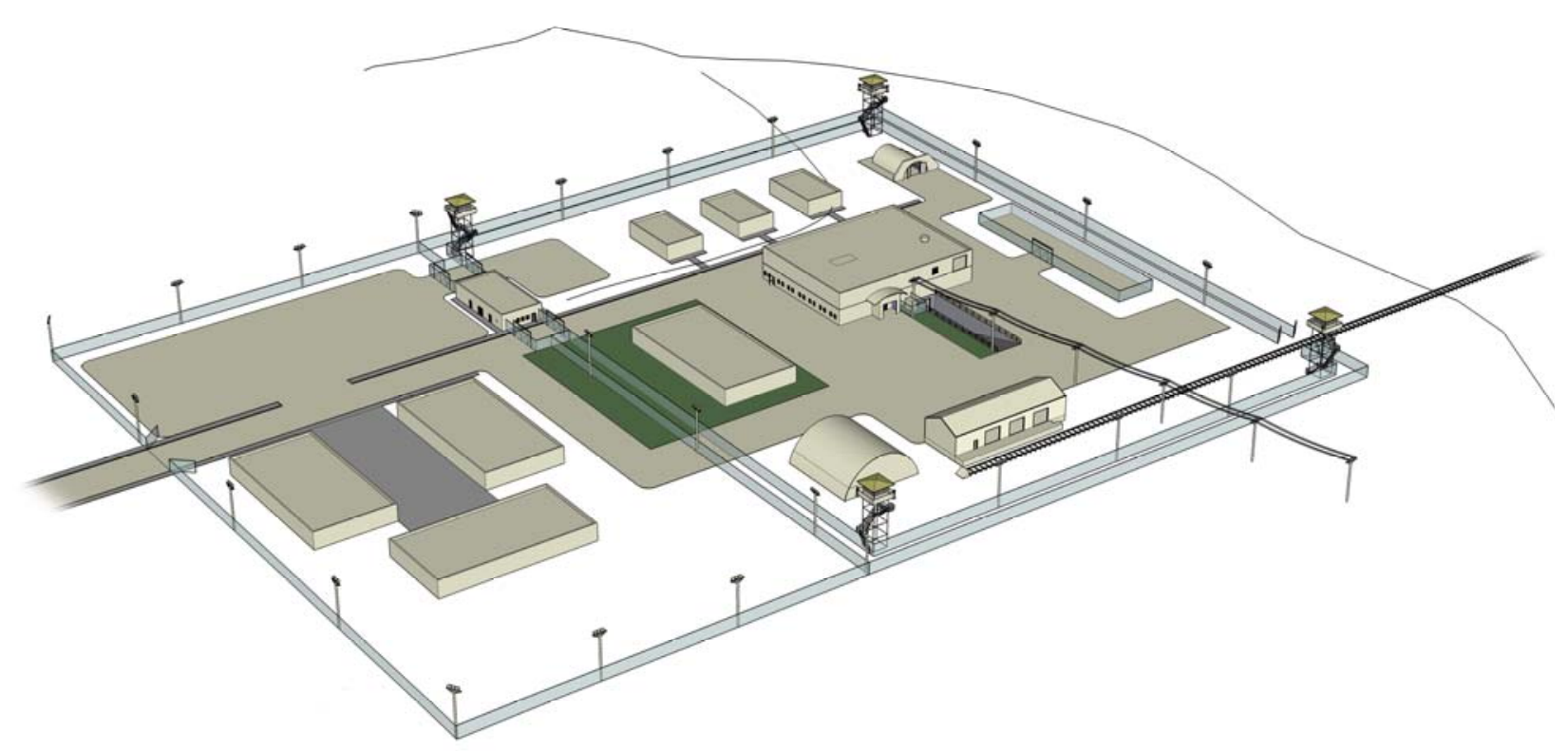

November 9, 2007

Final 
This page is intentionally blank. 


\section{Table of Contents}

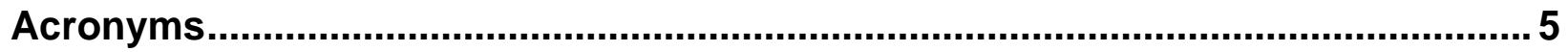

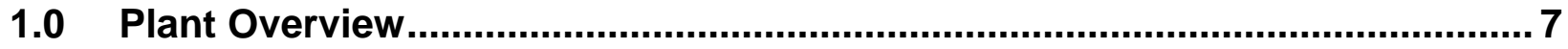

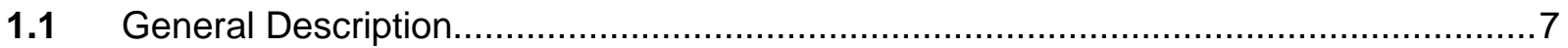

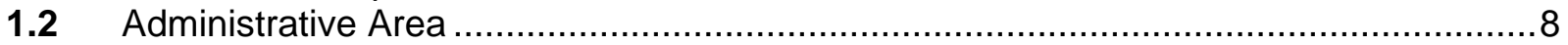

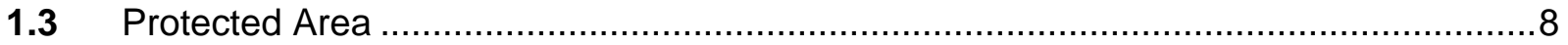

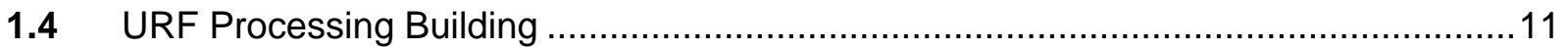

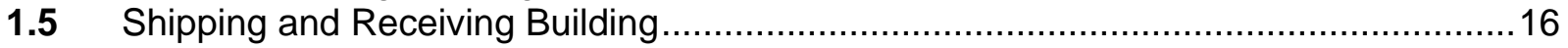

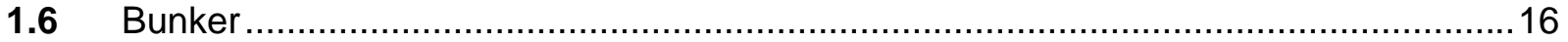

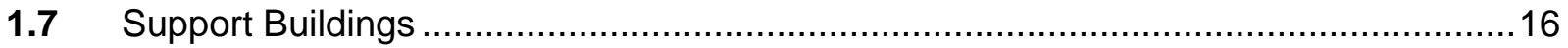

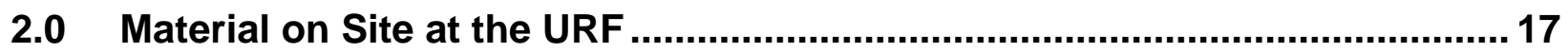

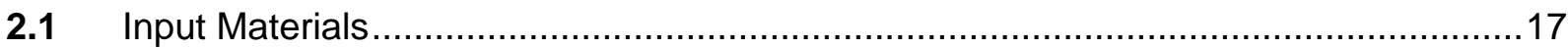

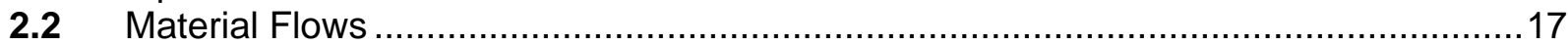

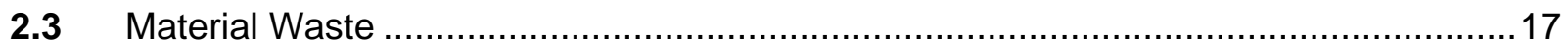

2.4 Materials in Processing Building Vaults ......................................................... 18

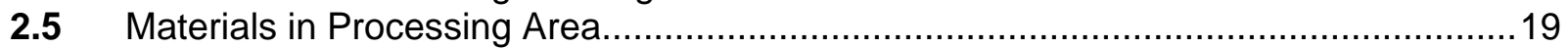

2.6 Materials Moved from the Processing Area .................................................. 19

2.7 Materials in Basement Recovery Area ................................................................ 19

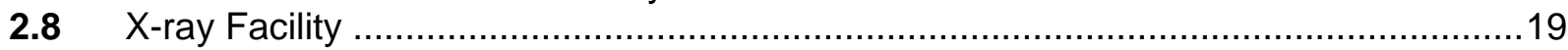

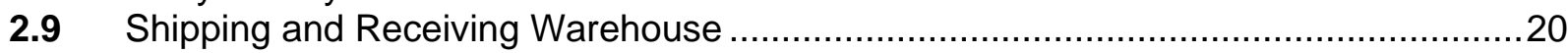

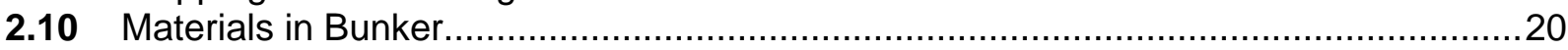

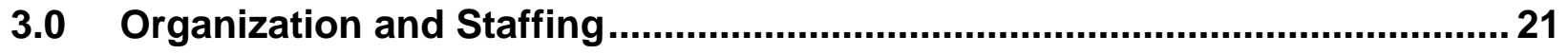

4.0 URF Material Control and Accountancy System ........................................ 25

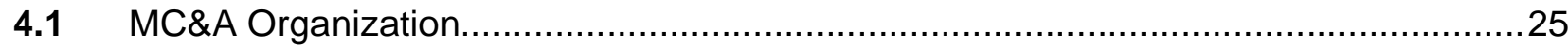

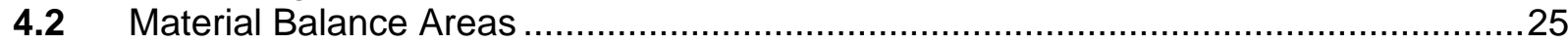

4.3 Measurements and Measurement Control Program ............................................25

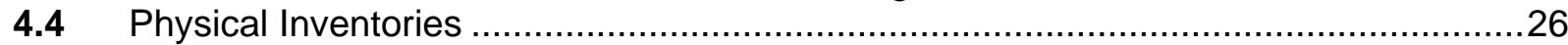

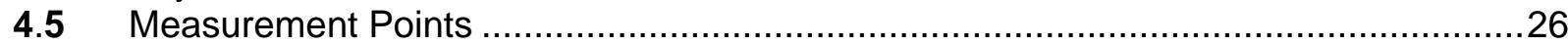

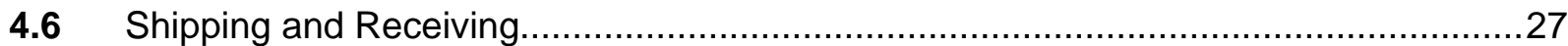

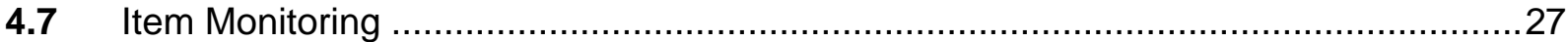

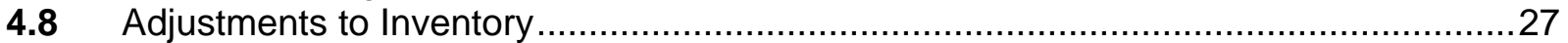

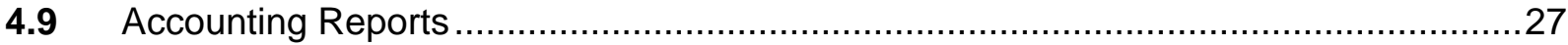

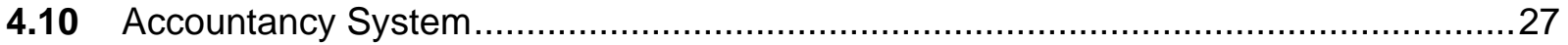

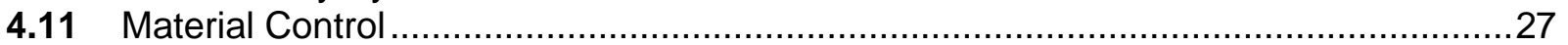

4.12 Personnel Access Control at Protected Area ECP ................................................28

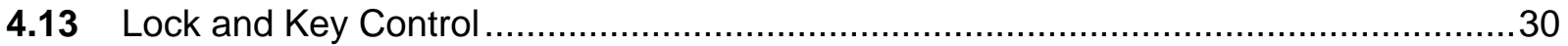

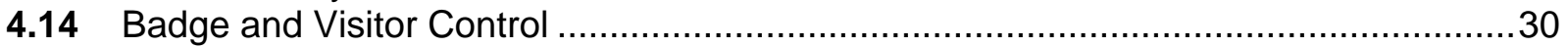

5.0 Operations at Gates and Portals at the URF ............................................... 31

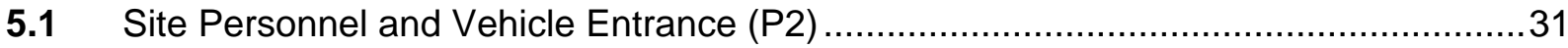

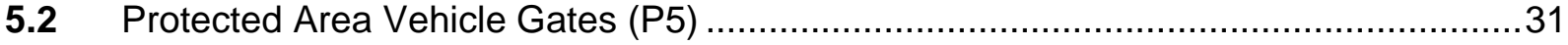

5.3 Protected Area Personnel Access Control Point (P6) ......................................... 31

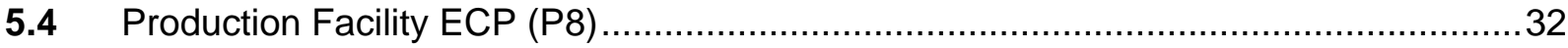

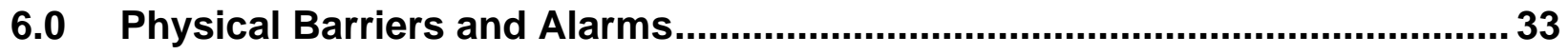

6.1 Area Specific Access Controls and Physical Barriers ............................................. 33

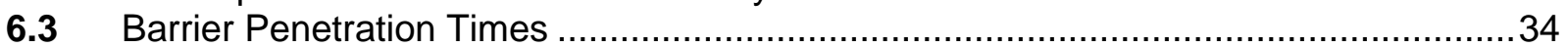

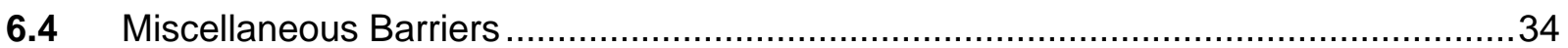




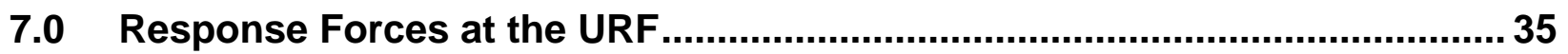

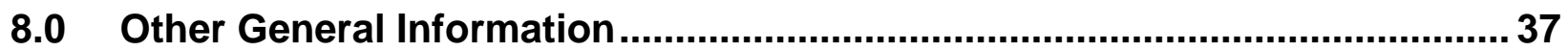

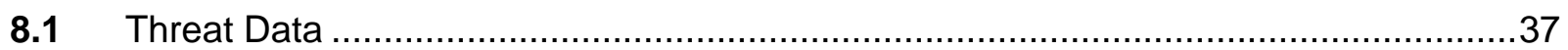

\section{Figures}

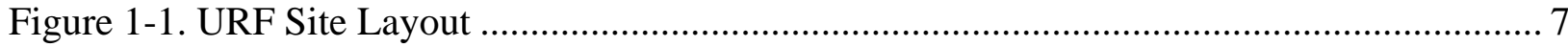

Figure 1-2. Entry Control Building Layout ............................................................................ 10

Figure 1-3. Production Facility Layout Ground Level ............................................................... 13

Figure 1-4. Production Facility Layout Basement Level................................................................ 14

Figure 1-5. Production Facility Layout Mezzanine Level ............................................................ 15

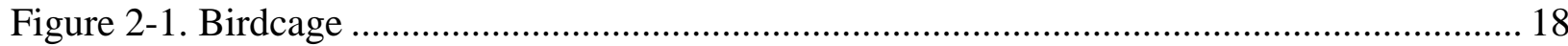

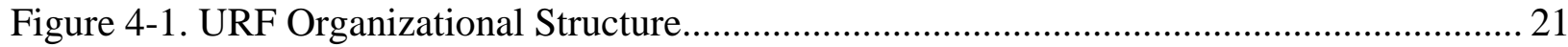

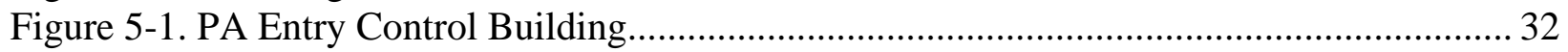

\section{Tables}

Table 1. Nominal URF SNM Inventory ................................................................................. 17

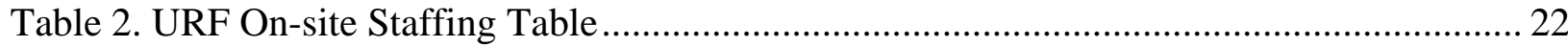

Table 3. Non-employee Access to URF Table ............................................................................... 24

Table 4. Nominal URF SNM Inventory .................................................................................. 26

Table 5. Access Controls and Physical Barriers ……………....................................................... 33

Table 6. Probabilities of Detection for Sensors ………………….............................................. 34

Table 7. Barrier Penetration Times.......................................................................................... 34

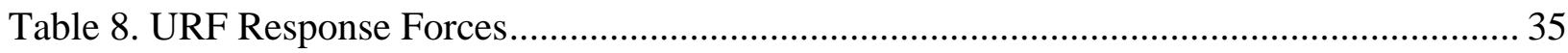

Table 9. Response Force Deployment Data................................................................................. 36

Table 10. Average Response Force Times ..................................................................................... 36 


\section{Acronyms}

$\begin{array}{ll}\text { AA } & \text { Administrative Area } \\ \text { BMS } & \text { balanced magnetic switch } \\ \text { CAS } & \text { Central Alarm Station } \\ \text { cm } & \text { centimeter } \\ \text { ECB } & \text { Entry Control Building } \\ \text { ECP } & \text { Entry Control Point } \\ \text { HEPA } & \text { high efficiency particulate air } \\ \text { HVAC } & \text { heating, ventilation, and air conditioning } \\ \text { kg } & \text { kilogram } \\ \text { LEID } & \text { Limit of Error of Inventory Difference } \\ \text { m } & \text { meter } \\ \text { MBA } & \text { Material Balance Area } \\ \text { MC\&A } & \text { Material Control and Accountancy } \\ \text { NDA } & \text { non-destructive analysis } \\ \text { PA } & \text { Protected Area } \\ \text { PIR } & \text { passive infrared } \\ \text { QA } & \text { quality assurance } \\ \text { SNM } & \text { special nuclear material } \\ \text { SRT } & \text { Special Reaction Team } \\ \text { TID } & \text { tamper indicating device } \\ \text { UO } 2 & \text { uranium dioxide } \\ \text { URF } & \text { Uranium Research Facility }\end{array}$


This page is intentionally blank. 


\subsection{Plant Overview}

\subsection{General Description}

The Uranium Research Facility (URF).is a national defense facility for the manufacture of uranium billets used in research. The site, which is located in a semi-arid high desert, is divided into two main areas. The first is the low security Administration Area, where much of the non-production activities take place. Approximately $30 \%$ of the staff works in this area. The second area is the Protected Area (PA). This very high-security area contains the main fabrication buildings, the production support buildings, storage vaults, road and rail transportation terminus, and the main cafeteria.

The main product of the URF is high-quality uranium billets that are used in nuclear material research. The input stream of this process begins with the delivery of uranium dioxide $\left(\mathrm{UO}_{2}\right)$ powder. This powder is processed into raw ingots through a casting process. The raw ingots are then further processed into standard billets of specific size, shape, and weight. The waste from these processes goes into a uranium recovery stream that reintroduces the scrap material into the input stream. The finished product undergoes quality assurance (QA) checks and is then stored at a bunker until it is transported by rail or truck to end users.

The Simplified Area diagram shown in Figure 1-1 illustrates both the major facilities of the URF and the defined material access areas.

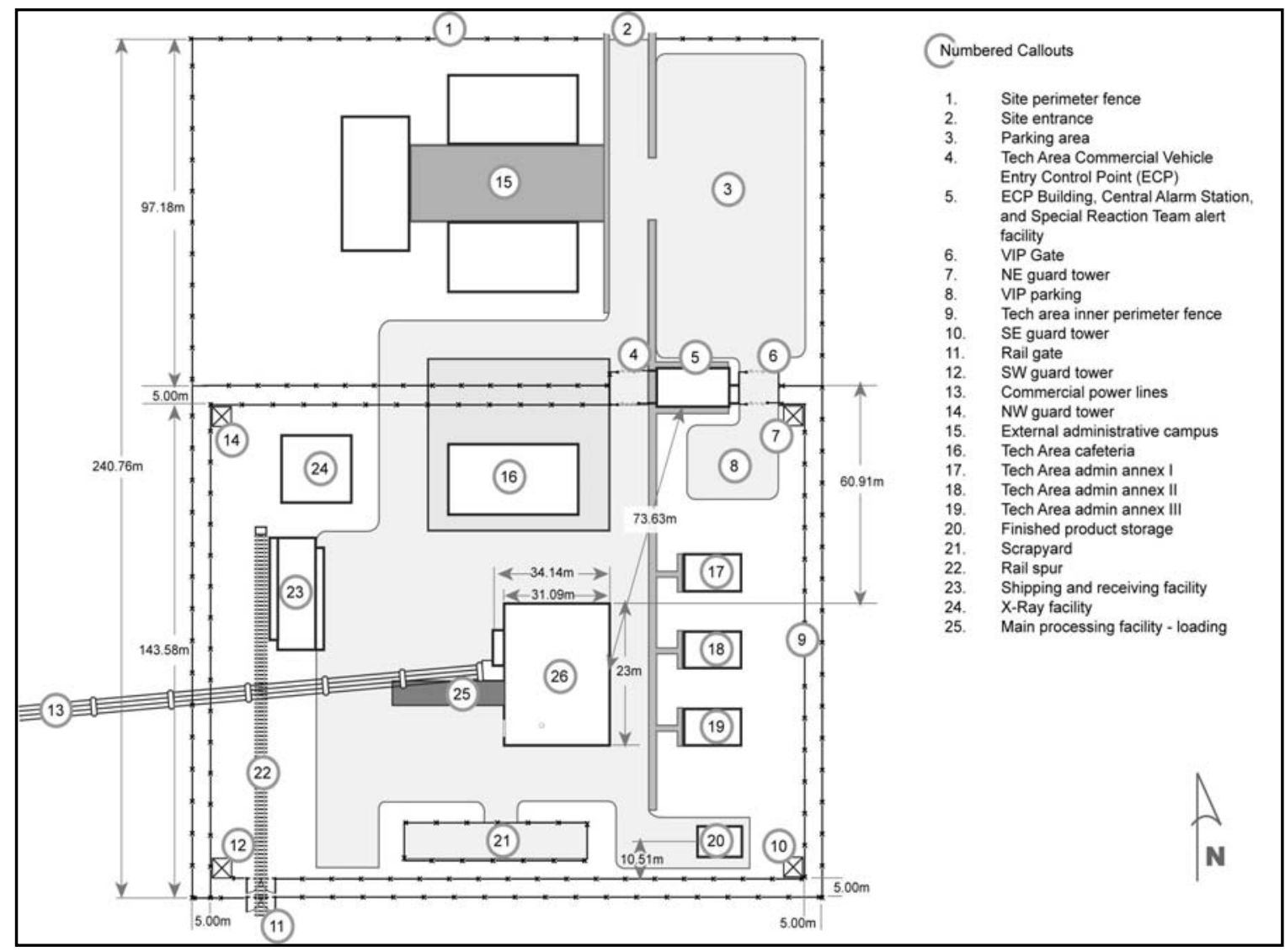

Figure 1-1. URF Site Layout 


\subsection{Administrative Area}

The northern two-fifths of the URF Site is the Administrative Area (AA). This area is surrounded by a fence along three sides_-known as the North Fence-and the PA fence along the southern side. The North Fence is 2.5 meters $(\mathrm{m})$ high and is constructed of standard chain-link fabric fastened to metal poles. The site entrance gate (located on the north side of the site) is unlocked and open during normal working hours and is locked during off hours. During these off hours, personnel needing to enter the site must phone the guard in the Central Alarm Station (CAS) from a telephone at the gate. A guard is then deployed to the gate to check the requester's badge. Possession of a valid site badge is all that is required for off-hour access.

The buildings in the AA are unlocked except on weekends and holidays. Most senior management personnel have keys to the outer doors of these buildings. Personnel all have keys to their specific work areas. Personnel needing access to the buildings notify the guard, who opens the gate, escorts them to the building, and lets them in. When the personnel leave the building, they must inform the guard that they will no longer be in the building. The doors lock automatically behind the departing employee. The guard meets the employees at the gate to let them off-site. All keys are controlled by the guard force and are stamped "Do not duplicate."

The buildings of the AA are not alarmed, except for the analytical lab on the first floor of the building nearest the PA. This analytical lab is alarmed with a balanced magnetic switch (BMS) sensor on the door and passive infrared (PIR) sensors, providing interior volumetric intrusion detection. The windows also have iron bars across them. The guard force responds to any alarms that occur in this area. Members of the guard force have a master key that allows them to enter and investigate the analytical lab after an alarm occurs.

\subsection{Protected Area}

There are nine buildings inside the PA perimeter. The main production building is the Process Facility located near the center of the area. There is also an Entry Control Building (ECB) that straddles the northern perimeter and houses pedestrian and vehicular entry control points, the CAS, and the Response Force Ready Room. Material shipments are processed through the shipping and receiving building. This building can support both road and rail transports. A storage bunker, located in the southeast corner of the PA, is used to store finished products prior to shipping. A full service x-ray diagnostic facility, located in northwest corner of the PA, is used for product quality control inspections. The PA also houses several small office buildings and the main cafeteria.

\subsubsection{PA Perimeter}

The PA perimeter is comprised of two 2.5-m-high chain-link fences that are $5 \mathrm{~m}$ apart. Guard towers are located at each corner just inside of the PA perimeter. These guard towers, which are manned continuously, are high enough for the guards to see all the walls, the roof, and entrances of the processing building. The towers have 360-degree viewing windows made of high-strength window glass. 
The area outside the perimeter has a 20 -m cleared zone that is bounded by trees in several locations. The terrain is relatively flat.

Patrols around the PA perimeter are conducted on the patrol road on a random basis. Patrols inside the PA perimeter are conducted by an guard on foot, also on a random basis. The lighting at the site is positioned as shown in the site specific data appendix.

\subsubsection{Entry Control Building}

The ECB houses the PA's Personnel Entry Control Point (ECP), the CAS, and the Special Reaction Team (SRT) alert facilities. The CAS and SRT are in continuous operation. The ECP is open for normal entry during operational work hours, (7 am to $6 \mathrm{pm}$ ), but the outer doors are locked during off-hours. The east side of the ECB houses a quick response team of four persons, who respond to verified alarms in the area and provide key service to personnel needing access to normally locked areas. The northwest corner of the ECB houses the CAS, which is staffed by a senior guard.

The primary means for personnel and vehicle egress to the PA is through the ECB and its two vehicle portals. Vehicle entry through the PA perimeter is done through one of the gates. Most traffic is directed through the vehicle portal at the ECP (located on the northeast corner of the PA). The sliding gates are controlled from inside the ECP by one of the guards. Vehicle authorization is done by the guards with a visual recognition check.

Pedestrians enter the main door of the ECP and present their site badges to one of the guards sitting at the desk. If the guard approves the entry, the authorized person passes through the metal detector and on into the PA. The guard also randomly checks packages for contraband and investigates any metal detector alarms. 


\section{Exercise Data}

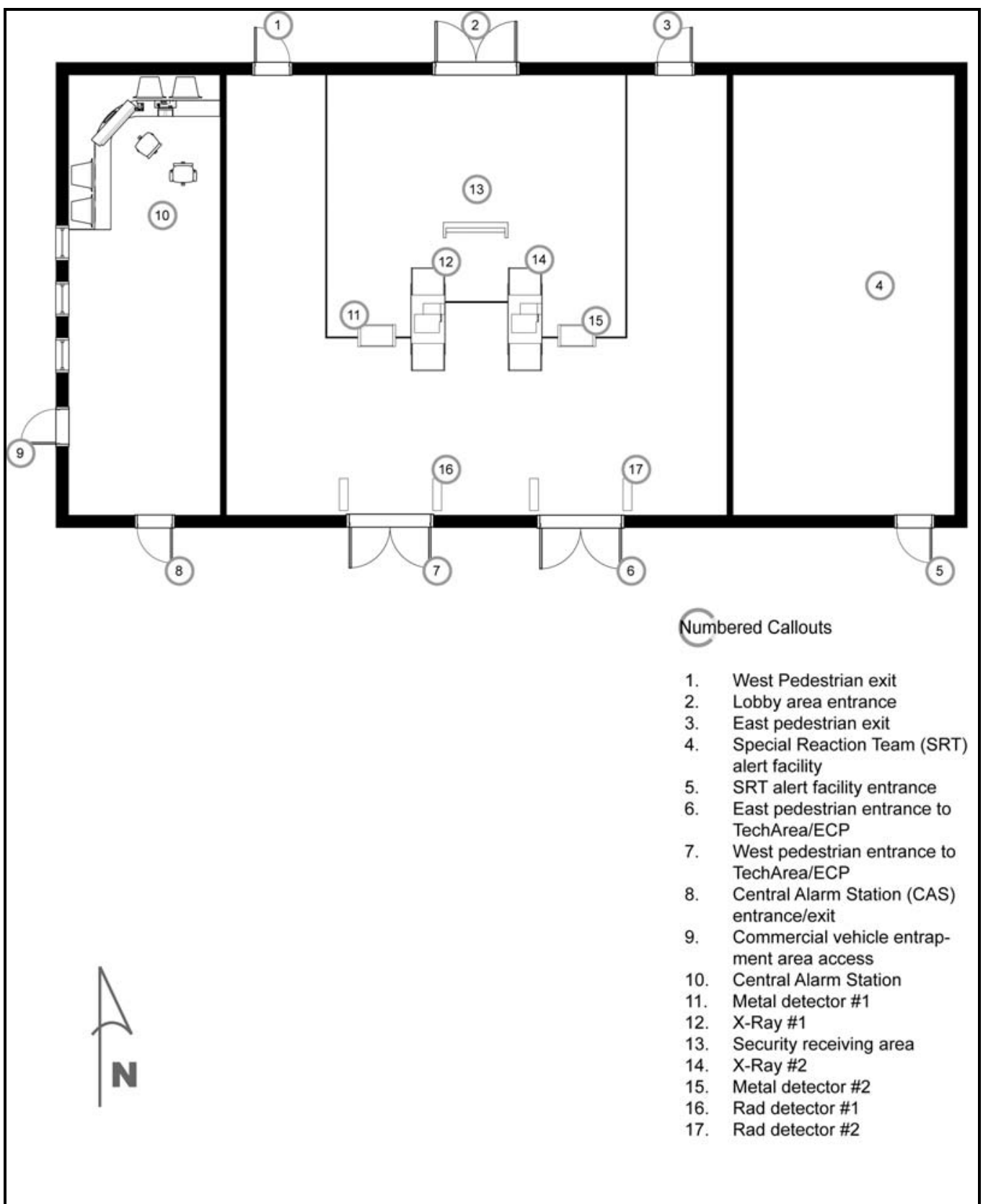

Figure 1-2. Entry Control Building Layout 


\subsection{URF Processing Building}

All manufacturing processes are contained within the URF Processing Building. This building is a multi-story facility with a basement, ground, and mezzanine level. It has a total area of approximately 1700 square meters. The partial basement is the machine cooling fluid processing area, the ground floor is the processing area, and the mezzanine is the heating, ventilation, and air conditioning (HVAC) area. The production areas of the building are under negative pressure and all ventilation from these areas is passed through high efficiency particulate air (HEPA) and/or charcoal filters to minimize plant releases.

The URF Processing Building houses the following areas/operations:

- Casting Furnace Area-This area holds the two furnaces where $\mathrm{UO}_{2}$ powder is cast into ingots.

- Billet Vault —Finished ingots are stored here until needed by machining process.

- Special Nuclear Material (SNM) Machining Area-This area holds nine milling machines that can be configured to work as three lines of a three-step milling process or as nine individual stations. The milling process converts raw ingots to finished billets.

- Product Vault - This vault stores finished billets before they are sent to QA or to the Storage Bunker.

- QA Vault-In-process billet samples and final products are measured and tested in this vault. Only a limited amount of material may be in this vault at any one time.

- AA-The Administrative Area is the general office area.

- Chip Vault-This vault stores return stream waste from the Casting Furnace and Machining areas before it is reintroduced into the input stream.

\subsubsection{Entryways in the Processing Building}

The Processing Building (26 in Figure 1-2) is the primary material area. There is a main personnel entrance to the building, and shipping entrances to both the nuclear material and non-nuclear material machine shop areas. The main personnel entrance allows access to the office areas, the non-nuclear material machining area, and the Process Area entry control portal. Pedestrians enter the main door and present their site badges to the receptionist at the desk. Emergency exits are located in both the administrative section and the processing areas. There are two chemical storage rooms that can only be accessed from outside and share the loading dock for the non-nuclear material machine shop. The Processing Building also has a shipping entrance to the partial basement that can be used for moving large equipment. There is also an overhead shipping door to the mezzanine with a crane attachment for moving HVAC units into the mezzanine. There is grillwork over the duct ends on the mezzanine outer surfaces for the HVAC and filter system.

\subsubsection{Processing Building-Construction Details}

The emergency exit doors in the Processing Building are hollow-core metal industrial doors. They have panic hardware on the interior and a key lock on the exterior. The guards have the key to the lock for emergency response situations. The emergency exit doors are alarmed with BMS. The main entry doors are glass, equipped with BMS, and are set in a wall of windows. The foyer is used as a showcase to display information about the facility for visiting dignitaries. The exterior walls of the AA are made of 20-centimeter (cm) (8-inch) 
hollow concrete block. Each office has a window to the outside. The interior walls in the AA are typical sheetrock walls. There are no alarms in the offices or sensors on the office doors. The walls of the processing areas (the machining and casting areas) are constructed of 20-cm (8-inch) reinforced concrete. There are no windows to the outside in the processing areas. The roof in the processing areas is constructed of 14-cm (5.5-inch) reinforced concrete on metal decking. 


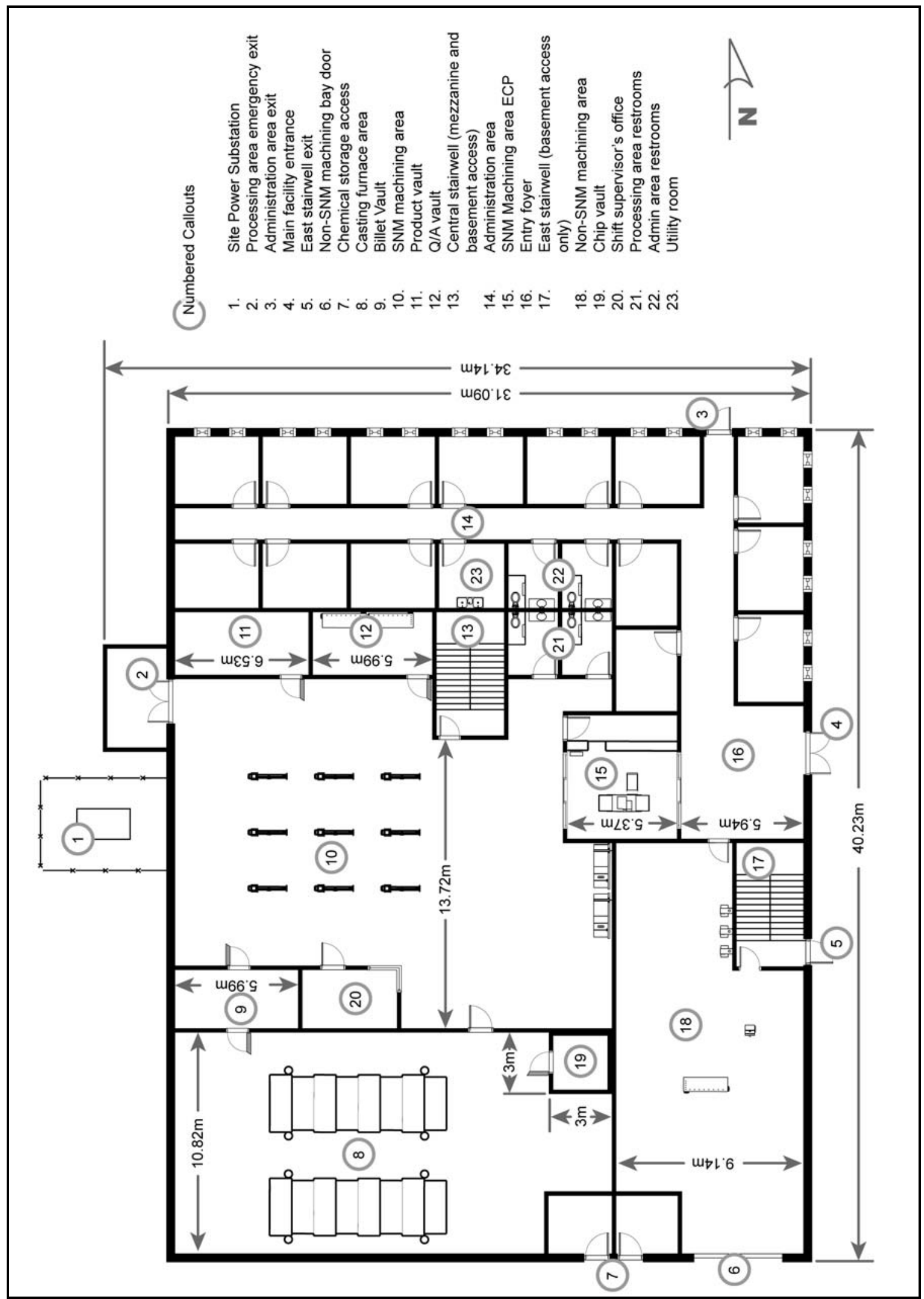

Figure 1-3. Production Facility Layout Ground Level 


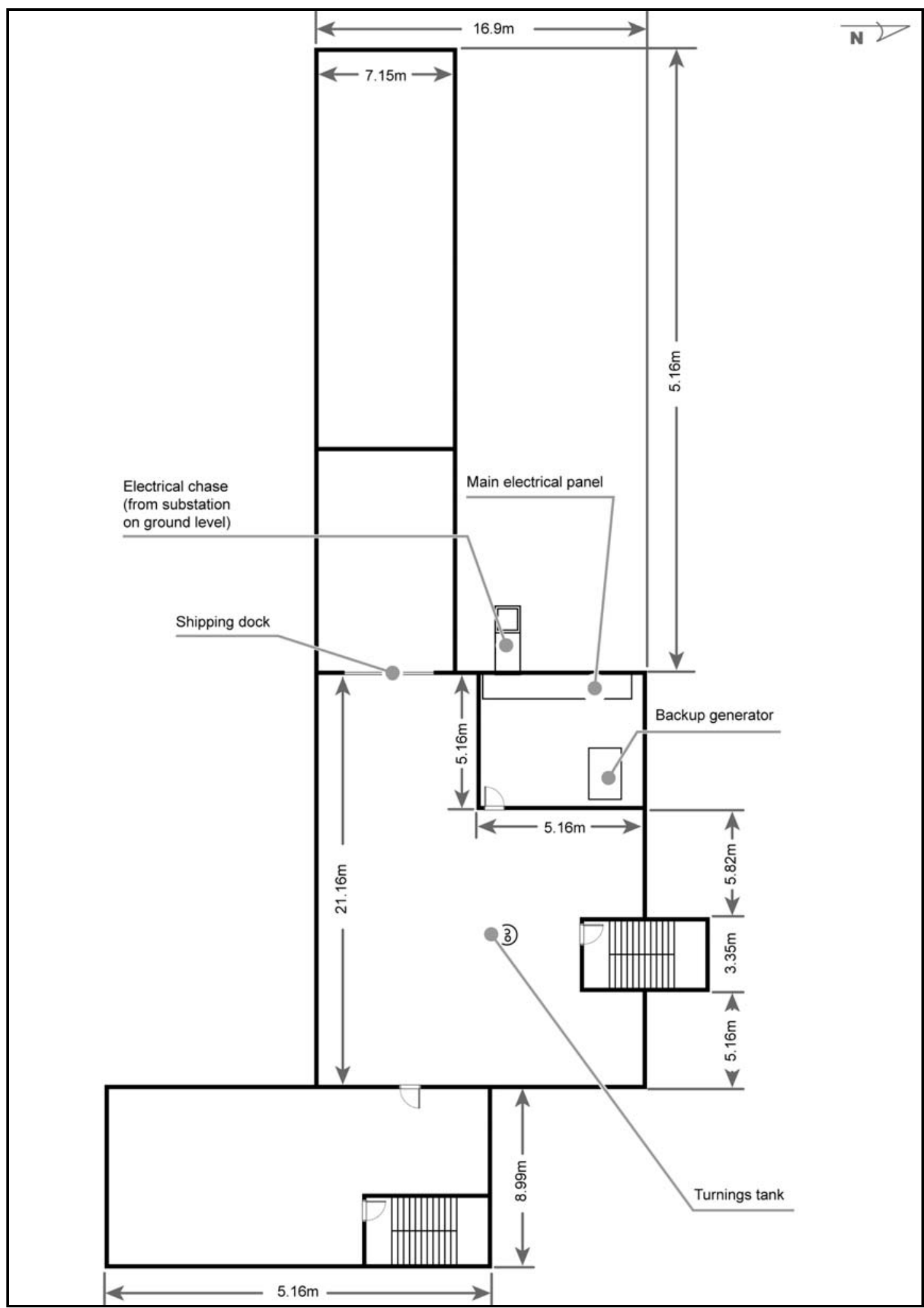

Figure 1-4. Production Facility Layout Basement Level 


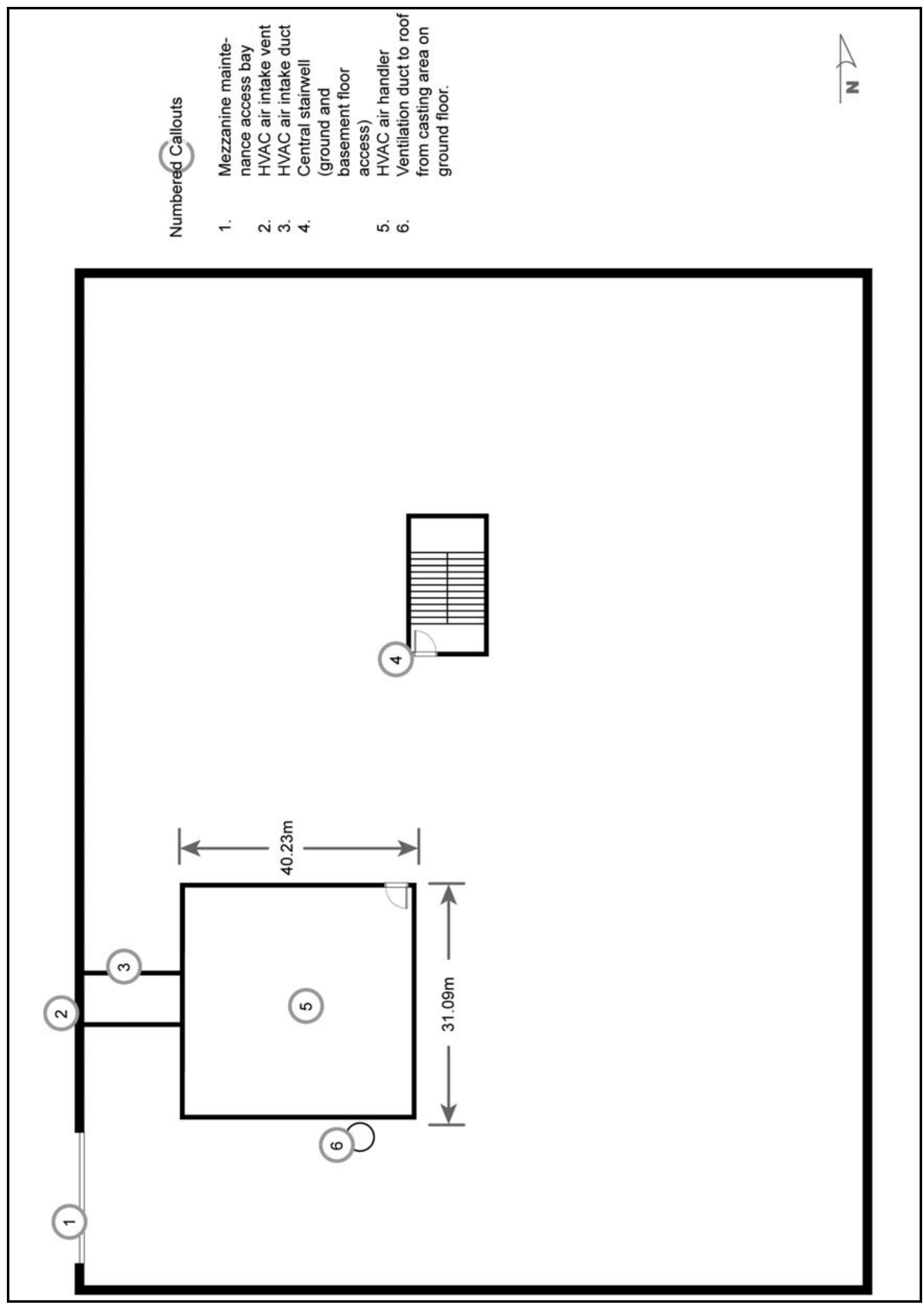

Figure 1-5. Production Facility Layout Mezzanine Level 


\subsection{Shipping and Receiving Building}

The Shipping and Receiving building (23 in Figure 1-2) is a one-story building with loading docks on both sides (one for rail shipments and one for trucks). Although several cubical office spaces are inside, it is basically an open warehouse.

\subsection{Bunker}

The Bunker (20 in Figure 1-2) is used to store nuclear material that was shipped in for recycling, and finished products that are packed and ready to ship.

\subsection{Support Buildings}

There are three single-story Support Buildings located east of the Processing Building which are Administration (e.g., offices) (Figure 1.1 Building 17), the Analytical Laboratory (Figure 1.1 Building 18), and Waste Measurement Facility (Figure 1.1 Building 19). The Administration Building stores some classified material in safes. The Analytical Laboratory stores small quantifies of nuclear material in the form of process samples and reference materials. The Waste Measurement Facility stores nuclear material in the form of waste drums. 


\subsection{Material on Site at the URF}

Table 1. Nominal URF SNM Inventory

\begin{tabular}{|l|l|l|}
\hline $\begin{array}{c}\text { Material Balance } \\
\text { Area }\end{array}$ & \multicolumn{1}{|c|}{ Form of Material } & \multicolumn{1}{c|}{$\begin{array}{c}\text { Allowable Material Inventory } \\
\text { (wt \% enrichment) }\end{array}$} \\
\hline X-Ray Facility & $\mathrm{UO}_{2}-$ billets & $5 \mathrm{~kg} \mathrm{U}(<86.6 \%)$ \\
\hline \multirow{2}{*}{ Product Bunker } & $\mathrm{UO}_{2}-$ billets & $30 \mathrm{~kg} \mathrm{U}(<86.6 \%)$ \\
\cline { 2 - 3 } & $\mathrm{UO}_{2}-$ powder & $10 \mathrm{~kg} \mathrm{U}(<86.6 \%)$ \\
\hline \multirow{3}{*}{ Processing Building } & $\mathrm{UO}_{2}-$ ingots & $30 \mathrm{~kg} \mathrm{U} \mathrm{(<86.6 \% )}$ \\
\cline { 2 - 3 } & $\mathrm{UO}_{2}-$ scrap & $50 \mathrm{~kg} \mathrm{U}(<86.6 \%)$ \\
\cline { 2 - 3 } & $\mathrm{UO}_{2}-$ billets & $20 \mathrm{~kg} \mathrm{U}(<86.6 \%)$ \\
\hline
\end{tabular}

\section{$2.1 \quad$ Input Materials}

Input material consists of $\mathrm{UO}_{2}$ powder or metal ingots formed at another plant and shipped in by request. Input material could also be un-irradiated billets that are to be recycled. Input material is stored in the product vault (11) until needed for processing. Initially, the nonpowder input material will be broken into "chips" and the chips will be transferred to the chip vault (19) until needed for casting.

\subsection{Material Flows}

Feed to the casting line is $\mathrm{UO}_{2}$, chips, turnings, flakes, etc. The feed for the casting line is stored in the chip vault (19). When an ingot is needed for machining, and there is not one available meeting requirements in the billet vault (9), a batch of chips and powder is put together that matches the requirements. This is done in the makeup area directly outside of the chip vault. A technician takes chips from various drawers in the vault or uses $\mathrm{UO}_{2}$ powder to make up a batch. Samples for destructive assay and quality control are taken and sent to the Analytical Laboratory for analysis. The batch goes to casting and is matched with a form mold, assembled, and input to the casting line where material is heated, melted, poured into a mold, moved to a cooling chamber, cooled for 8 to 12 hours, taken from the mold, inspected for obvious flaws and/or problems, and put in the billet vault. If the ingot is flawed, it is also put in the billet vault and marked for breaking into chips again.

When manufacturing parts, the ingot or partially processed part is taken from the vault, and moved to where it is needed in the machine shop area (10) (e.g., pressing, forming, lathes, punches, etc.). The ingots and partial parts are kept in small cages (birdcages) to enhance access control and to ensure criticality separation.

\subsection{Material Waste}

Nuclear material in the form of waste in generated from various parts of the process. Waste is collected placed in waste receptacles. The operation support personnel collect and package this waste into waste containers these on a regular schedule. Once packaged this material is moved on a bi-weekly basis to the Waste Measurement facility where it is assayed and the nuclear content determined. Once assay is completed the waste packages are transferred to the shipping receiving facility to await transport for burial. 
Clean waste is removed from the facility on a daily basis by operations support personnel on the $2^{\text {nd }}$ shift. Waste is placed in dumpsters adjacent to the shipping dock. On a bi-weekly basis a local garbage contractor has been contracted to pick up clean waste and transport it to a local dump site for disposal.

\subsection{Materials in Processing Building Vaults}

The material stored in the Processing Building vaults is in various forms and quantities:

- $\mathrm{UO}_{2}$ powder is stored in 0.5-kilogram (kg) cans.

- The chip vault has material in all sizes, shapes and enrichments. When parts to be recycled come to the facility, they are crushed into small chips (typically between 200 and 500 grams each). These chips are classified by enrichment and stored in 2-liter stainless steel cans. The amount of material in each can may vary, but nuclear safety has established a limit of $1 \mathrm{~kg}$ of material in each can regardless of the enrichment. These cans are stored on open shelves in the vault.

- The billet vault contains 5-kg ingots. The ingots (after a cooling period) are collected and stored in plastic bags inside metal cans. These metal cans are an integral part of the birdcages (see Figure 2-1). The birdcages ensure correct separation distances and add some delay to the material. Each birdcage weighs $20 \mathrm{~kg}$ and is stored on the floor or on open shelves.

- The product vault contains the finished parts before they are shipped. These parts are stored in a special birdcage inside an inert gas package. The birdcage is essentially the same as the billet birdcage with a different container integrated into it. The finished products normally weigh between 2 and $3 \mathrm{~kg}$ (depending on the particular product being manufactured). The birdcage weighs $20 \mathrm{~kg}$ and is stored inside an expanded metal enclosure within the vault.

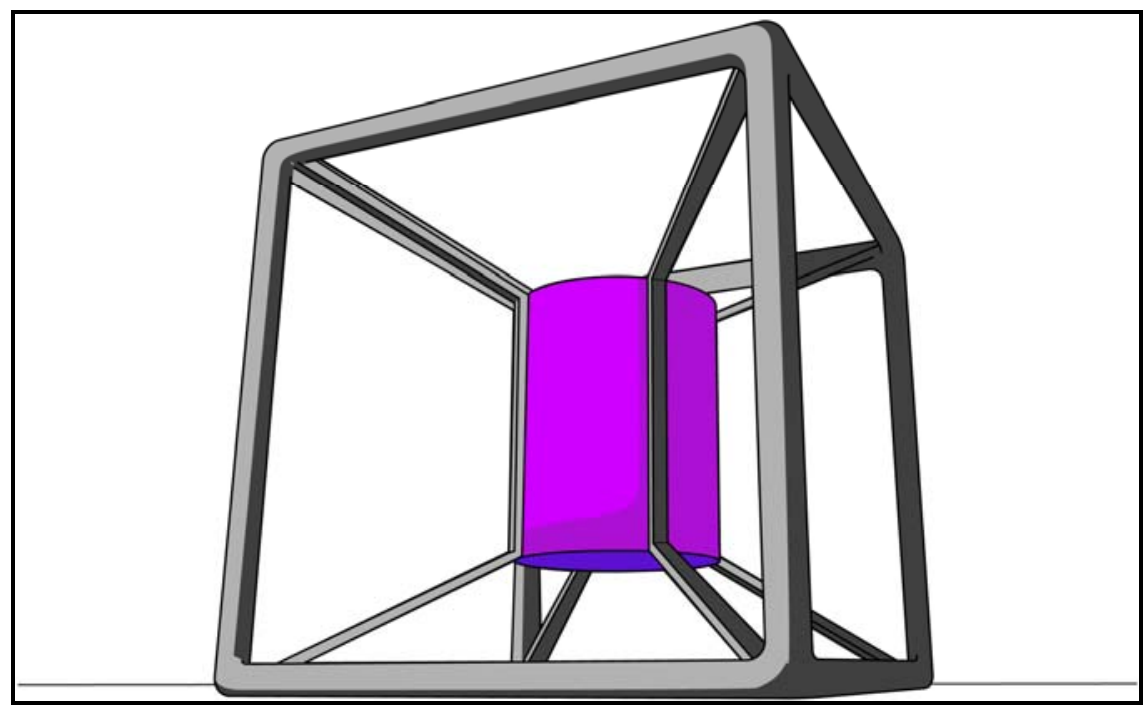

Figure 2-1. Birdcage 


\subsection{Materials in Processing Area}

The amount of material exposed in the processing area at any one time in the material process can range from 6 to $50 \mathrm{~kg}$, but is only present during the normal five-day work period. The birdcages with the material for specific machine input and output are moved by cart to the machine area at the start of each shift and are locked in place to a ring set in the floor. The material handlers have the key to lock the birdcage to the floor. The machinist has the key to open the cage to mount the material in the machine. Mounting the material can take 30 minutes, but dismounting can be done in 15 seconds. Since mounting takes so long on some machines, the material is left in the machine during breaks. When the machining is done, the product is put back in the birdcage and stored until it is collected on pickup rounds. The material custodian has a schedule of work and picks up the product soon after it is completed. If a problem occurs in the process, delaying the product's scheduled pickup time, the machinist notifies his supervisor, who notifies the Material Custodian. Material at various stages of machining is stored in the billet vault during the non-working hours.

\subsection{Materials Moved from the Processing Area}

When a product is complete, it is moved to the quality control area for inspection. This area is set up as a vault, since some materials may stay there for extended periods of time. Products will also be sent via inter-site convoy to the x-ray facility as part of quality control. Once material has passed quality control, it is packed in the material container and stored in the product vault. In preparation for off-site shipment, products are packaged in shipping containers and moved to the bunker for storage. Material is shipped out on schedule set by the military.

Other materials moved from the processing area include analytical samples and waste. Analytical samples are transferred form the processing area to the analytical laboratory on an as needed basis. Nuclear waste is removed bi-weekly when the facility is operating.

\subsection{Materials in Basement Recovery Area}

Material is also accumulated in the recovery area in the basement. The turnings from the machines that are taken up in the cooling fluid are stored in the recovery area until a significant amount has accumulated. When weight differences indicate that greater than $2 \mathrm{~kg}$ of material is in the recovery area, recovery operations are undertaken, and the fluid is filtered away from the material in a settling tank. When the fluid has been drawn away, the filter material is washed to recover the uranium. The recovered uranium is weighed, placed in a can, and sent back up to the chip vault for later re-use. A sample of the material is then taken and sent to the analytical lab to determine the isotope of the material (since several different enrichments may be machined in one batch).

\section{$2.8 \quad$ X-ray Facility}

During a normal test, parts are in the X-ray Facility for approximately six hours. When potential problems arise that need more investigation, parts can be left there overnight to preserve the diagnostic setup. When materials are in the X-ray Facility overnight, patrols place a seal on the door and check the seal every 30 minutes. The X-ray Facility is constructed like a vault-when material is left overnight, it requires 60 seconds for removal from the diagnostic test stand. 


\subsection{Shipping and Receiving Warehouse}

Shipments are put into the vault the same day they are received, but are often left in the shipping and receiving warehouse for two to three hours while the receiving paperwork is completed and all the weights and serial numbers are verified. While in the shipping and receiving warehouse, material is constantly attended and is checked by patrols every 30 minutes. Material in these locations are in 100-kg shipping containers.

A section of the warehouse is designated for storing nuclear waste containers. These containers are received from the Waste Measurement facility after they have been assayed. Waste materials may be stored from several hours to several weeks until a truck load quantity is accumulated.

\subsection{Materials in Bunker}

The uranium in the bunker consists of materials that were received for recycling or finished products that are packed and ready to ship. The material for recycling is on open shelves inside the bunker. Received material is in approved shipping containers. The containers consist of a heavy gauge steel drum that has a lid secured by six bolts. After the bolts are tightened down to a specified bolt tension, each bolt has a tamper indicating device (TID) run through it to indicate if any tampering has occurred. Inside the steel shipping container is the material container, which is secured by two packing sleeves. The material container is a heavy gauge steel container that also has a lid secured by six bolts. One of these bolts is sealed with a TID. The entire container weighs approximately $100 \mathrm{~kg}$ - the shipping container weighs $65 \mathrm{~kg}$, the packing material weighs $7 \mathrm{~kg}$, the material container weighs 25 $\mathrm{kg}$, and the material weighs between 2 and $3 \mathrm{~kg}$.

The product containers are inside an expanded metal locked enclosure and weigh 50 to 100 $\mathrm{kg}$ (depending on the type). The 100-kg product containers are essentially the same as the containers for received material. The $50-\mathrm{kg}$ containers are designed to fit inside a larger shipping over-pack container and are not as robust as the $100-\mathrm{kg}$ container. They are about one half as tall and the lids snap on with three quick-release levers. The same type of inner container is used for all items (with some variations in shape/size). 


\subsection{Organization and Staffing}

This section of the hypothetical facility description discusses the organization and staffing levels of the URF. It summarizes the access authorization of facility employees and other non-employees who have routine access to areas within the URF PA. During normal operation, 250 full-time employees work at the site in plant operations, maintenance, engineering, technical support, management and administrative support positions. Of these, 182 employees require some access to the PA.

Figure 4-1 shows the overall organization of the URF. The following table shows the distribution of employees by job category, their routine plant access, and their levels of authority and knowledge about the plant.

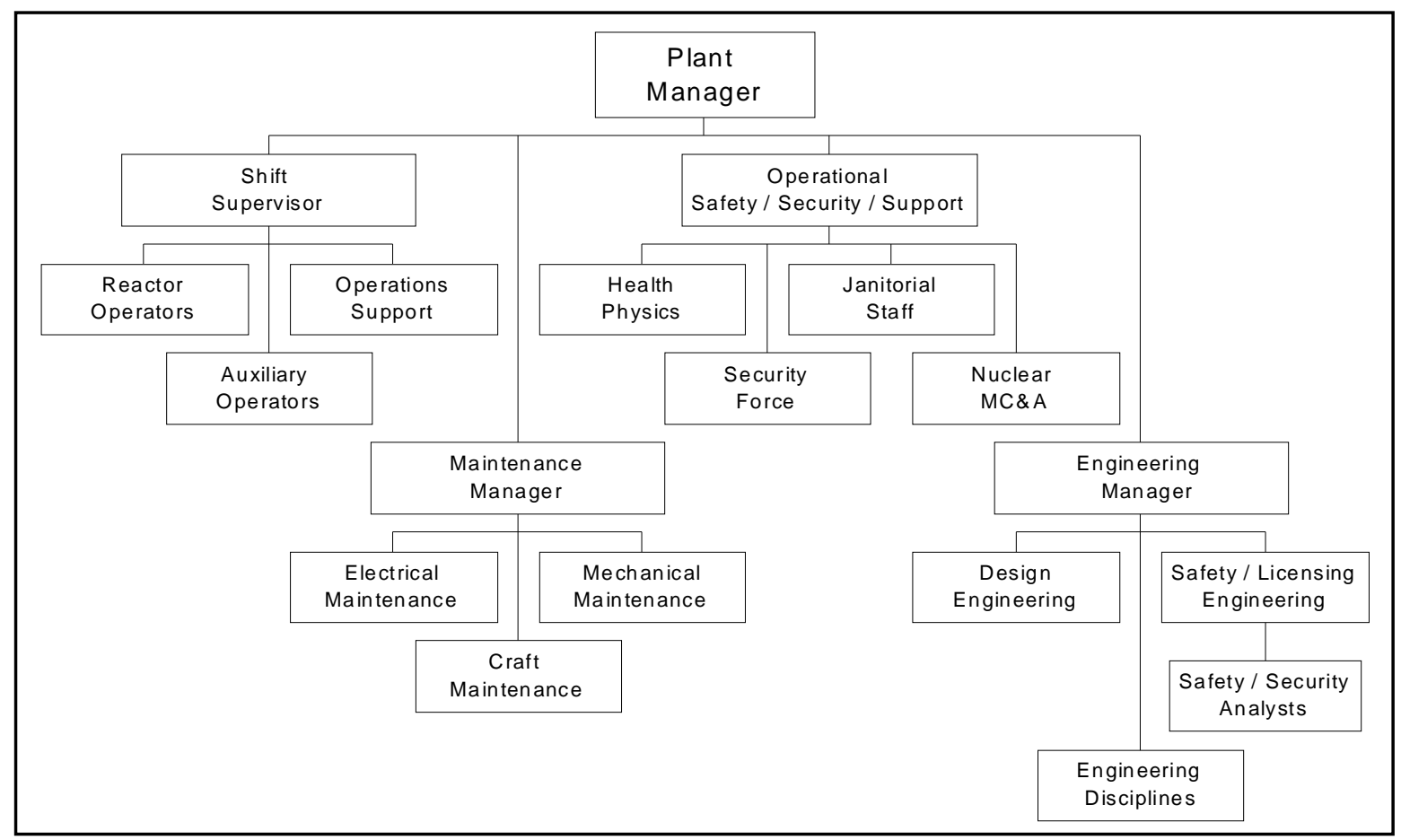

Figure 4-1. URF Organizational Structure 
Table 2. URF On-site Staffing Table

\begin{tabular}{|c|c|c|c|}
\hline Position (Number) & Routine Access & $\begin{array}{l}\text { Routine Authorityl } \\
\text { Responsibility }\end{array}$ & Knowledge \\
\hline $\begin{array}{l}\text { Plant Manager (1) } \\
\text { (Plant Manager Org.) }\end{array}$ & $\begin{array}{l}\text { PA, All Inner Areas } \\
\text { (usually escorted) }\end{array}$ & $\begin{array}{l}\text { - Overall direction } \\
\text { - Not authorized to direct } \\
\text { detailed facility } \\
\text { operations }\end{array}$ & $\begin{array}{l}\text { General knowledge of } \\
\text { plant operations, lacks } \\
\text { detailed understanding } \\
\text { of facility }\end{array}$ \\
\hline $\begin{array}{l}\text { Shift Supervisor (three } \\
\text { total with one per shift) } \\
\text { (Shift Supervisor Org.) }\end{array}$ & PA, All Inner Areas & $\begin{array}{l}\text { - Detailed direction of all } \\
\text { facility activities. } \\
\text { - Direction obeyed } \\
\text { without question in } \\
\text { most situations }\end{array}$ & $\begin{array}{l}\text { Extensive, detailed } \\
\text { knowledge about all } \\
\text { aspects of facility design } \\
\text { layout, and operation }\end{array}$ \\
\hline $\begin{array}{l}\text { Machining operator (6 } \\
\text { total with nominal } 4 \text { per } \\
\text { day shift) (Operations } \\
\text { Support Org.) }\end{array}$ & PA, All Inner Areas & $\begin{array}{l}\text { - Detailed direction of all } \\
\text { machining activities } \\
\text { - Under direction of shift } \\
\text { supervisor }\end{array}$ & $\begin{array}{l}\text { Extensive, detailed } \\
\text { knowledge about all } \\
\text { activities in the } \\
\text { machining area }\end{array}$ \\
\hline $\begin{array}{l}\text { Casting operator (6 total } \\
\text { with nominal } 4 \text { per day } \\
\text { shift) (Operations Support } \\
\text { Org.) }\end{array}$ & PA, All Inner Areas & $\begin{array}{l}\text { - Detailed direction of all } \\
\text { casting activities } \\
\text { - Under direction of shift } \\
\text { supervisor }\end{array}$ & $\begin{array}{l}\text { Extensive, detailed } \\
\text { knowledge about all } \\
\text { activities in the casting } \\
\text { area }\end{array}$ \\
\hline $\begin{array}{l}\text { Operations Support (6 } \\
\text { total with nominal } 4 \text { per } \\
\text { day shift) } \\
\text { (Operations Support } \\
\text { Org.) }\end{array}$ & PA, All Inner Areas & $\begin{array}{l}\text { - Perform specific } \\
\text { operations tasks under } \\
\text { direction of machining } \\
\text { and casting operators }\end{array}$ & $\begin{array}{l}\text { Specialized knowledge } \\
\text { related to their duties, } \\
\text { narrow knowledge of } \\
\text { complete facility systems }\end{array}$ \\
\hline $\begin{array}{l}\text { Maintenance Manager (3 } \\
\text { total with nominal } 1 \text { per } \\
\text { shift) } \\
\text { (Maintenance Org.) }\end{array}$ & $\begin{array}{l}\text { PA, All Inner Areas } \\
\text { (usually escorted) }\end{array}$ & $\begin{array}{l}\text { - Overall direction to } \\
\text { maintenance personnel }\end{array}$ & $\begin{array}{l}\text { General knowledge of } \\
\text { plant operations }\end{array}$ \\
\hline $\begin{array}{l}\text { Electrical Maintenance (6 } \\
\text { total with nominal } 4 \text { per } \\
\text { day shift) } \\
\text { (Maintenance Org.) }\end{array}$ & $\begin{array}{l}\text { PA, All Inner Areas } \\
\text { as work orders } \\
\text { specify }\end{array}$ & $\begin{array}{l}\text { - Perform activities on } \\
\text { specific systems } \\
\text { pursuant to work } \\
\text { orders and the plan of } \\
\text { the day }^{1}\end{array}$ & $\begin{array}{l}\text { Specialized knowledge } \\
\text { related to their duties, } \\
\text { narrow knowledge of } \\
\text { complete facility systems }\end{array}$ \\
\hline $\begin{array}{l}\text { Mechanical Maintenance } \\
\text { (6 total with nominal } 4 \text { per } \\
\text { day shift) } \\
\text { (Mechanical Maintenance } \\
\text { Org.) }\end{array}$ & $\begin{array}{l}\text { PA, All Inner Areas } \\
\text { as work orders } \\
\text { specify }\end{array}$ & $\begin{array}{l}\text { - Perform activities on } \\
\text { specific systems } \\
\text { pursuant to work } \\
\text { orders and the plan of } \\
\text { the day }\end{array}$ & $\begin{array}{l}\text { Specialized knowledge } \\
\text { related to their duties, } \\
\text { narrow knowledge of } \\
\text { complete facility systems }\end{array}$ \\
\hline $\begin{array}{l}\text { Administrative support } \\
\text { (40, all day shift) } \\
\text { (Operational / Safety / } \\
\text { Security Support Org.) }\end{array}$ & $\begin{array}{l}\text { Only to the outer } \\
\text { office complex; } \\
\text { occasional access } \\
\text { to other areas } \\
\text { requires escort } \\
\end{array}$ & - Administrative support & $\begin{array}{l}\text { No working knowledge } \\
\text { of facility systems }\end{array}$ \\
\hline $\begin{array}{l}\text { Health Physics } \\
\text { Technicians ( } 4 \text { total with } \\
\text { nominal } 3 \text { per day shift) } \\
\text { (Health Physics Org.) }\end{array}$ & $\begin{array}{l}\text { PA, all Inner Areas } \\
\text { and occasional } \\
\text { escorted access to } \\
\text { Storage Areas }\end{array}$ & $\begin{array}{l}\text { - Monitor radiological } \\
\text { conditions } \\
\text { - Not permitted to work } \\
\text { on plant equipment }\end{array}$ & $\begin{array}{l}\text { Specialized knowledge } \\
\text { related to their duties, } \\
\text { narrow knowledge of } \\
\text { facility systems }\end{array}$ \\
\hline
\end{tabular}

${ }^{1}$ The plan of the day establishes the maintenance tasks to be performed each day and the systems to be removed from service for maintenance. The shift supervisor or his designee is required to be informed and provide authorization before a system is taken out of service for maintenance. 


\begin{tabular}{|c|c|c|c|}
\hline Position (Number) & Routine Access & $\begin{array}{l}\text { Routine Authorityl } \\
\text { Responsibility }\end{array}$ & Knowledge \\
\hline $\begin{array}{l}\text { Guard Supervisor (5 total, } \\
1 \text { at all times) } \\
\text { (Security Force Org.) }\end{array}$ & PA, all Inner Areas & $\begin{array}{l}\text { - Direct activities of } \\
\text { security force }\end{array}$ & $\begin{array}{l}\text { No knowledge of facility } \\
\text { systems, but } \\
\text { knowledgeable about } \\
\text { plant security systems } \\
\text { and security procedures }\end{array}$ \\
\hline $\begin{array}{l}\text { Alarm Station Operators } \\
\text { ( } 5 \text { total, } 1 \text { at all times) } \\
\text { (Security Force Org.) }\end{array}$ & $\begin{array}{l}\text { PA, Central or } \\
\text { Secondary Alarm } \\
\text { station }\end{array}$ & $\begin{array}{l}\text { - Monitor alarms and } \\
\text { direct response under } \\
\text { the direction of the } \\
\text { Guard Supervisor }\end{array}$ & $\begin{array}{l}\text { No knowledge of facility } \\
\text { systems, but } \\
\text { knowledgeable about } \\
\text { plant security systems } \\
\text { and security operational } \\
\text { procedures }\end{array}$ \\
\hline $\begin{array}{l}\text { Patrol Guards (10 total, } 2 \\
\text { at all times) } \\
\text { (Security Force Org.) }\end{array}$ & PA, all Vital Areas & $\begin{array}{l}\text { Routine patrol of PAs } \\
\text { and non-radiological } \\
\text { vital areas and respond } \\
\text { to plant alarms }\end{array}$ & $\begin{array}{l}\text { No knowledge of facility } \\
\text { systems, but } \\
\text { knowledgeable about } \\
\text { plant security systems } \\
\text { and security operational } \\
\text { procedures }\end{array}$ \\
\hline $\begin{array}{l}\text { Post and tower Guards } \\
\text { ( } 34 \text { total, } 8 \text { during the day } \\
\text { shift, and } 6 \text { all other } \\
\text { times) } \\
\text { (Security Force Org.) }\end{array}$ & PA, all Vital Areas & $\begin{array}{l}\text { Staff access control } \\
\text { and other security } \\
\text { posts and respond to } \\
\text { plant alarms }\end{array}$ & $\begin{array}{l}\text { No knowledge of plant } \\
\text { safety / operational } \\
\text { systems or plant } \\
\text { response to abnormal } \\
\text { conditions, but } \\
\text { knowledgeable about } \\
\text { security operational } \\
\text { procedures }\end{array}$ \\
\hline $\begin{array}{l}\text { Quick response force (20 } \\
\text { total, } 4 \text { at all times) }\end{array}$ & & & $\begin{array}{l}\text { No knowledge of plant } \\
\text { safety / operational } \\
\text { systems or plant } \\
\text { response to abnormal } \\
\text { conditions, but } \\
\text { knowledgeable about } \\
\text { security operational } \\
\text { procedures }\end{array}$ \\
\hline $\begin{array}{l}\text { Janitorial Staff ( } 9 \text { total, } 5 \\
\text { during day shift and } 2 \text { at } \\
\text { all other times) } \\
\text { (Janitorial Staff Org.) }\end{array}$ & $\begin{array}{l}\text { Outer office area, } \\
\text { PA, and Specific } \\
\text { Inner Areas } \\
\text { dependent on work } \\
\text { assignment }\end{array}$ & 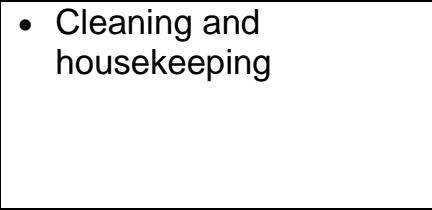 & $\begin{array}{l}\text { No knowledge of plant } \\
\text { systems or security } \\
\text { measures }\end{array}$ \\
\hline $\begin{array}{l}\text { Material Balance Area } \\
\text { Custodians ( } 2 \text { total, day } \\
\text { shift) } \\
\text { (Nuclear Material Control } \\
\text { and Accountancy [MC\&A] } \\
\text { Org.) }\end{array}$ & $\begin{array}{l}\text { PA, Inner Areas } \\
\text { and Storage Areas }\end{array}$ & $\begin{array}{l}\text { - Direct nuclear material } \\
\text { inventories, authorize } \\
\text { transfers }\end{array}$ & $\begin{array}{l}\text { Knowledgeable about } \\
\text { nuclear material status } \\
\text { and inventory } \\
\text { procedures, but no } \\
\text { knowledge of facility } \\
\text { systems }\end{array}$ \\
\hline $\begin{array}{l}\text { Nuclear Material } \\
\text { Technicians (2 total) } \\
\text { (Nuclear MC\&A Org.) }\end{array}$ & $\begin{array}{l}\text { PA, Inner Areas } \\
\text { and Storage Areas }\end{array}$ & $\begin{array}{l}\text { - Perform nuclear } \\
\text { material operations } \\
\text { and inventories at the } \\
\text { direction of Material } \\
\text { Balance Area (MBA) } \\
\text { custodians }\end{array}$ & $\begin{array}{l}\text { Knowledgeable about } \\
\text { nuclear material status } \\
\text { and inventory } \\
\text { procedures, but no } \\
\text { knowledge of facility } \\
\text { systems }\end{array}$ \\
\hline
\end{tabular}




\begin{tabular}{|c|c|c|c|}
\hline Position (Number) & Routine Access & $\begin{array}{l}\text { Routine Authorityl } \\
\text { Responsibility }\end{array}$ & Knowledge \\
\hline $\begin{array}{l}\text { Nuclear Material } \\
\text { Accountability } \\
\text { Technicians (2 total) } \\
\text { (Nuclear MC\&A Org.) }\end{array}$ & $\begin{array}{l}\text { Escorted access to } \\
\text { PA, Inner Areas } \\
\text { and Storage Areas }\end{array}$ & $\begin{array}{l}\text { - Maintain paper } \\
\text { accountability system } \\
\text { and generate required } \\
\text { nuclear material status, } \\
\text { transfer, and inventory } \\
\text { reports }\end{array}$ & $\begin{array}{l}\text { Knowledgeable about } \\
\text { nuclear material status } \\
\text { and inventory } \\
\text { procedures, but no } \\
\text { knowledge of facility } \\
\text { systems }\end{array}$ \\
\hline $\begin{array}{l}\text { Engineering Support (3, } \\
\text { all day shift) } \\
\text { (Engineering Manager } \\
\text { Org.) }\end{array}$ & $\begin{array}{l}\text { Only to the outer } \\
\text { office complex; } \\
\text { occasional access } \\
\text { to other areas } \\
\text { requires escort }\end{array}$ & $\begin{array}{l}\text { - Support plant } \\
\text { engineering activities }\end{array}$ & $\begin{array}{l}\text { Specialized knowledge } \\
\text { related to their duties }\end{array}$ \\
\hline $\begin{array}{l}\text { Design, Mechanical, } \\
\text { Electrical, Civil, Chemical } \\
\text { and Nuclear Engineers } \\
\text { (5, all day shift) } \\
\text { (Design Engineering \& } \\
\text { Engineering Discipline } \\
\text { Orgs.) }\end{array}$ & $\begin{array}{l}\text { PA, Inner Areas } \\
\text { with escort }\end{array}$ & $\begin{array}{l}\text { Perform design } \\
\text { activities and review } \\
\text { performance and } \\
\text { status of specific } \\
\text { systems }\end{array}$ & $\begin{array}{l}\text { Specialized knowledge } \\
\text { related to design and } \\
\text { performance of specific } \\
\text { plant systems, moderate } \\
\text { knowledge of complete } \\
\text { facility systems }\end{array}$ \\
\hline $\begin{array}{l}\text { Safety Engineers, (2 on } \\
\text { day shift) } \\
\text { (Safety / Licensing } \\
\text { Engineering Org.) }\end{array}$ & $\begin{array}{l}\text { PA, Inner Areas } \\
\text { with Escort }\end{array}$ & $\begin{array}{l}\text { Analyze safety and } \\
\text { impacts of proposed } \\
\text { changes, develop / } \\
\text { review procedures and } \\
\text { procedure revisions, } \\
\text { prepare documents for } \\
\text { State regulator } \\
\end{array}$ & $\begin{array}{l}\text { General knowledge of } \\
\text { performance and roles of } \\
\text { facility systems, but no } \\
\text { detailed knowledge of } \\
\text { operation of complete } \\
\text { facility systems }\end{array}$ \\
\hline Security Analysts (2) & $\begin{array}{l}\text { PA, Vital Areas with } \\
\text { escorts }\end{array}$ & $\begin{array}{l}\text { Perform security } \\
\text { analysis activities and } \\
\text { review performance } \\
\text { and status of specific } \\
\text { systems }\end{array}$ & $\begin{array}{l}\text { Specialized knowledge } \\
\text { related to design and } \\
\text { performance of security } \\
\text { systems }\end{array}$ \\
\hline
\end{tabular}

Table 3. Non-employee Access to URF Table

\begin{tabular}{|l|l|l|l|}
\hline \multicolumn{1}{|c|}{ Type } & Routine Access & $\begin{array}{l}\text { Routine Authority I } \\
\text { Responsibility }\end{array}$ & \multicolumn{1}{|c|}{ Knowledge } \\
\hline Vendors & $\begin{array}{l}\text { Only to the outer } \\
\text { office complex; } \\
\text { occasional access to } \\
\text { other areas requires } \\
\text { escort }\end{array}$ & $\begin{array}{l}\text { - No authority over plant } \\
\text { employees }\end{array}$ & $\begin{array}{l}\text { No knowledge of plant } \\
\text { systems, plant response } \\
\text { to abnormal conditions, } \\
\text { or security measures }\end{array}$ \\
\hline $\begin{array}{l}\text { State Safety/Security } \\
\text { Inspectors }\end{array}$ & $\begin{array}{l}\text { PA and Inner Areas; } \\
\text { employee escort } \\
\text { required for all } \\
\text { access }\end{array}$ & $\begin{array}{l}\text { - No direct authority over } \\
\text { plant employees } \\
\text { however suggestions } \\
\text { are given great weight }\end{array}$ & $\begin{array}{l}\text { General knowledge of } \\
\text { performance and roles of } \\
\text { facility systems }\end{array}$ \\
\hline
\end{tabular}




\subsection{URF Material Control and Accountancy System}

This section of the hypothetical facility description discusses the URF procedures for nuclear material control and accountancy (MC\&A) and briefly describes the accounting system.

\subsection{MC\&A Organization}

By letter of designation, the plant manager has delegated the responsibilities and authorities of all safeguard positions. A single individual is assigned the responsibility for technical coordination of the overall MC\&A program. This position is referred to as the Material Control Manager. This position is separate from production and any other responsibilities that might give rise to a conflict of interest. In addition, there is a Measurement Control Coordinator, and, if needed, multiple Material Balance Area (MBA) Custodians assigned specific authorities, responsibilities, and locations reporting directly to the Material Control Manager.

\subsection{Material Balance Areas}

Four MBAs have been established at the URF. These are the Production Floor, the X-Ray Facility, the Analytical Laboratory, and the Final Products Bunker. All accountable SNM at the URF is maintained in one of these four MBAs. Non-accountable SNM in the form of waste can be present in the Waste Measurement facility and the Shipping/Receiving Warehouse. The physical boundaries of the X-Ray Facility, Analytical Laboratory, and the Final Products Bunker MBAs are the structural boundaries of the respective building. The physical boundaries of the Production Floor MBA are the walls and access control point for the production area.

\subsection{Measurements and Measurement Control Program}

This program is under the control of the Measurement Control Coordinator. The measurement control program ensures the quality and reliability of the measurement data. This facility incorporates the following measurement control elements:

- $\quad$ various mass weighing stations

- destructive laboratory analysis and sampling

- $\quad$ non-destructive analysis (NDA) measurement systems

- weekly calibration or operability checks with reference standards

- a sampling program to ensure that portions of the bulk material taken for measurement are representative of the bulk material

- control programs associated with all measurement systems to assure the quality of data generated

The measurement Control Coordinator maintains the equipment and standards in a locked room in the non-nuclear material portion of the processing facility and is responsible for the proper use and calibration of the equipment.

In addition, the MC\&A organization would control and issue TIDs for use throughout the facility. MBA Custodians would be the only personnel trained to apply and remove TIDs. 


\subsection{Physical Inventories}

A physical inventory is conducted every two months under normal conditions. This physical inventory consists of a $100 \%$ inventory of items or containers with TIDs, and measurement of a statistical sample of items. The measurements are NDA measurements and the attributes are compared to the book data. Discrepancies are tracked in the measurement control system. If a measurement is beyond the control limits for that measurement from the recorded value, the item in question is subjected to additional confirmatory measurements, including opening the container and, if required, conducting destructive measurements.

Data obtained during the physical inventory, data from measurements during the material reconciliation period, and control program data are used to calculate the Limit of Error of Inventory Difference (LEID). Special inventories are conducted when custodial responsibilities are changed, items are believed to be missing, inventory differences exceed established control limits, and other abnormal occurrences take place. These special inventories may be limited to a single vault or MBA, depending on the occurrence. However, the facility may be impacted, depending on the circumstances. Investigation of inventory differences between accounting records and physical inventory results will be performed to determine the cause.

Table 4. Nominal URF SNM Inventory

\begin{tabular}{|l|l|l|}
\hline Material Balance Area & Form of Material & $\begin{array}{c}\text { Material Inventory } \\
\text { (wt\% enrichment) }\end{array}$ \\
\hline X-Ray Facility & & \\
\hline Final Product Bunker & & \\
\hline Analytical Laboratory & & \\
\hline \multirow{2}{*}{ Production Floor } & & \\
\cline { 2 - 3 } & & \\
\hline & & \\
\hline
\end{tabular}

\subsection{Measurement Points}

Material measurements may take place at several points in an item's life in the processing area. Material is normally measured on the following occasions:

- A receipt measurement is taken within five days of receipt.

- Depending on whether the mass limit exceeds $2 \mathrm{kgs}$, an item may require a measurement for Internal Transfers between MBAs.

- Measurements are taken when modifications are made to materials in the machining or casting process.

- Measurements are taken as part of Item Monitoring along the process path.

- Final product measurements are taken before containerization and TID application.

- A final measurement is performed within five days before shipment.

- Waste is measured at the Waste Measurement facility as packages are generated and staged. 


\subsection{Shipping and Receiving}

Items received are booked on shipper's values for element and isotope content. When shipments are received, the item count and item identifiers are verified against the shipping documents. Items shipped are sent based upon the book values for the element and isotope content. Where shipper receiver differences are identified on shipped items, the shipperreceiver difference is resolved by adjusting the URF book values to the receiver's measured values, as long as the difference does not reflect a difference in the number and identity of the items shipped and received.

\subsection{Item Monitoring}

In addition to the fixed periodic physical inventories, the process area has further designated several Inventory Control Locations, which provide the capability to physically locate (or confirm the location of items in a timely manner. This capability to localize losses (or thefts) of SNM allows for the identification of the mechanism for any such loss (or theft) in a more time-sensitive manner. Process boundaries are selected primarily on the basis of manufacturing control; however, this division also enables managerial assignment of specific material handling and control responsibilities, if required.

\subsection{Adjustments to Inventory}

Adjustments are made to inventory on the basis of the measurements at the key measurement points. Accountability values for billets/ingots are based on DA/weight. Inventory is adjusted for the difference between the measured input versus the final accountability weight. Adjustments are also made based on waste is removed from the process as established by NDA in the Waste Measurement Facility.

\subsection{Accounting Reports}

URF submits material balance reports for each MBA within 30 days of completion of a physical inventory. Nuclear material transaction reports for the MBA covering all transactions during the inventory period are submitted with the material balance report. URF provides a telephone report to the State regulator within four hours of determining that an item cannot be accounted for. This report is followed up by a written report within 24 hours of this determination.

\subsection{Accountancy System}

URF employs a computer-based accounting system that is managed and operated by personnel who are not authorized access to SNM. The computer on which the accounting system is run is a standalone machine. Entry of or access to accounting data or modification of the accounting software requires authorization via a password system. All data is input to the URF computer accounting system from paper records (e.g., inventory sheets and material transfer forms), which are uniquely numbered, accounted for, signed by the individuals completing them, and retained for the life of the plant. The URF accounting software is commercially procured and is not modified by plant staff.

\subsection{Material Control}

Physical control of the material is established through several individual programs. Access controls limit personnel access to the processing area, and additional access controls further limit personnel access to the processing floor in the processing building. Once on the 
processing floor, procedural measures limit access to material to those with an established need for access. The MBA Custodians for the various process area locations authorize all material movements. Material access is further enforced through the use of the two-person rule. Any time a material location is accessed, two persons must be present. Two persons must also be present when material is on the machines on the process floor. The machine operator is one of the two persons and the machining supervisor or MC\&A Representative acts as the second person for all material being worked on at any given time. Access to specific parts is controlled through the use of locks on the birdcages containing materials. The machine operator is only issued the keys for the work that is at his station for the day.

Transfers of samples to the Analytical Laboratory and Waste to the Waste Measurement Facility are handled by Operations Support Personnel. Since these are Category III/IV quantities the two person rule is not applied.

\subsection{Personnel Access Control at Protected Area ECP}

\subsubsection{Entry Process}

Personnel entering the PA must process through the ECP. The ECP is open from 0700 to 1800 Monday through Friday. Authorized personnel enter the area through the middle double doors to the ECP and process through contraband portal detectors. All hand-carried items are placed in plastic boxes and processed through the X-ray machine. Personnel then proceed through the portal metal detector. If they trigger an alarm, they may walk back through the portal, search themselves to determine what caused the alarm, place that material on the X-ray belt, and walk through the portal again. If they do not trigger another alarm, they may collect their materials and enter into the processing area. If they set off the portal alarm a second time, they must be searched by the guards with a hand-held unit. The guards also monitor the X-ray video for contraband. There are two guards at the portal area to process personnel.

\subsubsection{Exit Process}

Personnel exiting the PA enter the ECP through the double doors and pass through the nuclear material monitoring portal. If they do not set off the alarm, they continue through the exit doors (east and west). If there is an alarm, the guards will stop the person passing through the alarming portal and call the Health Physics personnel, who will respond to determine the cause of the alarm. If the portals alarm when personnel are passing through them to enter the area, the person is stopped and questioned regarding possible reasons the alarm might have gone off and Health Physics is called to check the equipment. That exit door will be locked until the monitor is certified to be in working order.

The ECP for the processing floor in the processing building is similar to the area ECP and contains the same equipment (although the metal detection threshold is lower).

\subsubsection{Contraband Detection Equipment}

All contraband detection equipment and alarm equipment at the ECPs is maintained and tested by the technical unit of the guard force. The X-ray and metal detection equipment is function-tested every shift. The guard supervisor walks through the metal detection portal (with his sidearm) to ensure that it alarms and will run a test item (such as a step wedge) through the X-ray detector to check the operability of the X-ray system. The nuclear material portals are only tested via the self-test button (which only tests the light and tone alarms), 
since getting access to a test source requires the coordination of the Health Physics or MC\&A staff.

The contraband detection equipment is performance-tested on a monthly basis. A special test item kit is used to test the metal detection portal. This kit contains sealed weapons that bound the less detectable, commercially available handguns. Two technicians from the technical unit perform the test; one passes the units through the field at specific locations, and the other reads through the test procedure and records results. The sensitivity of the X-ray unit is tested with a test kit containing various synthetic explosive materials, various gauges of wire, and various shielding materials. If any equipment is found to fall below specified performance specifications, it is readjusted per the manufacturer's instructions and tested again. The nuclear material portal monitor is also checked at this time. The Health Physics personnel bring a radiological source (Americium) and take it through the portal in several configurations (near the top of the portal, near the middle, and near the bottom). The Health Physics personnel make any required adjustments to the equipment, since the technical unit of the guard force does not receive training in nuclear detection equipment; however, someone from the technical unit must be present while the Health Physics personnel make these adjustments.

The nuclear material portal monitor controls and sensitivity adjustment are contained in a locked panel on one side of the portal. The head of the Health Physics department locks the key in a safe in his office. The unit is wired to the security power system for the CAS, which has an uninterruptible power supply (UPS) and a generator backup. The alarm for the unit is local with a light and tone alert. The metal detector sensitivity adjustment and controls are located in the top panel of the unit. There is a key pad for user input and a code is used to access the setup and adjustment menus. There are several basic sensitivity programs that come with the unit from the factory that can be selected with one key stroke, if the supervisor code was entered. These units are also wired into the CAS power system. The alarm for these units is local and consists of an alarm tone and a light bar indication of alarm strength. The X-ray units are powered by normal facility power, since they overran the capacity of the CAS power system. Sensitivity adjustment control is through software with a password required for access to any operation other than normal screening. A trained operator must watch the screen to notice if contraband is passing through the system. There is no automatic alarm indication.

If a system malfunction is noted in the daily report, it is required to be worked on within 24 hours. During normal operating hours, there are always two technicians available to assure adequate oversight of repair work. On weekends, there is often only one technician available, so a guard watches over the work. After any maintenance or repair work, the system is tested by the technician and then is put back in service.

\subsubsection{Intrusion Detection Systems}

The technical unit of the guard force is also responsible for testing intrusion detection systems in place at the site. The critical intrusion detection systems are tested monthly (e.g., in the vaults) and other systems are tested quarterly on a rotational basis. All tests are carried out according to a schedule that the guard force commander approves annually. BMS testing is considered to be completed by normal opening of doors for routine activities and is not specifically tested in the scheduled tests. The testing performed on a regular basis is 
classified as performance testing and is done to determine how the sensors detect people approaching a target. The technicians perform the walk test on interior sensors by starting at a logical starting point (e.g., a door or window) and progressing toward the target until an alarm is signaled. This is repeated at least ten times and at least once from all possible entry locations. If any detections are missed, they will be reported. If the problem is from the equipment or furniture in the detection area, the occupants will be contacted and will work with the technical unit to resolve the issue. If the blocking items cannot be moved, more detectors may be installed.

Two members of the technical unit conduct the tests - one reads through the procedure and record results while the other performs the walk test. Two members of the technical unit will also be on hand for any repairs to ensure oversight of repair work. Once repairs are made, the system will be performance-tested by the technical unit and turned over to the CAS.

All intrusion detection systems have an installed battery backup power system and are connected to a stand-by generator. A fully charged battery will power the intrusion system for at least ten minutes, which is sufficient time for the generator to be switched on. Backup batteries are checked when the systems are performance-tested. Generators are tested every three months on weekends by facilities management personnel.

All intrusion alarm communications wiring is run in conduit and has DC line supervision. All junction boxes are either sealed or have tamper switches. The data-gathering panels are locked with a special key that only the technical unit has access to. They are also protected with tamper switches.

\subsection{Lock and Key Control}

The technical unit is also charged with installing locks, making keys, and changing combinations. One master locksmith and several clerks assist with key control. The office for the lock unit is in Administrative Annex 1. All combinations and key blanks are stored in a safe. Records of keys and work requests and completions are kept on a computer in the office. Only the master locksmith and the clerical staff have the password to the system. Keys for office doors, building doors, and padlocks are cut on a special key blank registered to the site. There are not supposed to be any master keys. Once a certain number of keys have been lost (greater then 5\%), all locks are re-cored with a new keyway. All combination locks have the combinations changed at least annually. However, if a change in personnel occurs, the combination will be changed immediately.

\subsection{Badge and Visitor Control}

The site uses a new badge printing process that prints directly on plastic badge stock. The entire system has changed to this new type of badge, and a background has been designed and a tamper-resistant overlay has been provided for all national sites to use. Although each site has a special alpha-numeric identifier that shows where the particular badge was issued, the badges are designed to allow access at all affiliated sites. The badge office (in the Administrative Building outside of the PA) prints all employee and visitor badges for this site. Badge stock is locked up in a safe in the badge office when it is not occupied. Different colors around the border of the badge signify different access authorizations. A legend of these designators is posted in access control points to quickly resolve any questions about access. 


\subsection{Operations at Gates and Portals at the URF 5.1 Site Personnel and Vehicle Entrance (P2)}

Personnel are permitted access through an access control point after verification that they have a current site badge. The guard controlling access is required to verify that the picture matches the badge holder and that the badge has not expired or been revoked. There is an access control office in the Administration Building that issues permanent and temporary badges for access to the plant. There is no check on exiting personnel.

Vehicles authorized routine entry to the site are provided with decals. The security officer(s) on duty permit vehicles to enter upon verifying the vehicle decal and the badges of all vehicle occupants. Temporary vehicle passes may be obtained at the Administration Building with appropriate authorization from site management.

When a delivery vehicle arrives, the guards review the manifest and shipping documents to verify that the truck has a delivery for the institute. The guards then contact the recipient of the delivery to verify that it is expected. Once this is done, the guards inspect the truck for contraband. If the delivery vehicle passes inspection, it is permitted entry to the site. There are no checks on exiting vehicles.

\subsection{Protected Area Vehicle Gates (P5)}

These gates are normally closed and locked with high-security padlocks. When a vehicle arrives, an ECP guard verifies that the driver either has a URF badge permitting access to the URF PA, or has the required escorts. Once the guard has verified that the vehicle is expected, the guard inspects it for contraband. If the vehicle passes inspection, the guards contact the CAS to request that the PA intrusion detection system zone at the gates be placed in the access mode. The guards then unlock the vehicle gates to permit the vehicle entry to the URF PA. After the vehicle has entered the PA, the gates are locked and the PA intrusion detection system zone at the gates is returned to the secure mode.

On exit, vehicles are scanned with a radiation monitor to ensure that there is no contamination and are searched for SNM. Once guards verify that the vehicles are not contaminated and do not have unauthorized SNM, the vehicles are permitted to exit. The contamination scan and SNM search are performed inside the PA with the vehicle gates locked.

\subsection{Protected Area Personnel Access Control Point (P6)}

Personnel entering the PA undergo a search for contraband by passing through metal and explosive detectors. Hand-carried items are X-rayed and passed through metal detectors. Suspicious items are physically searched. Individuals who fail the metal detector search are either searched again with a hand-held metal detector or subjected to a pat-down search. The personnel then enter the URF PA via a key-card-accessed door. The guards who perform the badge checks have a "panic" button that will override the key card reader, freezing the doors and precluding any entry to the PA. In a Site Emergency, the doors can also be reconfigured to permit egress from the PA to facilitate evacuation. The layout of the entry control section of the URF PA Access Control point is shown in Figure 5.1.

Personnel exiting the PA undergo a search for SNM by passing through metal and SNM detectors. Hand-carried items are X-rayed. Suspicious items are physically searched. 
Individuals who fail the metal detector search are either searched again with hand-held metal detectors and SNM detectors or are subjected to a pat-down search. After verification that individuals are not carrying SNM, they undergo a badge exchange, turning in their URF picture badges and key cards and picking up their Site picture badges. The personnel then exit the URF PA via unlocked doors.

\subsection{Production Facility ECP (P8)}

The URF Production Area includes the controlled areas within the Production Building where a Category I quantity of SNM is accessible. The key card system for entry to and exit from this area requires two key cards in order to open the door.

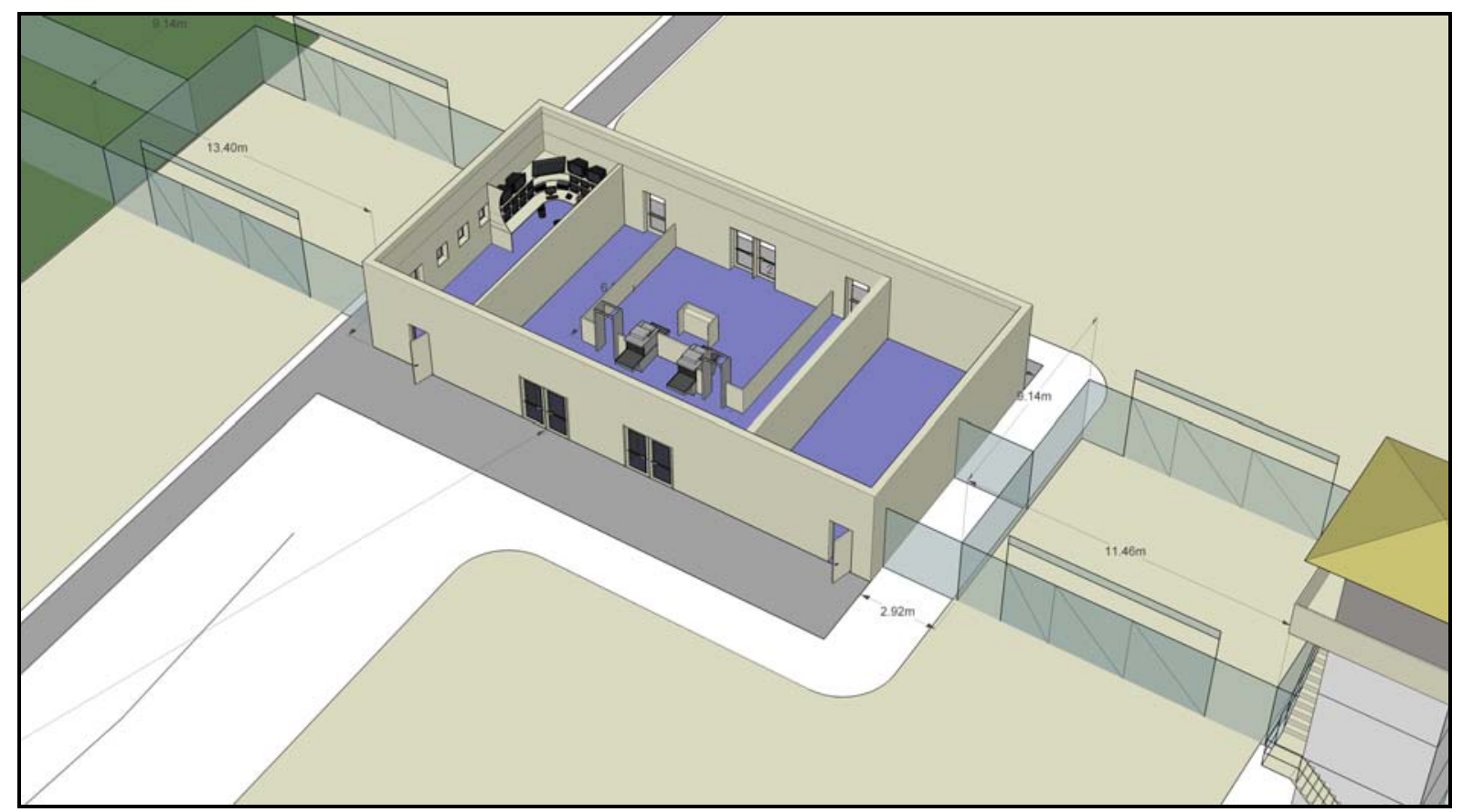

Figure 5-1. PA Entry Control Building 


\subsection{Physical Barriers and Alarms}

The URF Site is surrounded by an unalarmed 2.5-meter-high chain-link fence to delineate the legal boundary and keep out trespassers. The URF PA is surrounded by two 2.5-meter-high chain-link fences with an alarmed isolation zone between the two fences. The vital areas within the URF are enclosed by 20-cm-thick reinforced concrete walls with access through 0.75 -cm steel-plate water tight doors. Access is controlled by an electronic key card system that releases a door latch. In addition, each such door is alarmed with a BMS to detect unauthorized entry.

\subsection{Area Specific Access Controls and Physical Barriers}

Table 5. Access Controls and Physical Barriers

\begin{tabular}{|c|c|c|c|}
\hline Controlled Area & Access Controls & Physical Barriers & Detection Devices \\
\hline AA & Employee badge & $\begin{array}{l}\text { Chain-link fence; } \\
\text { vehicle gate }\end{array}$ & Guard checks \\
\hline PA & ECP & $\begin{array}{l}\text { Perimeter Intrusion } \\
\text { Detection and } \\
\text { Assessment System }\end{array}$ & $\begin{array}{l}\text { Perimeter sensors; tower } \\
\text { guards }\end{array}$ \\
\hline ECP & $\begin{array}{l}\text { Employee badge } \\
\text { with guard present } \\
\text { to ensure correct } \\
\text { procedures at } \\
\text { metal detectors } \\
\text { and SNM } \\
\text { detectors }\end{array}$ & Security doors; walls & $\begin{array}{l}\text { Guard; metal detectors } \\
\text { and SNM detectors }\end{array}$ \\
\hline X-Ray Facility & $\begin{array}{l}\text { 2-person control } \\
\text { on locks }\end{array}$ & $\begin{array}{l}\text { Vault-like construction } \\
\text { with Class } \vee \text { doors }\end{array}$ & $\begin{array}{l}\text { BMS door sensor; interior } \\
\text { PIR sensors }\end{array}$ \\
\hline Final Product Bunker & $\begin{array}{l}\text { 2-person control } \\
\text { on locks }\end{array}$ & $\begin{array}{l}\text { Vault-like construction } \\
\text { with Class } \vee \text { doors }\end{array}$ & $\begin{array}{l}\text { BMS door sensor; interior } \\
\text { PIR sensors }\end{array}$ \\
\hline Production Building & $\begin{array}{l}\text { Entry control } \\
\text { portal }\end{array}$ & $\begin{array}{l}\text { Security doors; walls; } \\
\text { guard }\end{array}$ & Metal and SNM detectors \\
\hline Product Vault & $\begin{array}{l}\text { 2-person control } \\
\text { on locks }\end{array}$ & $\begin{array}{l}\text { Vault-like construction } \\
\text { with Class } \vee \text { doors }\end{array}$ & $\begin{array}{l}\text { BMS door sensor; interior } \\
\text { PIR sensors }\end{array}$ \\
\hline QA Vault & $\begin{array}{l}\text { 2-person control } \\
\text { on locks }\end{array}$ & $\begin{array}{l}\text { Vault-like construction } \\
\text { with Class } \vee \text { doors }\end{array}$ & $\begin{array}{l}\text { BMS door sensor; interior } \\
\text { PIR sensors }\end{array}$ \\
\hline Chip Vault & $\begin{array}{l}\text { 2-person control } \\
\text { on locks }\end{array}$ & $\begin{array}{l}\text { Vault-like construction } \\
\text { with Class V doors }\end{array}$ & $\begin{array}{l}\text { BMS door sensor; interior } \\
\text { PIR sensors }\end{array}$ \\
\hline $\begin{array}{l}\text { Casting Furnace } \\
\text { Area }\end{array}$ & $\begin{array}{l}\text { 2-person control } \\
\text { on locks }\end{array}$ & $\begin{array}{l}\text { Vault-like construction } \\
\text { with Class } \mathrm{V} \text { doors }\end{array}$ & $\begin{array}{l}\text { BMS door sensor; interior } \\
\text { PIR sensors }\end{array}$ \\
\hline
\end{tabular}




\subsection{Likelihood of Detection for Sensors}

The following qualitative likelihoods of detection should be used in all sub-group exercises.

Table 6. Probabilities of Detection for Sensors

\begin{tabular}{|c|c|c|c|c|c|}
\hline & $\begin{array}{c}\text { No } \\
\text { Equipment }\end{array}$ & $\begin{array}{l}\text { Hand } \\
\text { Tools }\end{array}$ & $\begin{array}{l}\text { Power } \\
\text { Tools }\end{array}$ & $\begin{array}{c}\text { High } \\
\text { Explosives }\end{array}$ & $\begin{array}{c}\text { Land } \\
\text { Vehicle }\end{array}$ \\
\hline \multicolumn{6}{|l|}{ Exterior Sensors } \\
\hline Generic & $M$ & $M$ & $M$ & $M$ & $\mathrm{H}$ \\
\hline $\begin{array}{l}\text { Multiple } \\
\text { complementary }\end{array}$ & $\mathrm{H}$ & $\mathrm{H}$ & $\mathrm{H}$ & $\mathrm{H}$ & N/A \\
\hline \multicolumn{6}{|l|}{ Interior Sensors } \\
\hline Generic & $\mathrm{M}$ & $\mathrm{M}$ & $\mathrm{M}$ & $\mathrm{M}$ & N/A \\
\hline $\begin{array}{l}\text { Multiple } \\
\text { complementary }\end{array}$ & $\mathrm{H}$ & $\mathrm{H}$ & $\mathrm{H}$ & $\mathrm{H}$ & $\mathrm{N} / \mathrm{A}$ \\
\hline \multicolumn{6}{|l|}{ Position Sensors } \\
\hline Position Switch & $\mathrm{M}$ & $L$ & $\mathrm{~L}$ & $\mathrm{~L}$ & N/A \\
\hline $\begin{array}{l}\text { Balanced Magnetic } \\
\text { Switch }\end{array}$ & $\mathrm{H}$ & $\mathrm{H}$ & $\mathrm{H}$ & $\mathrm{H}$ & $\mathrm{N} / \mathrm{A}$ \\
\hline \multicolumn{6}{|l|}{ People } \\
\hline General Observation & VL & VL & $L$ & $\mathrm{H}$ & $\mathrm{H}$ \\
\hline Directed Observation & $M$ & $\mathrm{H}$ & $\mathrm{H}$ & $\mathrm{H}$ & $\mathrm{H}$ \\
\hline
\end{tabular}

\subsection{Barrier Penetration Times}

The following barrier penetration times should be used in all sub-group exercises. All times are in seconds.

Table 7. Barrier Penetration Times

\begin{tabular}{|c|c|c|c|c|c|c|}
\hline \multirow{2}{*}{ Barrier Description } & \multirow{2}{*}{$\begin{array}{c}\text { No } \\
\text { Equipment }\end{array}$} & \multirow{2}{*}{$\begin{array}{l}\text { Hand } \\
\text { Tools }\end{array}$} & \multirow{2}{*}{$\begin{array}{l}\text { Power } \\
\text { Tools }\end{array}$} & \multicolumn{2}{|c|}{ Explosives } & \multirow{2}{*}{$\begin{array}{c}\text { Land } \\
\text { Vehicle }\end{array}$} \\
\hline & & & & Stage 1 & Stage 2 & \\
\hline $\begin{array}{l}\text { Wood studs and } \\
\text { sheetrock }\end{array}$ & 60 & 30 & 30 & 30 & 0 & $N / A$ \\
\hline \multicolumn{7}{|l|}{ Doors } \\
\hline $\begin{array}{l}\text { 30-cm wood door } \\
\text { with metal sheeting }\end{array}$ & Infinite & Infinite & 530 & 160 & 30 & $N / A$ \\
\hline 5-cm wood door & Infinite & 12 & 12 & 12 & 0 & $\mathrm{~N} / \mathrm{A}$ \\
\hline $\begin{array}{l}0.75-\mathrm{cm} \text { steel plate } \\
\text { door }\end{array}$ & Infinite & 300 & 30 & 30 & 0 & N/A \\
\hline $\begin{array}{l}\text { Class V or VI vault } \\
\text { door }\end{array}$ & Infinite & 480 & 60 & 60 & 0 & N/A \\
\hline \multicolumn{7}{|c|}{ 6.4 Miscellaneous Barriers } \\
\hline Steel turnstile & Infinite & 72 & 18 & 18 & 0 & $N / A$ \\
\hline High-security padlock & Infinite & 90 & 60 & 30 & 0 & $\mathrm{~N} / \mathrm{A}$ \\
\hline $\begin{array}{l}\text { Tempered glass } \\
\text { window }\end{array}$ & 5 & 5 & 5 & 5 & 5 & $\mathrm{~N} / \mathrm{A}$ \\
\hline
\end{tabular}




\subsection{Response Forces at the URF}

Table 8. URF Response Forces

\begin{tabular}{|c|c|}
\hline $\begin{array}{l}\text { Types of } \\
\text { Response Force } \\
\text { Personnel }\end{array}$ & $\begin{array}{l}\text { The response force consists of two types of onsite security personnel: } \\
\text { - Unarmed guards } \\
\text { - Armed guards, including tactical response teams }\end{array}$ \\
\hline $\begin{array}{l}\text { Responsibilities } \\
\text { of Response } \\
\text { Force }\end{array}$ & $\begin{array}{l}\text { These security personnel are responsible for: } \\
\text { - assessment of alarms } \\
\text { - administrative duties, such as access control and key service } \\
\text { - routine patrol and staffing of fixed posts } \\
\text { - response to all security alarms } \\
\text { All posts and patrols have defined policies and procedures with which the } \\
\text { guard force must comply. }\end{array}$ \\
\hline Supervisors & $\begin{array}{l}\text { For each shift, one supervisor is present to supervise the guards that } \\
\text { conduct administrative duties, patrols, and intrusion alarm response. }\end{array}$ \\
\hline $\begin{array}{l}\text { Equipment: } \\
\text { Unarmed } \\
\text { Guards }\end{array}$ & $\begin{array}{l}\text { All unarmed guards are equipped with: } \\
\text { - a straight baton } \\
\text { - one set of handcuffs } \\
\text { - a small flashlight } \\
\text { - a handheld radio }\end{array}$ \\
\hline $\begin{array}{l}\text { Equipment: } \\
\text { Armed Guards }\end{array}$ & $\begin{array}{l}\text { All armed guards are equipped with: } \\
\text { - an automatic pistol with a fully loaded magazine } \\
\text { - two spare magazines of ammunition } \\
\text { - a straight baton } \\
\text { - one set of handcuffs } \\
\text { - a small flashlight } \\
\text { - a handheld radio }\end{array}$ \\
\hline $\begin{array}{l}\text { Equipment: } \\
\text { Tactical } \\
\text { Response Team }\end{array}$ & $\begin{array}{l}\text { The tactical response team members are equipped with: } \\
\text { - an automatic pistol with a fully loaded magazine } \\
\text { - an automatic assault rifle with a fully loaded magazine } \\
\text { - two spare magazines of ammunition for each weapon } \\
\text { - a straight baton } \\
\text { - handcuffs } \\
\text { - flashlight } \\
\text { - handheld radio } \\
\text { - body armor is readily available in the response force vehicles }\end{array}$ \\
\hline $\begin{array}{l}\text { Alarm Stations } \\
\text { and } \\
\text { Communication }\end{array}$ & $\begin{array}{l}\text { The Central Alarm Station (CAS) is located in P-1 and is staffed by a } \\
\text { minimum of one guard at all times. This guard is responsible for the } \\
\text { assessment of alarms and communication to the response force. The } \\
\text { security force supervisor is routinely at the CAS. } \\
\text { The CAS is equipped with: } \\
\text { - } 100 \text {-watt radios that can communicate to all posts and patrols within } \\
\text { the boundaries of the Institute } \\
\text { - } 2 \text { telephone lines-one is linked to each fixed post via a buried } \\
\text { telephone cable and the second is a direct link to the offsite response } \\
\text { force located in the city } \\
\text { All hand-held radios and fixed posts are equipped with a duress switch to } \\
\text { allow sending the CAS a covert signal of unauthorized activity. When the } \\
\text { CAS receives a duress alarm, the response force is contacted. }\end{array}$ \\
\hline
\end{tabular}




\begin{tabular}{|l|l|}
\hline $\begin{array}{l}\text { Security Force } \\
\text { Deployment }\end{array}$ & $\begin{array}{l}\text { The response force is deployed as described in Table } 9 \text { below. The } \\
\text { security posts and site layout are illustrated in the area diagrams. }\end{array}$ \\
\hline
\end{tabular}

Table 9. Response Force Deployment Data

\begin{tabular}{|c|l|c|c|}
\hline \multirow{2}{*}{ Post No. } & \multicolumn{1}{|c|}{ Description } & \multicolumn{2}{c|}{ No. of Guards } \\
\cline { 3 - 4 } & & $\begin{array}{c}\text { Day } \\
\text { Shift }\end{array}$ & Off-Shift \\
\hline P-1 & CAS (unarmed) & 1 & 1 \\
\hline P-2 & Site Personnel and Vehicle Entrance & 1 & 0 \\
\hline P-3 & PA Vehicle Gate & 1 & 0 \\
\hline P-4 & PA Personnel Portal & 2 & 1 \\
\hline P-5 & Production Facility ECP & 2 & 1 \\
\hline P-6 & Roving Patrol inside URF (unarmed) & 2 & 2 \\
\hline P-7 & Tactical Response & 4 & 4 \\
\hline & & $\mathbf{1 3}$ & $\mathbf{9}$ \\
\hline
\end{tabular}

Response

Process
All alarms are received at the CAS. For alarms that cannot be assessed via closed-circuit television, the CAS operator dispatches the nearest available guard to assess the alarm. If the assessment indicates a situation that cannot be handled by a single unarmed guard, the CAS operator dispatches additional guards.

Table 10. Average Response Force Times

\begin{tabular}{|l|l|}
\hline \multicolumn{1}{|c|}{ Alarm Location } & \multicolumn{1}{c|}{ Response Time } \\
\hline PA Fence & 30 seconds -2 minutes \\
\hline X-Ray Facility & 30 seconds -2 minutes \\
\hline Final Products Bunker & 30 seconds -3 minutes \\
\hline Production Floor & 30 seconds -2 minutes \\
\hline
\end{tabular}

${ }^{2}$ The variation in response times reflects the varying locations from which guards may be dispatched to respond to the alarm. 


\subsection{Other General Information}

\subsection{Threat Data}

- Items were recently confiscated from a political terrorist group's hiding place, which was located less than 200 kilometers from the URF. The items included internal engineering drawings of the URF with circles drawn around the Final Products Bunker; various weapons, including automatic weapons; some explosives; and evidence of correspondence and communication with a foreign terrorist group. Interviews with property owners and residents indicated the group consisted of three to five men.

- Intercepted communications from a neighboring country indicates that a large terrorist group has tried to acquire a large quantity of nuclear material.

- The local police report that several Special Forces members had been offered large cash payments to provide special training to unidentified individuals.

- A major bank robbery was committed in the capital two months ago. Four robbers escaped with a large amount of money. Investigation shows the bank vault was breached by the sophisticated use of high explosives stolen from the local army base.

- Nationally, many thefts of highly valuable items have occurred. The crimes do not appear to be related to each other. It is speculated that several groups committed the crimes. Organized crime may be involved.

- A recent meeting of the Atomic Energy Ministry included a special session on analysis of threat to nuclear facilities and material. No substantiated data on threat were available. However, the general feeling among members was that a threat to nuclear facilities does exist.

- During a meeting of the Industrialists Society, concern was expressed by managers of corporations that some of their employees had been approached by unnamed groups to help them carry out theft of valuable equipment and materials from the corporations. The employees had been offered large amounts of money.

- An analysis of the backgrounds of the employees of URF and of the population of the community did not provide any information that would suggest a concern of threat to the URF.

- There have been some internal disputes over labor issues at the URF in the past five years.

- Local news media publicized the recently upgraded security system at the URF as the latest in modern security system design with full International Atomic Energy Agency compliance.

- Two institute employees were recently caught stealing equipment and were terminated from the facility.

- A new employee drug and competency-screening program was recently introduced.

- A site-wide inventory recently discovered that several controlled site drawings were missing.

- Local reports of upcoming layoffs at the plant have recently been announced in the local news.

- The general attitude of the community is tolerant of the URF. However, certain activist groups have protested the plant during religious holidays. 


\section{1 (1) \\ I nsider Threat I dentification and Mitigation Workshop}

\section{J anuary 2008 Beijing, China}

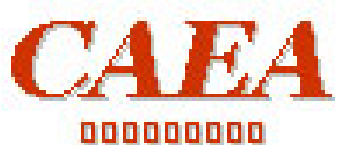

oudougaod

Lawrence Livermore National Laboratory

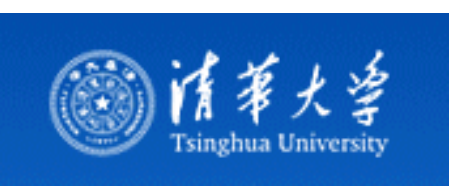

The

IINUNS

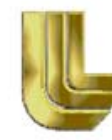

$\overbrace{\text { NOS AllamOS }}$

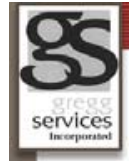




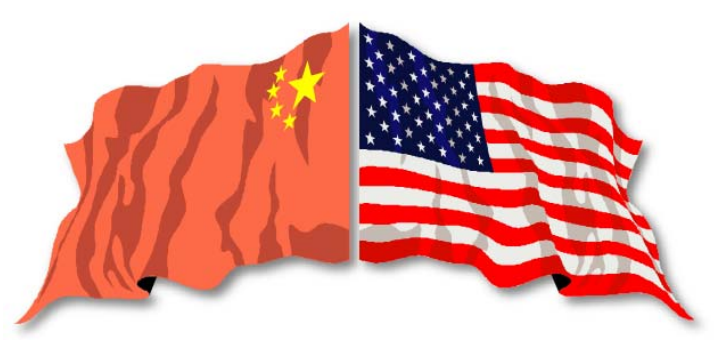

\section{Lecture 1}

\section{Overview/ Course Mechanics}

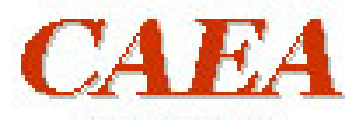

acougaudo

IIINA
Lawrence Livermore

National Laboratory

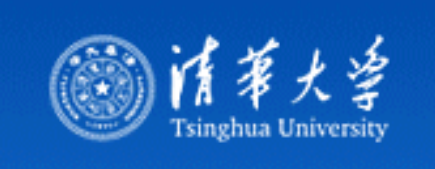

The

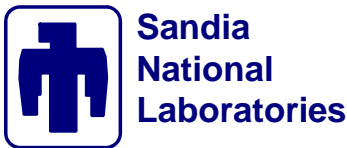




\section{Learning Objectives}

- Describe course and present the overall course goals

- Discuss course structure, schedule, and content

- Describe the insider analysis approach

- Capture participants' course expectations 


\section{Insider Protection Course Description}

A systematic analysis approach that is used to evaluate the ability of MPC\&A technical and administrative measures to meet performance requirements based on the capabilities and attributes of a defined insider threat 


\section{I nsider Protection System Approach}

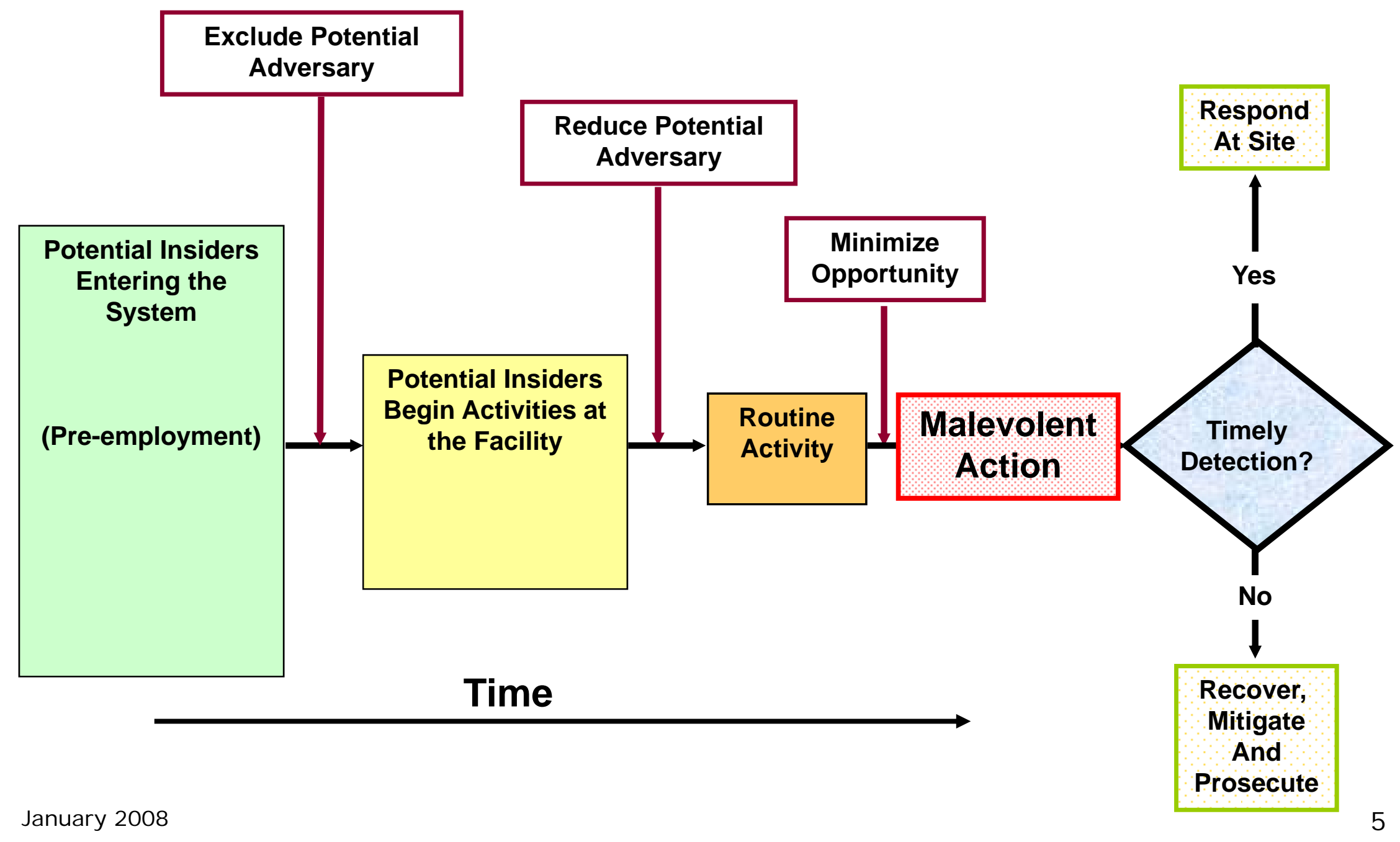




\section{Scope of Training Course}

- This Insider Protection Course is designed to apply to nuclear and radiological:

- Facilities

- Materials

- Transportation

- This course is designed to provide a structured analysis approach that can be used to prevent or detect two types of malevolent events

- Theft and/or diversion of nuclear materials
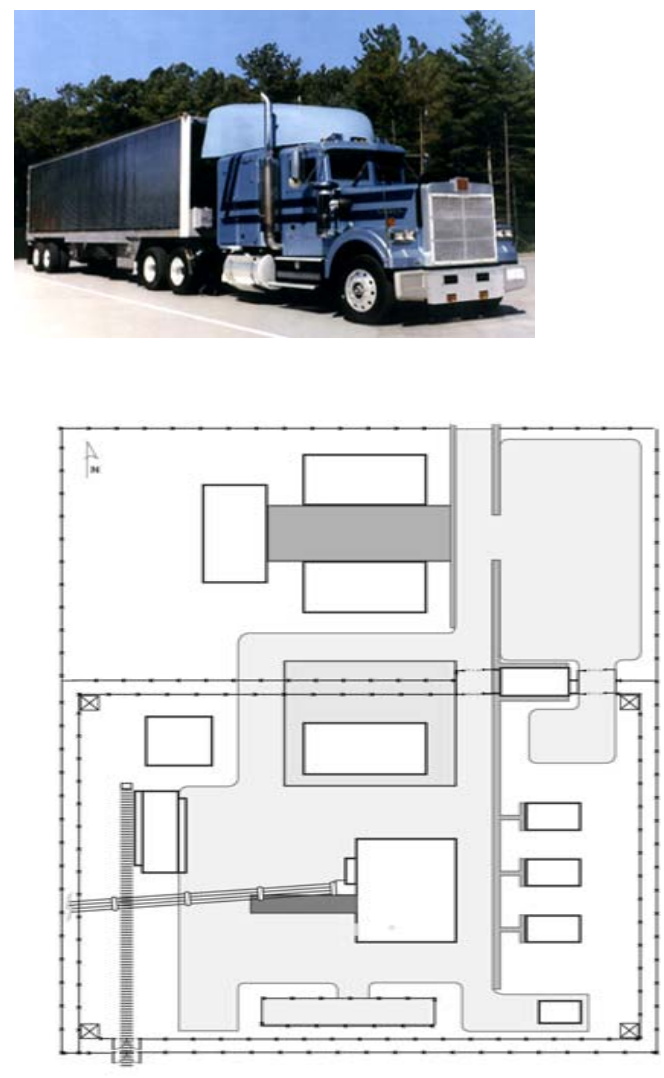


\section{Course Goals}

- By applying a structured analysis approach, participants will be able to:

- Identify and characterize potential Insider threat groups

- Identify potential targets of interest to Insider adversaries

- Identify and characterize MPC\&A measures to protect against the Insider

- Estimate the likelihood of an Insider causing undesirable consequences

- Evaluate the effectiveness of current and planned MPC\&A systems against an Insider threat

- Identify and evaluate MPC\&A upgrades that could reduce the risk of Insider malevolence 


\section{Insider Course Structure}

- The course consists of 5 days of training, including:

- Lectures

- Discussion - large and small group

- Exercises (in-class)

- Facility overview

- Student feedback

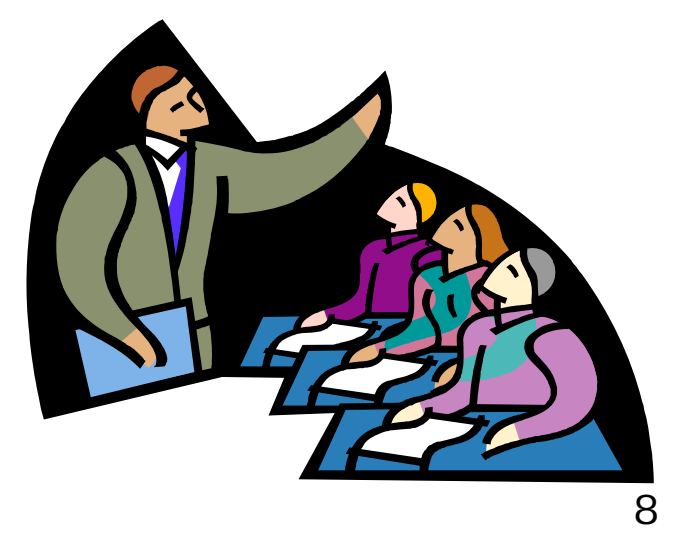




\section{Course Modules and Schedule}

\begin{tabular}{lc}
\multicolumn{1}{c}{ Module } & Day \\
Course Overview & $\mathbf{1}$ \\
Administrative Measures & $\mathbf{1}$ \\
Technical Measures & $\mathbf{1}$ \\
Facility Characterization & $\mathbf{1}$ \\
Target Characterization & $\mathbf{2}$ \\
Threat Definition & $\mathbf{2}$ \\
Insider Characterization & $\mathbf{2}$ \\
Path Analysis-Sequence of Actions & $\mathbf{2}$ \\
Path Analysis-Characterize Protection Measures & $\mathbf{3}$ \\
Scenario Development & $\mathbf{3}$ \\
Scenario Evaluation & $\mathbf{3}$ \\
Upgrade Analysis & $\mathbf{4}$ \\
Upgrade Exercise & $\mathbf{4}$ \\
Maintaining System Effectiveness & $\mathbf{5}$ \\
Closing Discussion & $\mathbf{5}$
\end{tabular}




\section{Insider Definition (DOE)}

"A person who, by reason of official duties, has knowledge of operations and/or security system characteristics, and/or position that would significantly enhance the likelihood of successful bypass or defeat of positive measures should that person attempt such an action."

- Insiders might include:

- Management

- Regular employees

- Security personnel

- Service providers

- Visitors

- Inspectors

- Past employees

- Others?

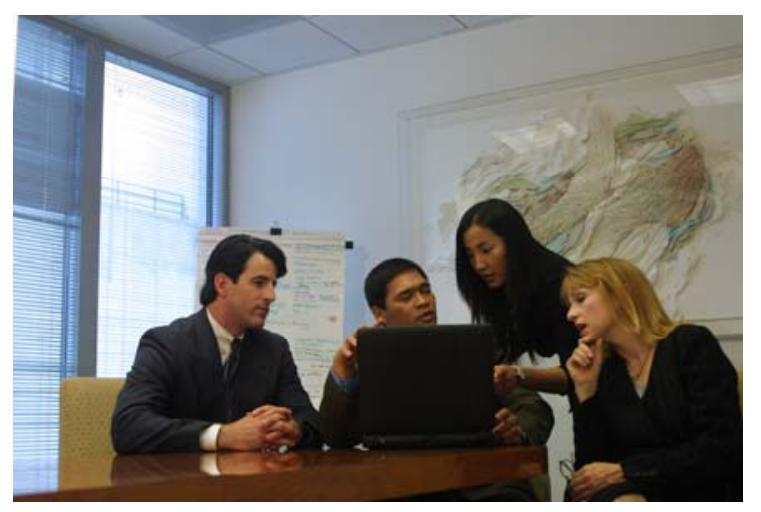




\section{Existing Systems Providing Insider Protection}

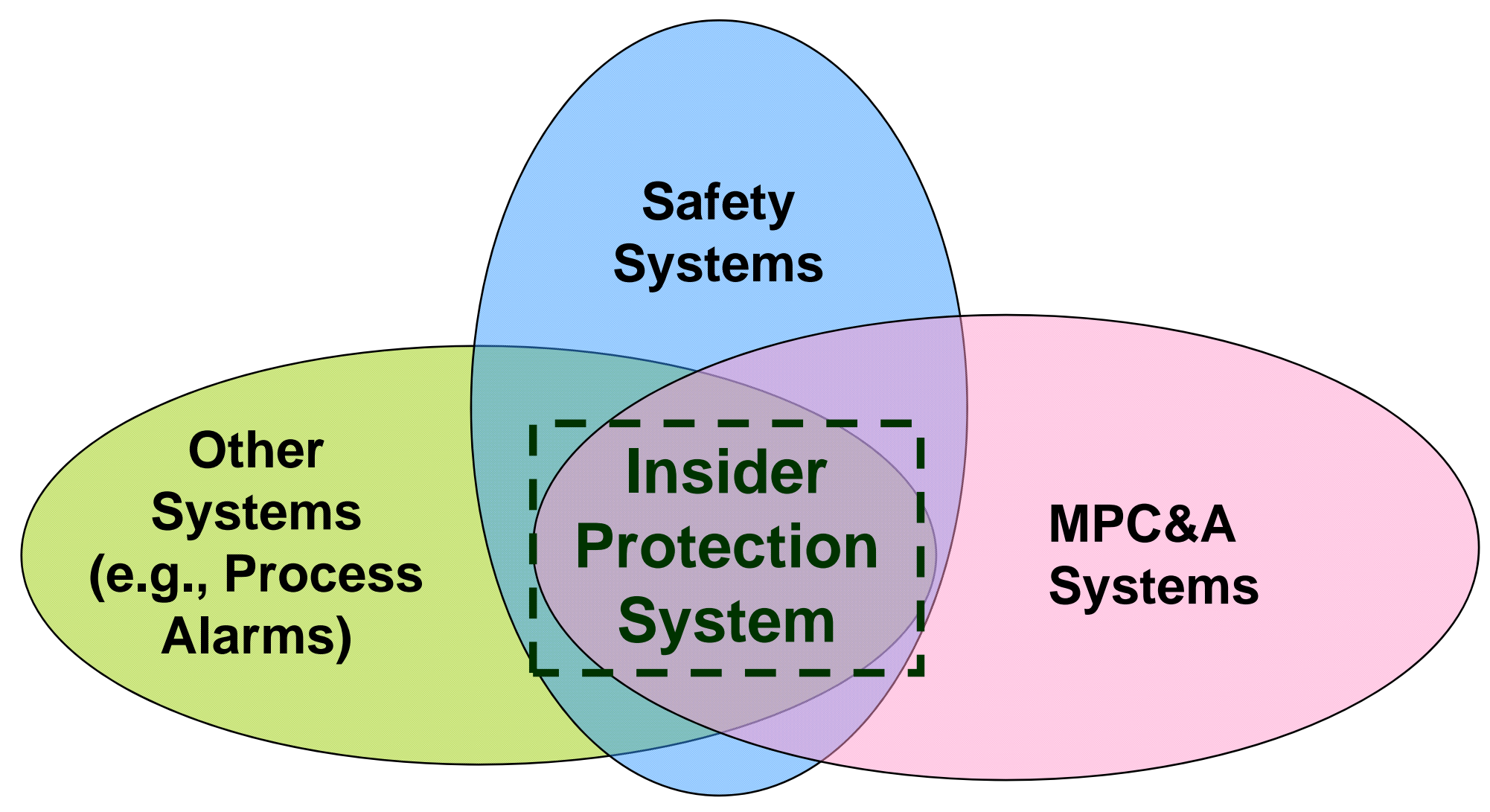




\section{Insider Analysis Approach}

- Develop and define the insider threat

- Identify MPC\&A technical and administrative measures for insider threat protection

- Identify and characterize the targets

- Evaluate effectiveness and relevance of MPC\&A measures

- Evaluate effectiveness of overall MPC\&A system

- Define and evaluate upgraded MPC\&A measures 


\section{Introductions}

- Introduce instructors

- Introduce administrative support/interpreters

- Introduce participants

- Name

- Where do you work?

- What do you do?

- Course expectations - why are you here?

- How will you use what you learn here? 


\section{Module Summary}

- Course and overall course goals

- Course structure, schedule, and content

- The insider analysis approach

- Participants' course expectations

Questions or Comments?? 


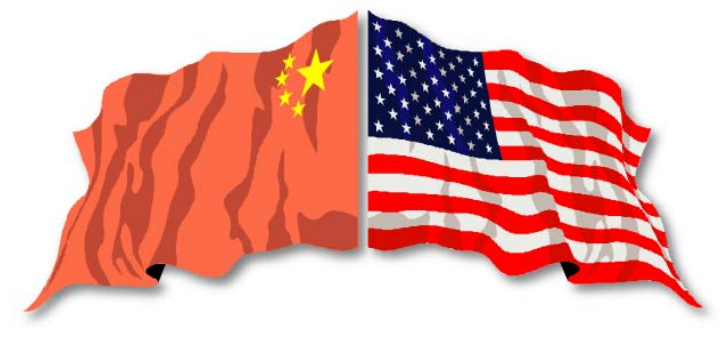

\section{Lecture 2a}

\section{Administrative Measures}

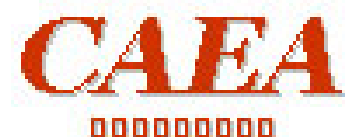

adougadou

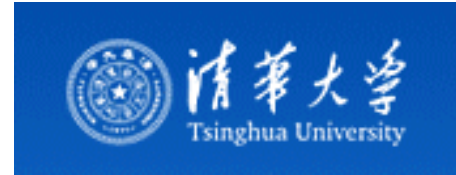

The

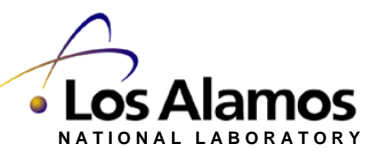




\section{Student Learning Objectives}

- Review Insider Protection System Approach

- Identify administrative measures of an MPC\&A system that can provide protection against insider threats

- Estimate the effectiveness of administrative measures 


\section{I nsider Protection System Approach}

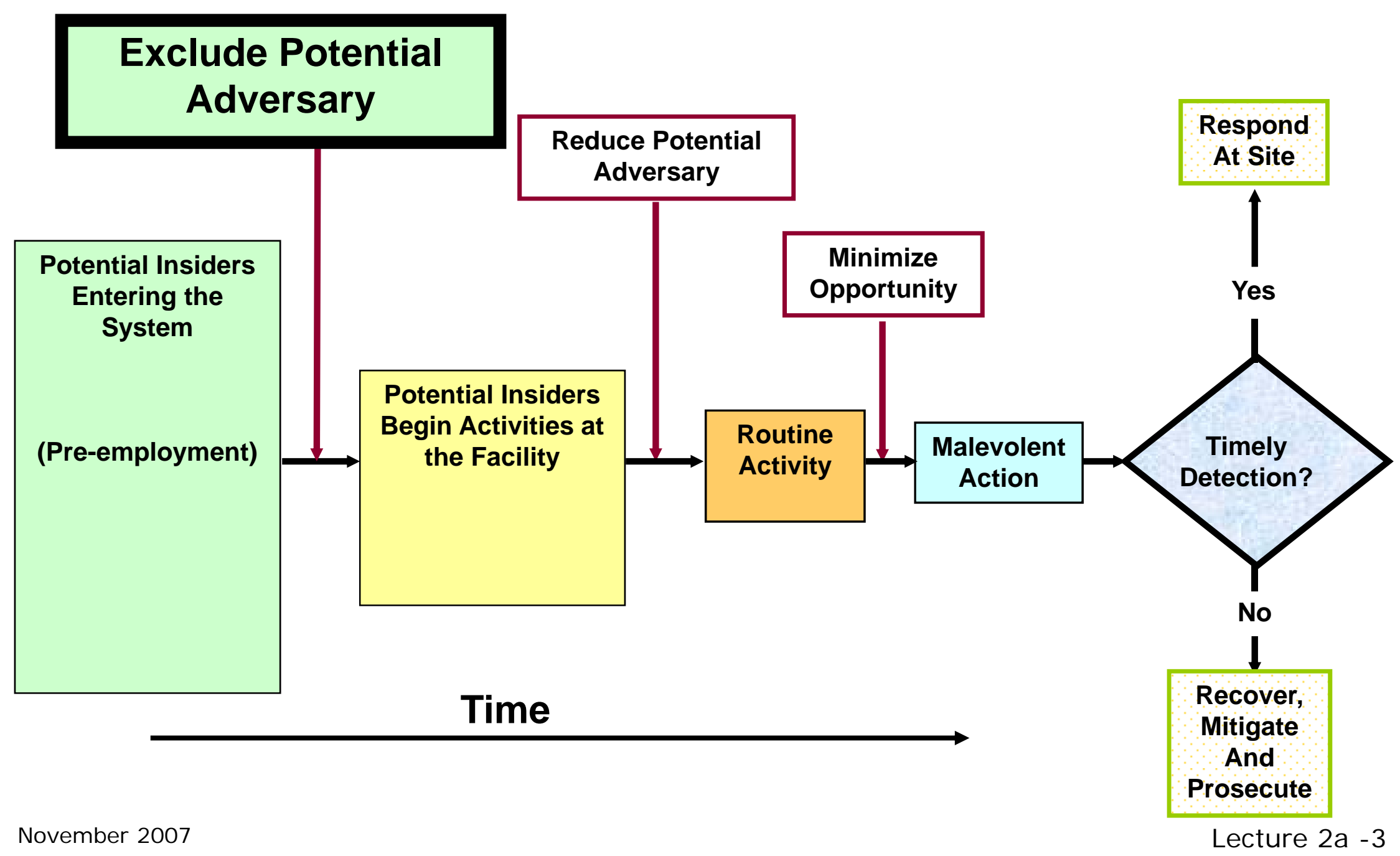




\section{Exclude Potential Adversary}

- Filter potential insiders entering the system

- Pre-employment:

- Application process

- Background checks

- Financial obligations

- Work history

- Other?

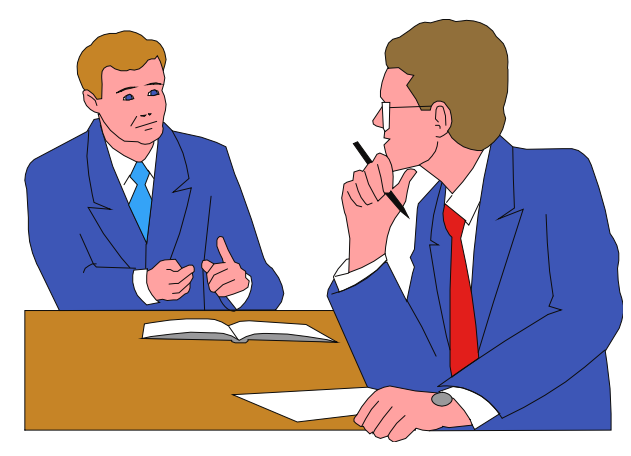

- Detection (identification) and response (not hiring) can be achieved by the above measures

- Deterrence is also achieved

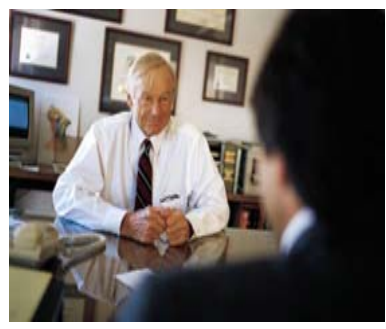




\section{Remove Potential Adversaries Based on Undesirable Behaviors}
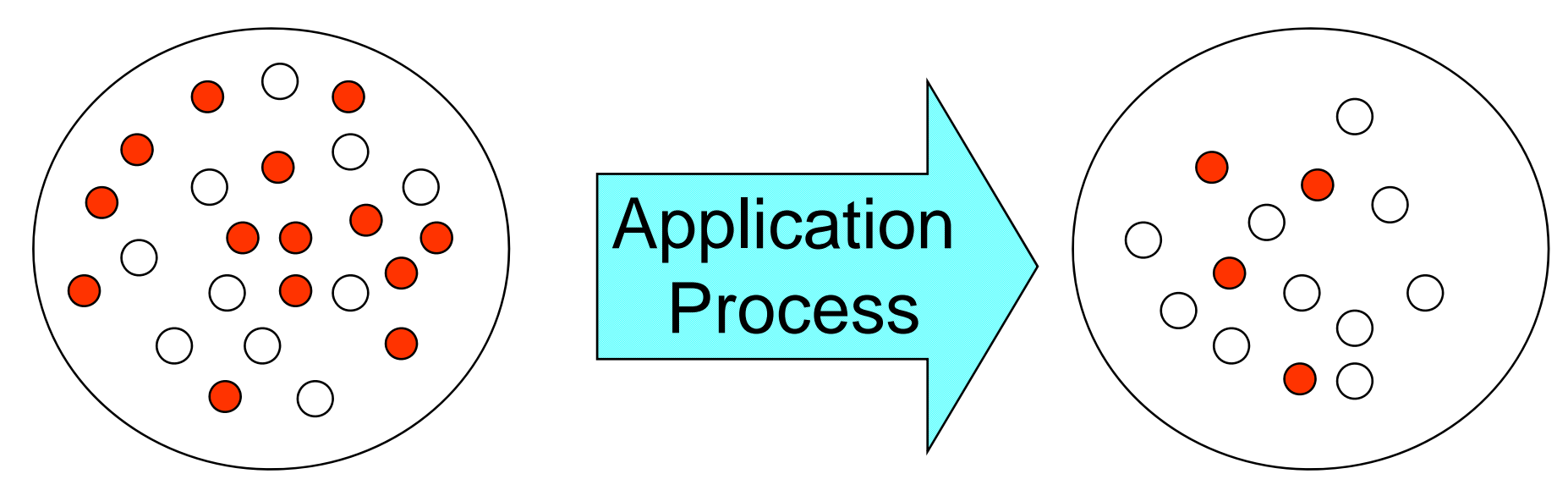

- persons with desirable behavior

- - persons with undesirable behavior 


\section{Remove Potential Adversary: Define Undesirable Behaviors}

- Based on your society, you may define undesirable behaviors as:

- Criminal behavior

- Financial instability

- Substance abuse

- Psychological instability

- Ideology

- Excessive lifestyle

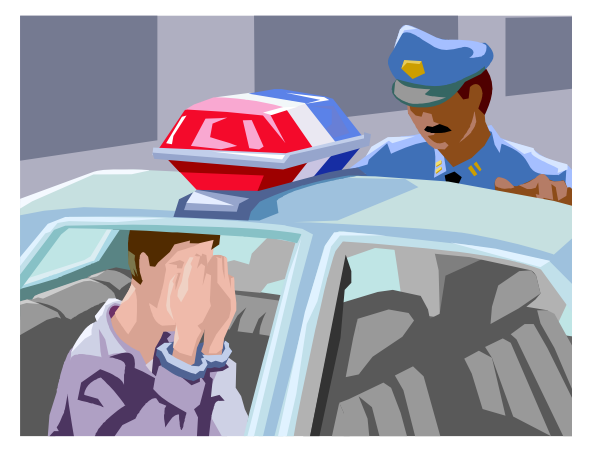

- Others?

- Who defines these?

- Management

- State 


\section{Why Check These Things?}

- Malevolent potential may be indicated by criminal history

- Financial affairs will provide some indication of stability as well as potential susceptibility to extortion

- Work history can reveal tendencies to anger, reliability, mental competency, honesty, etc.

- References may reveal information not provided on the application

- Don't limit interviews to only references the applicant provides

Note: established criteria will remove many potential employees before activity on-site commences, and can serve as cause to terminate employment later on 


\section{Application Process Example}

- Make background check requirements well known to the public

- Include a medical examination and substance abuse testing as requirements for certain positions

- Assure that application asks for all information needed to evaluate applicants behavior

- Financial instability

- Substance abuse

- Psychological instability

- Criminal activity

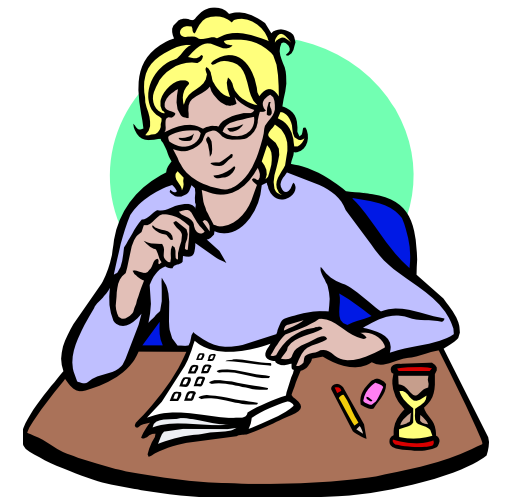

Lecture $2 a-8$ 


\section{Application Process Example (cont'd)}

- Post job opening and application acceptance details far enough in advance to allow time for the background check to be completed before hiring 


\section{Background Checks}

- There are several levels of checks that are used in various environments - graded approach

- Just the application form and an interview

- A search of national records

- Criminal

- Credit

- A cursory follow-up of the information on the application

- A rigorous follow-up of activity of last several years

- Interview references

- Investigate financial affairs

- Interview previous employers and colleagues 


\section{I nsider Protection System Approach}

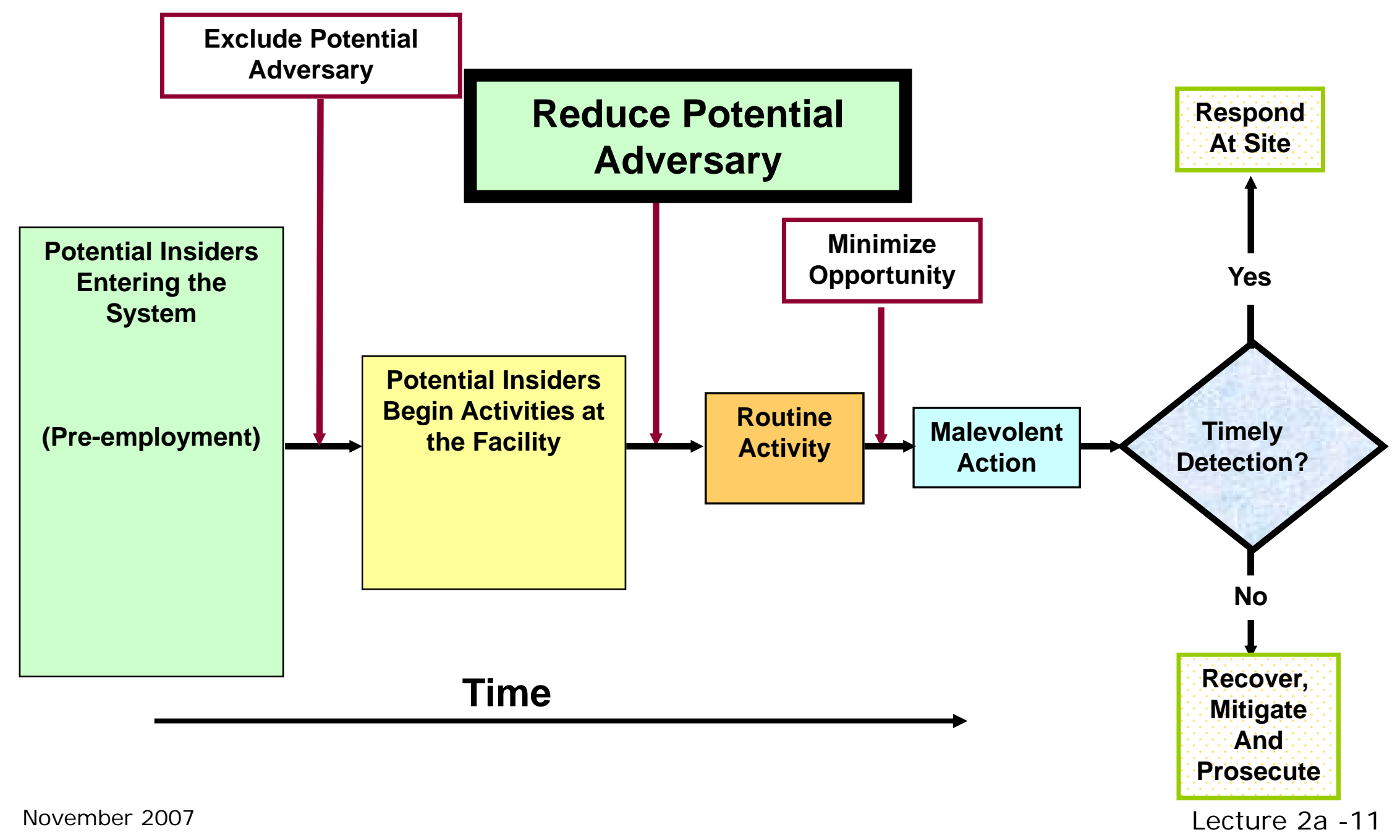




\section{Reduce Potential Adversary}

- For persons who are authorized to conduct activities at the site:

- Periodic background checks

- Security awareness program

- Fitness for duty program

- Human reliability program

- Employee satisfaction program

- Quality control program

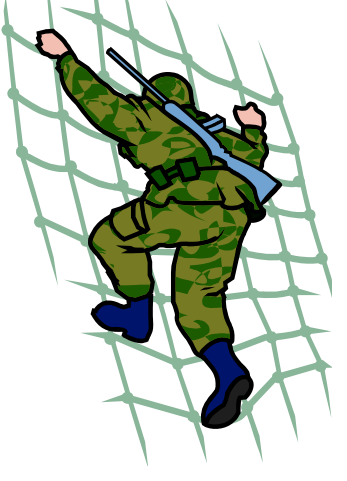

- Invoke disciplinary action when malevolence occurs 


\section{Further Reduce Potential Adversaries}

- Routinely screen employees for undesirable behavior

- Educate employees on correct behavior

- Reward employees for good behavior
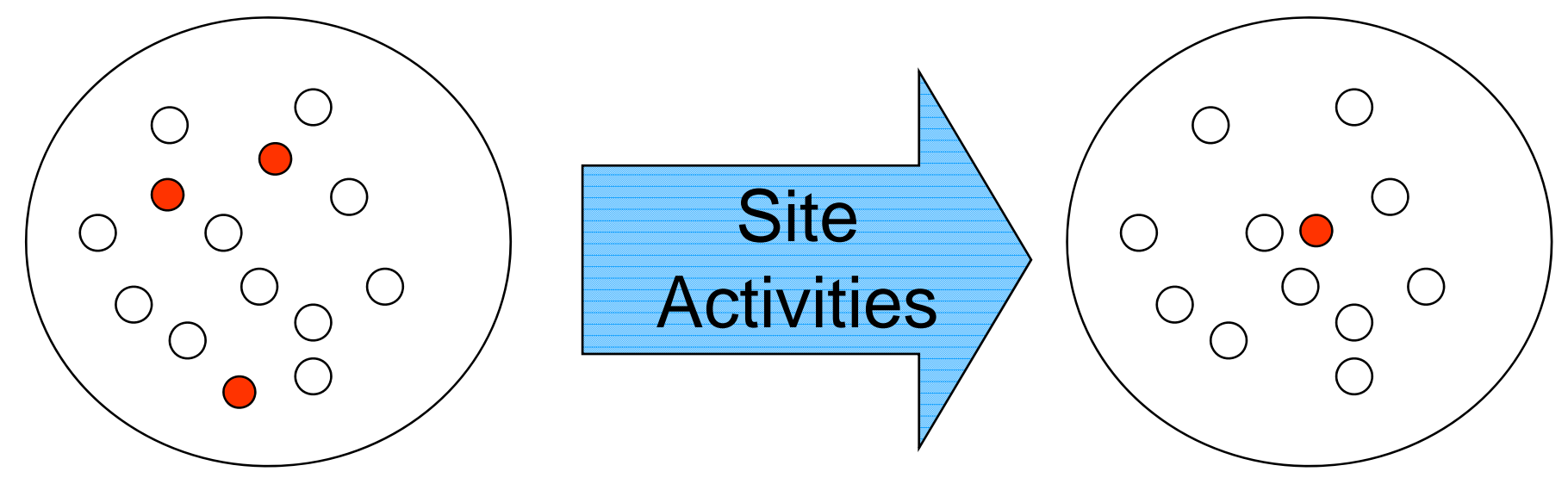

- - persons with desirable behavior

- - persons with undesirable behavior 


\section{Periodic Background Checks}

- Similar to the pre-employment check

- Emphasis on discovering changes in habits, activities, life style, health, etc.

- Perhaps done every 5 years

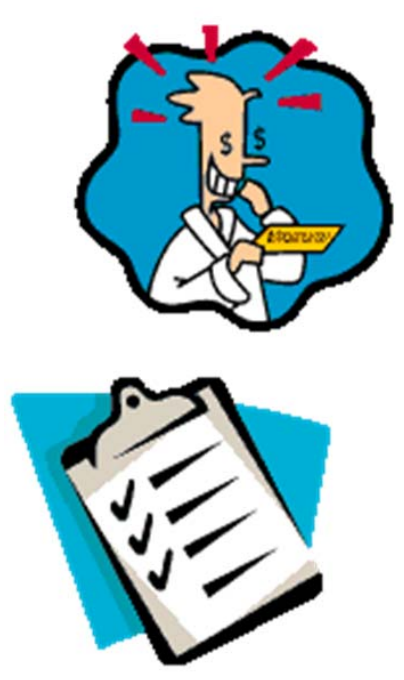




\section{Security Awareness Program}

- A program intended to remind employees of their security roles and responsibilities

- Usually part of routine frequent employee training

- Sensitizes employees to watch for and report or interfere with potential malevolent actions

- Spans the spectrum of concerns

- Cyber, physical protection, MC\&A, information, etc.

- A product of a strong security culture

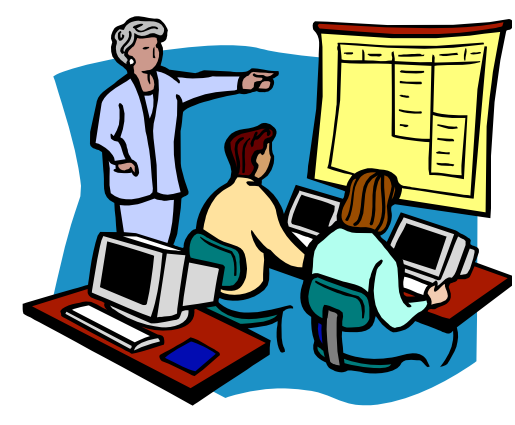




\section{Special Programs: Fit For Duty/ HRP}

- Implemented on a Graded Approach

- Usually restricted to persons in job areas which have greater capabilities to commit serious malevolent acts

- Includes activities such as frequent drug screening, financial reviews, supervisor and co-worker observation

- Frequent physical and mental evaluations

- More frequent full background checks

- Perhaps yearly

- Supported by a strong security culture 


\section{Employee Satisfaction Programs}

- Benefits

- Insurance

- Vacation I holidays

- Salary treatment

- Fairness

- Working environment

- Ergonomics

- Resources

- Training

- Quality, usefulness and relevance

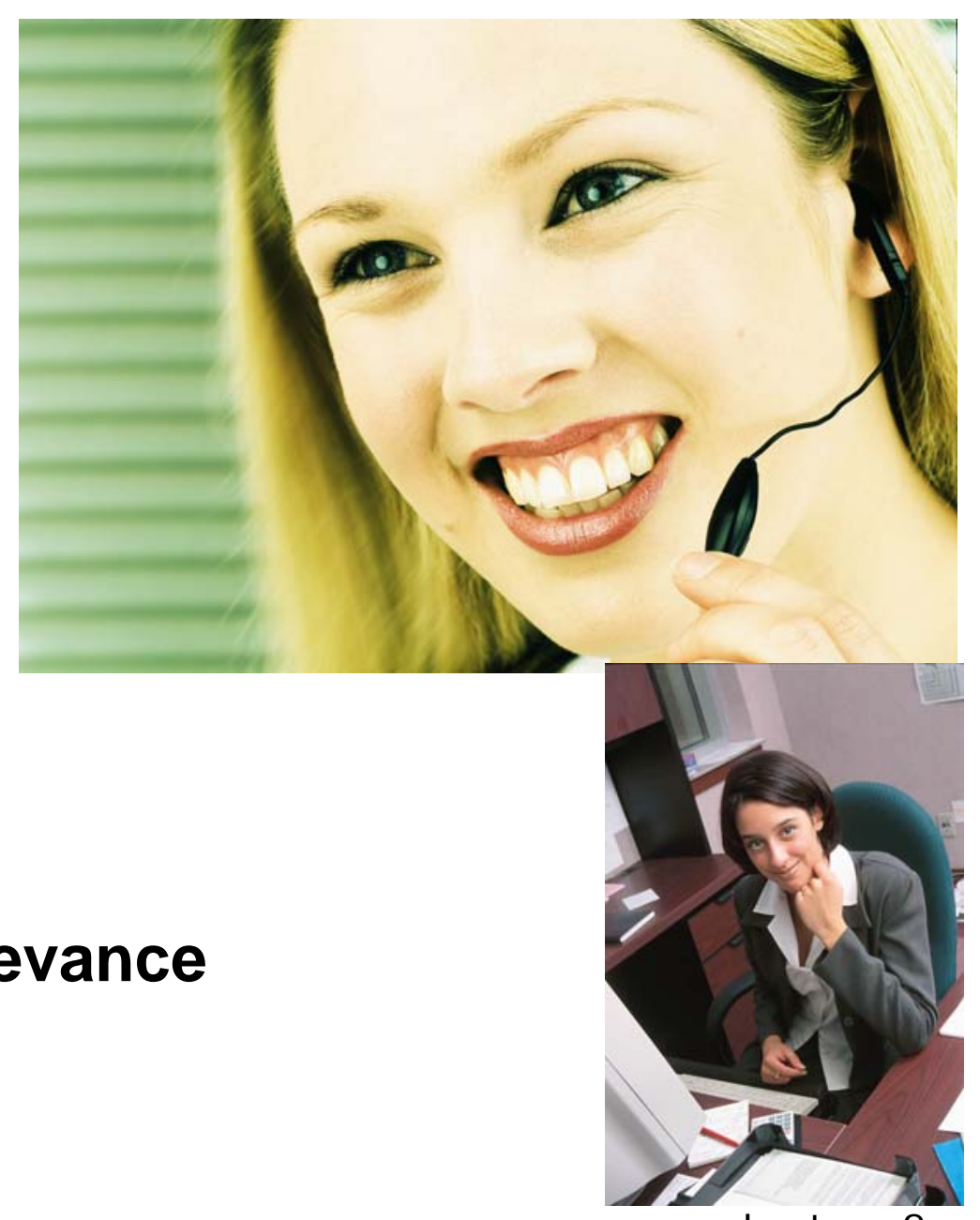




\section{I nsider Protection System Approach}

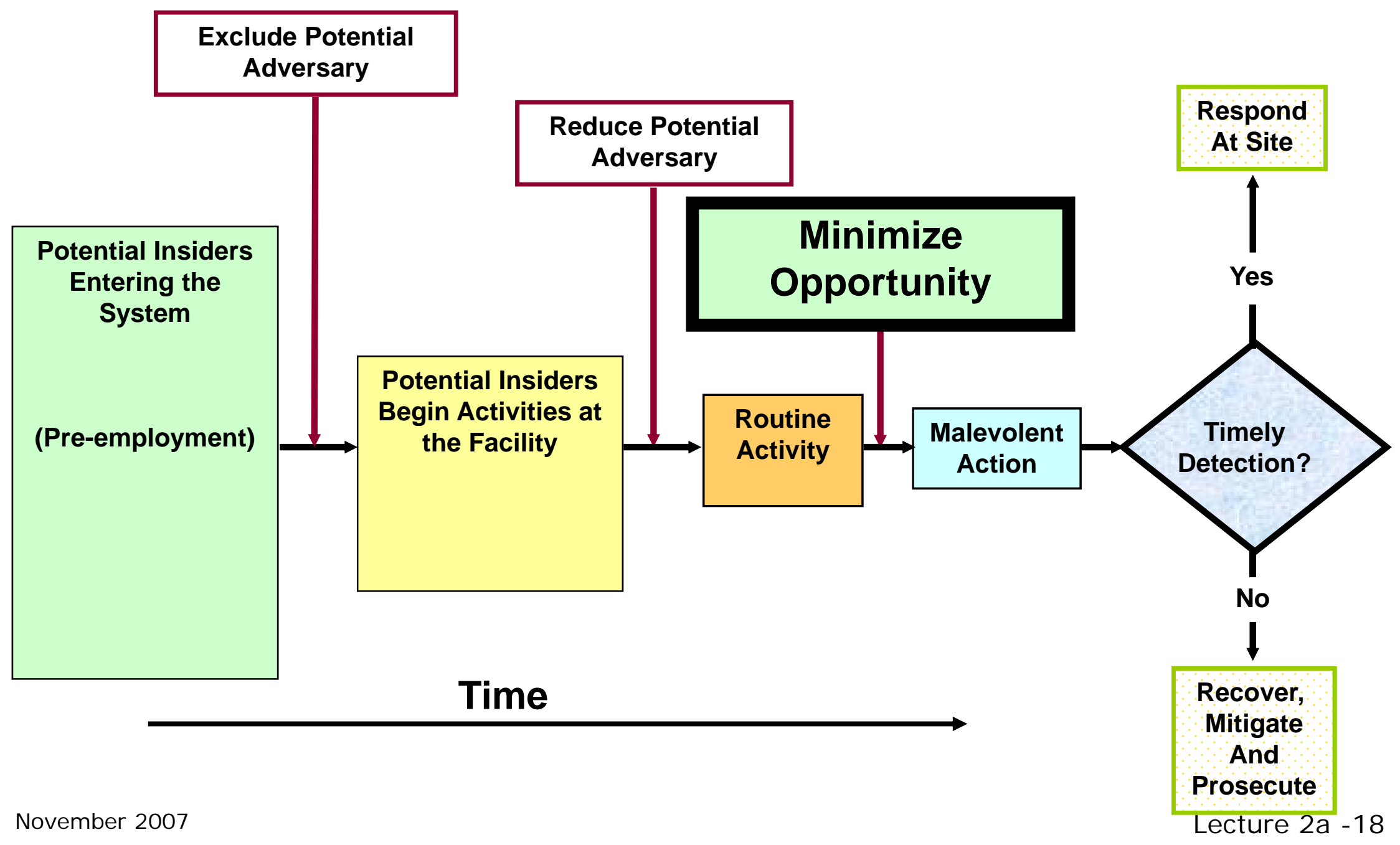




\section{Minimize Opportunity}

- Confidentiality and partitioning of information

- Operational Security Program

- Compartmentalize facility

- Access control

- Vital equipment operations

- Nuclear safety

- Inventory management

- Nuclear facility design

- Others?

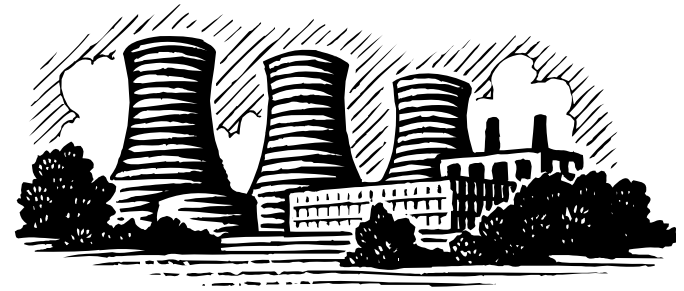




\section{Confidentiality and Compartmentalization of I nformation}

- Limit information available to each person that is needed to do the job

- Need to Know

- Separate information to prevent full knowledge of sensitive areas

- Information of concern

- Location and condition of sensitive targets

- Details of preventive and protective systems

- Critical elements of system design

- Vulnerabilities in the system

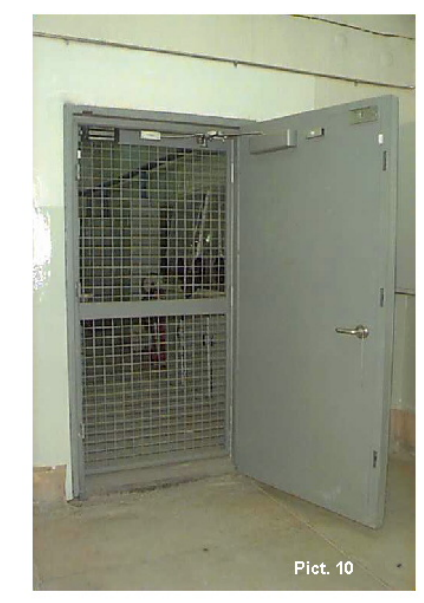




\section{Confidentiality and Compartmentalization of I nformation (cont'd)}

- Classified or restricted data

- Based on a state definition of what is sensitive information

- Could be company proprietary also

- Operational security program

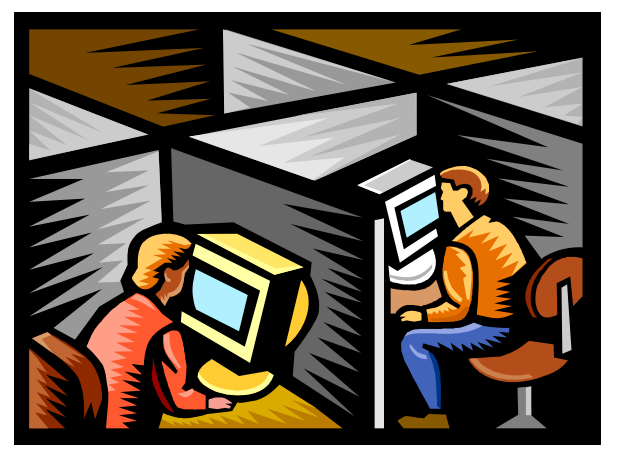




\section{Operational Security Program}

- Program to reduce the signature of sensitive operations so adversaries won't be able to gather spurious non-sensitive information

- Goal is to prevent sensitive, but unrestricted, operational information from being unintentionally released

- Shipment data, organization lists, etc.

- Imposes control on handling and disposition of hard copy, electronic media and other communication containing intellectual property 


\section{Operational Security Program (cont'd)}

- Can be enforced by monitored procedures

- Is most effective where the security culture is strong and security awareness by employees is high

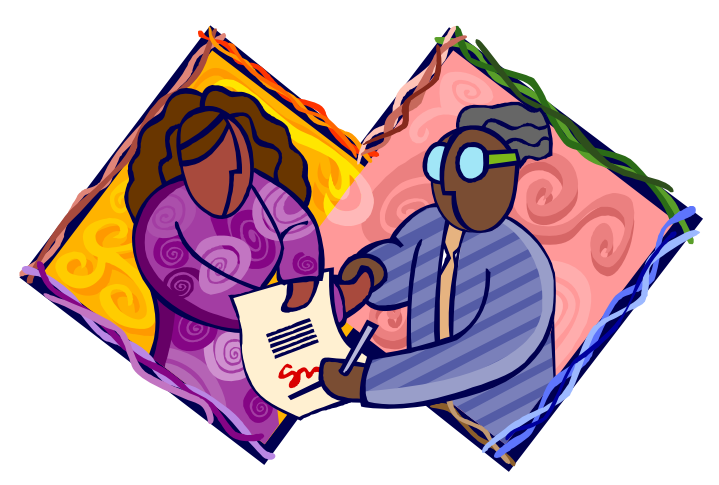




\section{Compartmentalize Facility}

- Control authorized access to nuclear materials and sensitive areas of the facility to:

- Restrict access to those needing it for job duties

- Location and time

- Allow access to only part of the equipment needed to complete a successful high consequence sabotage event

- Incorporate monitoring of activities to detect potential malevolence and determine who is responsible for such acts

- Separate duties

- Limit access and authority

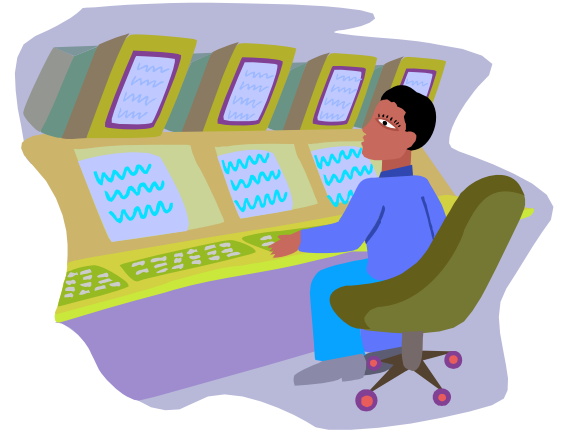




\section{Vital Equipment Operations}

- Preventive and corrective maintenance

- Under controlled conditions

- Escort maintenance personnel

- Provides oversight

- Inspect and test after equipment has been accessed or maintained

- McGuire example

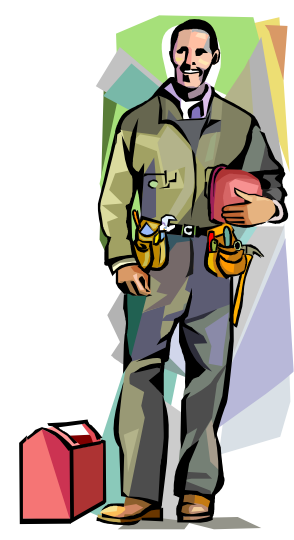

- Daily tests assure operability

- Protect spare parts by security or separation 


\section{Nuclear Safety}

- Criticality concerns

- Personnel safety issues

- Safety criteria and/or layout criteria are established for important systems or equipment

- Safety criteria: redundancy, technology diversification

- Layout criteria: physical or geographical separation

- Margins of safety are included to be able to cope with abnormal situations and severe sequences of events

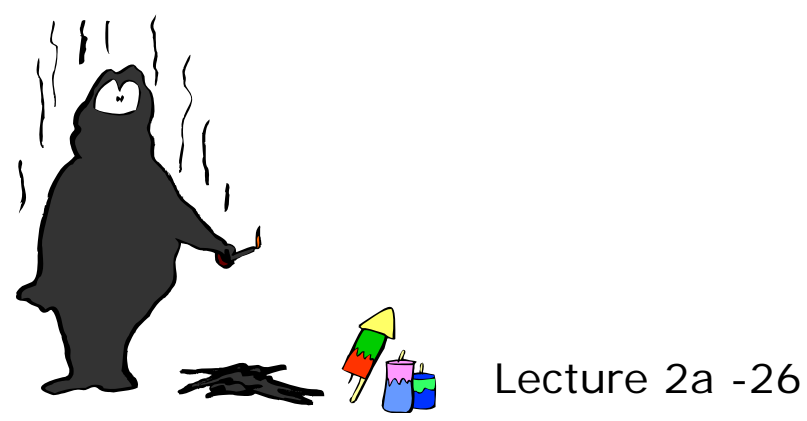




\section{I nventory Management - Reduced I nventory}

- Reduced inventory

- Restricts the amount of material available for theft or radiological dispersal

- Supports material accountancy since less material is present at any location

- Consolidation may reduce insider exposure to materials

- May also increase risk by providing a more attractive target 


\section{I nventory Management - Materials Accountability}

- Materials accountability

- Accounting provides material traceability

- Inventory verifies

- Material location

- Type

- Amount

- Measurements confirm material type and quantity

- Transfer control maintains integrity between system elements 


\section{Nuclear Facility Design}

- Facility design can minimize opportunities for sabotage and theft

- Balanced protection

- Protection-in-depth

- Survivability of critical systems

- Process design and/or the way the process is operated can minimize physical inventory uncertainty (LEID) 


\section{Subjective Effectiveness Comparison}

- The effectiveness of administrative measures in minimizing opportunity varies widely depending on the application

- An example may be:

- Most effective

- Compartmentalize facility

- Nuclear facility design

- Equipment operations

- Less effective

- Information confidentiality and compartmentalization

- Least effective

- Inventory reduction 


\section{Suggested Guidance for Estimating Effectiveness of Measures}

\begin{tabular}{|c|l|l|}
\hline Effectiveness & \multicolumn{1}{|c|}{ Weaknesses } & \multicolumn{1}{|c|}{ Defeat methods } \\
\hline High (H) & $\begin{array}{l}\text { Very difficult to determine the } \\
\text { weakness } \\
\text { Cannot significantly compromise } \\
\text { the measure }\end{array}$ & $\begin{array}{l}\text { Nearly impossible to accomplish because } \\
\text { of complexity and unavailability of } \\
\text { necessary equipment }\end{array}$ \\
\hline Medium (M) & $\begin{array}{l}\text { Effort required to determine the } \\
\text { weakness } \\
\text { Cannot completely compromise } \\
\text { the measure }\end{array}$ & $\begin{array}{l}\text { Difficult to accomplish because of } \\
\text { complexity or need for difficult to obtain } \\
\text { equipment }\end{array}$ \\
\hline Low (L) & $\begin{array}{l}\text { Obvious weakness } \\
\text { Can completely compromise the } \\
\text { measure }\end{array}$ & $\begin{array}{l}\text { Easily accomplished without training or } \\
\text { equipment }\end{array}$ \\
\hline
\end{tabular}




\section{Example of an Evaluation of an Administrative Measure}

- Example for a criminal record check

- Weaknesses of measure

- Does not contain data from all parts of country / world

- Does not contain minor crimes or those crimes where you're not caught

- Potential defeat methods

- Alter records by bribery, stealth, or hacking

- Intercept report and alter it

- Influence recipient of record

- Effectiveness of measure in detecting the truth

- Medium

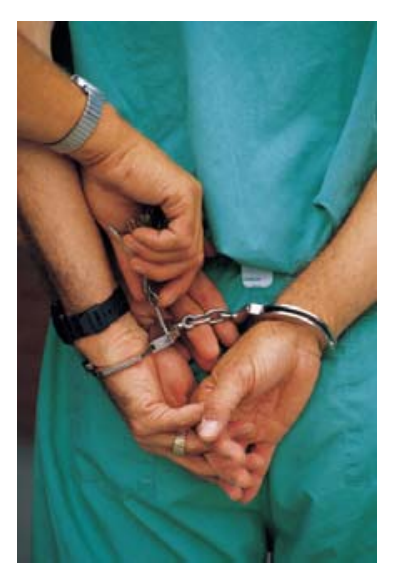




\section{Administrative Measures Summary}

- Administrative measures used in the insider protection system have the following goals:

- Exclude potential insiders during pre-employment process

- Reduce potential insiders after employment via periodic checks to identify changes in behavior

- Minimize opportunities for malevolent action by insiders

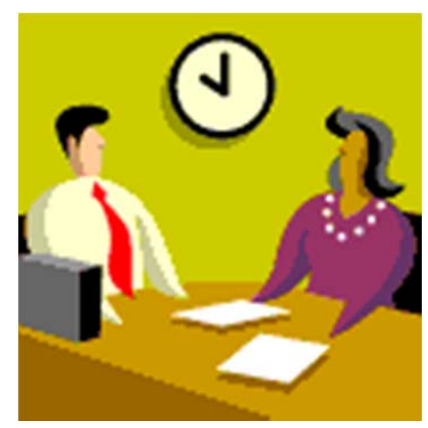




\section{Subgroup Exercise: Administrative Measures}

- Each subgroup will evaluate the following preventive measures:

- Pre-employment process

- Employment checks

- Information compartmentalization

- Equipment operations

- Consider the administrative measures for each of the above (see worksheets in exercise)

- For each administrative measure describe its weaknesses 


\section{Subgroup Exercise: Administrative Measures (cont'd)}

- Devise covert and/or overt defeat methods by which an insider adversary could attempt to defeat each of these measures

- Estimate the effectiveness of each administrative measure

- Use the Guidance Table for estimating effectiveness

- Summarize results for large group discussion 


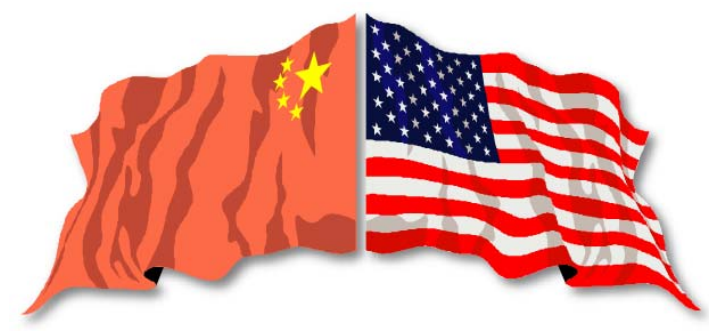

\section{Lecture 2b}

\section{Technical Measures}

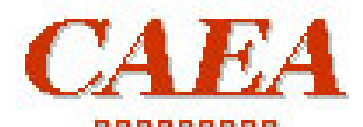

uadougado

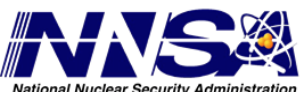

Lawrence Livermore

National Laboratory

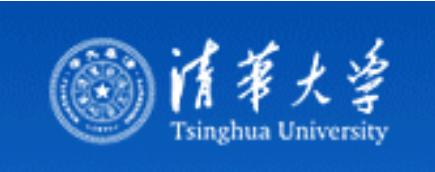

The

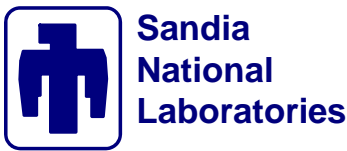




\section{Student Learning Objectives}

- Review Insider Protection System Approach

- Identify technical measures of an MPC\&A system that can provide protection against insider threats

- Estimate the effectiveness of technical measures 


\section{Technical Measures}

- Entry and exit control

- Metal detectors

- Explosives detectors

- X-ray package inspection

- Nuclear radiation monitors

- Signal line tamper protection

- Operational alarms

- Material Control and Accountability (MC\&A) programs
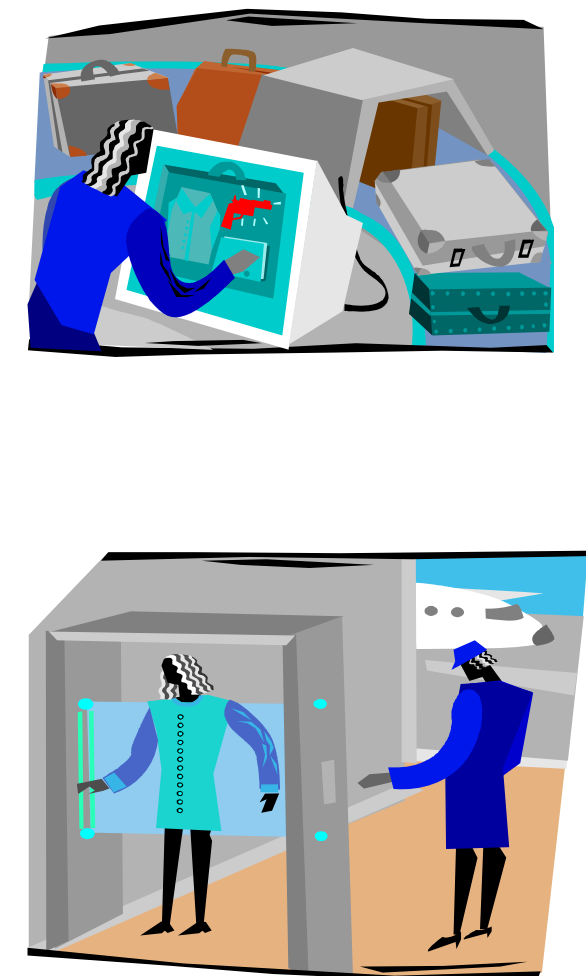


\section{Entry Control}

- Authorization using:

- Picture badge inspection

- Electronic credential

- Personal identification number (PIN)

- Badge exchange

- Biometrics
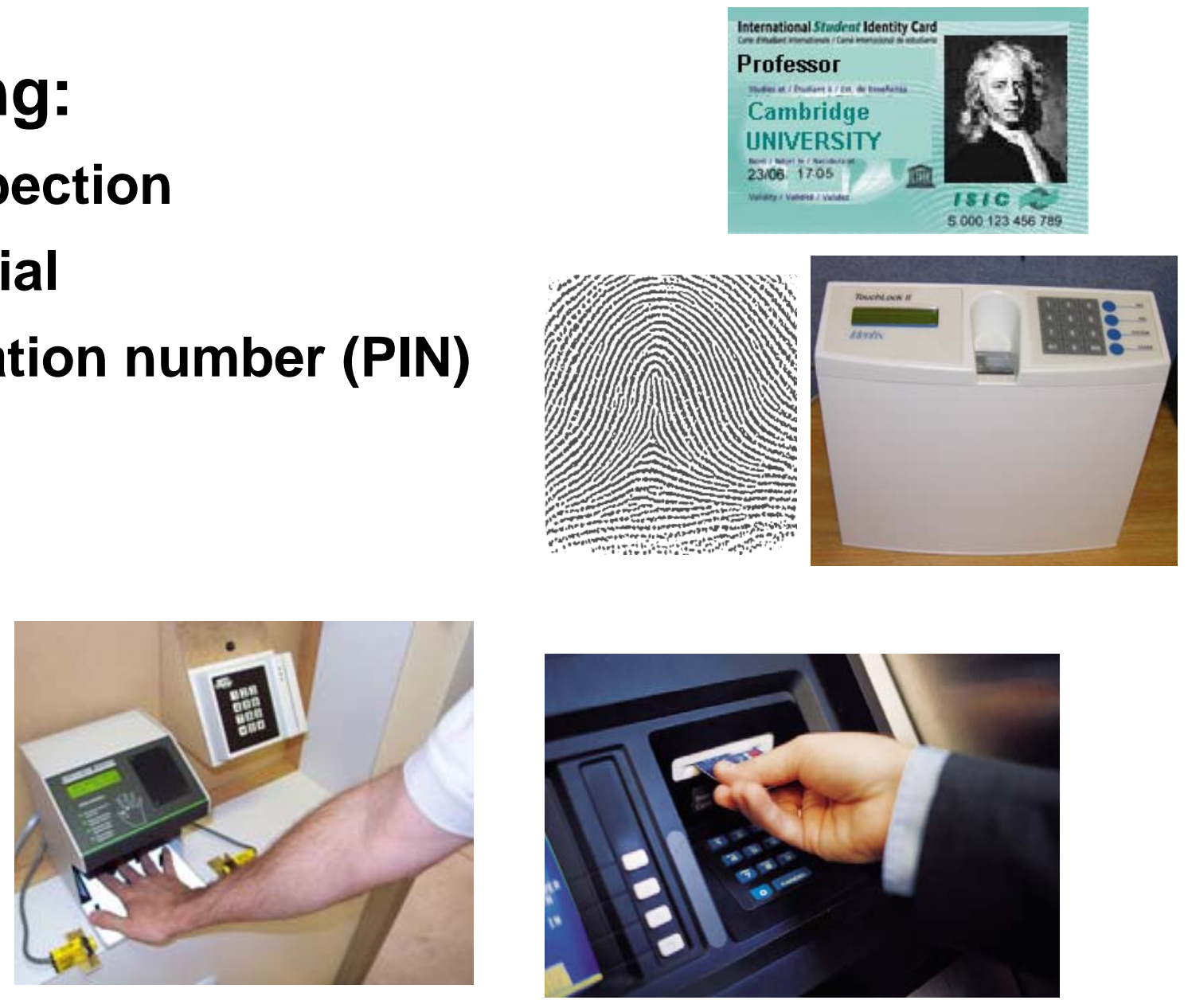


\section{Entry Control (cont'd)}

- Contraband detection

- Metal detector

- Explosives detector

- X-ray for packages

- Nuclear material detector

- Medical isotopes

- Package inspection by personnel

- Personnel search

- Routine and random
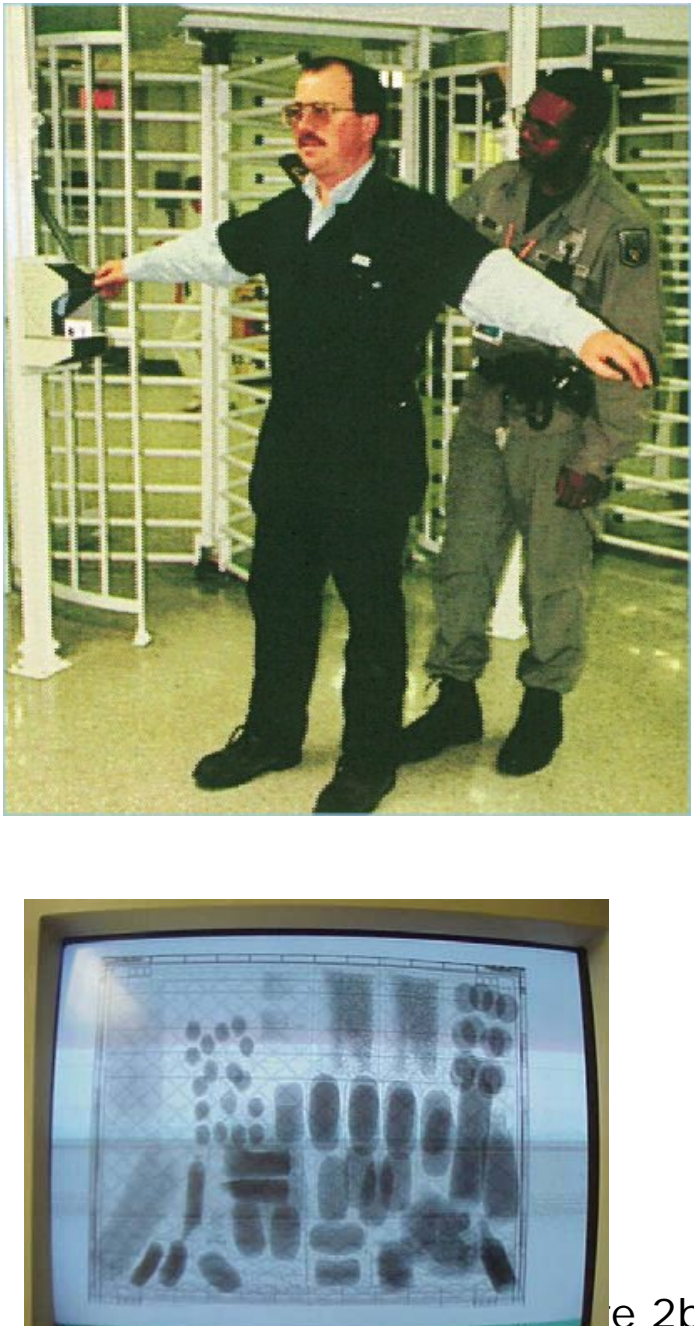


\section{Exit Control}

- Authorization not usually used to exit

- Can be structured to enforce multi-person rule inside an area

- Safety systems may have an ongoing inventory of personnel inside a facility

- Also serves as a protection feature if the system has an anti-pass back feature for badges

- Radioactive material contamination monitoring

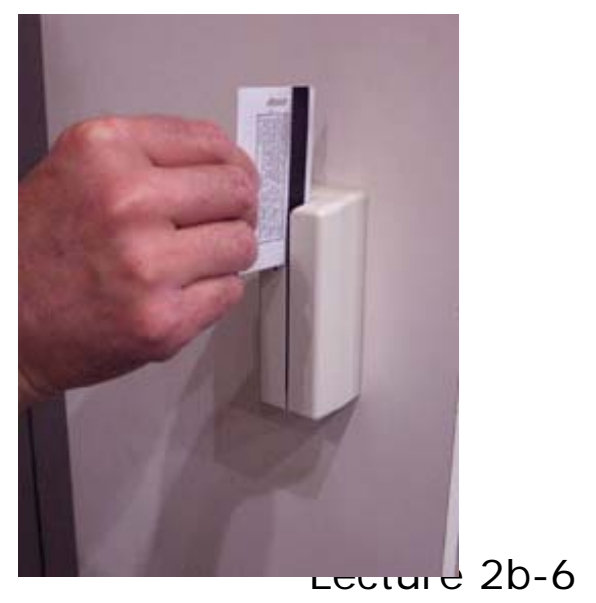




\section{Exit Control (cont'd)}

- Material detection

- Metal detector for shielding

- X-ray for packages

- Nuclear material monitor

- Package inspection by personnel

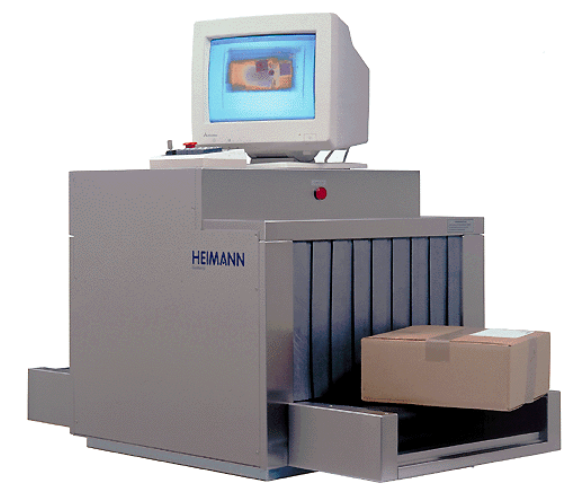

- Personnel restriction after emergency exit

- Emergency exit controls and procedures 


\section{Metal Detectors}

- Entry

- Adjusted to detect weapons

- Exit

- Adjusted to detect shielding material

- General

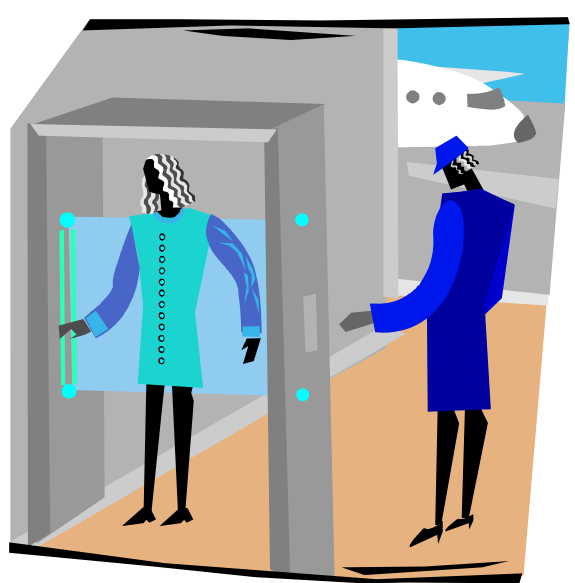

- Operational testing

- Sensitivity testing and calibration

- Personnel training 


\section{Trace Explosives Detectors}

- Entry

- Detects either macroscopic amounts of material or minute amounts of vapor or particles

- Must consider likely nuisance alarm sources

- General

- Operational testing
- Sensitivity testing and calibration
- Personnel training
- Can use either electronic or animal

- Operational testing
- Sensitivity testing and calibration
- Personnel training
- Can use either electronic or animal

- Operational testing
- Sensitivity testing and calibration
- Personnel training
- Can use either electronic or animal

- Operational testing
- Sensitivity testing and calibration
- Personnel training
- Can use either electronic or animal

- Operational testing
- Sensitivity testing and calibration
- Personnel training
- Can use either electronic or animal
detectors
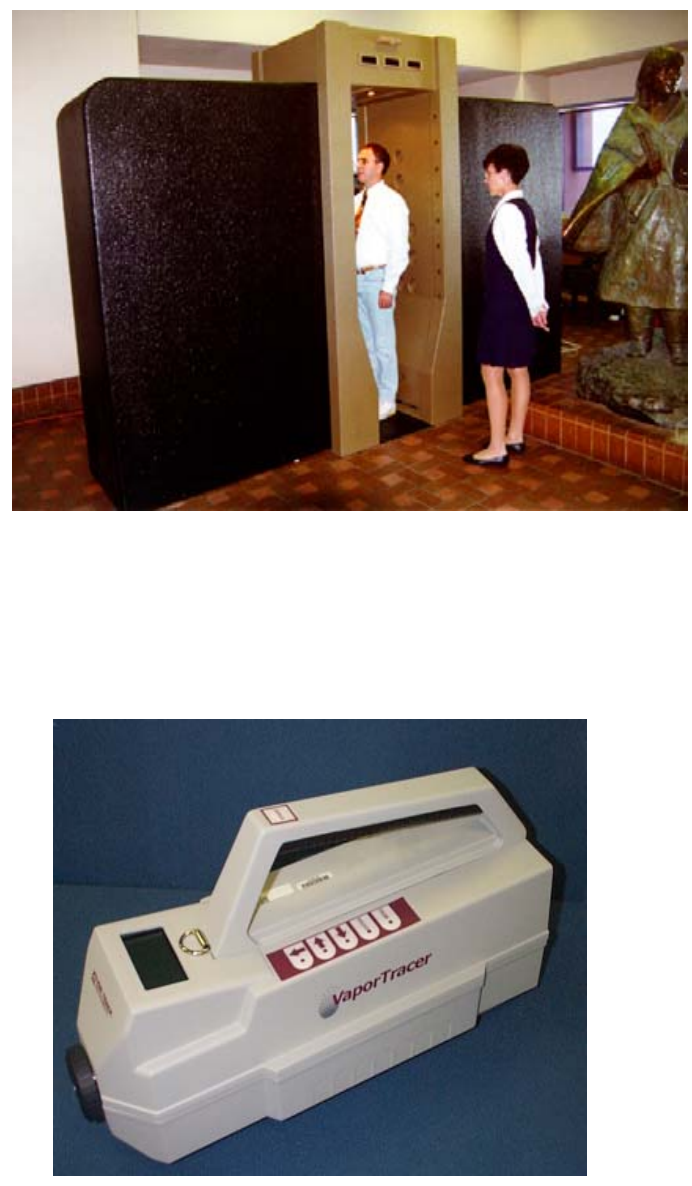


\section{X-ray Package I nspections}

- General

- Calibration is needed - use a step wedge or suitable approved test kit

- Personnel training is critical to success

- Entry

- Inspect packages for weapons and explosives

- Exit

- Inspect packages for shielding or nuclear material

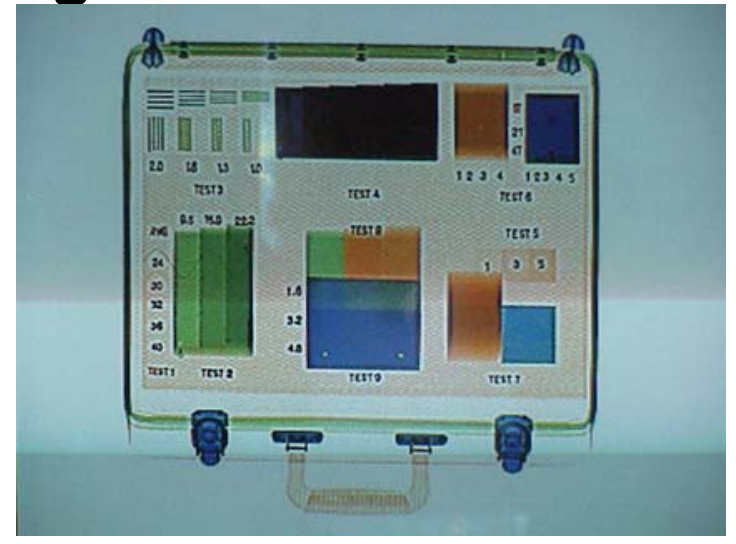




\section{Nuclear Radiation Monitors}

- Entry

- To prevent those persons from entering who will cause alarms when they leave the facility because of medical isotopes or off-site contamination

- Exit (two types)

- NM - to detect nuclear material leaving the facility

- Safety - to detect contamination

- General

- Operational testing

- Sensitivity testing and calibration

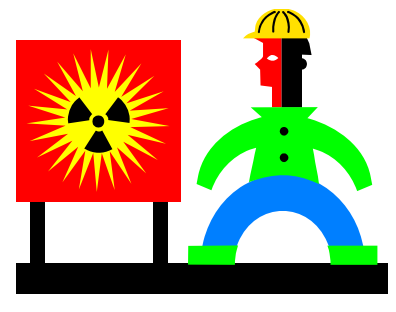




\section{Signal Line Tamper Detection}

- Provides assurance that the data on protection system signal lines has not been tampered with

- Protects against an insider compromising either the data or the signal path as part of a malevolent act

- A multi-person maintenance rule, knowledgeable escort, or detailed testing after maintenance is needed to assure desired capability is not compromised

- Periodic testing

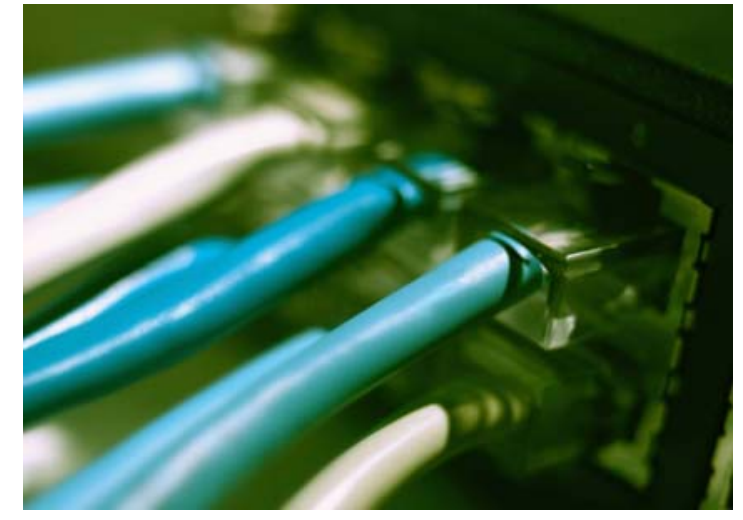




\section{Operational Process Alarms}

- Monitor normal operational process / safety alarms for abnormal conditions

- Alarm on sensor threshold violations or equipment failures

- Alarms can trigger automatic actions or alert operators to take action

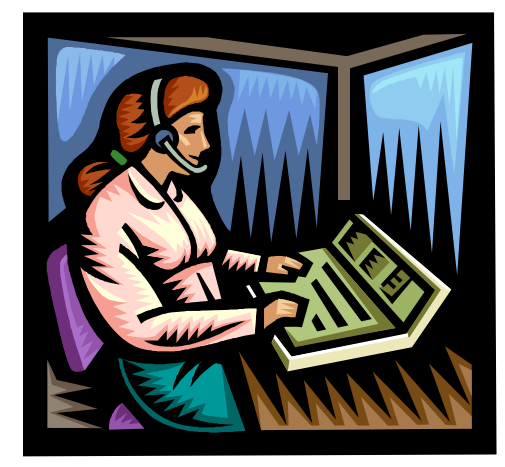




\section{Nuclear Material Control and Accountability (MC\&A) Program}

- Similar to the State System of Accounting and Control (SSAC) to detect loss of sensitive material

- Materials Accountability

- Tracks material quantities and locations

- Establishes material balance areas and identifies physical protection levels

- Provides loss detection/assessments

- Materials Control

- Minimizes access to materials and data

- Governs material movement, location and use

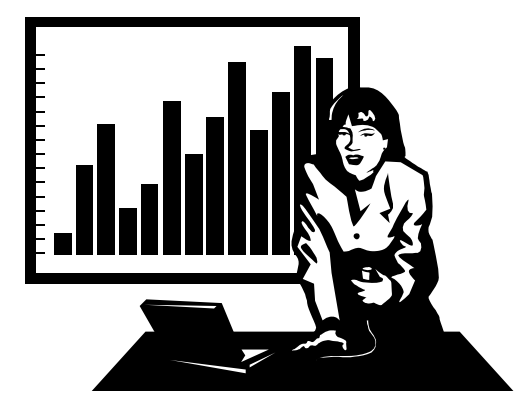

- Detects and assesses unauthorized activities 


\section{MC\&A Functional Areas}

- Materials accountability

- Accounting systems

- Physical inventories

- Measurement and measurement control

- NM transfers

- Material control indicators

- Materials control

- Access controls

- Materials surveillance

- Material containment

- Detection and assessment
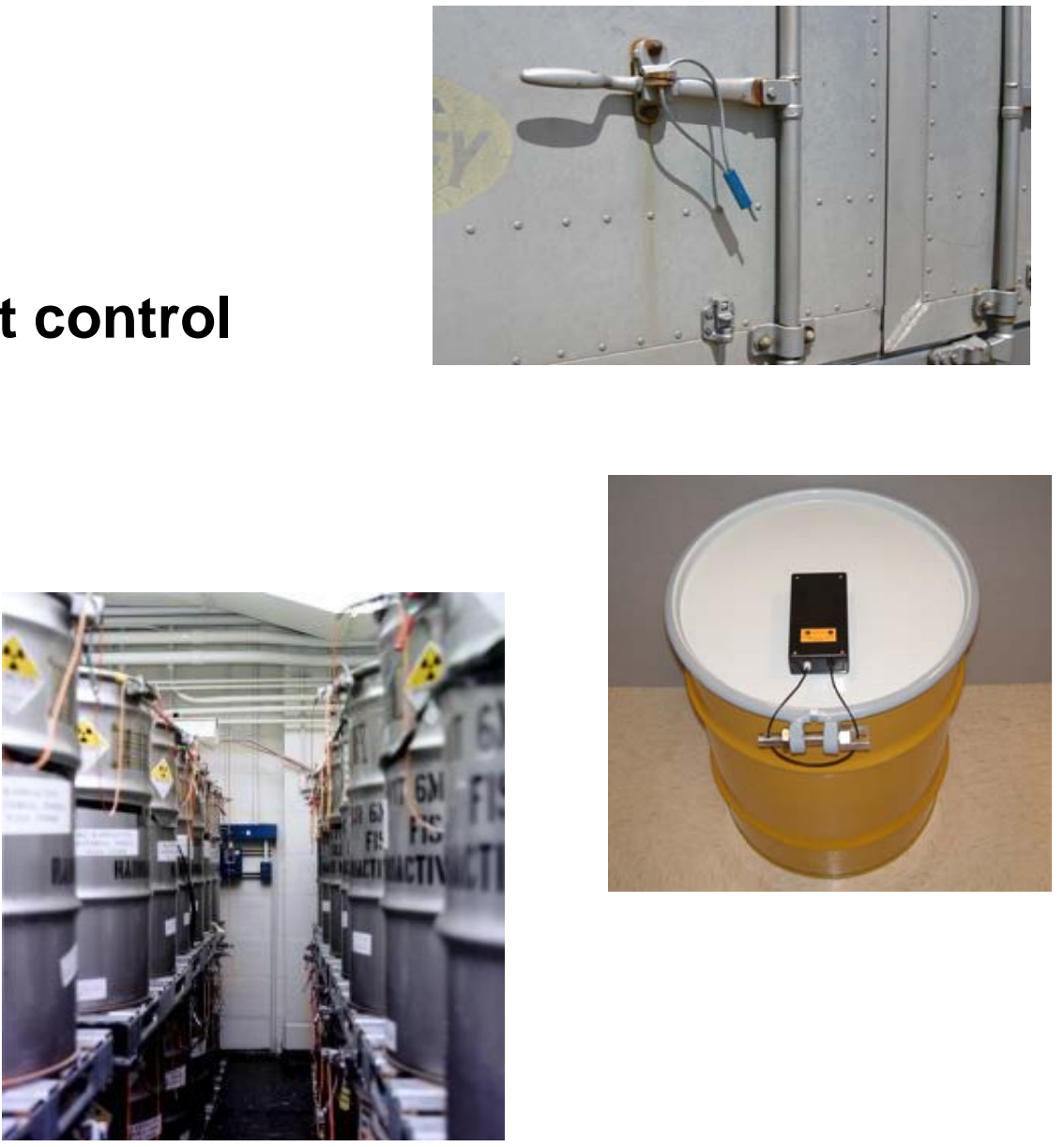


\section{Materials Accountability}

- Accounting systems

- Database and procedures

- Near real time data entry

- Transaction history

- Checks and balances

- Establish material balance areas

- Localize inventory differences

- Establish protection strategies

- Track/control roll-up potentials

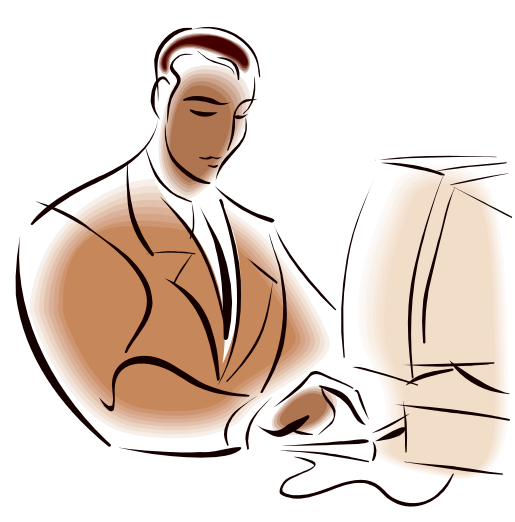




\section{Materials Accountability (cont.)}

- Measurement

- Shipment and receipts

- External moves

- Internal moves

- Changes during processing

- Validation/Confirmation of inventory

- Measurement control

- Ensure measurements accurate

- Periodic calibration checks

- Traceable to national standards

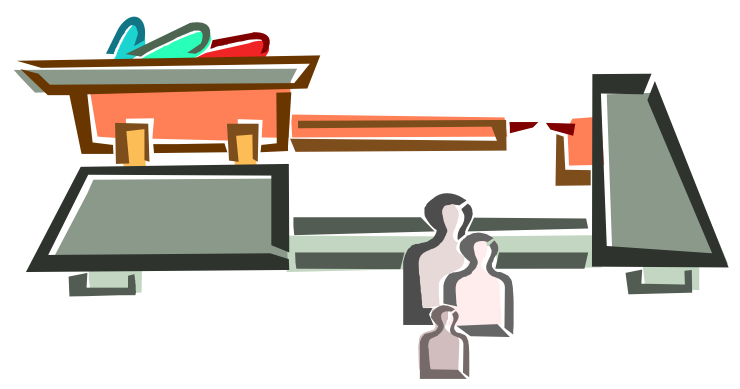




\section{Materials Accountability (cont.)}

- Physical Inventory

- Graded approach

- Frequency

- Statistical versus complete

- Validates book inventory

- Process monitoring

- Neal real time balance

- MBA level

- Process or individual system

- Item monitoring

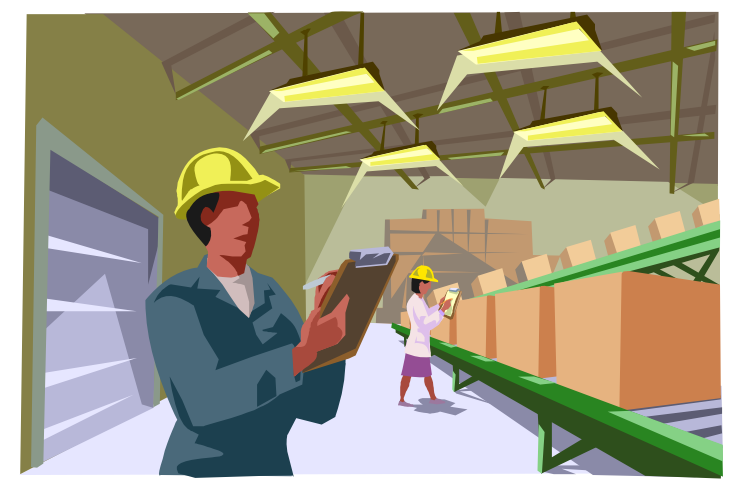




\section{Materials Accountability (cont.)}

- Assessments

- Inventory difference evaluation

- Shipper receiver evaluations

- Verification/Confirmation measurements

- Transfer checks

- Nuclear material moves

- Other movements
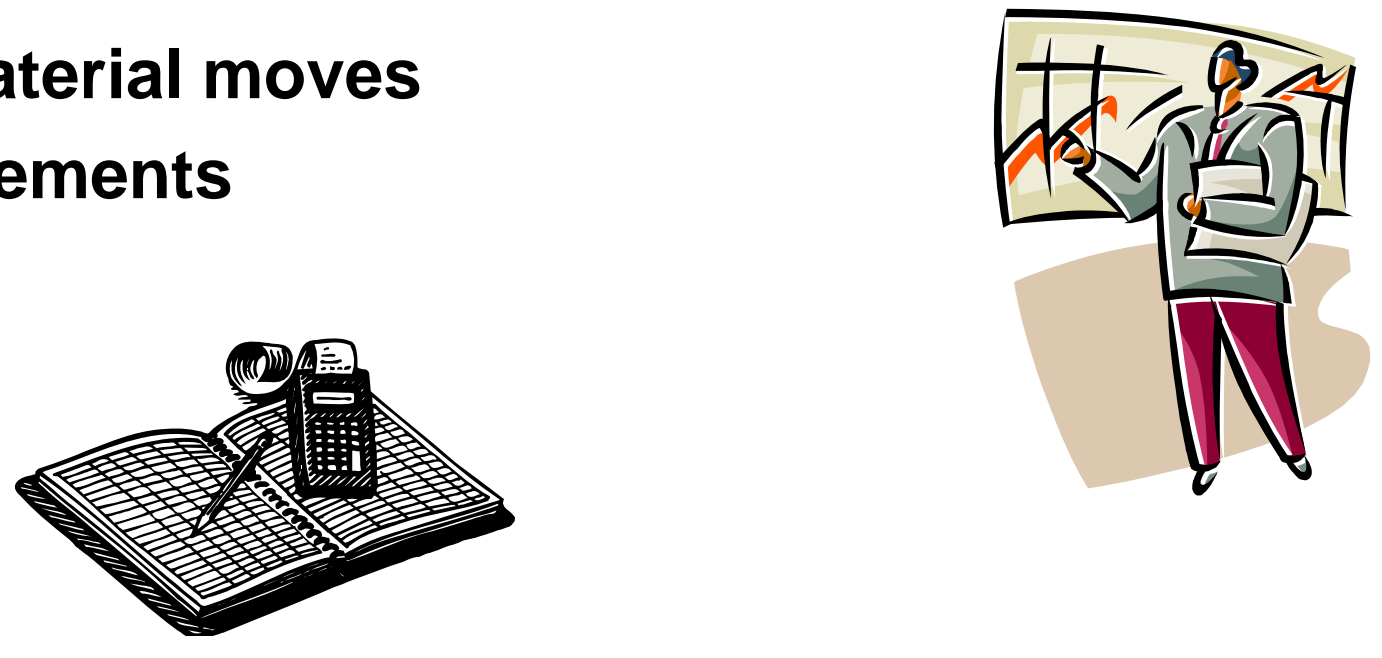


\section{Nuclear Materials Control}

"That part of the [MC\&A] program encompassing management and process controls to:

- Assign and exercise responsibility for nuclear material;

- Maintain vigilance over the material;

- Govern its movement, location and use;

- Monitor the inventory and process status;

- Detect unauthorized activities for all nuclear materials, and

- Help investigate and resolve apparent losses of nuclear material."

As defined in DOE Safeguards and Security Glossary of Terms, 1995 


\section{Materials Control}

- Access Controls

- Materials access

- Processing areas

- Vaults and storage areas

- Data access

- Accounting data

- Accounting programs

- Measurement data

- Scheduling

- Equipment access

- Measurement equipment

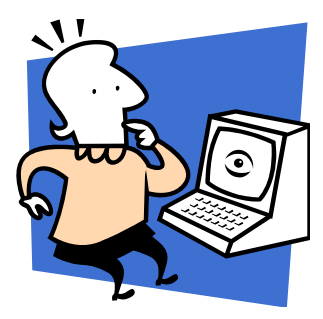

- Special Processing needs 


\section{Materials Control (cont.)}

\section{Materials surveillance}

- Automated or visual

- Cameras

- Switches

- Motion sensors

- Item sensors

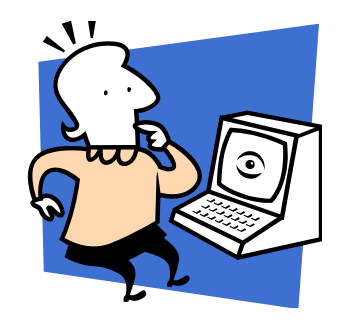

- Two person rules

- Daily administrative checks

- Roving monitors

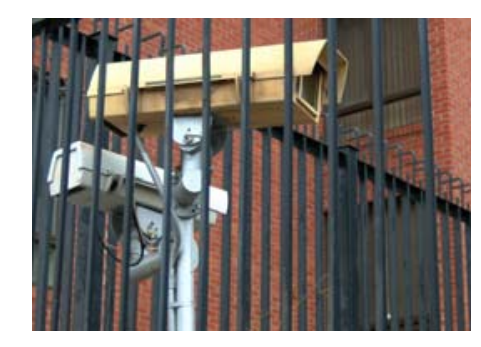




\section{Materials Control (cont.)}

- Material containment

- Relative to Limited Area (LA), Protected Areas (PA), Material Access Areas (MAA), and Storage Areas procedural controls

- Transfer authorizations

- Roll up considerations

- Waste monitoring

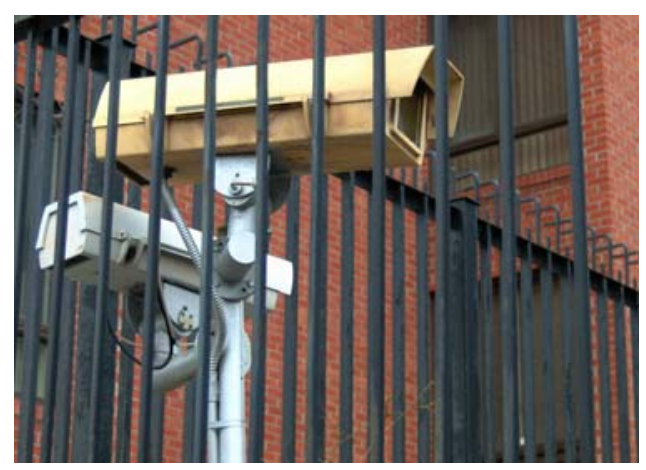




\section{Materials Control (cont.)}

- Detection and assessment

- Systems to detect and assess unauthorized removals consistent with graded safeguards concept

- TID program

- Transfer checks

- Daily administrative checks

- Roving monitors

- Emergency response

- Personnel accountability

- Areas sweeps

- Inventories

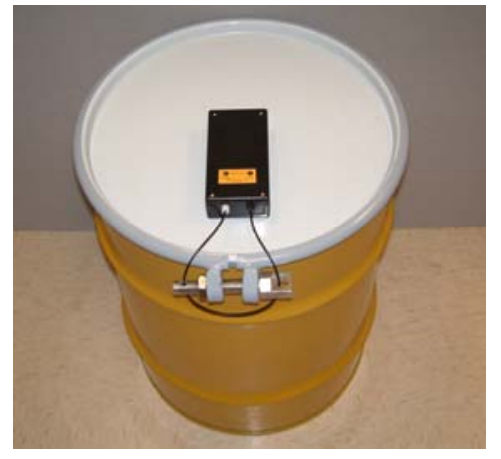




\section{Quality Assurance Programs}

- Quality management system should include:

- Process monitoring

- Performance testing

- Procedure compliance

- Provides traceability

- Quality records

- Example: verify compliance to the two-person rule by observing the actual actions of the personnel involved and monitoring the associated quality records

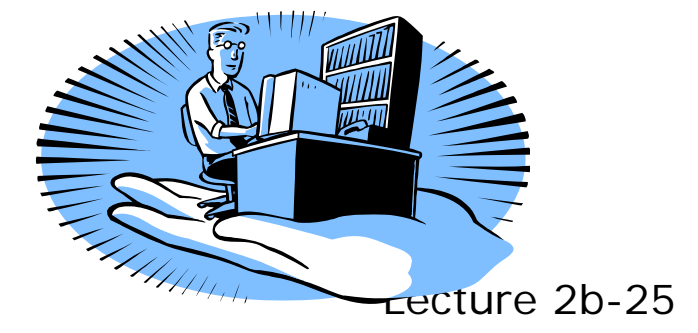




\section{Safety/ Security I nspections}

- Can detect compromises of equipment or unusual conditions

- Example

- Beaver Valley incident

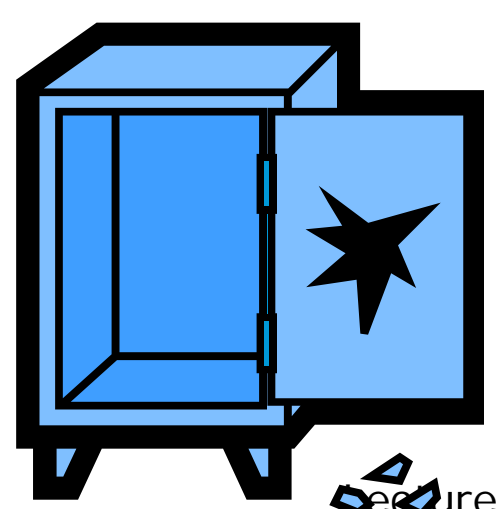




\section{Consider Delay Also}

- Almost all of the preceding slides have been directed at detecting a malevolent act

- Must also consider delay for the insider adversary

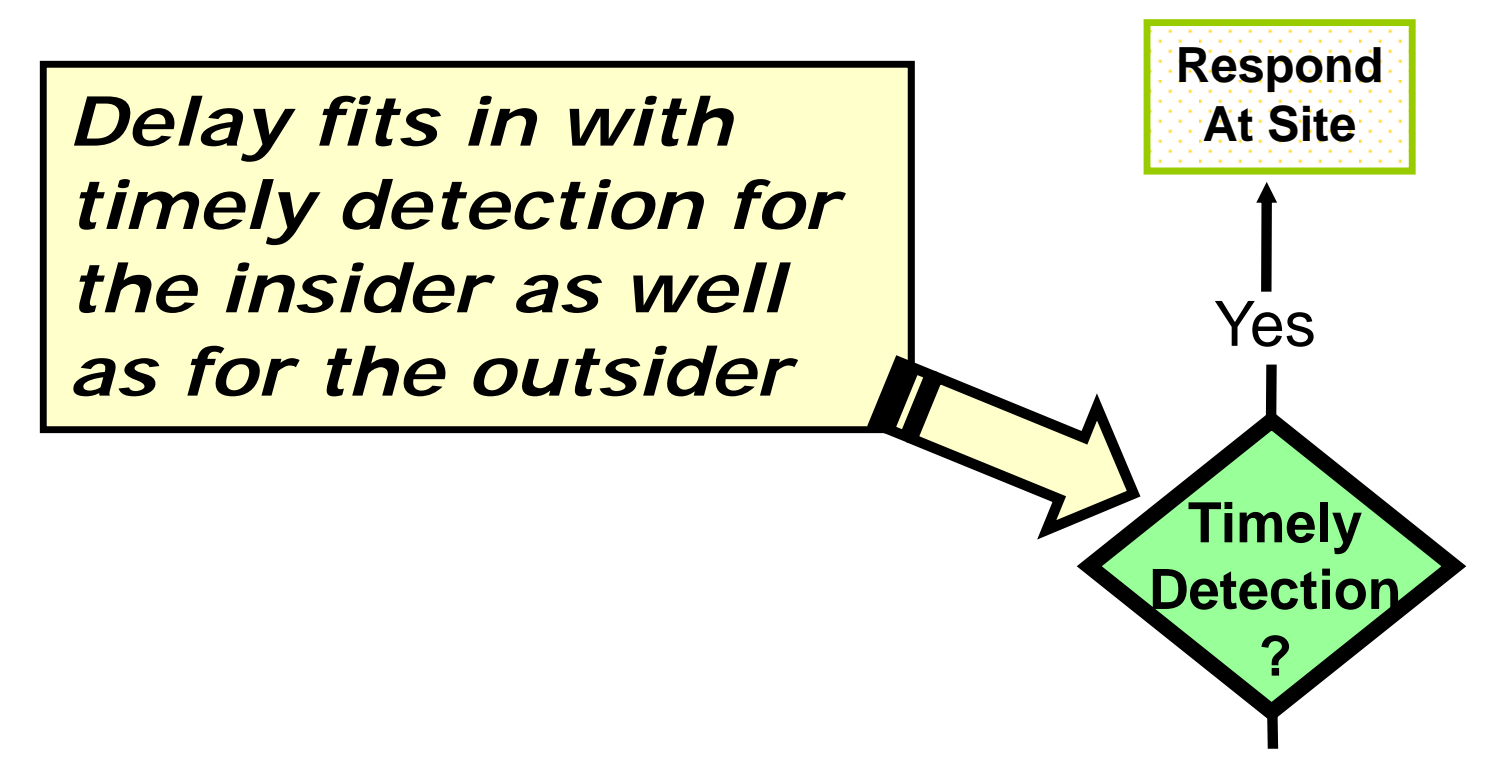




\section{Delay Measures and Material Control}

- Barriers

- Doors, cages, etc. are effective for some but not all adversaries since opening is necessary for operations

- Access to critical targets can be minimized

- Often a challenge to balance protection needs with safety and operational needs

- Procedures can also effect some delay

- Two-person rules

- Operational procedures

- Access control

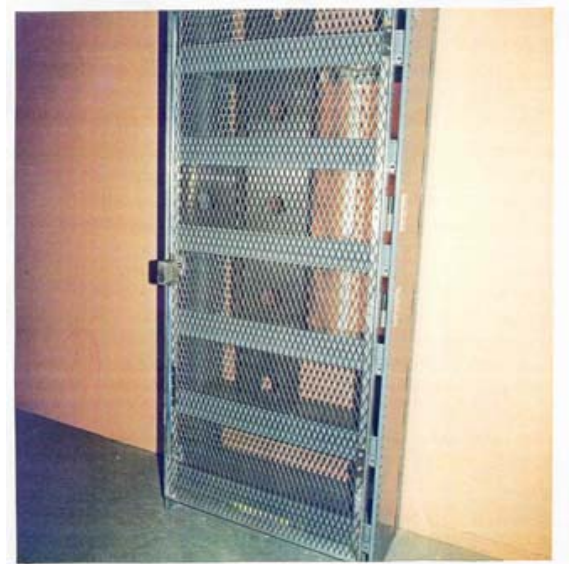




\section{Summary of Technical Protection Measures}

- Elements of the technical protection approach include:

- Detection of malevolent actions

- Entry and exit control

- Metal, explosive, and nuclear material detectors

- Package inspection

- Signal line tamper protection

- Operational alarms

- Material accountancy program

- Response at site

- Recovery, mitigation, and prosecution

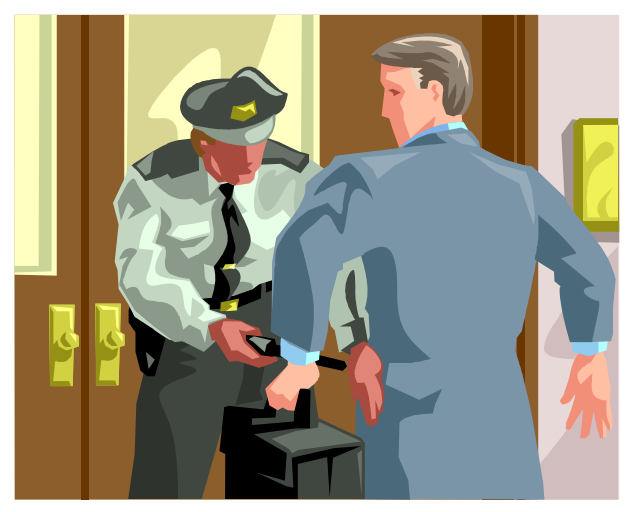




\section{I nsider Protection System Approach}

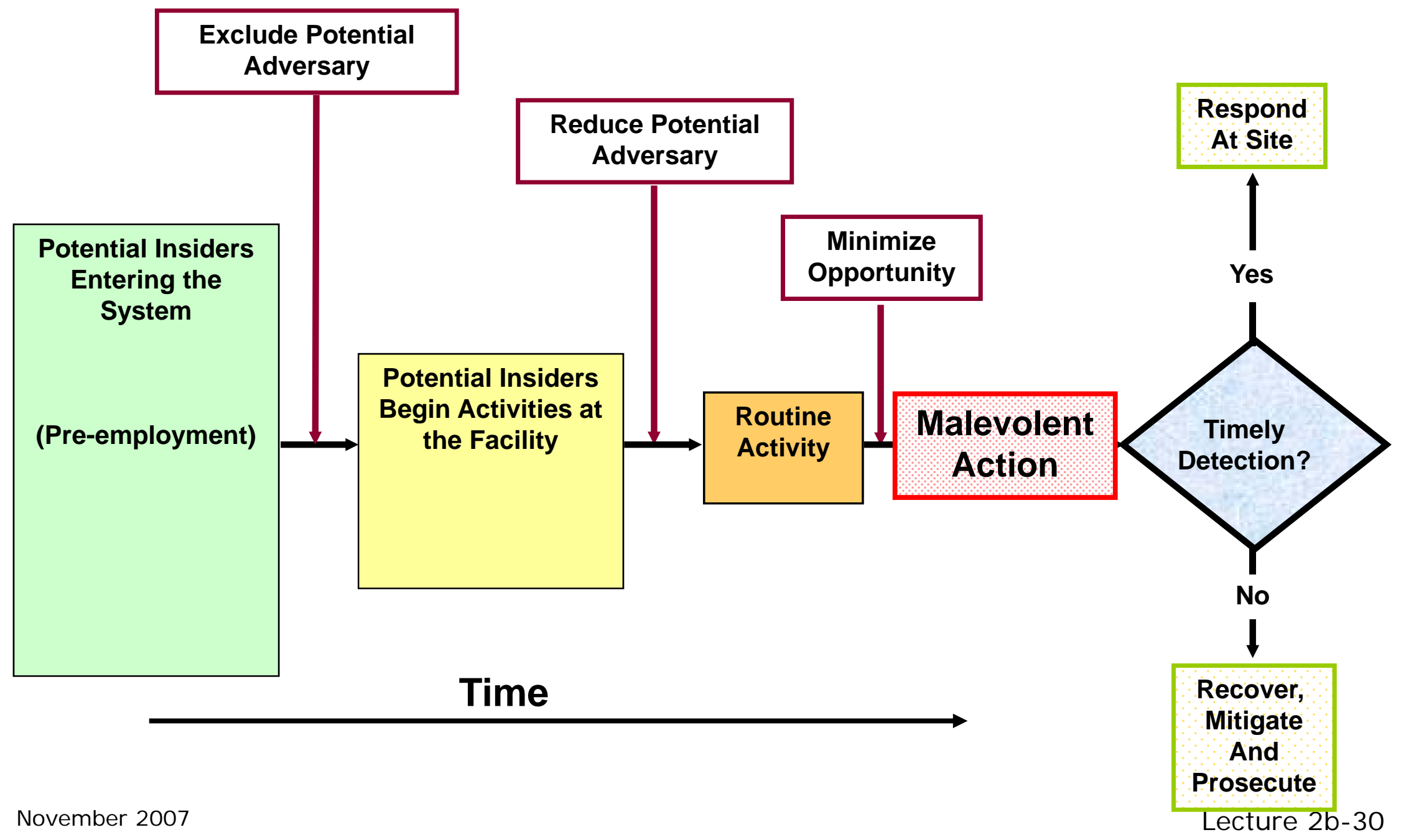




\section{Malevolent Actions - Examples}

- Removing material

- Defeating or attempting to defeat the MC\&A system

- Bypassing or compromising plant safety or security measures

- Defeating or attempting to defeat the operational process monitoring

- Damaging or compromising equipment

- Attacking or influencing personnel

- Falsifying records

- Others?

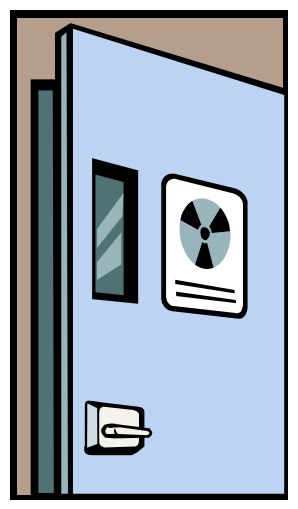




\section{Detection Of Malevolent Actions -}

\section{Issues}

- Insider tries to hide his actions or make them look normal

- Uses deceit and stealth much more than force

- Detecting actions

- Includes administrative, technical, and procedural measures

- A continuous timeline may be relevant in some cases and not in others

- Detection may be a function of time and/or the number of events

- Analysis and investigation can result in detection 


\section{Detection Of Malevolent Actions -}

\section{I ssues (cont'd)}

- Detection for insiders can only be possible when they do something abnormal or malevolent

- Assessment to confirm malevolence may be difficult

- Assumption of innocence

- Hesitation to report co-worker

- Fear of questioning authority

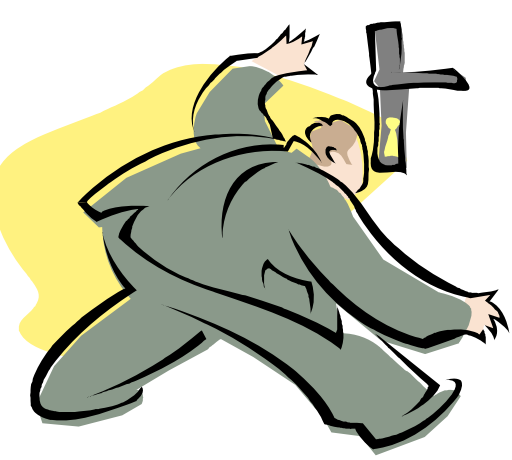




\section{Detection Considerations}

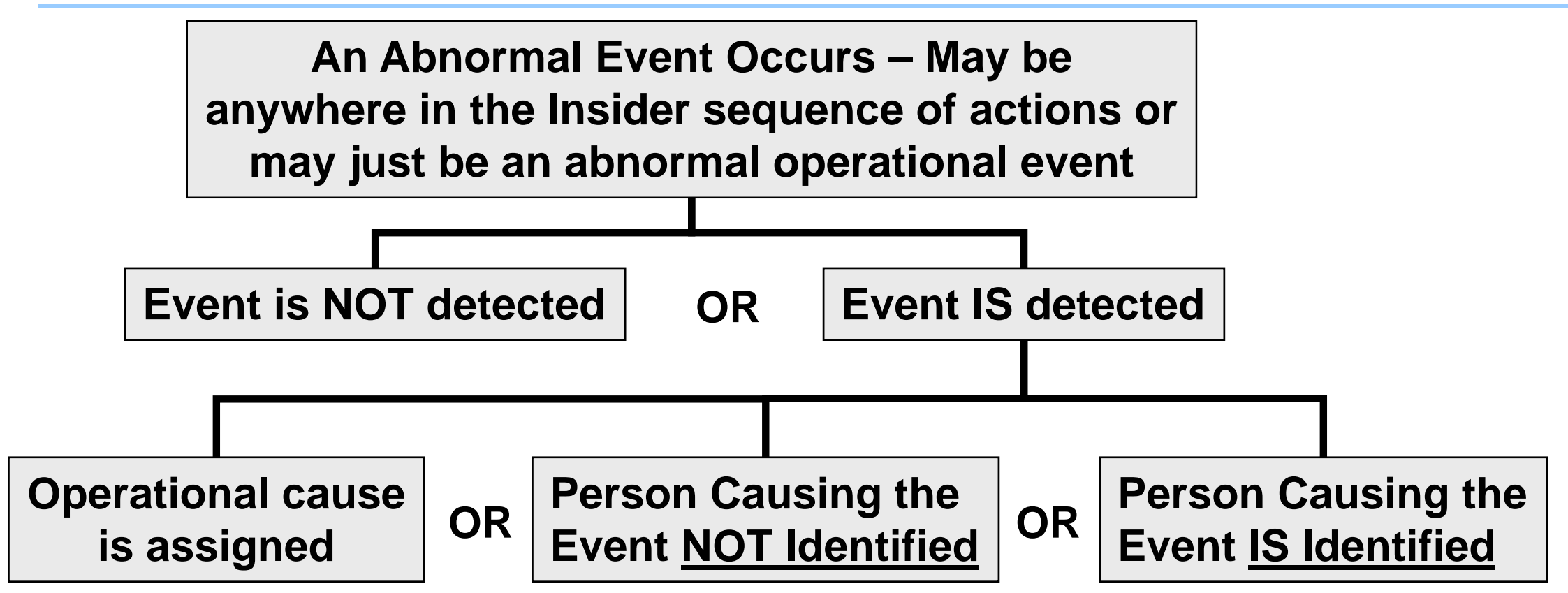

We will continue the development of this diagram when we consider response later 


\section{Detection Of Malevolent Actions}

- Observation by co-workers or supervisors

- Technical measures

- Access control

- Signal line tamper detection

- Operational alarms

- Material Control and Accountancy programs

- Safety inspections

- Quality Assurance

- Other?

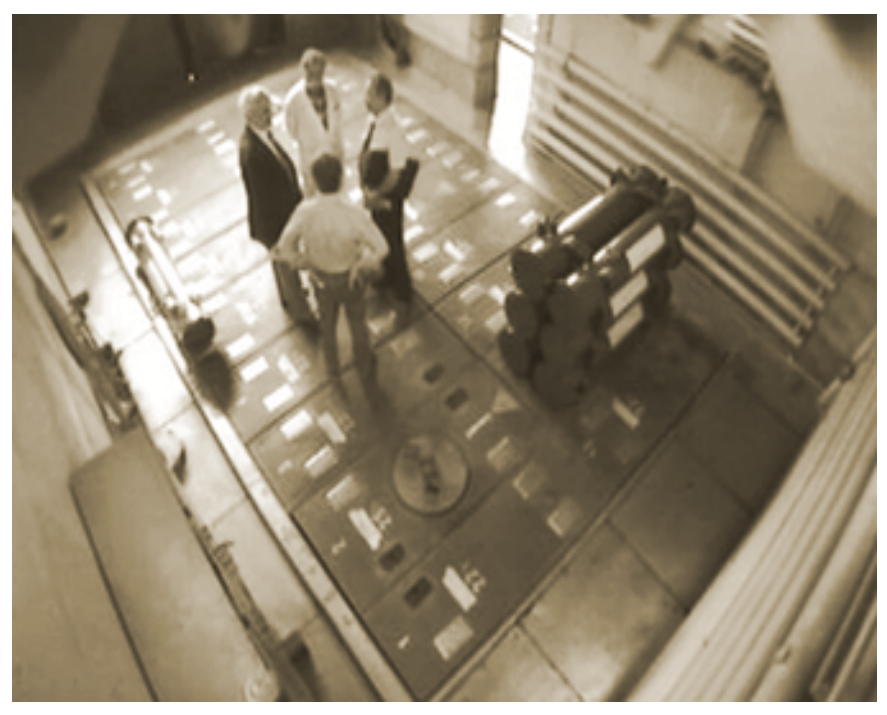




\section{Observation Of Material/ Personnel By Co-workers Or Supervisors}

- Administrative measures

- Multi-person presence - two-person rule

- Escort observation of those with limited authorization

- Monitoring key control

- Badge exchange

- Behavior observation

- Procedure compliance

- Technical measures

- Item and process monitoring

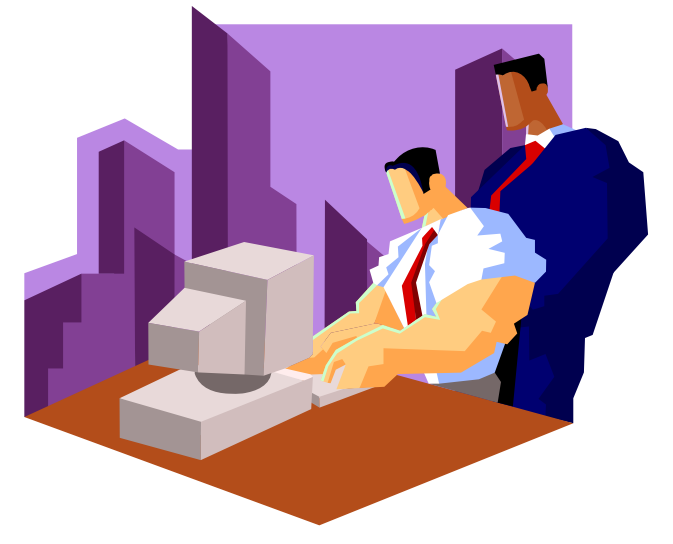

- Insider may "test" some of these measures to assess the effectiveness of the protection system 


\section{I nsider Protection System Approach}

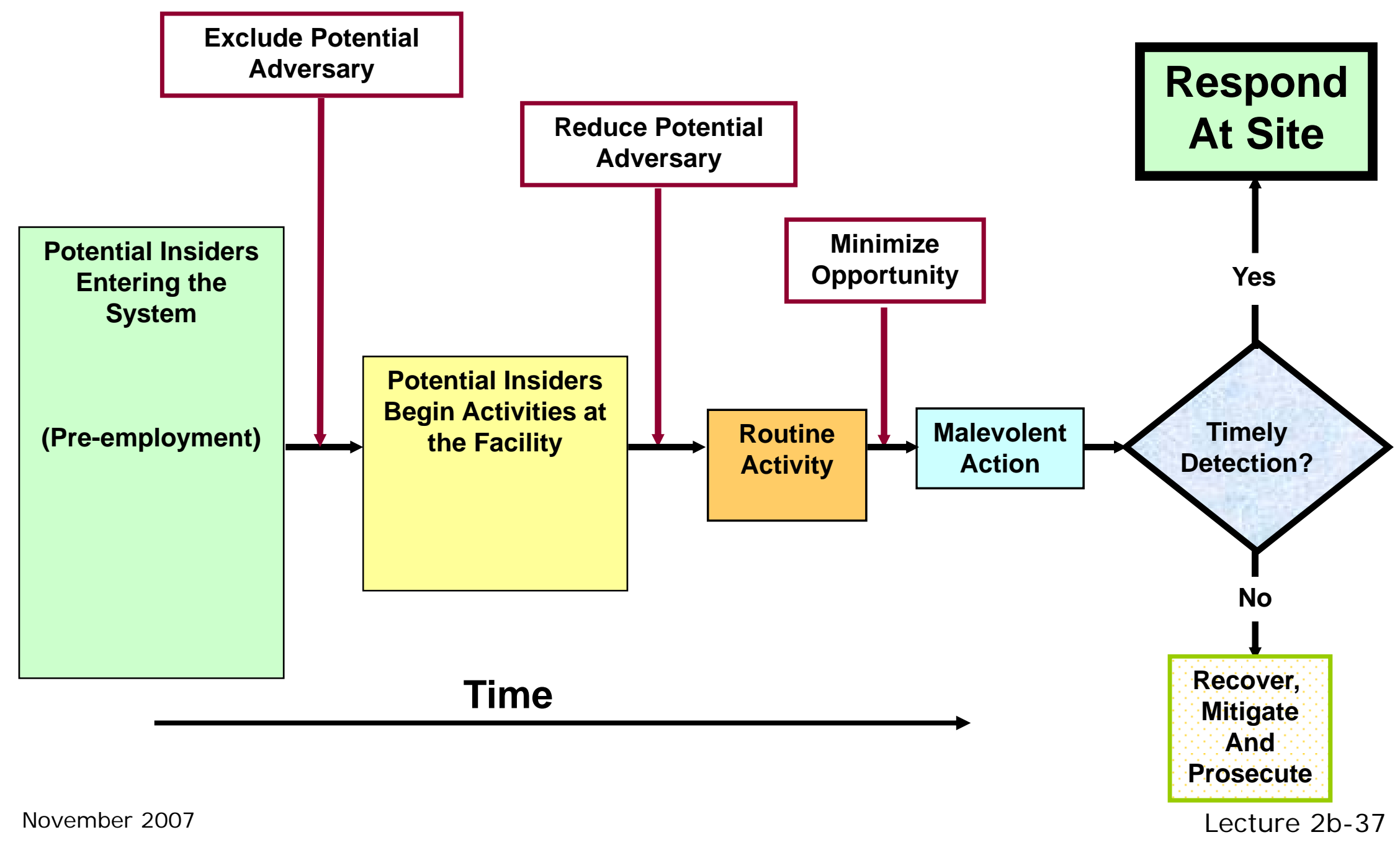




\section{Respond At Site: Two Steps}

1. The immediate response to prevent the malevolent action from occurring security personnel, operations personnel

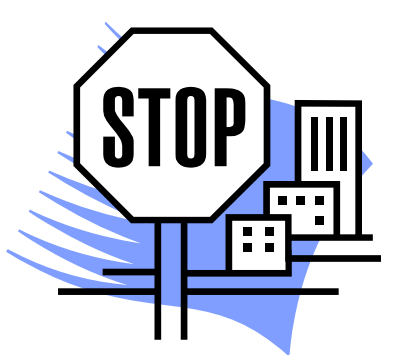

2. Immediate operational action taken by the system and operating personnel to prevent the malevolent act from resulting in the undesired consequences

- Safety and emergency personnel (applies to sabotage) 


\section{Detection/ Response Considerations}

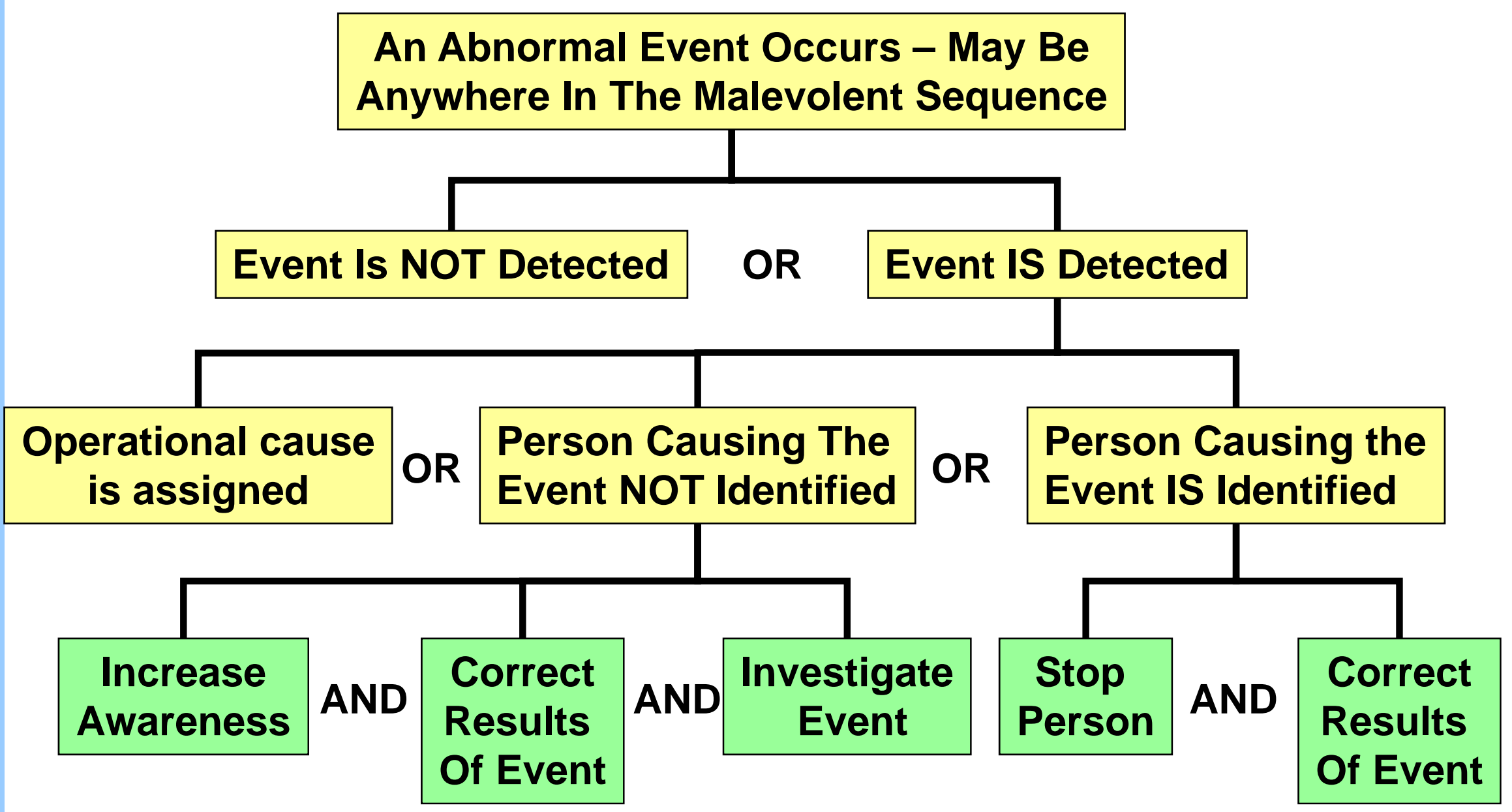




\section{I mmediate Personnel Response to Prevent Malevolent Action}

- Response may vary depending on the type of adversary

- Covert insider

- Overt insider(s)

- Response will also vary depending on

- How detection occurs

- Protective force

- Co-workers

- Operational / safety system

- What is detected

- Obvious malevolence

- Operational procedure error

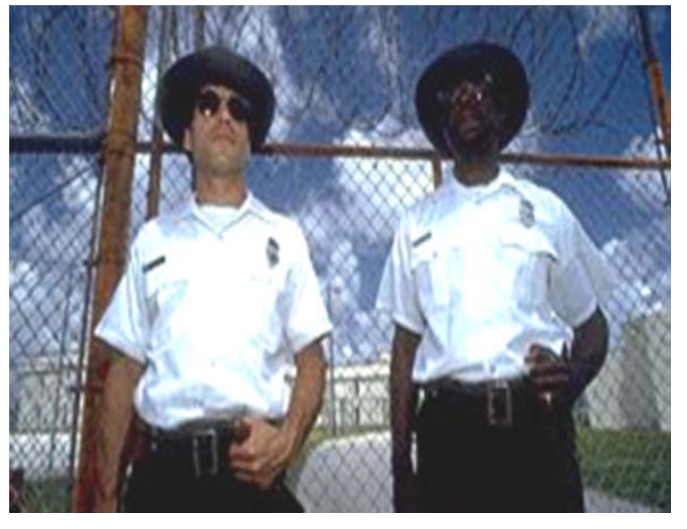




\section{I mmediate Personnel Response}

- Detection by coworkers or security system might have occurred during procedure violation, unusual activity, etc.

- First response might be by the person detecting the activity (co-worker) - part of security awareness training:

- Security should be immediately notified and rapidly confront both the violent and non-violent adversary

- Could include challenging the adversary to delay or stop his action

- Notify manager 


\section{Operational Process Response}

- Operations immediately negate the undesirable consequence

- Follow safety and security emergency response plans under a technical crisis team

- Identify anomalies

- Return system to protected state

- Repair damage

- Replace parts

- Compensate for security weaknesses

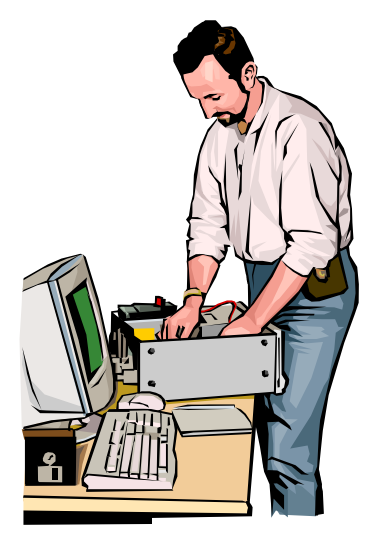




\section{I nsider Protection System Approach}

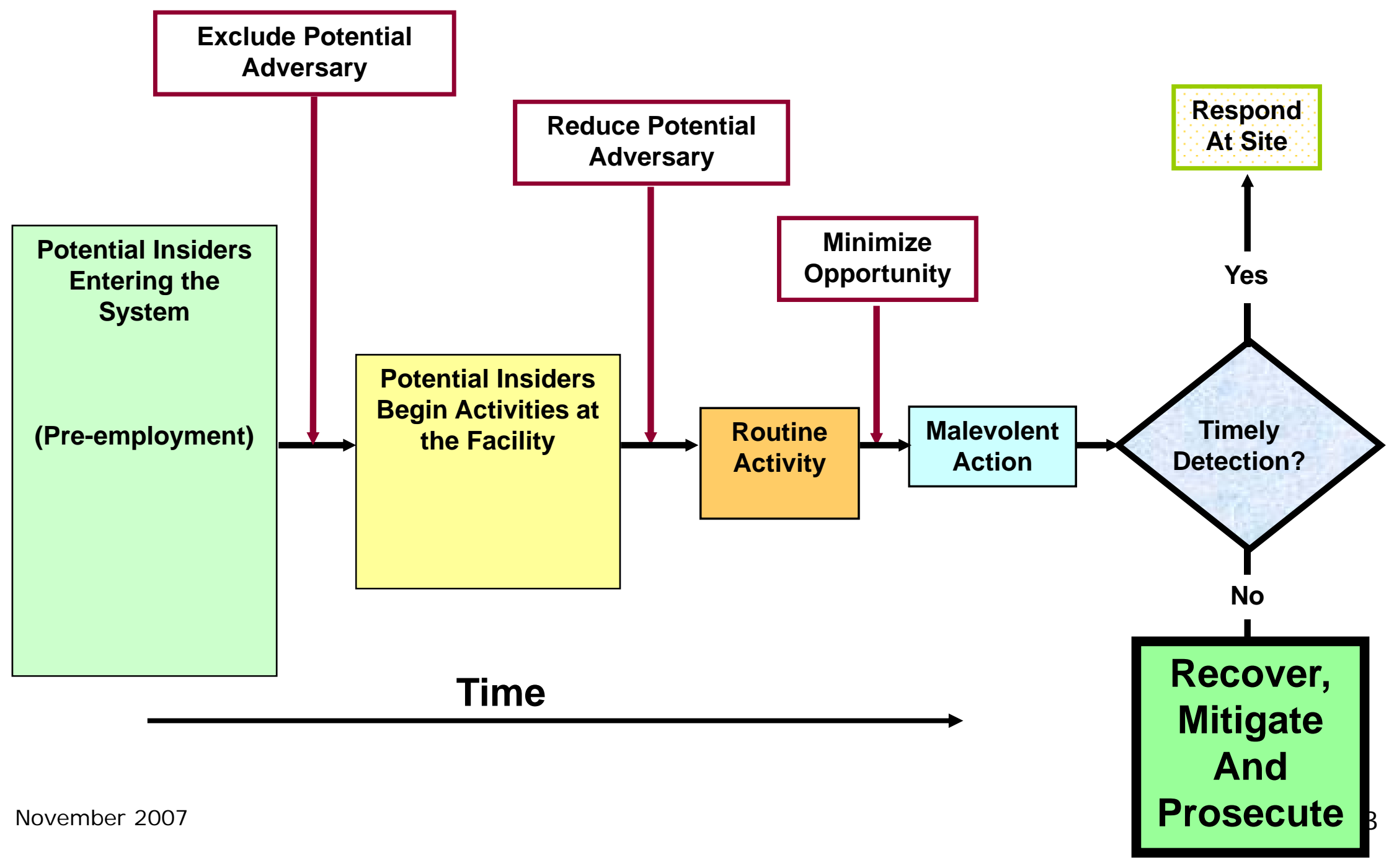




\section{Recovery, Mitigate, and Prosecute}

- Response if malevolent action is not prevented or action / consequence is detected late

- Recovery includes retrieval of stolen or diverted material

- Physical inventories will need to be performed

- Mitigation includes actions that will minimize the consequences (sabotage)

- Prosecution of adversary

- Provides justice

- Deters others by demonstrating penalties

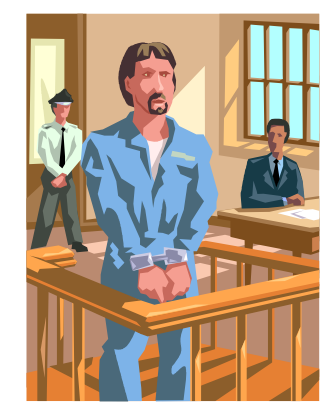

- Establishes the resolve to address insider problems

- Adjust system to react more favorably based on lessons learned 


\section{Compromise of I nformation}

- Often not detected in a timely manner

- Coworkers could detect compromise such as unauthorized faxing, copying, conversation, E-mail, activities, etc.

- Reporting could be by the person detecting the activity

- Part of security awareness training

- Security organization should be notified

- Incident program

- Investigation of perpetrator and information passed should begin immediately

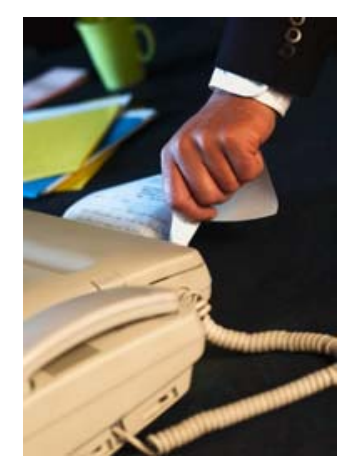




\section{Module Summary}

- Summarize the Insider Protection System approach

- Describe the administrative and technical measures in an MPC\&A system that can provide protection against insider threats in general

- Estimate the effectiveness of administrative and technical measures

Questions or Comments?? 


\section{Subgroup Exercise: Estimate Effectiveness of Technical Measures}

- Evaluate the URF for both of the following specific technical measures:

- Subgroups 1 \& 2: PA entry control portal

- Subgroups 3 \& 4: Material control and accounting system

- Devise methods by which an insider adversary could try to defeat these measures

- Estimate the effectiveness of the measure considering the defeat method

- Include pertinent delay considerations

- Summarize and discuss with large group 


\section{PA Entry Control Portal}

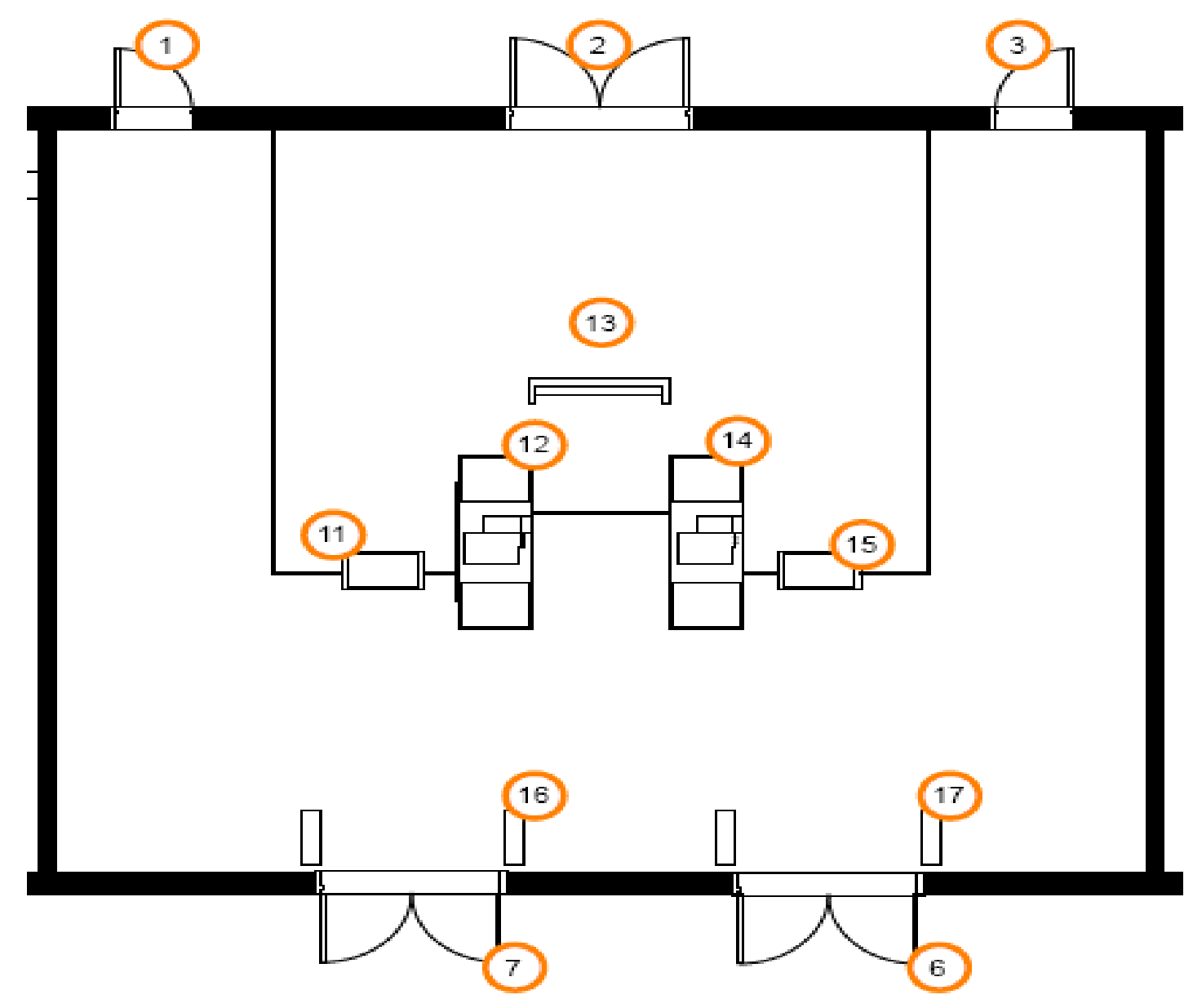
1, 2, 3 - Doors into PA Portal

13 - Guard post

12,14 - X-ray machines

11, 15 - Metal Detectors

16, 17 - Rad detectors

6, 7 - Doors into PA 


\section{Exercise: Protective Technical Measures - PA Portal}

\begin{tabular}{|l|l|l|l|}
\hline Measures & $\begin{array}{l}\text { Weaknesses } \\
\text { Of the } \\
\text { Measure }\end{array}$ & $\begin{array}{l}\text { Potential } \\
\text { Defeat } \\
\text { Methods }\end{array}$ & $\begin{array}{l}\text { Estimate } \\
\text { Effectiveness } \\
(\mathrm{H}, \mathrm{M}, \mathrm{L})\end{array}$ \\
\hline Doors into PA & & & \\
\hline Posted Guard & & & \\
\hline X-ray Search & & & \\
\hline Metal Detector & & & \\
\hline SNM Detector & & & \\
\hline $\begin{array}{l}\text { Doors into } \\
\text { portal }\end{array}$ & & & \\
\hline
\end{tabular}




\section{Material Control and Accountancy System}

- Four Material Balance Areas

- Items are tracked and inventoried by a unique TID identifier

- Measurements

- Limited assay measurements

- Several weight measurements

- Monthly physical inventories

- Shipper / receiver document comparison

- All documentation sent to a computer based accounting system 


\section{Exercise: Protective Technical Measures - MC\&A System}

\begin{tabular}{|l|l|l|l|}
\hline Measures & $\begin{array}{l}\text { Weaknesses } \\
\text { Of the } \\
\text { Measure }\end{array}$ & $\begin{array}{l}\text { Potential } \\
\text { Defeat } \\
\text { Methods }\end{array}$ & $\begin{array}{l}\text { Estimate } \\
\text { Effectiveness } \\
(\mathrm{H}, \mathrm{M}, \mathrm{L})\end{array}$ \\
\hline Four MBAs & & & \\
\hline Unique TID Identifier & & & \\
\hline Measurements & & & \\
\hline Physical Inventory & & & \\
\hline Shipper I Receiver & & & \\
\hline $\begin{array}{l}\text { Manual documentation } \\
\text { to Computer System }\end{array}$ & & & \\
\hline
\end{tabular}




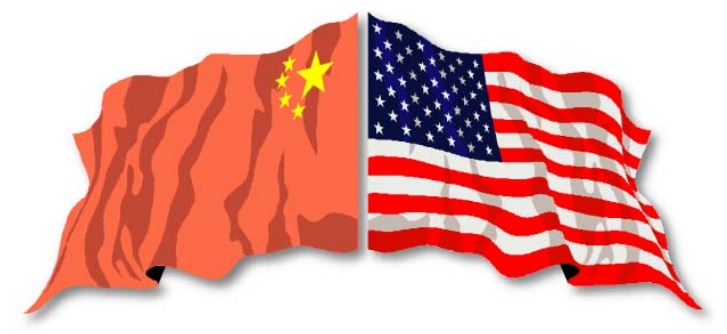

\section{Lecture 3}

\section{Facility Overview}

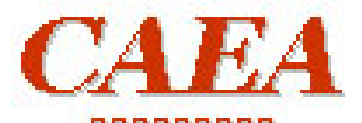

ucouguado

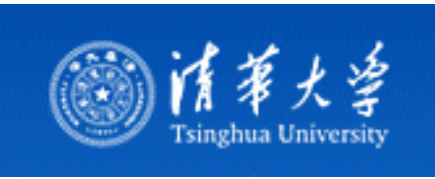

Sandia

National

Laboratories

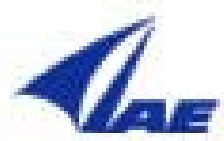

- LOS Alamos

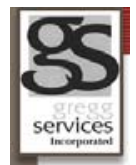




\section{Student Learning Objectives}

- In this module we will:

- Discuss the important steps in characterizing a facility

- Conduct an overview of the Facility

- Simulate interviews with facility management in order to:

- Determine the mission and operations of the facility

- Determine the physical characteristics of the facility

- Teams consolidate notes from the facility overviews 


\section{The Facility Characterization Process}

- Philosophy of facility characterization

- Document major assumptions underlying VA

- Be methodical and comprehensive

- Steps

- Gather information

- Documentation

- Interviews

- Obtain or draw facility schematics for analyzing possible adversary paths and target(s)

- Characterize safeguards and security measures

- Identify facility states 


\section{Gather information}

\section{Sources:}

- Facility tours

- Architectural diagrams

- Interviews with management and workers

- Safeguards and security and material control and accountability plans

- Maintenance and operating procedures

- Safety analysis reports

- Previous vulnerability assessments, audits, surveys, etc. 


\section{Tour Preparation}

- Tour the facility and gather information from interviews

- Review schematic diagrams to determine:

- areas,

- protection layers, and

- path elements

- For each path element, note safeguards components

- Note information on how hardware and procedures are implemented

- The system can be characterized at various levels of detail 


\section{Interviews with Facility Management}

- Overview by Corporate President

- Overview of the facility mission

- Introduction of Key Personnel

- Facility Manager

- Overview of facility operations

- Materials Manager

- Overview of material operations

- Security Manager

- Overview of security operations 


\section{Interview with Corporate President}

- The Mission

- The Corporate Philosophy

- Introduction of Key Staff

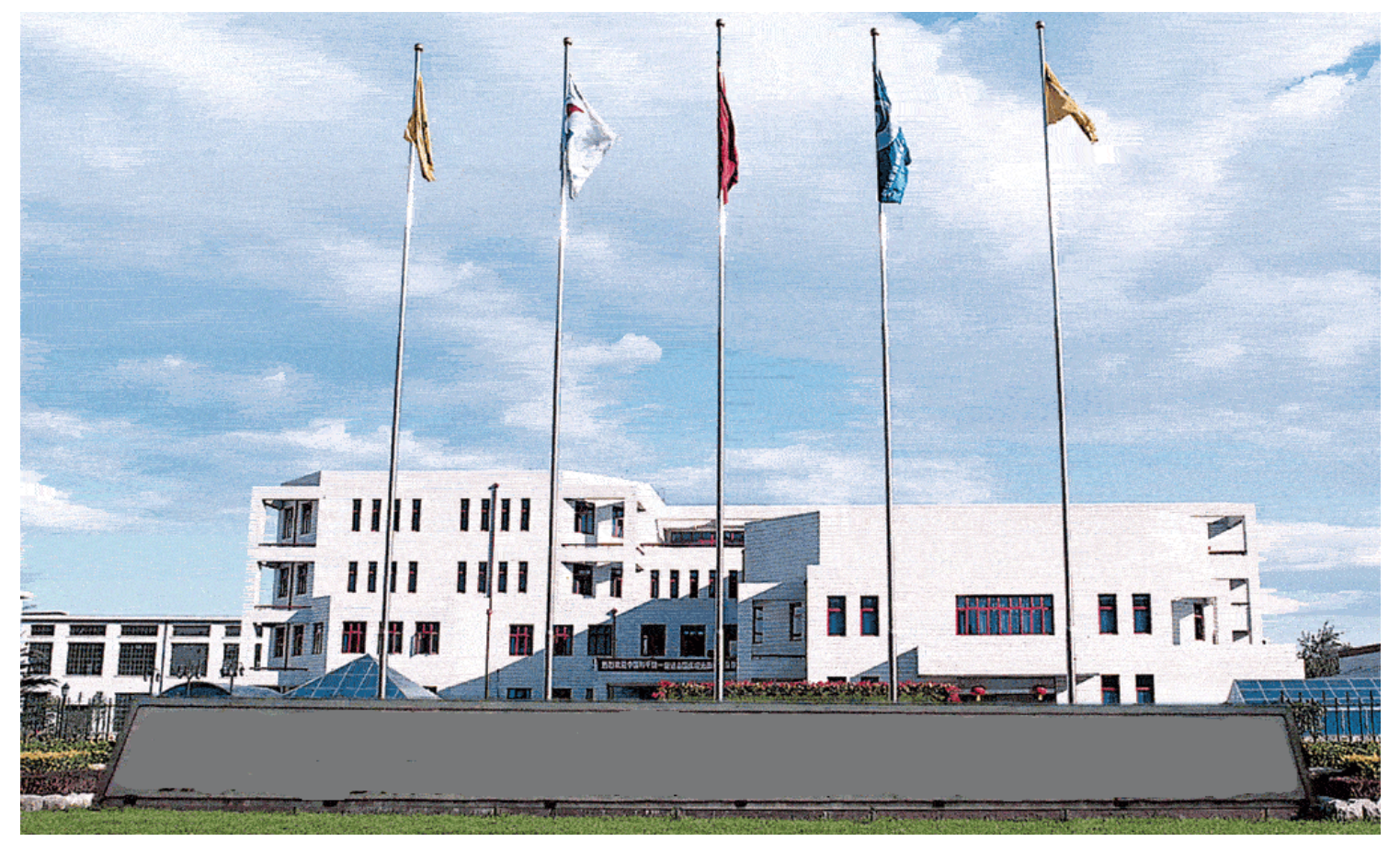




\section{Interview with Plant Manager}

\section{Overview of facility organization}

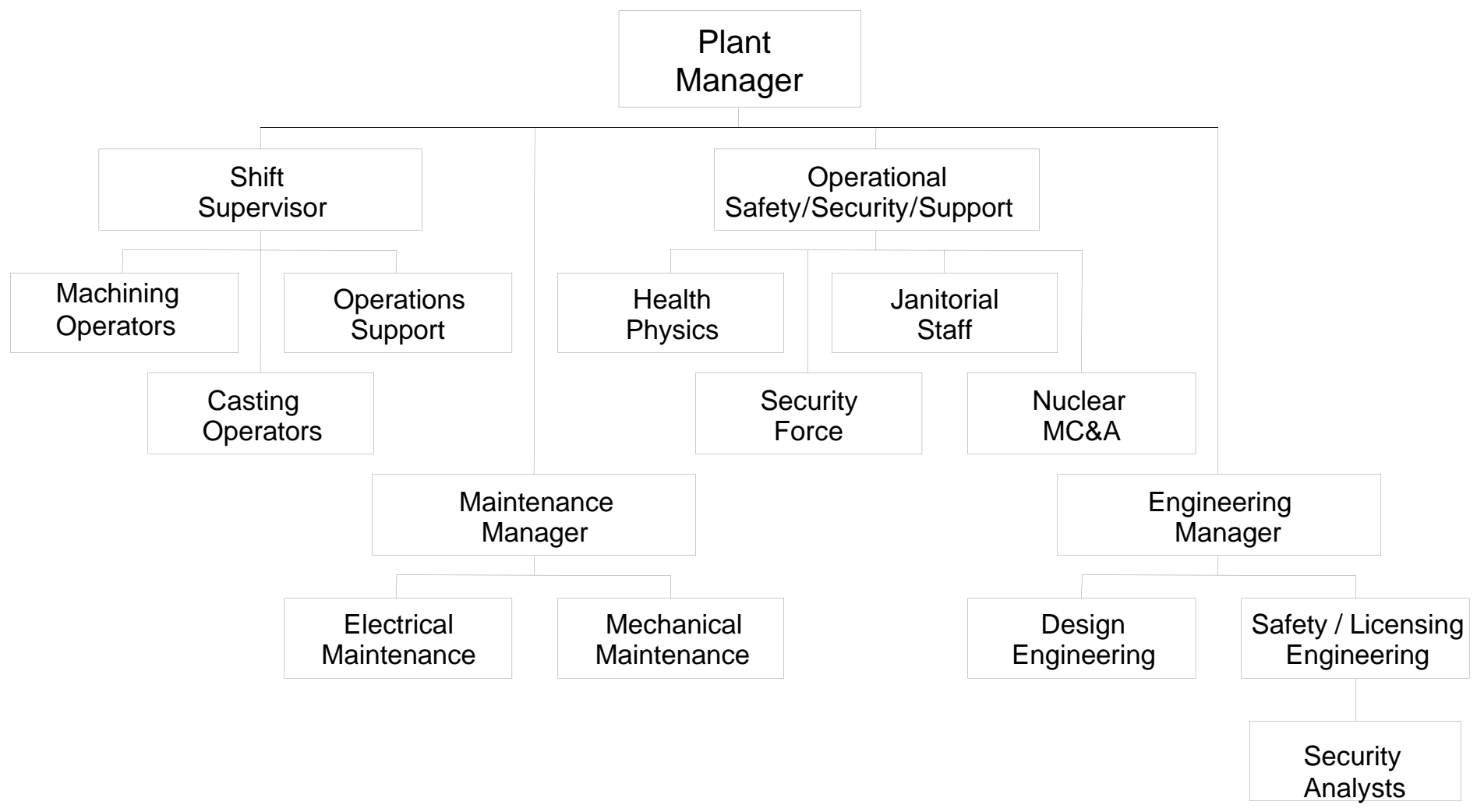




\section{I nterview with Plant Manager, con't}

- Overview of facility operations

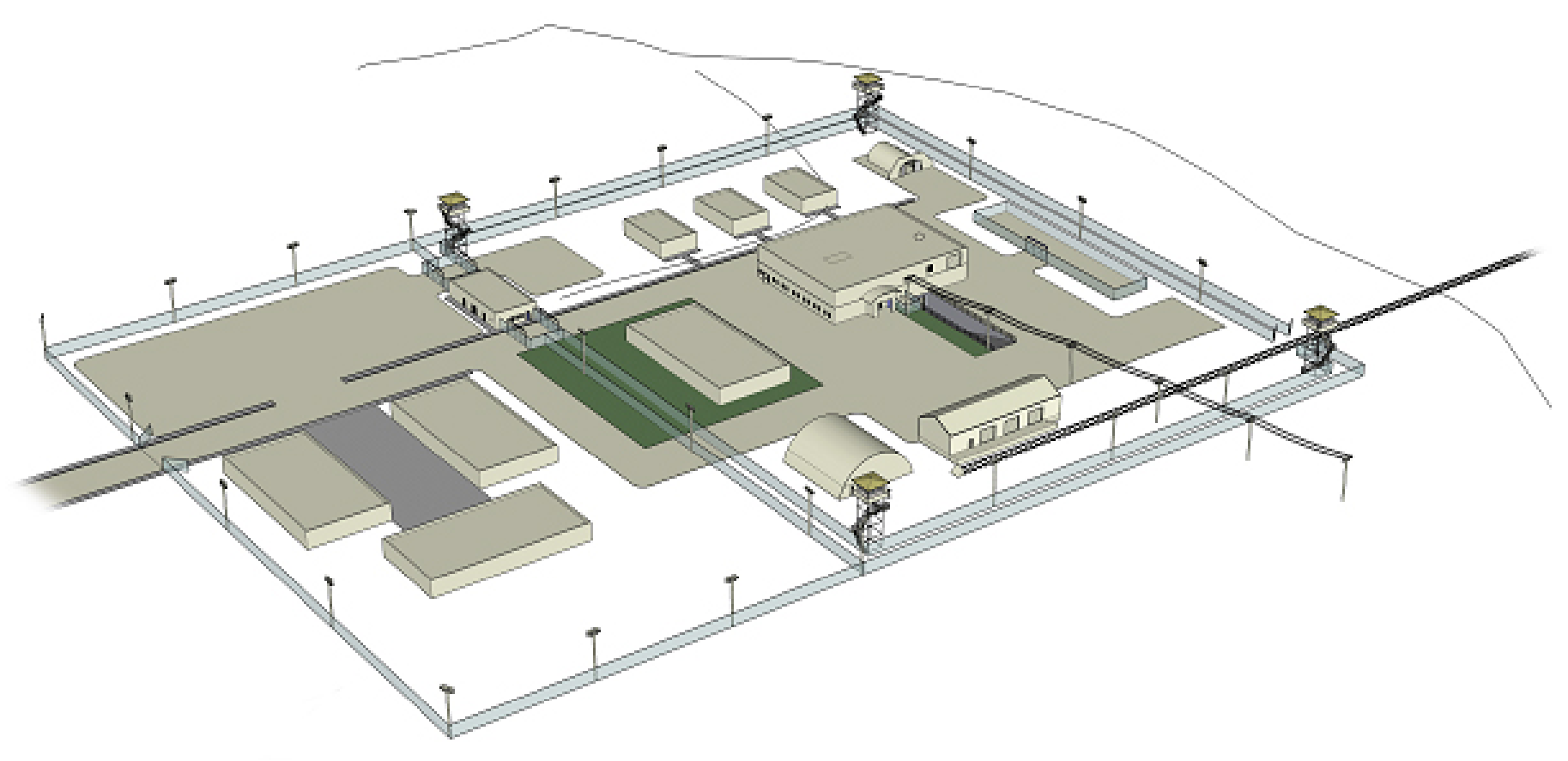




\section{I nterview with Materials Manager}

- Overview of material operations

\begin{tabular}{|l|l|l|}
\hline $\begin{array}{c}\text { Material Balance } \\
\text { Area }\end{array}$ & \multicolumn{1}{|c|}{ Form of Material } & $\begin{array}{c}\text { Allowable Material Inventory } \\
\text { (wt \% enrichm ent) }\end{array}$ \\
\hline X-Ray Facility & $\mathrm{UO}_{2}-$ billets & $5 \mathrm{~kg} \mathrm{U}(<86.6 \%)$ \\
Product Bunker & $\mathrm{UO}_{2}-$ billets & $30 \mathrm{~kg} \mathrm{U}(<86.6 \%)$ \\
& $\mathrm{UO}_{2}-$ powder & $10 \mathrm{~kg} \mathrm{U}(<86.6 \%)$ \\
\hline \multirow{3}{*}{ Proc essing Building } & $\mathrm{UO}_{2}-$ ingots & $30 \mathrm{~kg} \mathrm{U}(<86.6 \%)$ \\
& $\mathrm{UO}_{2}-$ scrap & $50 \mathrm{~kg} \mathrm{U}(<86.6 \%)$ \\
\cline { 2 - 3 } & $\mathrm{UO}_{2}-$ billets & $20 \mathrm{~kg} \mathrm{U}(<86.6 \%)$ \\
\hline
\end{tabular}




\section{I nterview with Security Manager}

- Overview of security operations

\begin{tabular}{|c|c|c|c|}
\hline Area & Access Controls & Physical Barriers & Detection Devices \\
\hline AA & Employee badge & $\begin{array}{l}\text { Chain-link fence; vehicle } \\
\text { gate }\end{array}$ & Guard checks \\
\hline PA & ECP & $\begin{array}{l}\text { Perimeter Intrusion } \\
\text { Detection and Assessment } \\
\text { System }\end{array}$ & $\begin{array}{l}\text { Perimeter sensors; tower } \\
\text { guards }\end{array}$ \\
\hline ECP & $\begin{array}{l}\text { Employee badge with } \\
\text { guard present to } \\
\text { ensure correct } \\
\text { procedures at metal } \\
\text { detectors and SNM } \\
\text { detectors }\end{array}$ & Security doors, walls & $\begin{array}{l}\text { Guard; metal detectors and } \\
\text { SNM detectors }\end{array}$ \\
\hline X-Ray Facility & $\begin{array}{l}\text { 2-person control on } \\
\text { locks }\end{array}$ & $\begin{array}{l}\text { V ault-like construction } \\
\text { with Class V doors }\end{array}$ & $\begin{array}{l}\text { BMS door sensor; interior PIR } \\
\text { sensors }\end{array}$ \\
\hline Final Product Bunker & $\begin{array}{l}\text { 2-person control con } \\
\text { locks }\end{array}$ & $\begin{array}{l}\text { V ault-like construction } \\
\text { with Class V doors }\end{array}$ & $\begin{array}{l}\text { BMS door sensor; interior PIR } \\
\text { sensors }\end{array}$ \\
\hline Production Building & Entry contr ol portal & $\begin{array}{l}\text { Security doors; walls; } \\
\text { guerd }\end{array}$ & Metal andSNM detectors \\
\hline Prochact V ault & $\begin{array}{l}\text { 2-person control on } \\
\text { locks }\end{array}$ & $\begin{array}{l}\text { V ault-like construction } \\
\text { with } \mathrm{Cl} \text { ass } \mathrm{V} \text { doors }\end{array}$ & $\begin{array}{l}\text { BMS door sensor; interior PIR } \\
\text { sensors }\end{array}$ \\
\hline QA V ault & $\begin{array}{l}\text { 2-person control on } \\
\text { locks }\end{array}$ & $\begin{array}{l}\text { V ault-like construction } \\
\text { with Class V doors }\end{array}$ & $\begin{array}{l}\text { BMS door sensor; interior PIR } \\
\text { sensors }\end{array}$ \\
\hline Chip V atalt & $\begin{array}{l}\text { 2-person control con } \\
\text { locks }\end{array}$ & $\begin{array}{l}\text { Vautt-like construction } \\
\text { with Class V doors }\end{array}$ & $\begin{array}{l}\text { BMS door sensor; interior PIR } \\
\text { sensors }\end{array}$ \\
\hline Casting Fumace Are: & $\begin{array}{l}\text { 2-person control on } \\
\text { locks }\end{array}$ & $\begin{array}{l}\text { Vault-like construction } \\
\text { with Class V doors }\end{array}$ & $\begin{array}{l}\text { BMS door sensor; interior PIR } \\
\text { sensors }\end{array}$ \\
\hline
\end{tabular}




\section{Summary}

- Questions and Answers

- Note consolidation

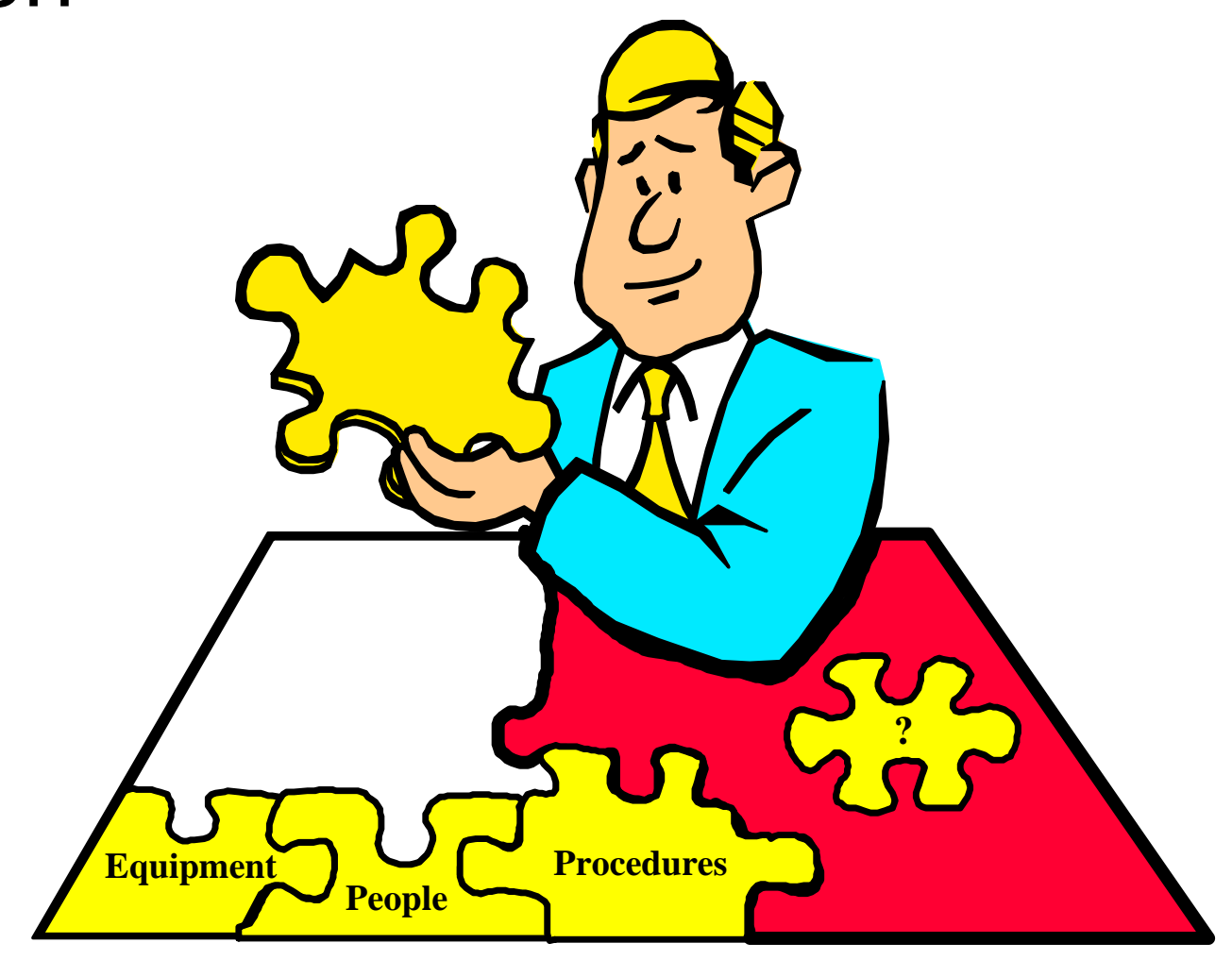




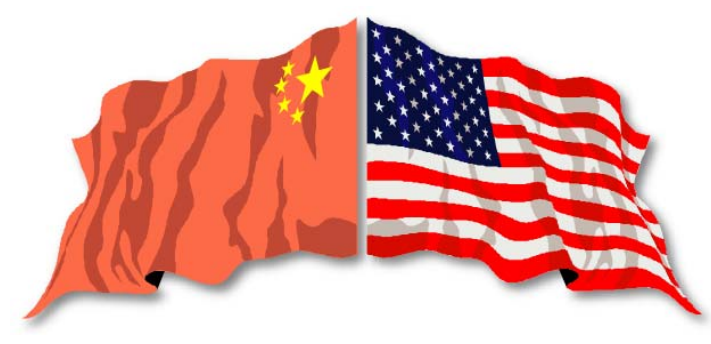

\section{Lecture 4}

\section{Target Analysis}

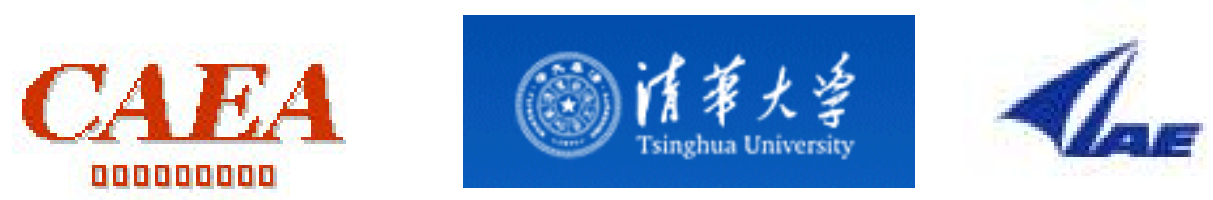




\section{Outline \& Objectives}

- Understand the basic steps of target identification

- Recognize the considerations necessary to establish protection goals

- Identify the two basic types of target identification methodologies 


\section{Steps in Target I dentification}

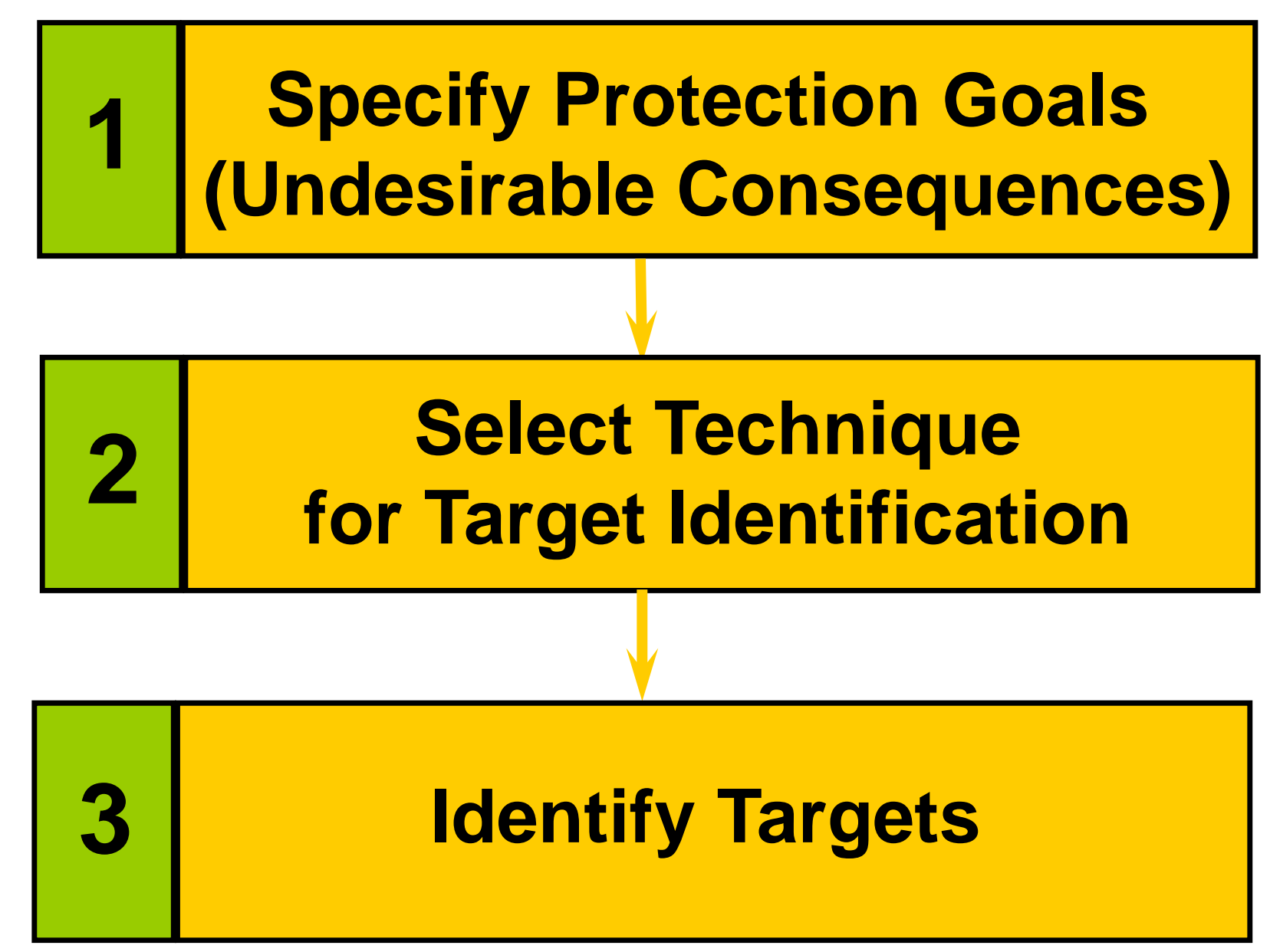




\section{I dentify Protection Goals}

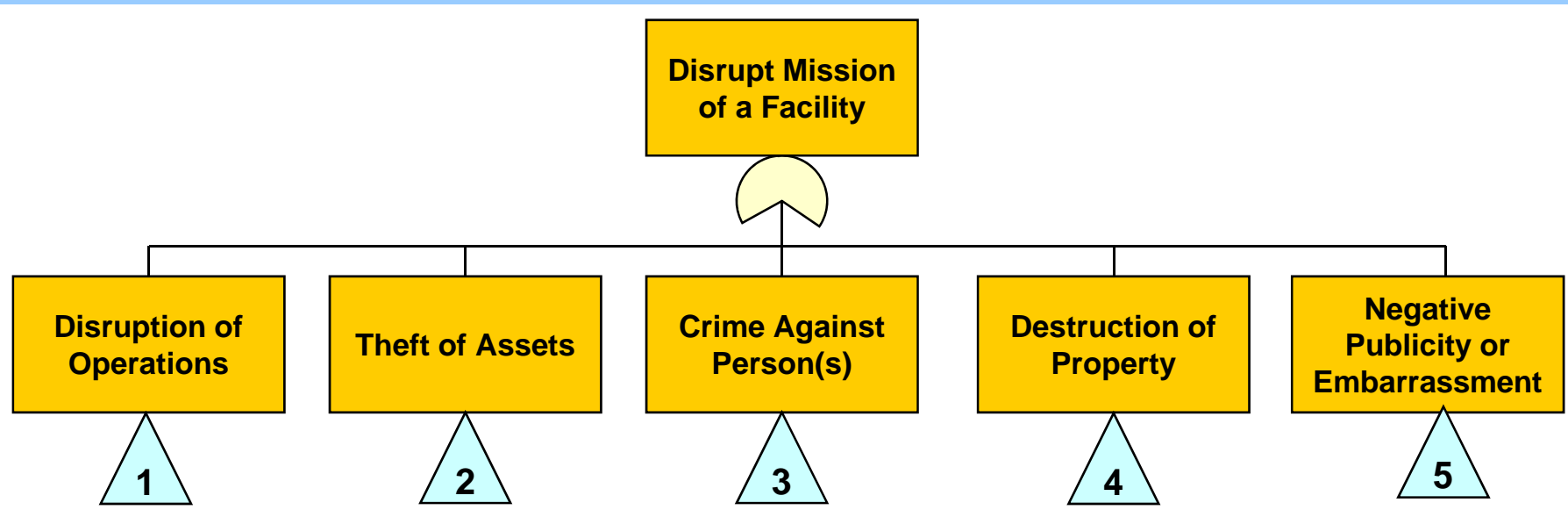

Some form of consequence analysis is required to:

1. Identify what to protect; and

2. Allocate resources to the protect function

- Must be able to compare undesired event or loss consequences of different critical asset categories if a "rational" security policy is to be implemented. 


\section{Security I nterests}

- Identify security interests to be evaluated:

- Nuclear materials

- Theft Targets

- Discrete items

- Roll-up

- Abrupt Theft

- Protracted Theft

- Sabotage Targets

- Critical facilities / systems

- Processes and operations

- Classified information and/or matter

- Others as appropriate

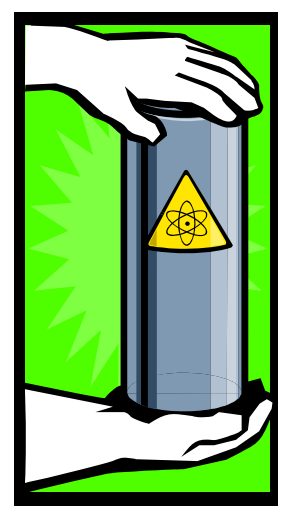




\section{Roll Up}

\section{What is Roll-Up?}

- The accumulation of smaller quantities of special nuclear material to a higher category

\section{Why is it a concern?}

- MPC\&A Measures may be less restrictive for smaller quantities

- Less physical protection

- Surveillance measures not as strict

- Limited access controls

- Less frequent inventories

\section{Is it always an issue?}

- Credibility of roll up depends on material type, form and likelihood that the Insiders could accumulate a goal quantity before detection 


\section{Is Roll Up Credible?}

- Materials outside of MAAs

- Is the total amount SNM greater than a goal quantity

- Can the Insiders gain access to enough areas to accumulate a goal quantity

- Can the Insiders credibly accumulate a goal quantity before detection (or with a lower probability of detection)

- Materials within a MAA

- Are lesser attractive materials treated differently

- Can Insiders accumulate a goal quantity before detection (or with a lower probability of detection)

- Can Insiders divert and hide and accumulate the material undetected prior to removal 


\section{Protracted Theft or Diversion}

- Theft or diversion that is accomplished by repeated occurrences.

What is Diversion?

- Removal of material from its authorized location to a staging point for a later theft attempt 


\section{Protracted Theft or Diversion}

- Protracted theft from MAA

- Small quantities - easier to remove undetected

- Requires multiple attempts

- Longer time line than an abrupt theft

- Chances of being detected increase as the number of attempts needed increases

- Protracted diversion - abrupt theft

- Small quantities - easier to divert undetected

- Requires multiple attempts

- Longer time line than an abrupt theft

- Chances of being detected during accumulation process increases with each diversion attempt

- Still requires undetected removal from MAA 


\section{Protracted Theft or Diversion}

- Protracted Theft or Diversion may involve the substitution of material to reduce the probability of being detected

- Credible Substitution Materials

- Material that can be successfully used in place of accountable special nuclear material. This substitution is possible because of one or more physical properties shared by the substitution material and the special nuclear material. 


\section{Techniques for Target I dentification}

- Manual listing

- Theft of localized items

- Examples?

- Sabotage of simple process systems

- Generally results in a location to protect (e.g., storage vault)

- Logic models for complex facilities

- Theft of material in process

- Examples?

- Sabotage of critical components

- Generally results in a set of areas to protect (referred to as vital areas) 


\section{Categorization of Nuclear Material (U.S. DOE)}

\begin{tabular}{|c|c|c|c|c|c|c|c|c|c|c|}
\hline & & \multicolumn{4}{|c|}{$\begin{array}{l}\mathrm{Pu} / \mathrm{U}-233 \text { Category } \\
(\mathrm{kg})\end{array}$} & \multicolumn{4}{|c|}{$\begin{array}{l}\text { Contained U-235/Separated Np- } \\
\text { 237/Separated Am-241 and -243 } \\
\text { Category (kg) }\end{array}$} & \multirow[t]{2}{*}{$\begin{array}{l}\text { All E } \\
\text { Materials } \\
\text { Category IV }\end{array}$} \\
\hline & $\begin{array}{l}\text { Attractiveness } \\
\text { Level }\end{array}$ & I & II & III & IV & I & II & III & IV & \\
\hline $\begin{array}{l}\text { WEAPONS } \\
\text { Assembled weapons and test } \\
\text { devices }\end{array}$ & A & All & N/A & N/A & N/A & All & N/A & N/A & N/A & N/A \\
\hline $\begin{array}{l}\text { PURE PRODUCTS } \\
\text { Pits, major components, button } \\
\text { ingots, recastable metal, directly } \\
\text { convertible materials }\end{array}$ & B & $>2$ & $>0.4<2$ & $>0.2<0.4$ & $<0.2$ & $>5$ & $>1<5$ & $\begin{array}{ll}>0.4< & \\
& 1\end{array}$ & $<0.4$ & N/A \\
\hline $\begin{array}{l}\text { HIGH-GRADE MATERIALS } \\
\text { Carbides, oxides, nitrates, solutions } \\
\text { (>25 g/L) etc.; fuel elements and } \\
\text { assemblies; alloys and mixtures; } \\
\text { UF4 or UF6 ( > 50\% enriched) }\end{array}$ & $\mathrm{C}$ & $>6$ & $>2<6$ & $>0.4<2$ & $<0.4$ & $>20$ & $>6<20$ & $>2<6$ & $<2$ & N/A \\
\hline $\begin{array}{l}\text { LOW-GRADE MATERIALS } \\
\text { Solutions ( } 1 \text { to } 25 \text { g/L), process } \\
\text { residues requiring extensive } \\
\text { reprocessing; moderately irradiated } \\
\text { material; Pu-238 (except waste); } \\
\text { UF4 or UF6 ( }>20 \%<50 \% \\
\text { enriched) }\end{array}$ & $\mathrm{D}$ & N/A & $>16$ & $>3<16$ & $<3$ & N/A & $>50$ & $>8<50$ & $<8$ & N/A \\
\hline $\begin{array}{l}\text { ALL OTHER MATERIALS } \\
\text { Highly irradiated forms, solutions } \\
\text { ( }<1 \mathrm{~g} / \mathrm{L}) \text {, uranium containing }<20 \% \\
\text { U-235 or }<10 \% \text { U-2332 (any form, } \\
\text { any quantity) }\end{array}$ & $\mathrm{E}$ & N/A & N/A & N/A & $\begin{array}{l}\text { Reportable } \\
\text { Quantities }\end{array}$ & N/A & N/A & N/A & $\begin{array}{l}\text { Reportable } \\
\text { Quantities }\end{array}$ & $\begin{array}{l}\text { Reportable } \\
\text { Quantities }\end{array}$ \\
\hline
\end{tabular}




\section{Target Characteristics - DOE}

For each target specify:

- Attractiveness level with description

- Isotope (Pu,U-233, U-235, Np-237, Am-241, Am-243)

- Quantities (mass)

- Irradiation Level

- Location 


\section{Prioritization of Targets}

- Create a list of all targets and and target locations (the same target material may be stored in multiple locations)

- Determine the consequence value for the targets using consequence tables for theft and sabotage

- Insert the consequence value for each target

- Identify any other target characteristics that would affect target priorities

- For other target characteristics, assign a range of values for High, Medium, and Low and an importance rating for that characteristic

- Sort the resulting list by consequence value, and then by other factors (by importance) to determine the priority for each target 


\section{Manual Listing Example - DOE}

\begin{tabular}{|l|l|l|l|}
\hline \multicolumn{1}{|c|}{ Location } & SNM Type & $\begin{array}{l}\text { Category/ } \\
\text { Attractiveness } \\
\text { Level }\end{array}$ & $\begin{array}{l}\text { Goal Quantity/ } \\
\text { Portability }\end{array}$ \\
\hline Bldg. 1, Vault & Pu-239 ingots & Cat. I/B & $\begin{array}{l}2 \text { ingots/ } \\
\text { man portable }\end{array}$ \\
\hline $\begin{array}{l}\text { Bldg. } 1 \text {, Assay } \\
\text { Room }\end{array}$ & Pu-239 ingots & Cat. I/B & $\begin{array}{l}2 \text { ingots/ } \\
\text { man portable }\end{array}$ \\
\hline $\begin{array}{l}\text { Bldg. } 1, \\
\text { Fabrication Room }\end{array}$ & Pu-238 oxide powder & Cat. II/D & $\begin{array}{l}2 \text { canisters/ } \\
\text { man portable }\end{array}$ \\
\hline Bldg. 2 & $\begin{array}{l}\text { U-235 fuel } \\
\text { elements }\end{array}$ & $\begin{array}{l}\text { Cat. II, roll-up to } \\
\text { Cat. I/C }\end{array}$ & $\begin{array}{l}20 \text { fuel element/ } \\
\text { not man portable }\end{array}$ \\
\hline Bldg. 3 & $\begin{array}{l}\text { U-235 fuel } \\
\text { elements }\end{array}$ & $\begin{array}{l}\text { Cat. II, roll-up to } \\
\text { Cat. I/C }\end{array}$ & $\begin{array}{l}20 \text { fuel element/ } \\
\text { not man portable }\end{array}$ \\
\hline
\end{tabular}




\section{Process Considerations}

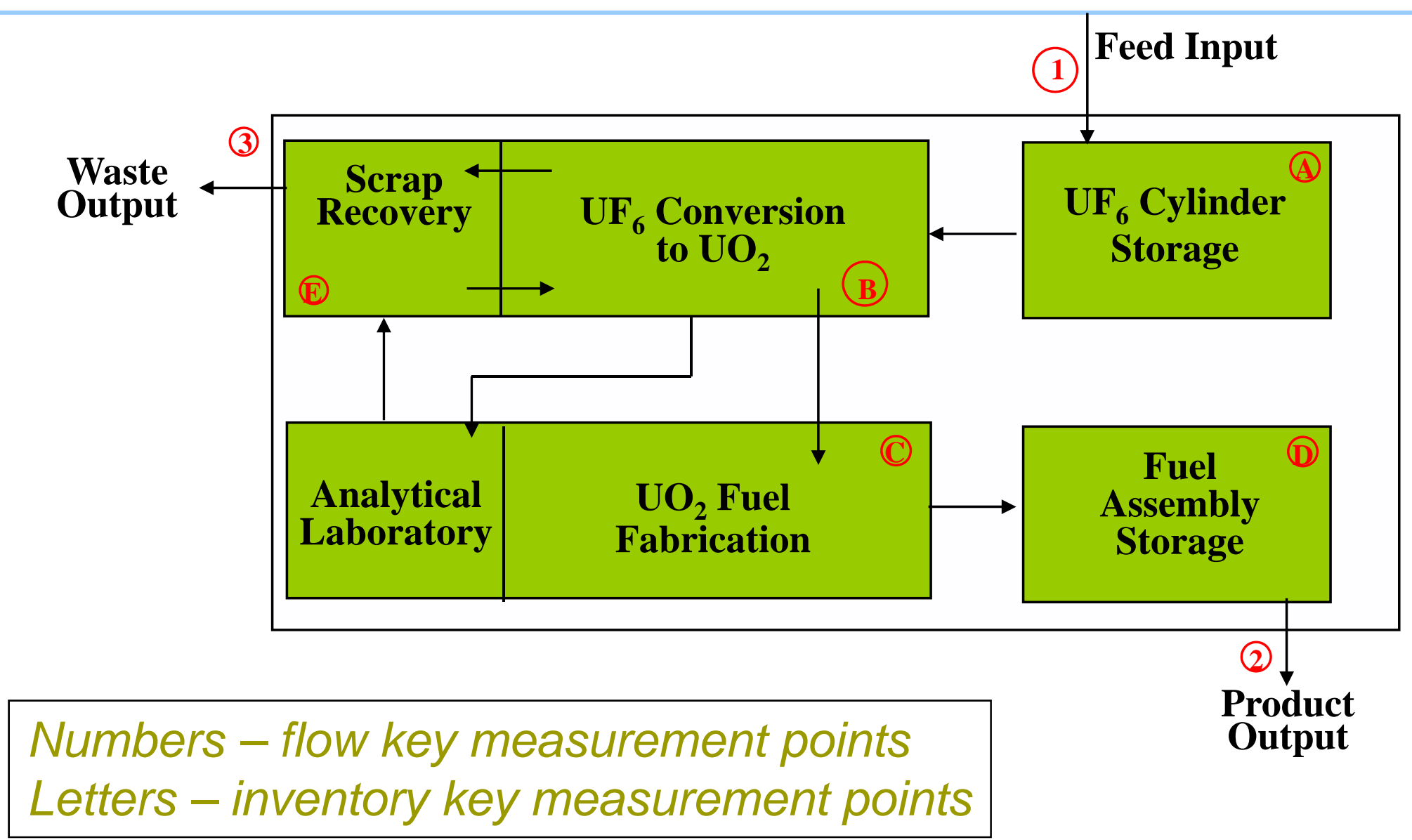




\section{Target I D Methodologies}

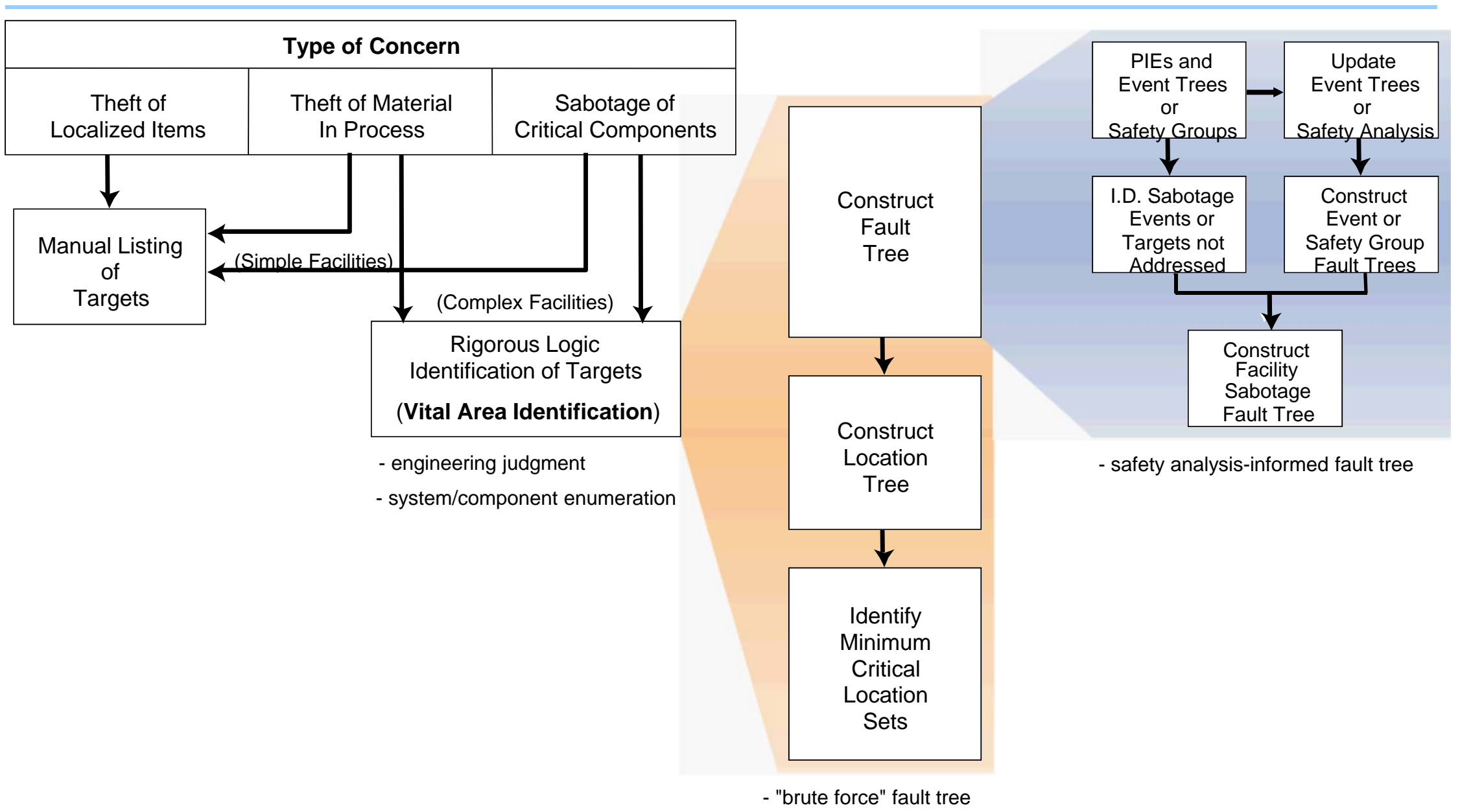




\section{Target Characteristics - 2}

At each location and transport specify:

- Isotopes

- Forms

- Quantities

- Radiation level

- Regulatory category

- MAA

- Vulnerable conditions

- Duration at location

- Frequency

- Theft or sabotage target

- Accounting system ID

- Accounting system report

- Last physical inventory

- Material transfer policy and authorities

- Measurement system specifications

- Potential for 'roll-up'

- Security enhancements or deviations 


\section{Example Sabotage Fault Tree}

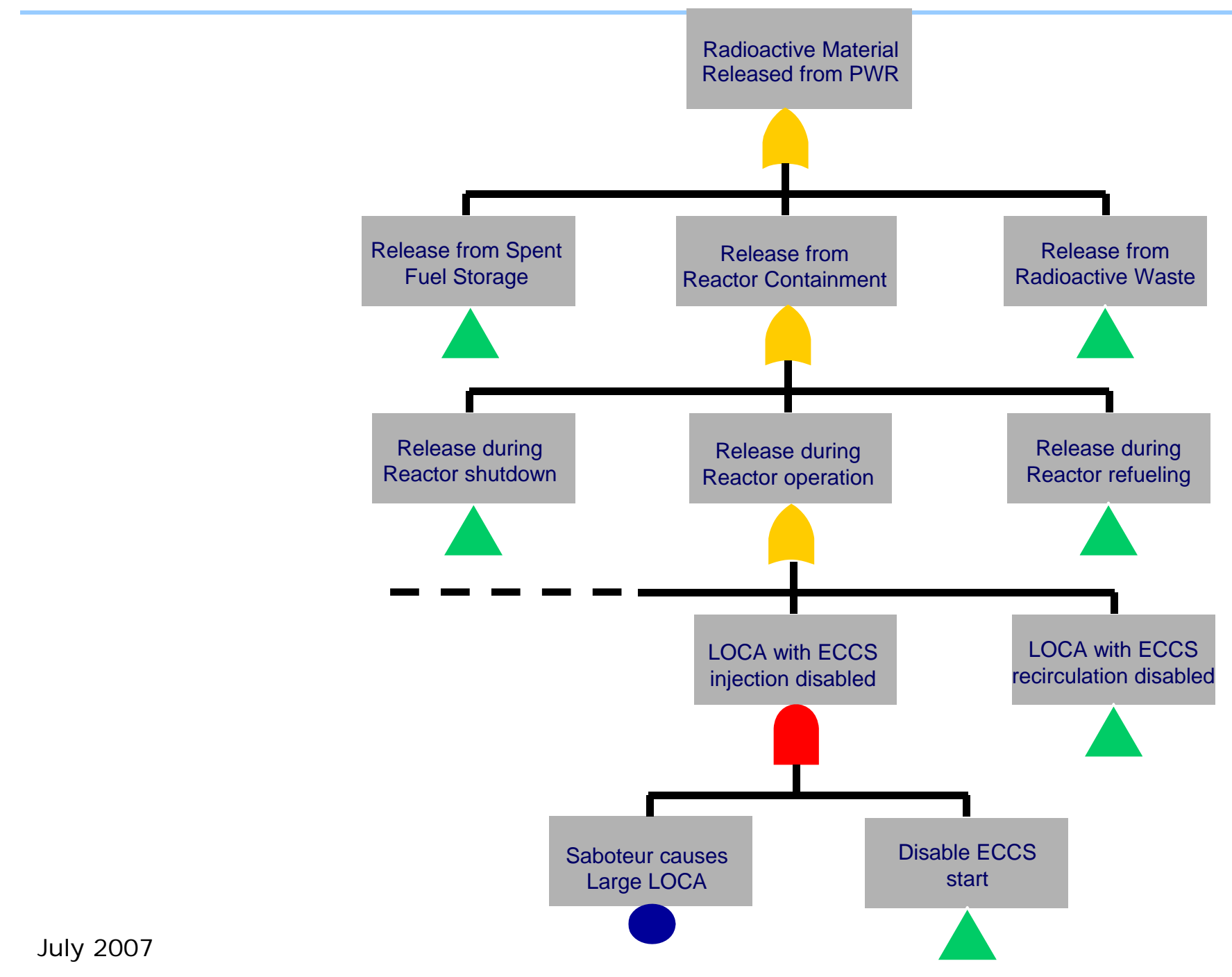




\section{"Brute-force" Fault Trees}

1. Identify the undesired event (consequence).

2. Identify individual or combinations of contributing intermediate events that can be combined through the use of logical operators (AND or OR).

3. Successively develop (decompose) the contributing events until primary events (sabotage events) terminate each branch of the tree. 


\section{Safety-Analysis I nformed Method}

1. Establish requirements (resolve policy issues)

2. Identify radioactive inventories and possible Malevolent Act Initiating Events (MAIEs)

- For various operating states

- Includes definition of safety functions (\& equipment)

3. Develop sabotage fault tree

4. Develop sabotage location tree and solve for "minimum cut sets" (sabotage scenarios)

5. Develop protection location tree and solve for "minimum path sets" (vital area sets)

6. Develop recommendations for set selection 


\section{Summary}

- Target identification must begin with definition of the risks or consequences of what is to be protected against.

- Target identification methodologies are based on manual listings for simple systems or use logic models for complex systems.

- The output of the target identification process is referential information (location) tied to consequence levels (target importance). 


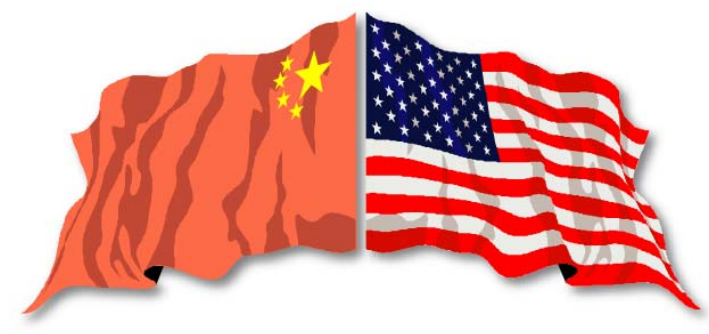

\section{Lecture 5a}

\section{Insider Threat}

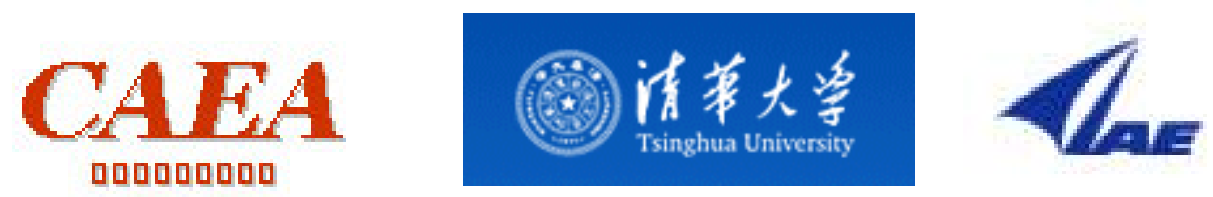




\section{Student Learning Objectives}

- In this module we will:

- Understand the insider threat basic concepts

- List the three major insider attributes

- List insider motivations

- List advantages that an insider has over an outsider with respect to theft of nuclear material

- Be able to match insider attributes and motivations with documented examples

- Understand the role of a national design basis threat for insiders 


\section{Insiders}

"Insiders represent formidable threats because they can often circumvent system elements and interact directly with the target without being detected. The delay and detection timelines are not as relevant because insiders can choose the most opportune times and optimum strategies." 


\section{I nsider Definition (DOE)}

A person who, by reason of official duties,

has knowledge of operations and/or

security system characteristics, and/or

position that would significantly enhance

the likelihood of successful bypass or

defeat of positive measures

should that person

attempt such an action.

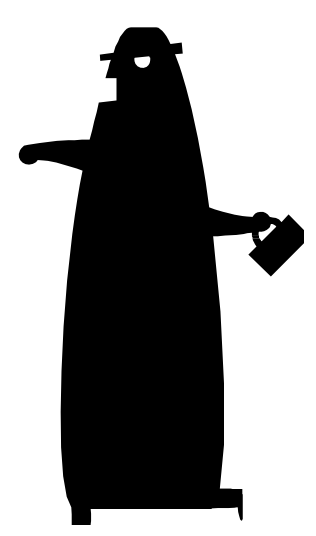




\section{Insider Definition}

Any individual with authorized access to nuclear facilities or transport who might attempt unauthorized removal or sabotage, or who could aid outsiders to do so.

- Insiders might include:

- Management

- Regular employees

- Security personnel

- Service providers

- Visitors

- Inspectors

- Past employees

- Others? 


\section{Insider Categories}

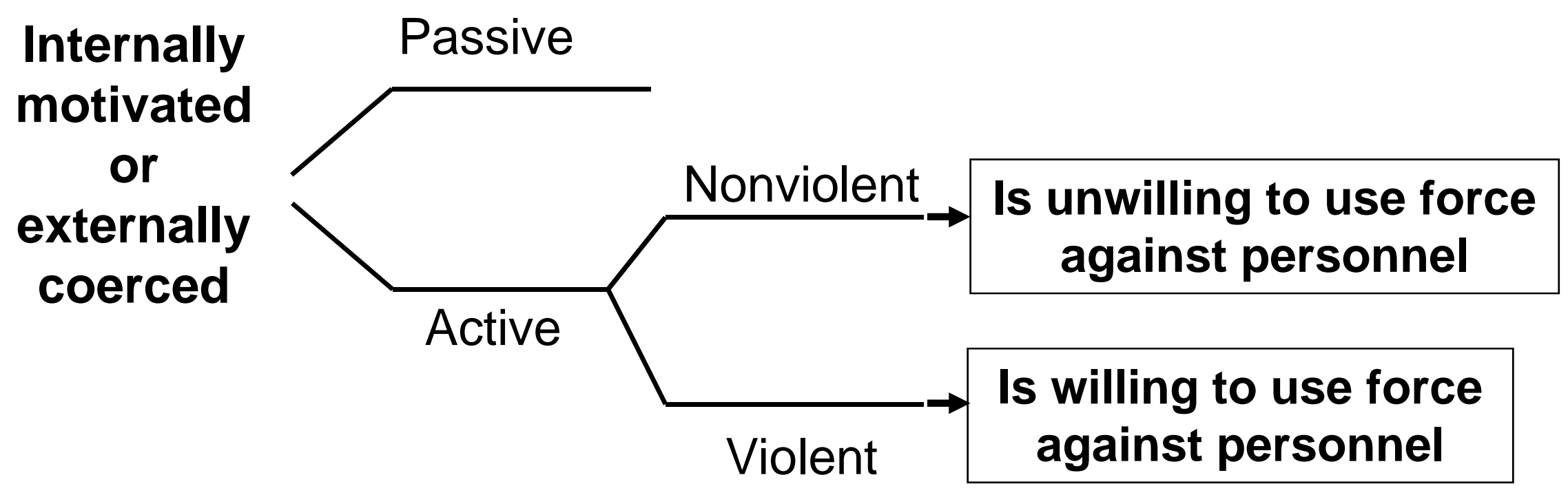

- All insiders can use stealth and deceit

- Violent insiders may be rational or irrational 


\section{Insider Motivations}

- Ideological - fanatical conviction

- Russian school

- Financial - wants / needs money

- General Electric

- Revenge - disgruntled employee or customer

- Ego - "look what I am smart enough to do"

- Hackers

- Psychotic - mentally unstable but capable

- Idaho 1950s impalement

- Coercion - family or self threatened

- \$92M London Robbery

- Others?

Motivation an important indicator for both level of malevolence and likelihood of attempt 


\section{Opportunity}

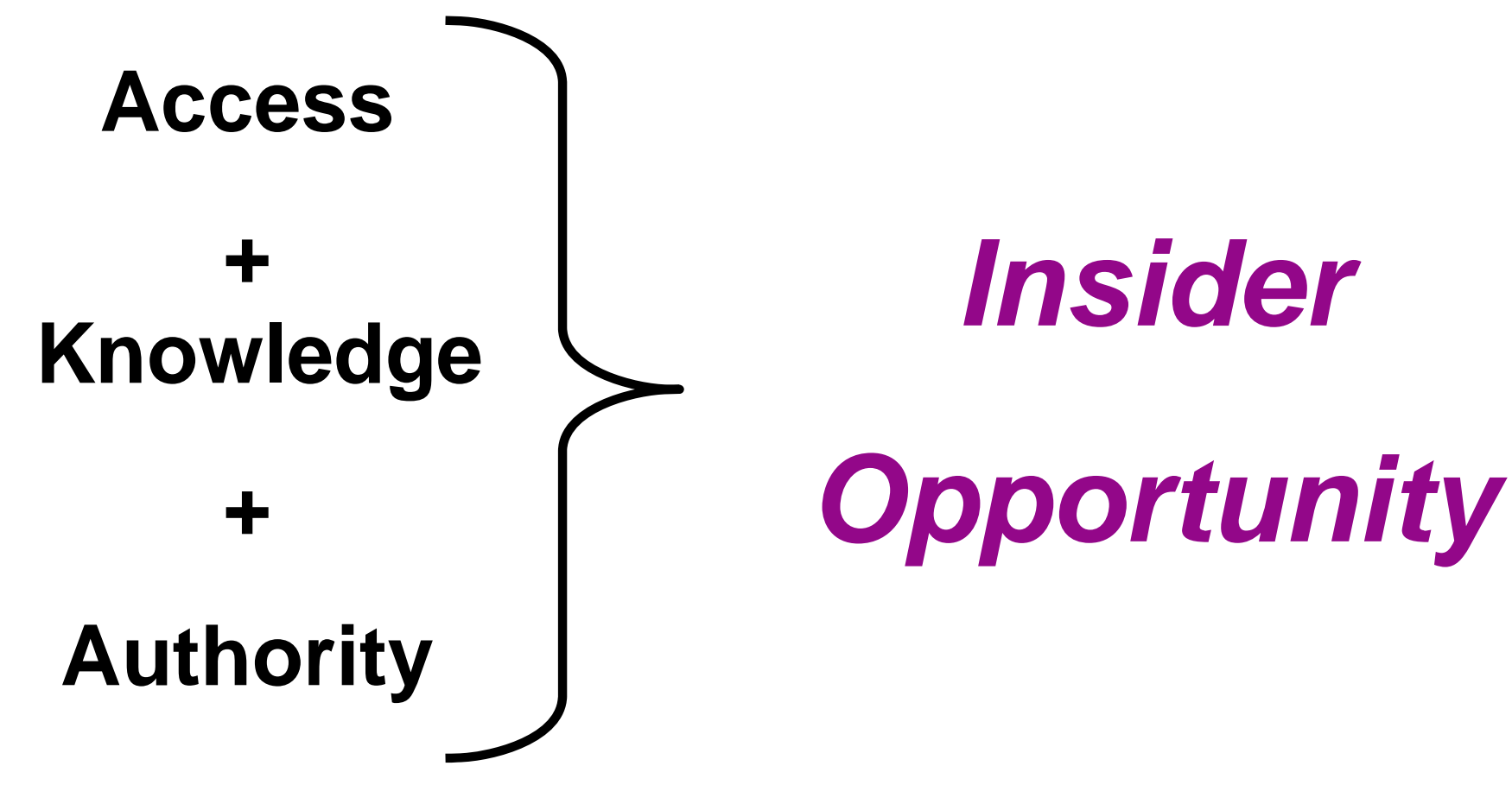




\section{Factors Affecting Unauthorized I nsider Actions}

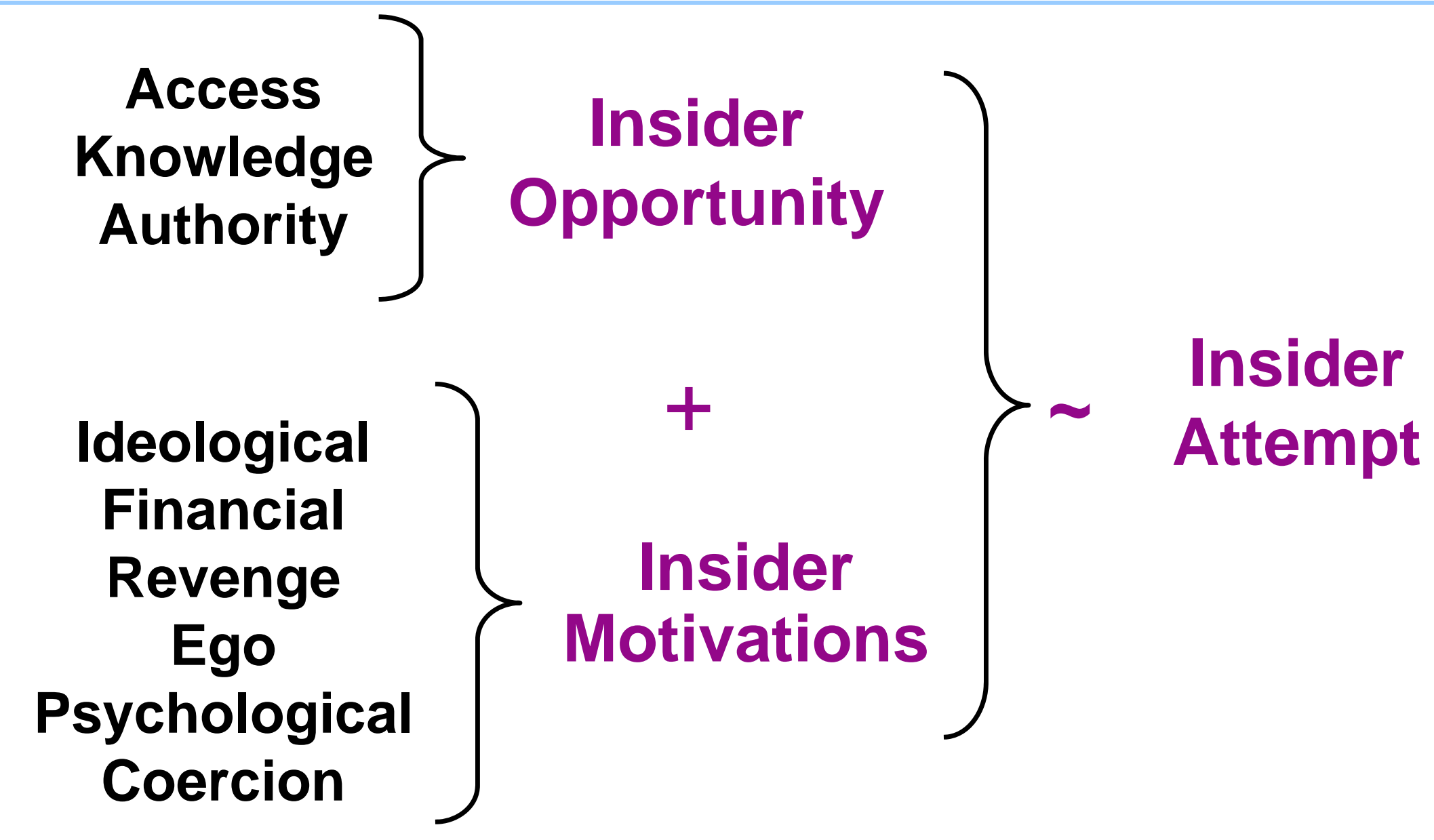




\section{Insider Advantages}

- Time

- Can select optimum time to implement plan

- Can extend acts over long periods of time

- Tools

- Has capability to use tools and equipment at work location

- Can attempt to introduce new tools as necessary

- Tests

- Can test the system with normal "mistakes"

- Collusion

- May recruit / collude with others, either insiders or outsiders

Insider can exploit these unique capabilities 


\section{Insider Access}

- Authorized work areas

- Special temporary access

- Escorted or unescorted

- Restrictions on insider during access

- Emergency access (fire, medical, police, etc.)

- Unauthorized access

- Easy to obtain?

- Duration of target exposure

- Conditions of target during insider access

- Protection equipment and process tools

- Special site equipment

- Other? 


\section{I nsider Authority}

- Authority over people

- Designated authority over others

- Personal influence over others

- Authority over tasks and equipment

- Assessment of alarms

- Preparation of sensitive forms

- Authorization of processes and procedures

- Temporary authority?

- Falsified authority?

- Exemption from procedures?

- Other? 


\section{Insider Knowledge}

- Targets

- Locations, characteristics, and details of targets

- Details of facility layout

- Security systems

- Security forces capabilities and communications

- Details of facility and security operations

- Location and details of safety and security protection systems

- Operations and processes

- Materials accounting

- Operational processes

- Tools and equipment

- Other? 


\section{I nsider Definition Summary}

- Likelihood of unauthorized action

- Motivation

- Opportunity

- Insider advantages

- Time

- Tools

- Tests

- Collusion

- Facility insider characteristics

- Access

- Authority

- Knowledge 


\section{Malevolent I nsider Examples}

- See handout 


\section{Summary}

- In this module we covered:

- Insider threat basic concepts

- Three major insider attributes

- Insider motivations

- Advantages that an insider has over an outsider with respect to theft of nuclear material

- Discussed insider attributes and motivations with respect to documented examples

- Discussed the role of a national design basis threat for insiders 


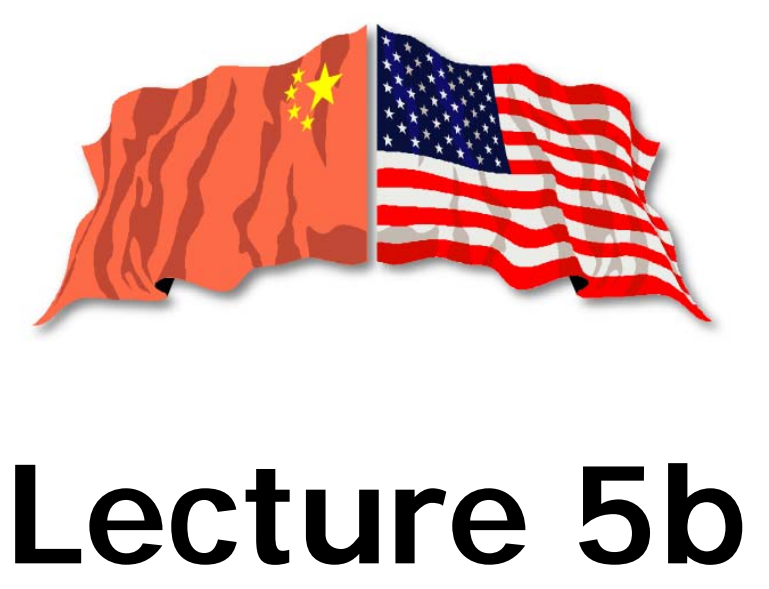

\section{I nsider Characterization I dentify Potential I nsiders}

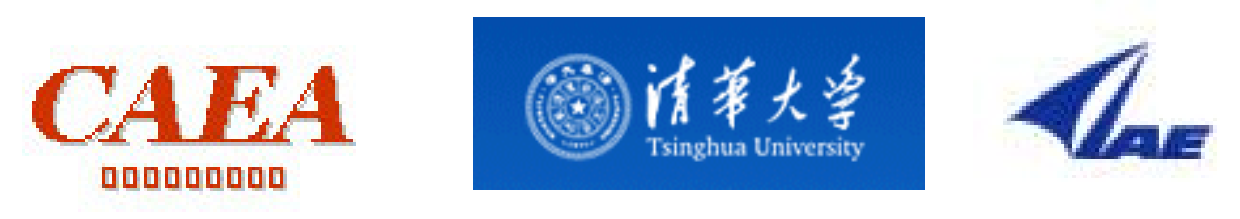




\section{Learning Objectives}

- Gather information on potential insiders based on job functions

- Generate threat group tables for targets 


\section{Gather Facility-specific I nformation about Potential Threat}

- Facility conditions

- Employee morale

- Operations going well?

- Union disagreements

- Organization / security culture

- Conditions outside the facility

- Community approval of facility

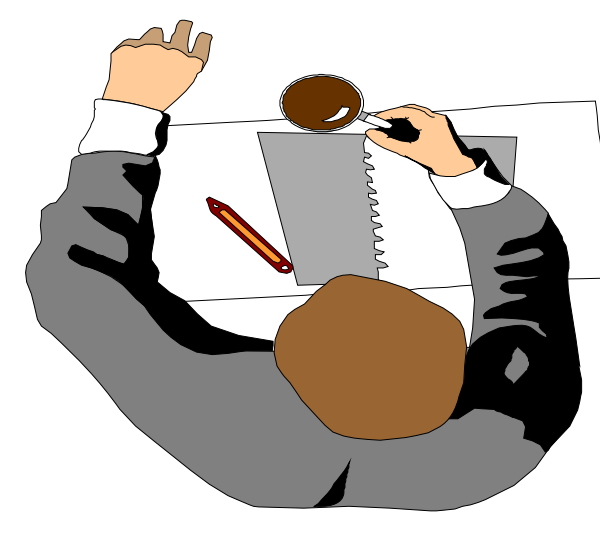

- Activists in the community

- Facility features

- Operating conditions at all times

- Built-in protection features and weaknesses 


\section{Collect Potential I nsider I nformation}

- Identify general personnel assignments

- Ensure that all assignments to critical areas are included

- Identify unique groups that could be responsible for theft or sabotage

- Understand each work group's potential capabilities

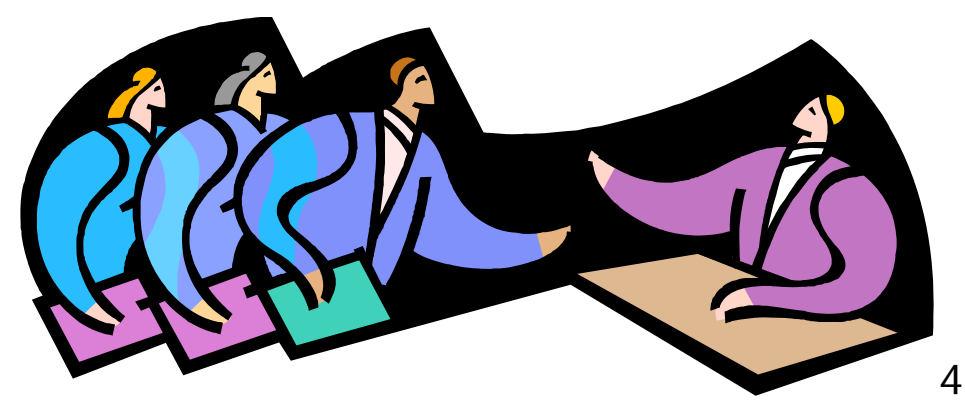




\section{Guidelines and Methods for Grouping}

- Personnel should be grouped whenever:

- Types have identical access, authority, knowledge and capability

- Access, authority, and knowledge of one type is completely a subset of another

- Access, authority, and knowledge are nearly identical

- Create a composite group to cover both (be conservative)

- Groups may be target-dependent

- Two methods for grouping

- Expert judgment

- Data based 


\section{Two Methods for Grouping}

1. Expert judgment grouping

- Preliminary grouping

- Limited site access

- Incomplete data

2. Data based grouping

- Job descriptions

- Site access data

- Personnel discussions / interviews

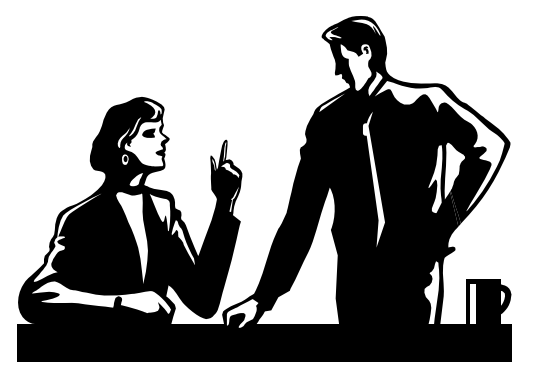




\section{Attributes to Consider during Grouping}

- Access

- Authority

- Knowledge

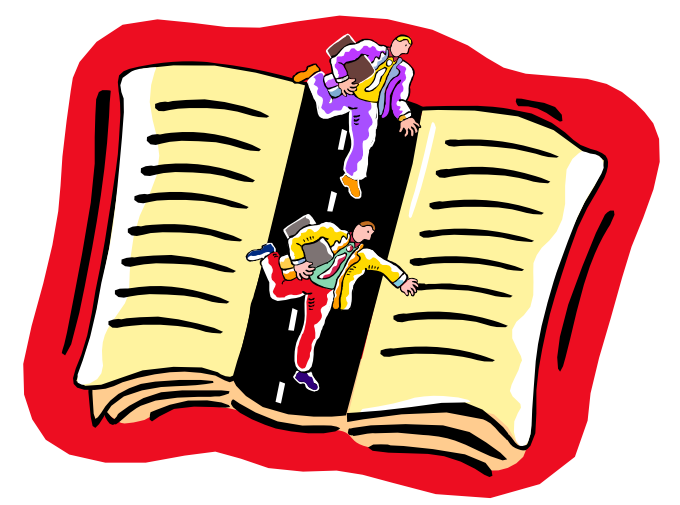




\section{Potential I nsider ACCESS Attribute Considerations}

- Limited areas

- Protected areas

- Vital areas

- Nuclear materials

- CAS

- Alarms

- Keys
- Badging

- Information management of access system

- NM records

- NM forms

- Site vehicles

- Tools

- Controlled information 


\section{Potential Insider AUTHORI TY Attribute Considerations}

- Supervisory

- Supervisory over guards

- Personal vehicle

- Exempt searches

- Exempt metal detector

- Exempt NM detector

- Authorize NM transfers

- Prepare NM transfers
- Verify NM transfers

- Verify inventory

- Assess alarms

- Issue badges

- Issue access codes

- Prepare access lists

- Equipment maintenance 


\section{Potential Insider KNOWLEDGE Attribute Considerations}

- Procedures

- Processes

- Target Locations

- Site details

- MPC\&A System details

- Guard postings

- Response Plans
- Frequency of events

- Potential vulnerabilities

- Tools and equipment

- Procedure violations

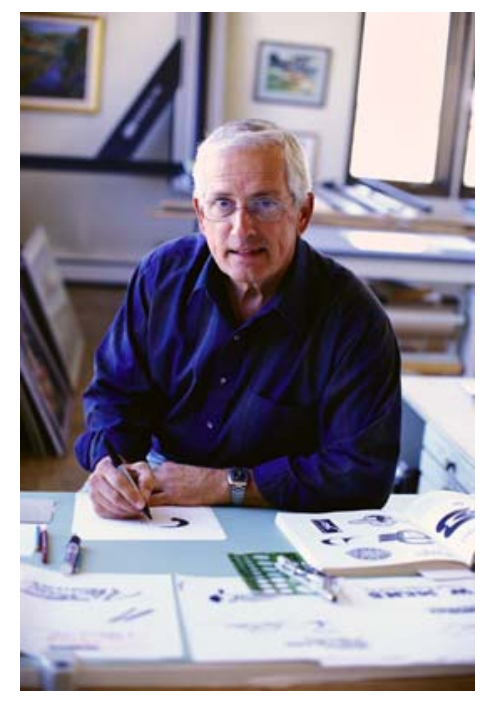




\section{Develop I nsider Groups - Method 1 (Expert J udgment Grouping)}

1. Review site documentation

- Review organizational information and job descriptions

2. Examine organization chart

- Group common job functions

3. Identify possible persons not on organization chart

- Examine site and targets access lists

4. Interview representatives from each group to determine insider overall capability for each target

- Access

- Authority

- Knowledge

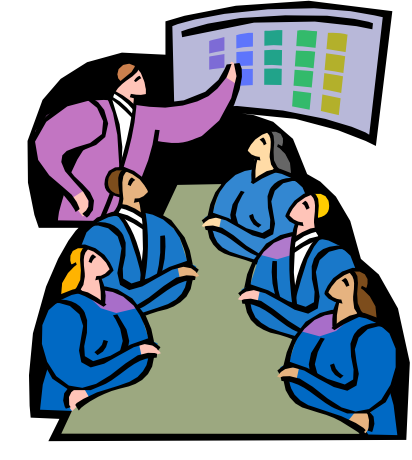




\section{Examine Organization Chart}

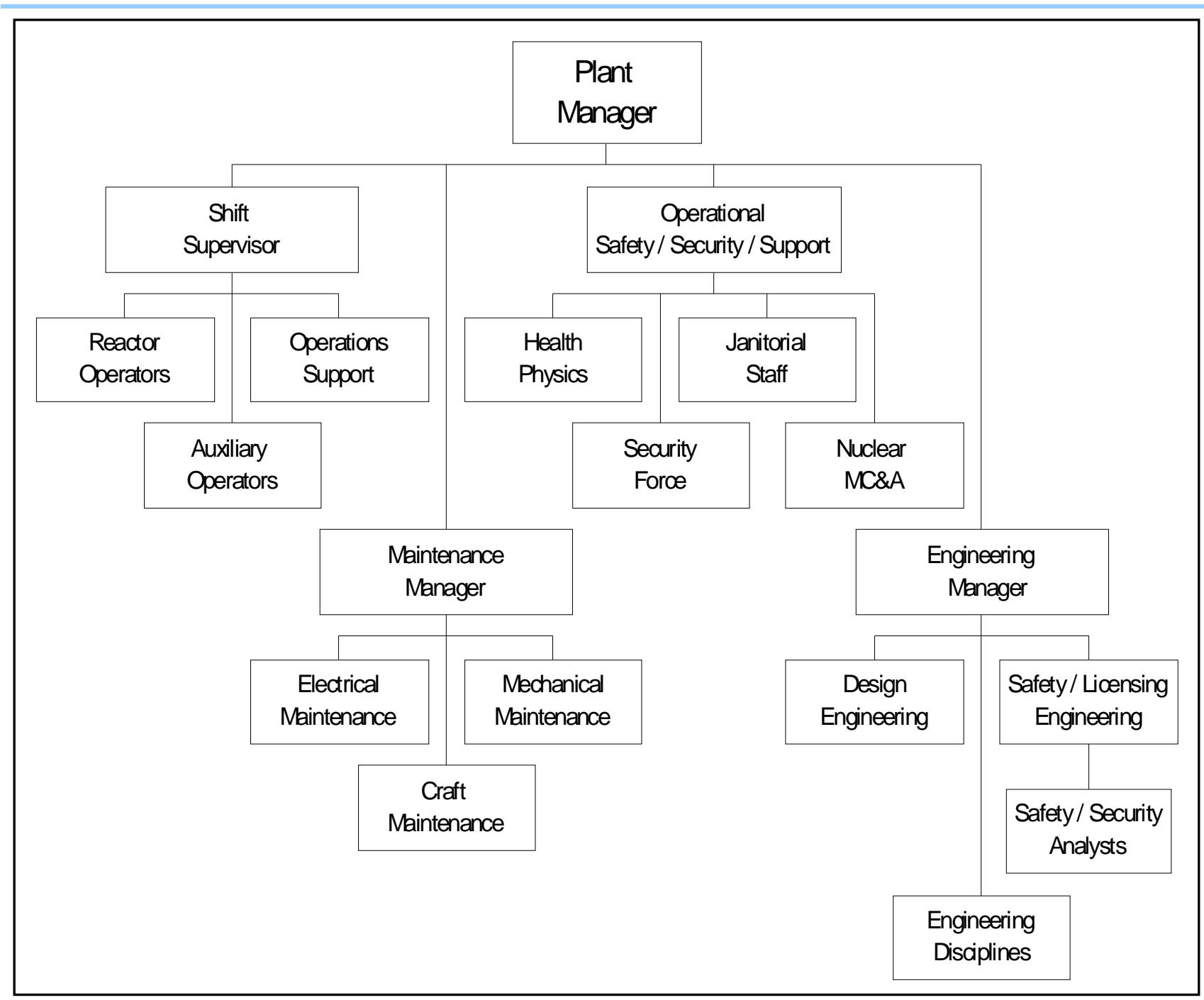

Inspectors?

Vendors?

Official visitors?

Contractors?

Public visitors?

Emergency

personnel? 


\section{Personnel Types}

\begin{tabular}{|l|l|}
\hline 1 & Plant Manager \\
\hline 2 & Shift Supervisor \\
\hline 3 & Machining Operator \\
\hline 4 & Casting Operator \\
\hline 5 & Operations Support \\
\hline 6 & Maintenance Manager \\
\hline 7 & Electrical Maintenance \\
\hline 8 & Mechanical Maintenance \\
\hline 9 & Crafts Maintenance \\
\hline 10 & Administrative Support \\
\hline 11 & Health Physics Technicians \\
\hline 12 & Guard Supervisor \\
\hline 13 & Alarm Station Operators \\
\hline 14 & Patrol Guards \\
\hline 15 & Post/Tower Guards \\
\hline 16 & Quick Response Force Guards \\
\hline
\end{tabular}

\begin{tabular}{|l|l|}
\hline 17 & Janitorial Staff \\
\hline 18 & Material Balance Area Custodians \\
\hline 19 & Nuclear Material Technicians \\
\hline 20 & $\begin{array}{l}\text { Nuclear Material Accountability } \\
\text { Technicians }\end{array}$ \\
\hline 21 & Engineering Support \\
\hline 22 & $\begin{array}{l}\text { Design, Mechanical, Electrical, Civil, } \\
\text { Chemical and Nuclear Engineers }\end{array}$ \\
\hline 23 & Safety Engineers \\
\hline 24 & Security Analysts \\
\hline
\end{tabular}

Non-Employee Access to URF

\begin{tabular}{|l|l|}
\hline 25 & Vendors \\
\hline 26 & State Safety/Security Inspectors \\
\hline
\end{tabular}




\section{Expert J udgment Attribute Grouping Example}

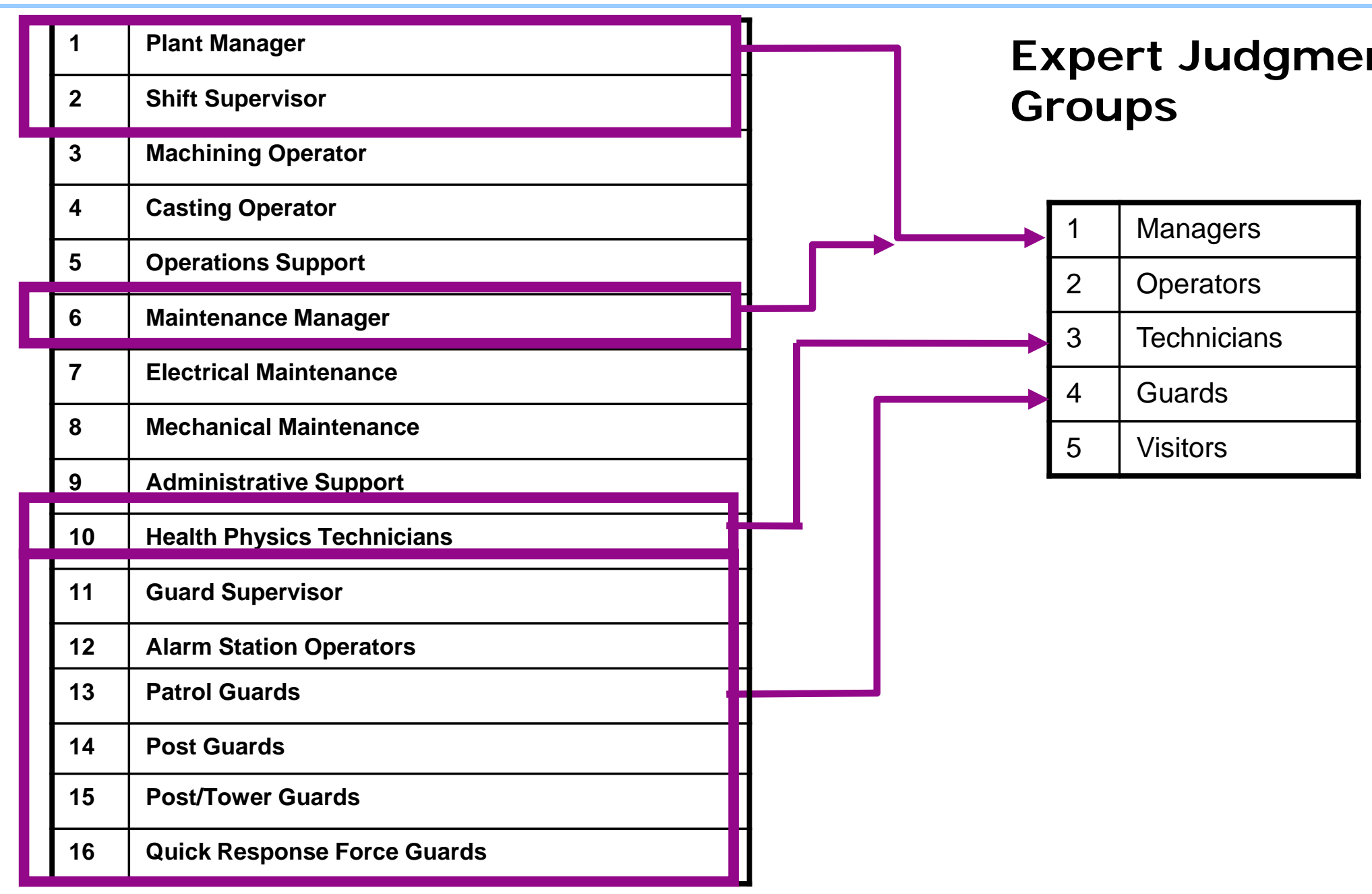




\section{Develop I nsider Groups - Method 2 (Data Based Grouping)}

1. Review site documentation including organization chart

- Review organizational information and job descriptions

- Examine site and targets access lists

2. Generate a comprehensive list of personnel with access by job function

3. Interview representatives from each job function to determine insider characteristics for each target

- Access

- Authority

- Knowledge

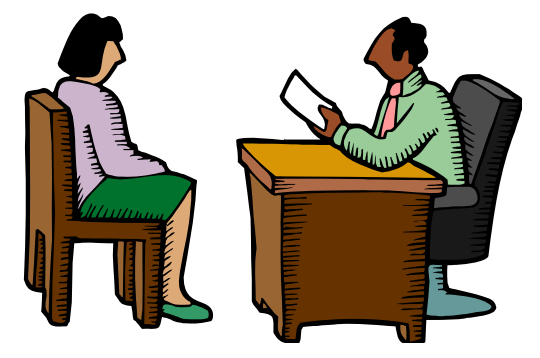




\section{Develop I nsider Groups - Method 2 (Data Based Grouping) (cont'd)}

4. Group job functions by access, authority, and knowledge attributes

5. Prioritize job function groups for analysis based on attribute evaluation

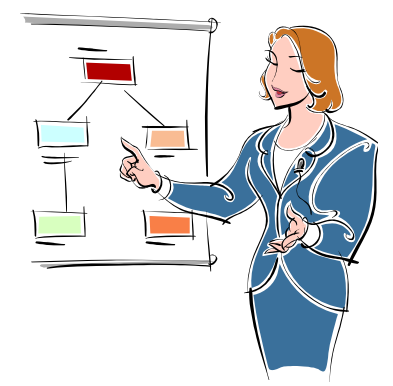




\section{Interview Representatives}

- Interviews are essential to gain unknown information

- Mutual cooperation is essential for success

- Results must be attributed to personnel types

- An unbiased professional approach is necessary

- Be prepared and as knowledgeable as possible

- Ensure that the person understands the purpose of the interview

- Generate an environment of comfort for the person

- Ask probing questions that require an explanation

- Do not argue or take personal offense

- Take notes, thank the person, and summarize 


\section{Suggestions for Qualitative Designators (H, M, L)}

\begin{tabular}{|l|l|l|l|}
\hline \multicolumn{1}{|c|}{ Attribute } & \multicolumn{1}{|c|}{ High } & \multicolumn{1}{c|}{ Medium } & \multicolumn{1}{c|}{ LOW } \\
\hline Access & $\begin{array}{l}\text { Authorized at all times } \\
\text { normally on site - } \\
\text { Target always available }\end{array}$ & $\begin{array}{l}\text { Authorized on specific } \\
\text { occasions - Limited target } \\
\text { availability }\end{array}$ & No authorization \\
\hline Authority & $\begin{array}{l}\text { Almost anything } \\
\text { commanded is done } \\
\text { without question }\end{array}$ & $\begin{array}{l}\text { Has limited or temporary } \\
\text { authority or considerable } \\
\text { personal influence }\end{array}$ & Little authority \\
\hline Knowledge* & $\begin{array}{l}\text { Details of operations } \\
\text { and systems. Has the } \\
\text { equipment, tools, and } \\
\text { skills to accomplish the } \\
\text { malevolent acts. }\end{array}$ & $\begin{array}{l}\text { General understanding of } \\
\text { operations and systems or } \\
\text { detailed knowledge of } \\
\text { limited areas. Might have } \\
\text { some of the equipment, } \\
\text { tools and skills to } \\
\text { accomplish the malevolent } \\
\text { acts. }\end{array}$ & $\begin{array}{l}\text { Little } \\
\text { understanding. } \\
\text { Does not have } \\
\text { the equipment, } \\
\text { tools and skills } \\
\text { to accomplish } \\
\text { the malevolent } \\
\text { acts. }\end{array}$ \\
\hline
\end{tabular}

* Assume only the knowledge and capability requilred

to conduct assigned responsibilities 


\section{Example Form for Collecting / Recording Data}

Job Type

Date

\begin{tabular}{|l|l|l|l|l|}
\hline Target & $\begin{array}{l}\text { Level of } \\
\text { Access }\end{array}$ & $\begin{array}{l}\text { Level of } \\
\text { Authority }\end{array}$ & $\begin{array}{l}\text { Level of } \\
\text { Knowledge }\end{array}$ & Notes \\
\hline & & & & \\
\hline & & & & \\
\hline & & & & \\
\hline & & & & \\
\hline
\end{tabular}




\section{Example Form for Collecting / Recording Data}

\section{Job Type: Health Physics Date: 12 Nov 06}

\begin{tabular}{|c|c|c|c|c|}
\hline Target & $\begin{array}{l}\text { Level of } \\
\text { Access }\end{array}$ & $\begin{array}{l}\text { Level of } \\
\text { Authority }\end{array}$ & $\begin{array}{l}\text { Level of } \\
\text { Knowledge }\end{array}$ & Notes \\
\hline Bunker & M & $L$ & $L$ & $\begin{array}{l}\text { MBA Custodian } \\
\text { controls vault - } \\
\text { escorts }\end{array}$ \\
\hline Casting Area & $H$ & $L$ & $L$ & \\
\hline $\begin{array}{l}\text { Product } \\
\text { Vault }\end{array}$ & M & $L$ & $L$ & $\begin{array}{l}\text { MBA Custodian } \\
\text { controls vault - } \\
\text { escorts }\end{array}$ \\
\hline $\begin{array}{l}\text { Billet } \\
\text { Vault }\end{array}$ & M & $L$ & $L$ & $\begin{array}{l}\text { MBA Custodian } \\
\text { controls vault - } \\
\text { escorts }\end{array}$ \\
\hline
\end{tabular}




\section{Learning Objectives}

- Gather information on potential insiders based on job functions

- Generate threat group tables for targets 


\section{Threat Group Tables}

- Develop characteristics of insider groups

- Generate a list of groups at the facility

- Define qualitatively (High, Medium, or Low) the level of access, authority, and knowledge that each insider group has for each target

\section{The lists for different targets will be very similar but the differences are important as we conduct the analysis}




\section{Example for Developing Threat Group Tables}

- Use the descriptors in slide 21 "Suggestions for Qualitative Designators"

- Apply the $H, M, L$ rules for each characteristic

- Access

- Authority

- Knowledge

- As an example, create a threat group table for:

- Five job positions

- Bunker targets

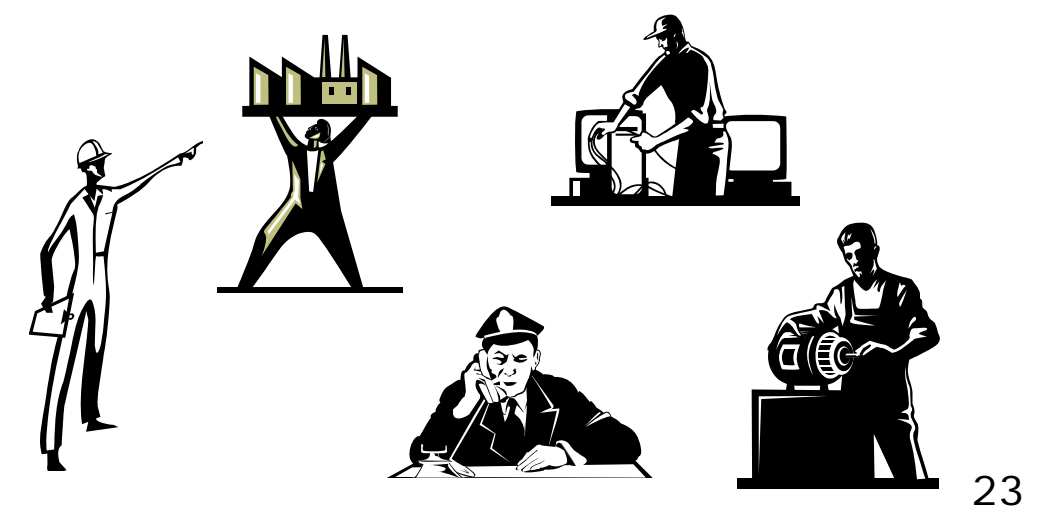




\section{Example of H,M,L Applied to Threat Group Table for the Bunker}

\begin{tabular}{|c|c|c|c|}
\hline Position (Number) & Routine Access & $\begin{array}{l}\text { Routine Authority I } \\
\text { Responsibility }\end{array}$ & Knowledge \\
\hline $\begin{array}{l}\text { Plant Manager (1) } \\
\text { (Plant Manager Org.) }\end{array}$ & $\begin{array}{l}\text { Protected Area, All Inner } \\
\text { Areas (usually escortec) }\end{array}$ & $\begin{array}{l}\text { Overall direction. Not } \\
\text { authorized to direct detail }=1 \\
\text { facility operations }\end{array}$ & $\begin{array}{l}\text { General knowledge of } \\
\text { plant operations, lacks } \\
\text { detailed understanding of } \\
\text { facility }\end{array}$ \\
\hline $\begin{array}{l}\text { Shift Supervisor (3 total with } 1 \\
\text { per shift) } \\
\text { (Shift Supervisor Org.) }\end{array}$ & $\begin{array}{l}\text { Protected Area, All Inner } \\
\text { Areas }\end{array}$ & $\begin{array}{l}\text { Detailed direction of all } \\
\text { facility activities. Direction } \\
\text { obeyed without question in } \\
\text { most situations }\end{array}$ & $\begin{array}{l}\text { Extensive, detailed } \\
\text { knowledge about all } \\
\text { aspects of facility design, } \\
\text { layout, and operation. }\end{array}$ \\
\hline $\begin{array}{l}\text { Machining operator (6 total } \\
\text { with nominal } 4 \text { per day shift) } \\
\text { (Operations Support Org.) }\end{array}$ & $\begin{array}{l}\text { Protected Area, All InnE } r \\
\text { Areas }\end{array}$ & $\begin{array}{l}\text { Detailed direction of all } \\
\text { machining activities. Unde| } \\
\text { direction of shift } \\
\text { supervisor. }\end{array}$ & $\begin{array}{l}\text { Extensive, detailed } \\
\text { knowledge about all } \\
\text { activities in the } \\
\text { machining area. }\end{array}$ \\
\hline $\begin{array}{l}\text { Health Physics Technicians ( } 4 \\
\text { total with nominal } 3 \text { per day } \\
\text { shift) } \\
\text { (Health Physics Org.) }\end{array}$ & $\begin{array}{l}\text { Protected Area, all Inner } \\
\text { Areas and occasional } \\
\text { escorted access to } \\
\text { Storage }\end{array}$ & \begin{tabular}{|l|} 
Monitor radiological \\
conditions. Not permitted \\
to work on plant equipment.
\end{tabular} & $\begin{array}{l}\text { Specialized knowledge } \\
\text { related to their duties. } \\
\text { Narrow knowledge of } \\
\text { facility systems. }\end{array}$ \\
\hline $\begin{array}{l}\text { Operations Support (6 total } \\
\text { with nominal } 4 \text { per day shift) } \\
\text { (Operations Support Org.) }\end{array}$ & $\begin{array}{l}\text { Protected Area, All Inner } \\
\text { Areas and occasional } \\
\text { escorted access to } \\
\text { Storage }\end{array}$ & $\begin{array}{l}\text { Perform specific operations } \\
\text { tasks under direction of } \\
\text { machining and casting } \\
\text { operators }\end{array}$ & $\begin{array}{l}\text { Specialized knowledge } \\
\text { related to their duties. } \\
\text { Narrow knowledge of } \\
\text { complete facility } \\
\text { systems. }\end{array}$ \\
\hline
\end{tabular}




\section{Partial Position Listing for the Bunker}

\begin{tabular}{|l|c|c|c|}
\hline \multicolumn{1}{|c|}{ Job Position } & Access & Authority & Knowledge \\
\hline Plant Manager & $L$ & $M$ & $M$ \\
\hline Shift Supervisor & $L$ & $\mathbb{H}$ & $M$ \\
\hline Machining Operator & $L$ & $\mathbb{L}$ & $M$ \\
\hline Health Physics Technician & $M$ & $\mathbb{L}$ & $M$ \\
\hline Operations Support & $M$ & $L$ & \\
\hline Maintenance Manager & & & \\
\hline Mechanical Maintenance & & & \\
\hline Health Physics Technicians & & & \\
\hline Alarm Station Operators & & & \\
\hline Post Guards & & & \\
\hline
\end{tabular}




\section{Bunker Example - Prioritize I nsider Groups}

- Preliminarily rank the five positions for the bunker using the following rules:

- Utilize the access characteristic first and select those groups with the highest level of access

- For groups with equally high access, utilize the authority characteristics of these groups to differentiate

- Use the knowledge characteristics as needed for additional differentiation 


\section{Highest Degree of Access for the Bunker Targets}

\begin{tabular}{|c|c|c|c|}
\hline Position & $\begin{array}{l}\text { Routine } \\
\text { Access }\end{array}$ & \begin{tabular}{|l|} 
Routine \\
Authority I \\
Responsibility
\end{tabular} & Knowledge \\
\hline $\begin{array}{l}\text { Health Physics } \\
\text { Technician }\end{array}$ & 1) & 1 & 18 \\
\hline $\begin{array}{l}\text { Operations } \\
\text { support }\end{array}$ & ) & I! & 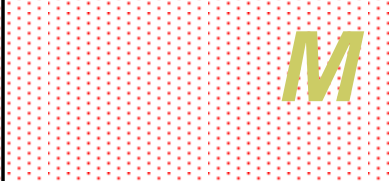 \\
\hline
\end{tabular}




\section{Next Highest Degree of Access for the Bunker Targets}

\begin{tabular}{|l|c|c|c|}
\hline $\begin{array}{c}\text { Position } \\
\text { (Number) }\end{array}$ & $\begin{array}{c}\text { Routine } \\
\text { Access }\end{array}$ & $\begin{array}{c}\text { Routine } \\
\text { Authority I } \\
\text { Responsibility }\end{array}$ & Knowledge \\
\hline $\begin{array}{l}\text { Shift } \\
\text { Supervisor }\end{array}$ & $L$ & $H$ & $M$ \\
\hline Plant Manager & $L$ & $M$ & $M$ \\
\hline $\begin{array}{l}\text { Machining } \\
\text { Operator }\end{array}$ & $L$ & $L$ & $M$ \\
\hline
\end{tabular}

\section{Continue the process for all the insider positions}




\section{Insider Threat Characterization Summary}

- We now have:

- A definition of targets that we will be applying the threat against

- Ranked positions of specific potential insider groups at the facility

- They have been generated considering access, authority, and knowledge 


\section{Module Summary}

- Review the insider threat basic concepts

- List the three major insider attributes

- Recognize the role of the National DBT

- Characterize the insider portion of the DBT for the facility

- Gather information on potential insiders based on job functions

- Generate threat group tables for targets 


\section{Sub-Group Exercise: Prioritize the Insider Threat}

- Use the URF personnel tables from the exercise materials in this module - identify job positions

- Create threat group table with descriptor for each insider attribute (access, authority, knowledge)

- Assign qualitative designators $(H, M, L)$ to each job position for the same theft targets you used in your target sub-group exercise:

- The X-ray facility during day shift

- The processing building

- The product vault during night shift

- The machining area during day shift

- The chip vault during night shift 


\section{Sub-Group Exercise: Prioritize the I nsider Threat (cont'd)}

- Select the five "highest insider threat" positions for each target

- Present your results for a large group discussion

- We will use these as the insider threat groups for the rest of the overview course 


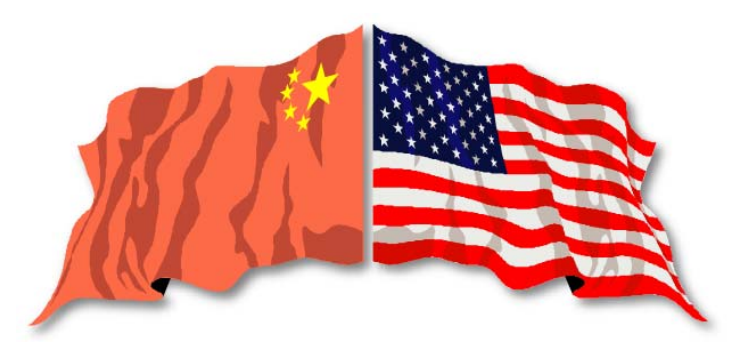

\section{Lecture 6a}

\section{Path Analysis - Sequence of Actions}

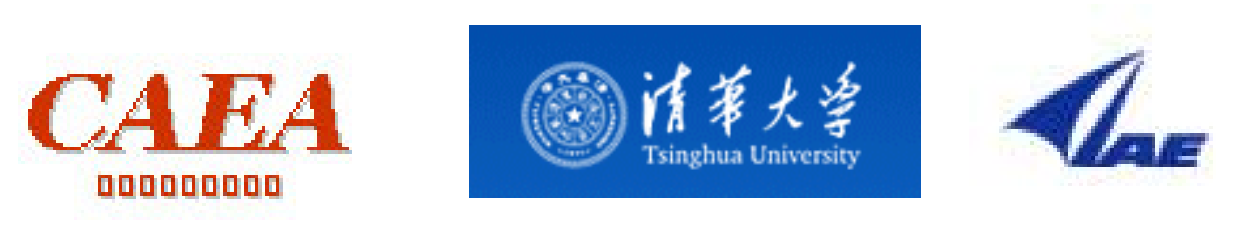




\section{Learning Objectives}

- Review the methodology to evaluate the protection system

- Apply this methodology to produce a sequence of insider threat actions

- Identify measures to protect the targets 


\section{I nsider Protection System Approach}

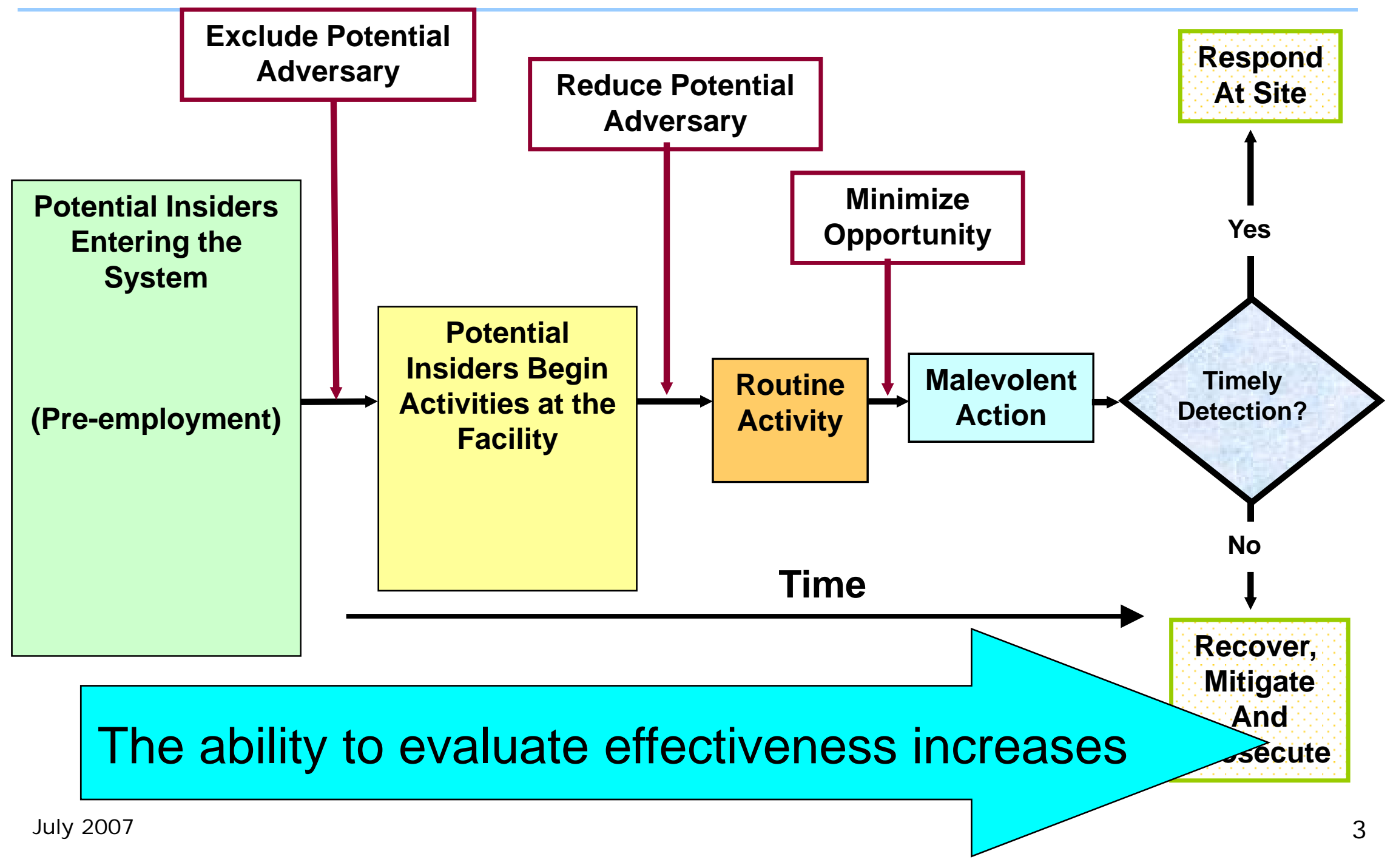




\section{Evaluation Approaches}

- Expert opinion

- Rely on expert judgment

- Feature approach (checklist)

- Good things to do but difficult to quantify value and/or effectiveness

- Performance approach (based on data)

- Provides quantitative support for conclusions and decisions

- Our thrust is to do as much performance-based evaluation as possible

- All three approaches are necessary for evaluating insider scenarios 


\section{Taking Credit For Early Preventive Measures}

- Data to quantitatively evaluate the measures is not generally available

- Approaches

- Monitor facility activities to verify program is helpful

- Historical incidents relative to undesirable behavior

- Modify program as needed and continue monitoring

- Used to limit adversary capabilities for threat definition

- A scheme could be developed for using this information to develop likelihood of occurrence or measure of effectiveness parameters

- Must develop consensus among decision makers (management, government) to assure consistency 


\section{Remove/ Reduce Potential Adversaries Based On Undesirable Behaviors}

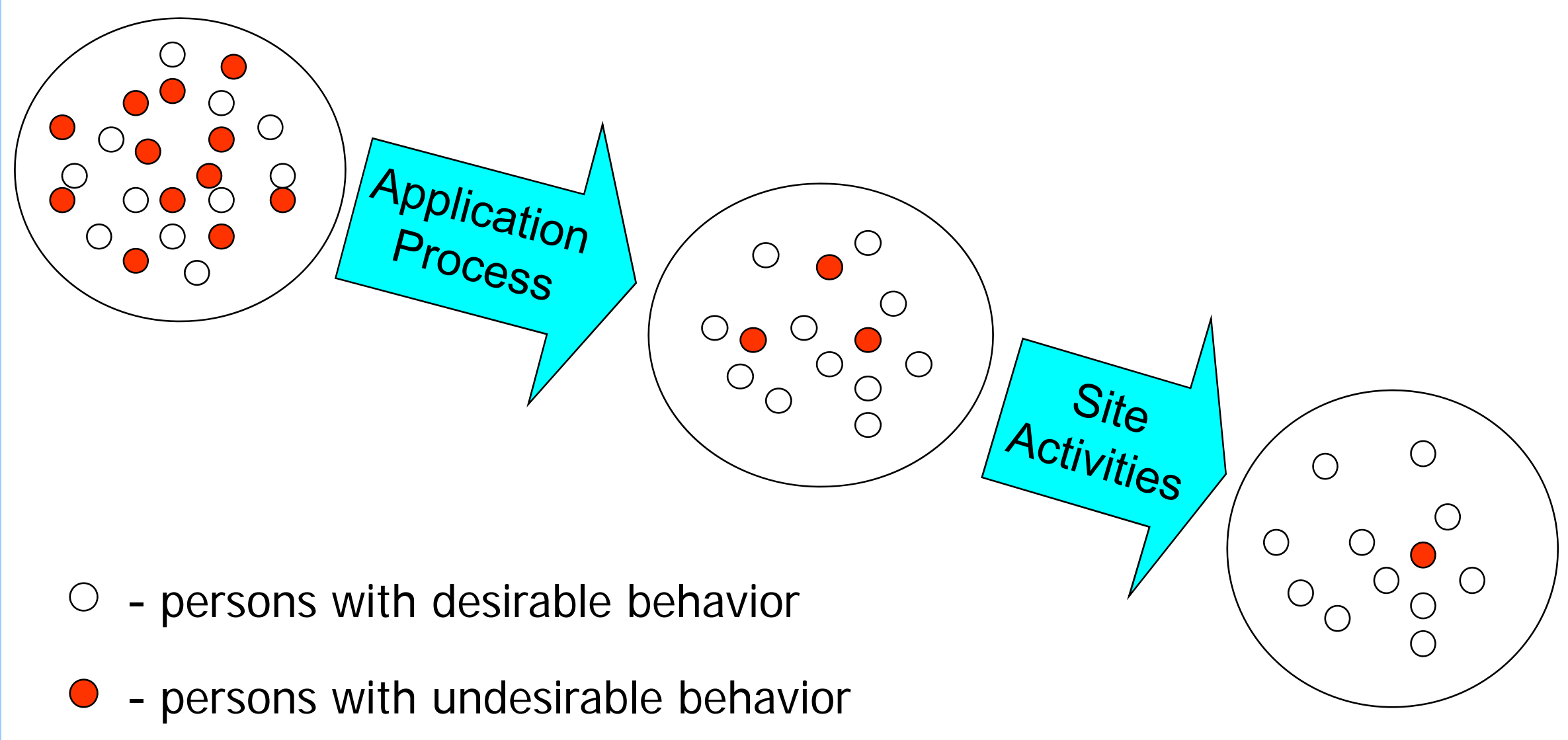




\section{Support I nformation - Pre-employment Checks}

- Cases where background checks were not done

- Detective

- Doctor

- Banker

- Athletic Coach

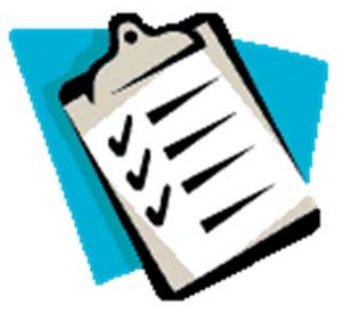

- Application information is often incorrect

- $23 \%$ of resumes found to be in error

- 52\% claimed a degree but didn't have one

- We do not know how many potentially malevolent persons get through a check, BUT many will enter the facility if no background checks are conducted 


\section{Limiting Adversary Capabilities In The Threat Definition}

- Background check could justify removing certain types of behavior from the threat definition

- Minimize persons with criminal intent

- Reduce insider capabilities if certain elements are in place (i.e., human reliability programs)

- Human Reliability Programs might eliminate violent behavior

- Limit actions if rigid controls and observation are in place during equipment operations

- Procedural training could provide detection

- Two-person rule 


\section{Limiting Adversary Capabilities In The Threat Definition (cont'd)}

- Reduce knowledge of vulnerabilities if information availability is limited

- Unescorted access not granted to VA analysts 


\section{Methodology for Evaluating the Protection System}

1. Develop a sequence of adversary actions for each target

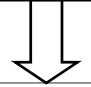

2. Identify measures to protect against these actions

¿

3. Characterize protection measures

\)

4. Develop most vulnerable paths

$\sqrt{3}$

5. Develop worst case scenarios 


\section{Limitations}

- The analysis is specifically applicable to timely detection on site

- Late detection after the action has been completed is considered in recovery and mitigation

- Analysis of insider in collusion with an outsider threat is NOT included

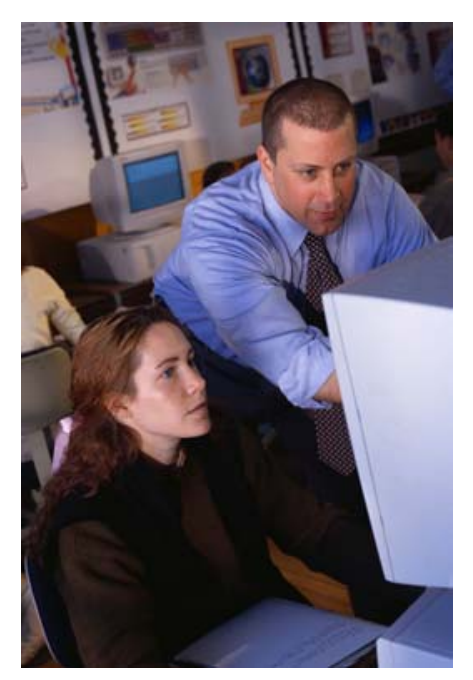




\section{Methodology for Evaluating the Protection System}

1. Develop a sequence of adversary actions for each target

\&

2. Identify measures to protect against these actions

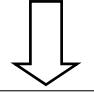

3. Characterize protection measures

4. Develop most vulnerable paths

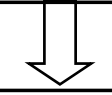

5. Develop worst case scenarios 


\section{Select A Threat Group/ Target Combination}

- Select the highest priority targets first

- Select the highest threat group for each specific target as a starting point

Note: All the threat group and target combinations need to be evaluated. Many of the details developed for the higher threat groups will also be applicable to the lower threat groups. 


\section{Develop a General Sequence of Actions}

- Describe the general actions that need to be accomplished

- Identify the areas to be crossed by the adversary

- Identify the actions needed to accomplish the adversary goal

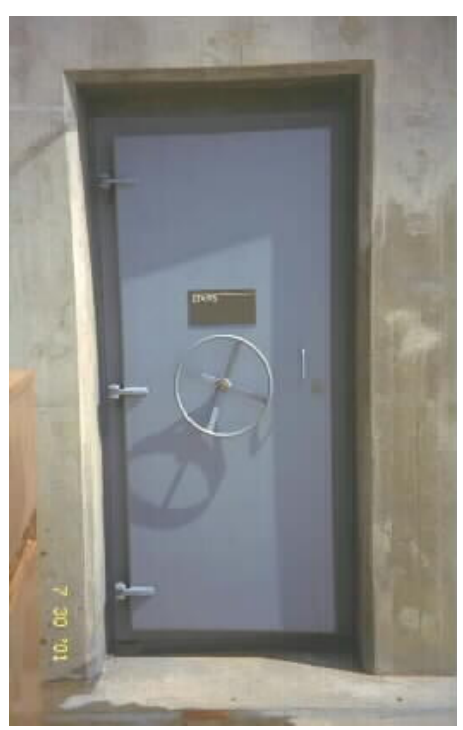




\section{Example: Develop a General Sequence of Actions for Theft Target}

Threat - Health Physics Technician Target - Material in Bunker

\begin{tabular}{|c|l|l|}
\hline Step & Area & \multicolumn{1}{|c|}{ Action } \\
\hline 1 & PA & $\begin{array}{l}\text { Enter and } \\
\text { traverse }\end{array}$ \\
\hline 2 & Bunker & Enter door \\
\hline 3 & $\begin{array}{l}\text { Inside } \\
\text { bunker }\end{array}$ & $\begin{array}{l}\text { Covertly remove } \\
\text { a container }\end{array}$ \\
\hline 4 & Bunker & $\begin{array}{l}\text { Covertly remove } \\
\text { a container }\end{array}$ \\
\hline 5 & PA & $\begin{array}{l}\text { Covertly remove } \\
\text { a container }\end{array}$ \\
\hline
\end{tabular}




\section{Methodology for Evaluating the Protection System}

1. Develop a sequence of adversary actions for each target

2. Identify measures to protect against these actions

ᄂ

3. Characterize protection measures

4. Develop most vulnerable paths

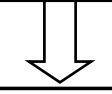

5. Develop worst case scenarios 


\section{I dentify Protection Measures Along The Action Sequence}

1. Identify all protection measures that may prevent, detect, or delay the general action

- Identify technological measures that may detect or delay the adversarial actions

- Identify procedural or administrative measures that may detect or delay the adversarial actions

2. Include every countermeasure the adversary may encounter as he progresses through the sequence

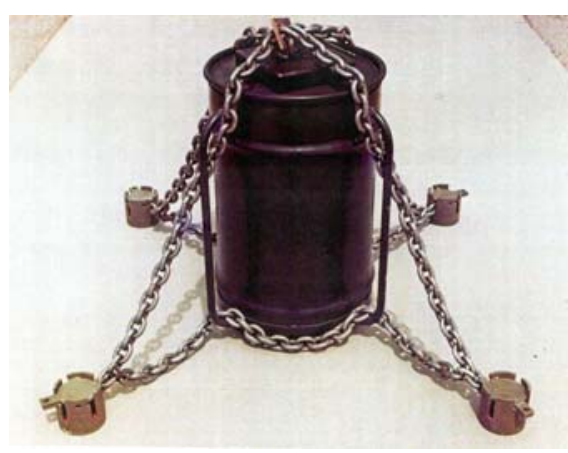




\section{General Action Sequence for Theft Target - Add Measures to Defeat}

\section{Threat - Health Physics Technician Target - NM in Bunker}

\begin{tabular}{|c|l|l|l|}
\hline Step & Area & Action & Measures to Defeat \\
\hline $\mathbf{1}$ & PA & Enter and traverse & $\begin{array}{l}\text { Entry control or instrumented perimeter and } \\
\text { general observation }\end{array}$ \\
\hline $\mathbf{2}$ & Bunker & Enter door & $\begin{array}{l}\text { Combination lock, General observation, BMS } \\
\text { sensor, MBA custodian oversight, door, walls }\end{array}$ \\
\hline $\mathbf{3}$ & $\begin{array}{l}\text { Inside } \\
\text { bunker }\end{array}$ & $\begin{array}{l}\text { Covertly remove a } \\
\text { container }\end{array}$ & $\begin{array}{l}\text { General observation, MBA custodian } \\
\text { oversight, Cage for product packages, } \\
\text { Product package, Remove 20 Kg }\end{array}$ \\
\hline 5 & Bunker & $\begin{array}{l}\text { Covertly remove a } \\
\text { container }\end{array}$ & $\begin{array}{l}\text { General observation, MBA custodian } \\
\text { oversight, Carry 20 kg }\end{array}$ \\
\hline & $\begin{array}{l}\text { Covertly remove a } \\
\text { container }\end{array}$ & $\begin{array}{l}\text { General observation, Carry 20 kg, Material } \\
\text { detectors, Perimeter zone }\end{array}$ \\
\hline
\end{tabular}




\section{Sequence of Actions and Measures to Protect Target Summary}

- In evaluating a system against an insider threat:

- The first step is to identify the sequence of adversary actions for each target

- Select a threat group and target combination to evaluate the protective measures along the path(s)

- The second step is to identify measures which protect against these actions

- Both administrative and technical measures

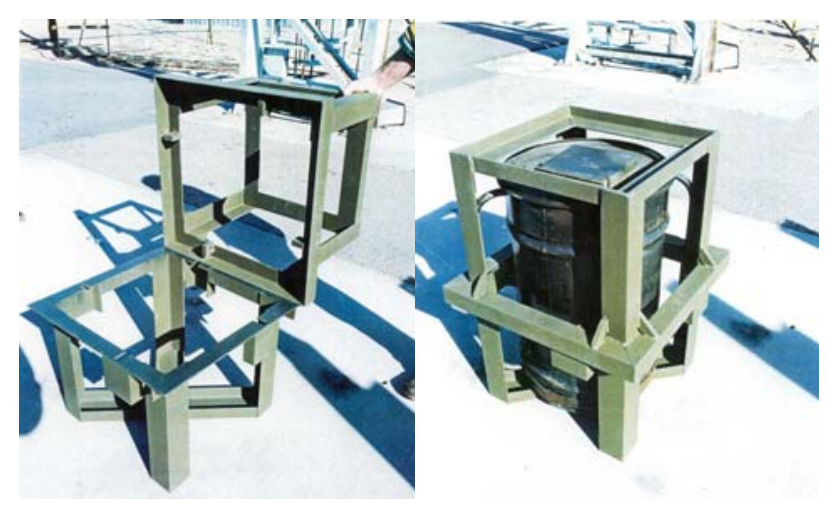




\section{Module Summary}

- Review the methodology to evaluate the protection system

- Apply this methodology to produce a sequence of insider threat actions

- Identify measures to protect the targets

Questions or Comments?? 


\section{Exercise 6a: Sequence of Actions and Measures to Protect Target}

- Use the target and insider group tables

- Develop paths for your specific target and two insider threat groups

- Describe the areas to be crossed and the actions in the sequence

- Identify the protection measures at each step in the sequence

- Present summary to the large group 


\section{Worksheet: Action Sequence and Measures}

\begin{tabular}{|c|l|l|l|}
\hline \multicolumn{2}{|l|}{ Target: } & Insider Threat Group: \\
\hline Step & Area & Action & $\begin{array}{l}\text { Measures to defeat - both } \\
\text { administrative and technical }\end{array}$ \\
\hline 1. & & & \\
\hline 2. & & & \\
\hline 3. & & & \\
\hline
\end{tabular}




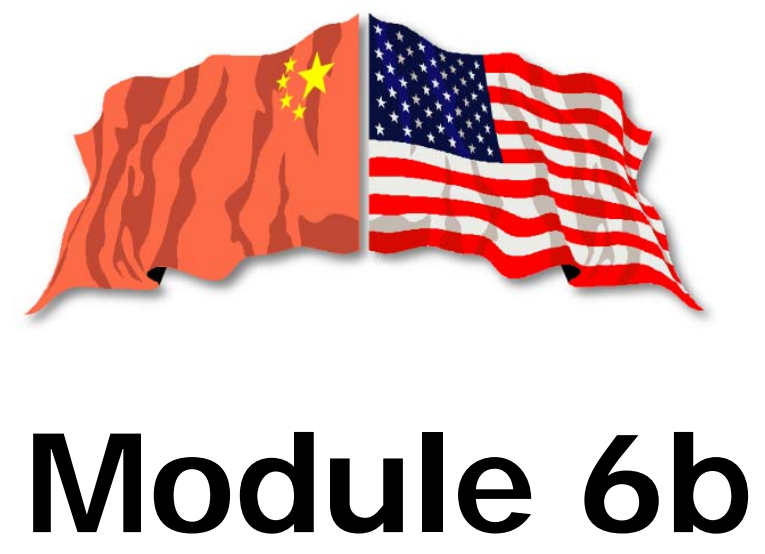

\section{Path Analysis - Characterize Protection Measures}

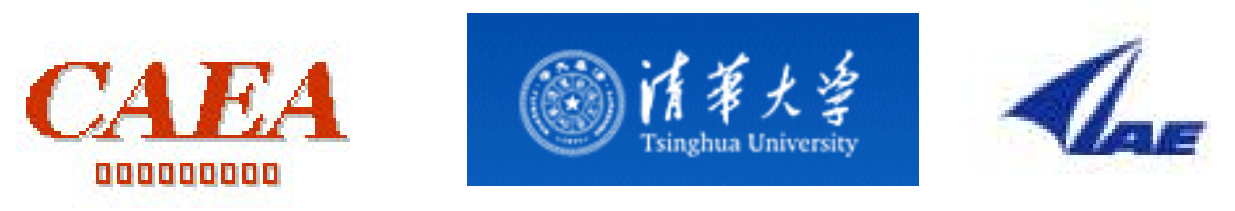




\section{Learning Objectives}

- Review the steps to estimate the effectiveness of each protective measure

- Apply this methodology to characterize the protective measures at the URF 


\section{Methodology for Evaluating the Protection System}

1. Develop a sequence of adversary actions for each target

$\sqrt{1}$

2. Identify measures to protect against these actions

$\sqrt{2}$

3. Characterize protection measures

4. Develop most vulnerable paths

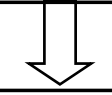

5. Develop worst case scenarios 


\section{Estimate The Effectiveness Of Each Measure}

1. Define the possible methods and resources used by the adversary to minimize detection and/or delay at each measure

2. Identify the detection likelihood of each measure in defeating the adversary

3. Estimate the time required for the adversary to accomplish the actions at each step in the sequence 


\section{Defining the Methods}

- Use normal authorized actions as far as possible along the path

- Detection can only occur with deviation from routine activity

- When the insider does deviate from routine, it is most likely that they will try to minimize detection and overtly act to minimize delay

- The analyst selects these approaches based on the data available and expert opinion

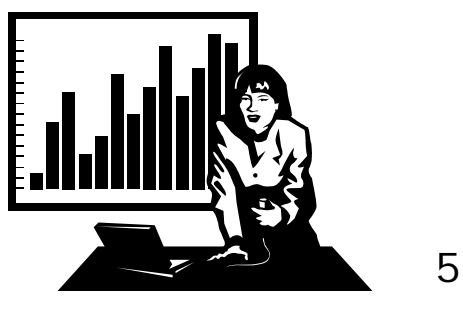




\section{Methods Used By The Health Physics}

Technician (Target location is the bunker with intent

to steal a $20 \mathrm{~kg}$ package)

\begin{tabular}{|l|l|l|l|}
\hline Step & Action & $\begin{array}{l}\text { Measures along } \\
\text { path }\end{array}$ & Possible Methods \\
\hline 2 & $\begin{array}{l}\text { Enter the } \\
\text { bunker }\end{array}$ & $\begin{array}{l}\text { Combination lock, } \\
\text { General observation, } \\
\text { MBA custodian } \\
\text { oversight }\end{array}$ & Normal entey \\
\cline { 3 - 4 } & $\begin{array}{l}\text { Combination lock, } \\
\text { General observation, } \\
\text { BMS sensor }\end{array}$ & $\begin{array}{l}\text { Covertly obtain the } \\
\text { combination }\end{array}$ \\
\cline { 3 - 4 } & $\begin{array}{l}\text { Walls, Door, BMS } \\
\text { sensor }\end{array}$ & $\begin{array}{l}\text { Breach one of surfaces using } \\
\text { tool acquired within facility }\end{array}$ \\
\hline
\end{tabular}




\section{Example: Covertly Obtain the Combination}

- Some possible methods to be used by the health physics technician for getting the combination to steal a $20 \mathrm{~kg}$ package from the bunker

- Covertly look over the shoulder of the material custodian during normal openings

- Obtain the combination from the safe

- Others?

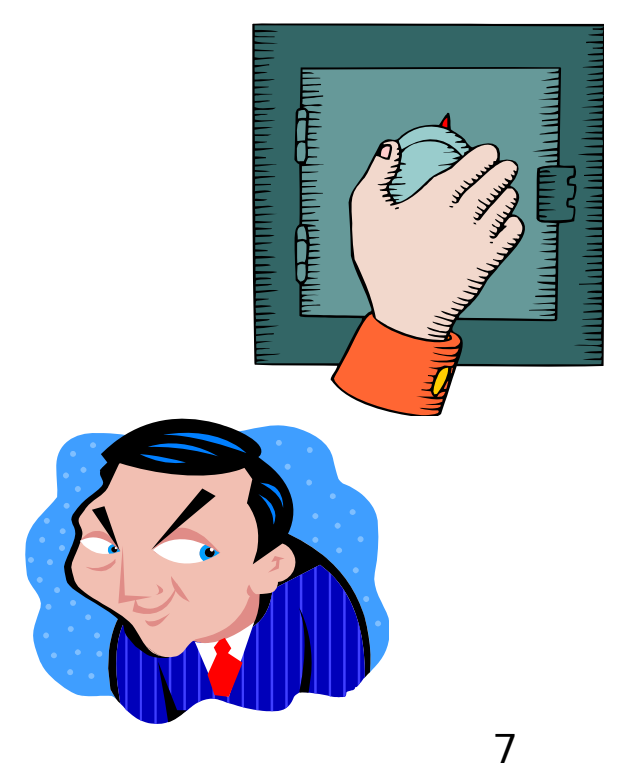




\section{Estimate The Effectiveness of Each Measure}

1. Define the possible methods and resources used by the adversary to minimize detection and/or delay at each countermeasure

2. Identify the detection likelihood of each measure in defeating the adversary

3. Estimate the time required for the adversary to accomplish the actions at each step in the sequence 


\section{Likelihood Of Detection Guidelines}

- When the action is perceived by others as normal, detection likelihood is very low

- Use quantitative data where possible

- Use information about the specific facility AND your judgment

- In many cases the best approach is to use relative qualitative likelihood in the beginning of an analysis since data often does not exist on many insider detection mechanisms

- Document rationale for decisions 


\section{Estimate The Likelihood Of Detection For The Health Physics Technician (Target is the \\ bunker with intent to steal a $20 \mathrm{~kg}$ package)}

\begin{tabular}{|l|l|l|l|l|}
\hline Step & Action & $\begin{array}{l}\text { Measures } \\
\text { along path }\end{array}$ & $\begin{array}{l}\text { Possible } \\
\text { Methods }\end{array}$ & $\begin{array}{l}\text { Likelihood } \\
\text { of Detection }\end{array}$ \\
\hline 2 & $\begin{array}{l}\text { Enter the } \\
\text { bunker }\end{array}$ & $\begin{array}{l}\text { Combination } \\
\text { Lock, General } \\
\text { observation, MBA } \\
\text { custodian } \\
\text { oversight }\end{array}$ & Normal entry & $\begin{array}{c}\text { Very Low } \\
\text { (VL) }\end{array}$ \\
\cline { 2 - 4 } & $\begin{array}{l}\text { Combination lock, } \\
\text { General } \\
\text { observation, BMS } \\
\text { sensor }\end{array}$ & $\begin{array}{l}\text { Covertly obtain } \\
\text { the combination }\end{array}$ & \\
\cline { 2 - 5 } & $\begin{array}{l}\text { Walls, Door } \\
\text { Breach one of } \\
\text { surfaces using } \\
\text { tool acquired } \\
\text { within facility }\end{array}$ & \\
\hline
\end{tabular}




\section{Estimate The Effectiveness Of Each Measure}

- Define the possible methods and resources used by the adversary to minimize detection and/or delay at each countermeasure

- Identify the detection likelihood of each measure in defeating the adversary

- Estimate the time required for the adversary to accomplish the actions at each step in the sequence

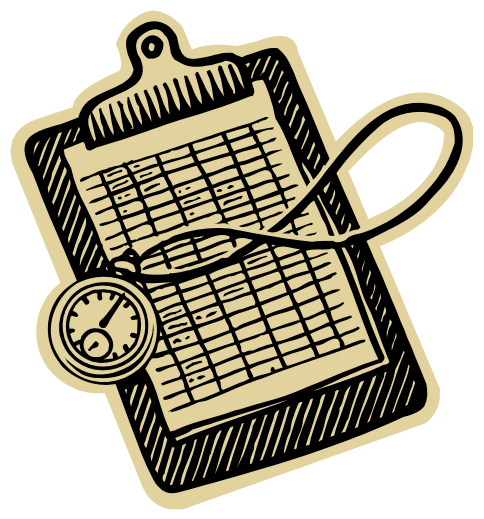




\section{Two Types of Timelines}

1. Continuous timeline

- The scenario will occur in contiguous steps

2. Discontinuous timeline

- The scenario will occur in steps that may be separated by significant periods of time

At this point establish the times for each step as being independent of the others - we will discuss discontinuous later 


\section{Calculate Or Estimate Time Taken For The Health Physics Technician (Target is the bunker with intent to steal a $20 \mathrm{~kg}$ package)}

\begin{tabular}{|l|l|l|l|l|l|}
\hline Step & Action & $\begin{array}{l}\text { Measures Along } \\
\text { Path }\end{array}$ & $\begin{array}{l}\text { Possible } \\
\text { methods }\end{array}$ & $\begin{array}{l}\text { Likelihood } \\
\text { of Detection }\end{array}$ & $\begin{array}{l}\text { Time } \\
(\mathrm{Sec})\end{array}$ \\
\hline 1 & $\begin{array}{l}\text { Enter and } \\
\text { traverse PA }\end{array}$ & $\begin{array}{l}\text { Entry control and } \\
\text { General } \\
\text { observation } \\
\text { OR }\end{array}$ & $\begin{array}{l}\text { Normal entry } \\
\text { No contraband }\end{array}$ & VL & 300 \\
\cline { 2 - 5 } & $\begin{array}{l}\text { Perimeter and } \\
\text { General } \\
\text { observation }\end{array}$ & $\begin{array}{l}\text { Cut or climb } \\
\text { fences }\end{array}$ & $\begin{array}{l}\text { Medium } \\
(.36)\end{array}$ & 25 \\
\hline
\end{tabular}

Note: Strive for realistic times through performance testing where possible 


\section{Estimate Measure Effectiveness Summary}

- To estimate the effectiveness of each insider protection measure:

- Define possible methods

- Estimate the detection likelihood of each measure

- Estimate the time for the adversary to complete each step 


\section{Module Summary}

- Review the steps to estimate the effectiveness of each protective measure

- Apply this methodology to characterize the protective measures at the URF

Questions or Comments?? 


\section{Exercise 6b: Characterize Protection Measures}

- Complete the worksheets started in previous Exercise describing:

- The potential defeat approaches used by the adversary at each of the steps in the sequence

- The likelihood of detection for each measure

- The estimated time taken to accomplish the task at each measure

- Present summary to the large group 


\section{Worksheet: Action Sequence, Defeat Methods, Detection, and Time}

Insider threat Target

\begin{tabular}{|c|c|c|c|c|c|}
\hline Step & Action & $\begin{array}{l}\text { Measures } \\
\text { Along Path }\end{array}$ & Possible Method & $\begin{array}{l}\text { Likelihood } \\
\text { of } \\
\text { Detection }\end{array}$ & $\begin{array}{l}\text { Time } \\
\text { (Sec.) }\end{array}$ \\
\hline & & & & $\bar{Z}$ & $\bar{Z}$ \\
\hline & & & & 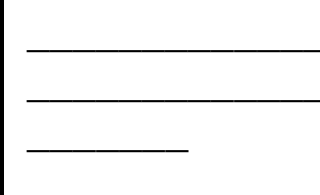 & 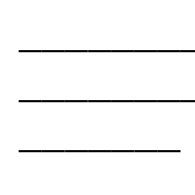 \\
\hline & & & & $\bar{\square}$ & $\bar{Z}$ \\
\hline & & & & 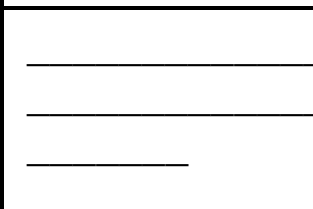 & $\bar{\square}$ \\
\hline
\end{tabular}




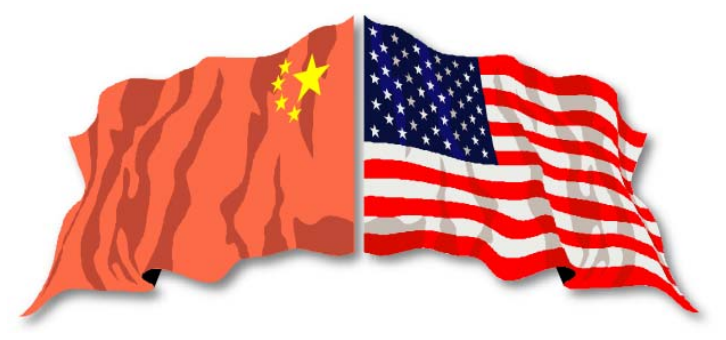

\section{Lecture 7}

\section{Scenario Development}

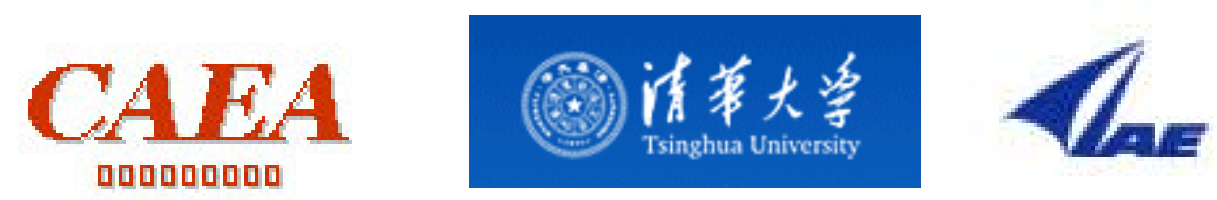




\section{Learning Objectives}

- Identify most vulnerable protection measures

- Develop most vulnerable paths for threat / target combination

- Estimate likelihood of detection and time for each path step 


\section{Methodology for Evaluating the Protection System}

1. Develop a sequence of adversary actions for each target

$\sqrt{1}$

2. Identify measures to protect against these actions

ᄂ

3. Characterize protection measures

4. Develop most vulnerable paths

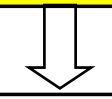

5. Develop worst case scenarios 


\section{Develop Most Vulnerable Paths}

1. Select the protection measures most advantageous to the adversary, i.e., the measures with the lowest effectiveness

- Consider the complexity of the actions required to assure that each action and defeat approach is credible

- Be consistent with methods used, for example don't use covert after overt

2. Consider the time to defeat, the detection likelihood and adversary capabilities, etc.

3. Select the protection measures based on logic and judgment

This collection of measures leads to the most vulnerable path for a specific threat / target combination 


\section{Some Measure Selection Guidelines}

-When several measures are encountered at a step but only one needs to be addressed by the adversary, select the measure that has the lowest detection unless the times are significantly different

-When several measures must be encountered in the same step, select the highest detection likelihood of all the measures or combine them using an agreed upon algorithm 


\section{Examples for Developing Most Vulnerable Path}

- We will examine two examples using the bunker

- Theft of NM from the bunker by the HP tech

- Example 1: Covert theft during routine bunker access

- Example 2: Covert theft by stealing the door combination

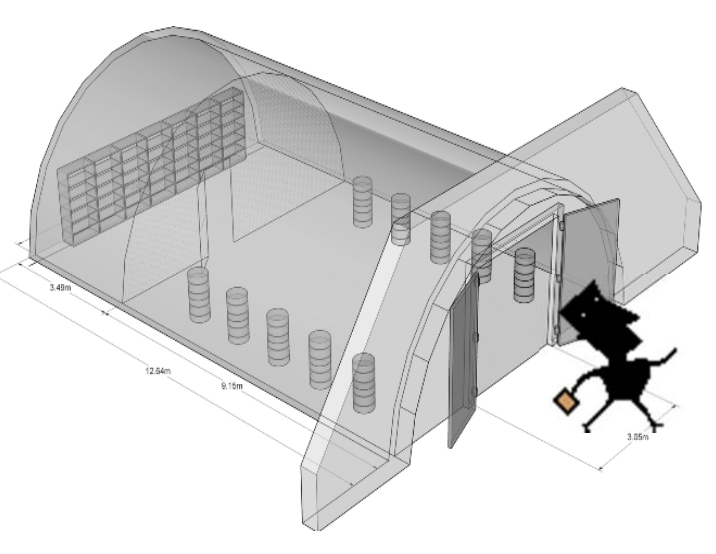




\section{Select Measure Along Path (Target is the bunker}

with intent to steal a $20 \mathbf{~ k g}$ package under normal operations)

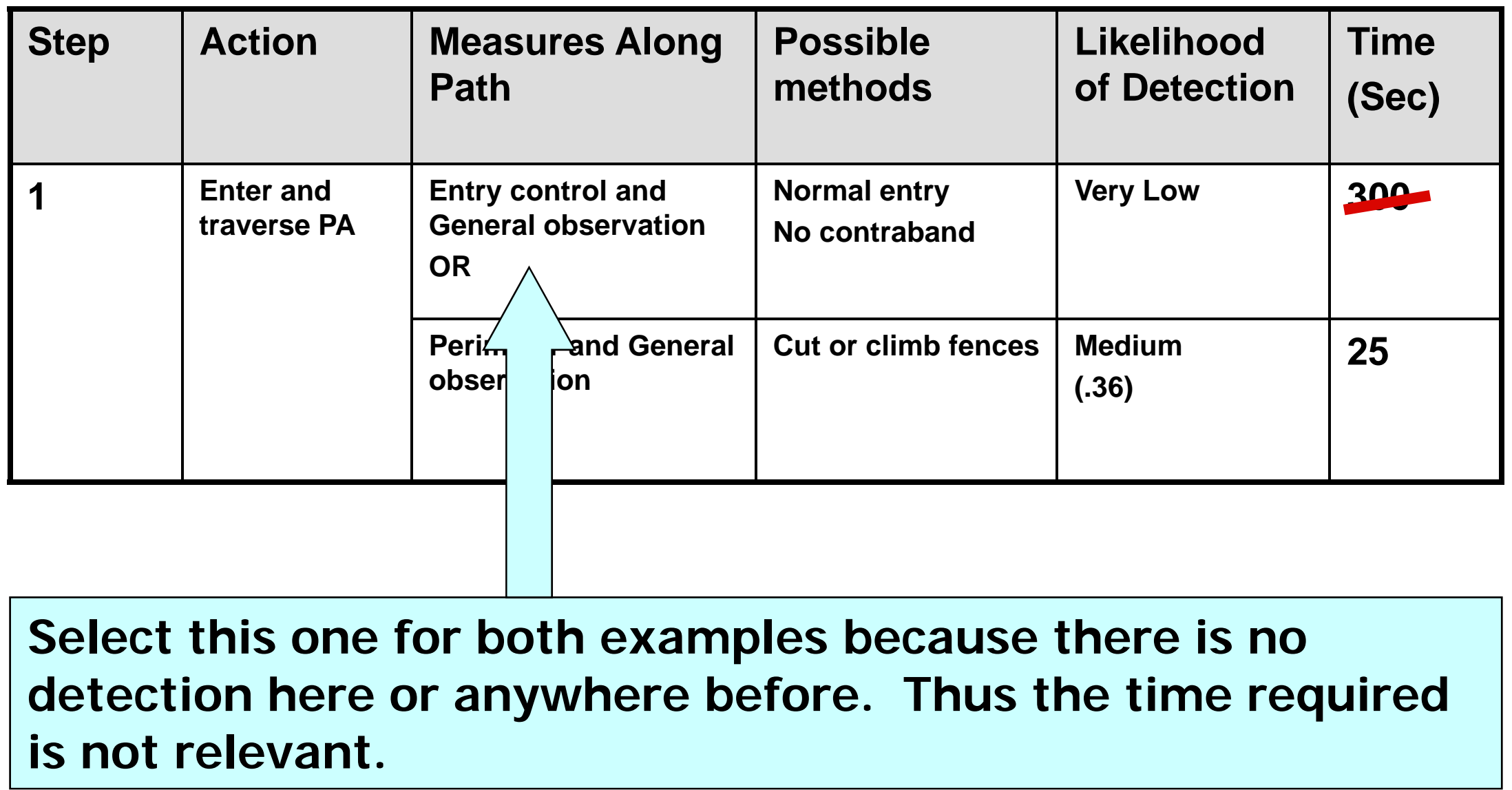




\section{Review Possible Methods (Target is the bunker}

\section{with intent to steal a $20 \mathrm{~kg}$ package)}

\begin{tabular}{|l|l|l|l|l|l|}
\hline Step & Action & $\begin{array}{l}\text { Measures } \\
\text { along path }\end{array}$ & $\begin{array}{l}\text { Possible } \\
\text { Methods }\end{array}$ & $\begin{array}{l}\text { Likelihood of } \\
\text { Detection }\end{array}$ & $\begin{array}{l}\text { Time } \\
\text { (Sec) }\end{array}$ \\
\hline 2 & $\begin{array}{l}\text { Enter } \\
\text { the } \\
\text { bunker }\end{array}$ & $\begin{array}{l}\text { Combination } \\
\text { Lock, General } \\
\text { observation, } \\
\text { MBA custodian } \\
\text { oversight }\end{array}$ & Normal entry & Very Low & 120 \\
\cline { 2 - 6 } & $\begin{array}{l}\text { Combination } \\
\text { lock, General } \\
\text { observation }\end{array}$ & $\begin{array}{l}\text { Covertly obtain } \\
\text { the combination }\end{array}$ & Medium & 60 \\
\cline { 2 - 6 } & $\begin{array}{l}\text { Walls, Door } \\
\text { Breach one of } \\
\text { surfaces using } \\
\text { tool acquired } \\
\text { within facility } \\
\text { High }\end{array}$ & $\begin{array}{l}60 \text { for } \\
\text { door } \\
174 \text { for } \\
\text { walls }\end{array}$ \\
\hline
\end{tabular}

Each of these three methods will lead to a different scenario 


\section{Select Possible Method for Step 2 (Target is}

\section{the bunker with intent to steal a $20 \mathbf{~ k g}$ package)}

\begin{tabular}{|c|c|c|c|c|c|}
\hline Step & Action & $\begin{array}{l}\text { Measures } \\
\text { along path }\end{array}$ & $\begin{array}{l}\text { Possible } \\
\text { Methods }\end{array}$ & $\begin{array}{l}\text { Likelihood of } \\
\text { Detection }\end{array}$ & $\begin{array}{l}\text { Time } \\
\text { (Sec) }\end{array}$ \\
\hline \multirow[t]{3}{*}{2} & \multirow[t]{3}{*}{\begin{tabular}{|l}
$\begin{array}{l}\text { Enter the } \\
\text { bunker }\end{array}$ \\
\end{tabular}} & $\begin{array}{l}\text { Combination } \\
\text { Lock, General } \\
\text { observation, } \\
\text { MBA custodian } \\
\text { oversight }\end{array}$ & Normal entry & Very Low & 120 \\
\hline & & $\begin{array}{l}\text { Combination } \\
\text { lock, General } \\
\text { observation }\end{array}$ & \begin{tabular}{l|l} 
Cov & y obtain \\
the & nbination
\end{tabular} & Medium & 60 \\
\hline & & Walls, Door & \begin{tabular}{|l|l|} 
Bre & one of \\
surf & s using \\
tool & quired \\
with & Eacility \\
\end{tabular} & High & $\begin{array}{l}60 \text { for } \\
\text { door } \\
174 \text { for }\end{array}$ \\
\hline & r & arnoml & $\begin{array}{l}\text { it may be t } \\
\text { ection here } \\
\text { levant. }\end{array}$ & $m a r d y$ & $\begin{array}{l}\text { rable } \\
\text { sefore. }\end{array}$ \\
\hline
\end{tabular}




\section{Select Possible Method for Step 3 (Target is}

\section{the bunker with intent to steal a $20 \mathrm{~kg}$ package)}

\begin{tabular}{|c|c|c|c|c|c|}
\hline Step & Action & $\begin{array}{l}\text { Measures along } \\
\text { path }\end{array}$ & $\begin{array}{l}\text { Possible } \\
\text { Methods }\end{array}$ & $\begin{array}{l}\text { Likelihood } \\
\text { of Detection }\end{array}$ & $\begin{array}{l}\text { Time } \\
\text { (Sec) }\end{array}$ \\
\hline \multirow[t]{3}{*}{3} & \multirow[t]{3}{*}{\begin{tabular}{|l|} 
Covertly \\
remove a \\
container
\end{tabular}} & $\begin{array}{l}\text { General } \\
\text { observation, MBA } \\
\text { custodian } \\
\text { oversight, Cage for } \\
\text { product packages, } \\
\text { Product package, } \\
\text { Remove } 20 \mathrm{Kg}\end{array}$ & $\begin{array}{l}\text { Wait until cage } \\
\text { and product } \\
\text { package } \\
\text { opened, take } \\
\text { package and } \\
\text { hide package } \\
\text { inside coat }\end{array}$ & High & 60 \\
\hline & & $\begin{array}{l}\text { General } \\
\text { observation after } \\
\text { covert entry }\end{array}$ & $\begin{array}{l}\text { Ope fage and } \\
\text { prd } \\
\text { pac fe with } \\
\text { han pols }\end{array}$ & Low & 30 \\
\hline & & $\begin{array}{l}\text { General observation } \\
\text { after overt entry }\end{array}$ & \begin{tabular}{|l|l} 
Ope & age and \\
prod & $t$ \\
pac & e with \\
han & pols
\end{tabular} & Low & 30 \\
\hline
\end{tabular}




\section{What happens at Step 3 if a criticality alarm occurs while the cage is open?}

\begin{tabular}{|c|c|c|c|c|c|}
\hline Step & Action & $\begin{array}{l}\text { Measures along } \\
\text { path }\end{array}$ & $\begin{array}{l}\text { Possible } \\
\text { Methods }\end{array}$ & $\begin{array}{l}\text { Likelihood } \\
\text { of Detection }\end{array}$ & $\begin{array}{l}\text { Time } \\
\text { (Sec) }\end{array}$ \\
\hline \multirow[t]{3}{*}{3} & \multirow[t]{3}{*}{$\begin{array}{l}\text { Covertly } \\
\text { remove a } \\
\text { container }\end{array}$} & $\begin{array}{l}\text { General } \\
\text { observation, MBA } \\
\text { custodian } \\
\text { oversight, Cage for } \\
\text { product packages, } \\
\text { Product package, } \\
\text { Remove } 20 \mathrm{Kg}\end{array}$ & $\begin{array}{l}\text { Wait until cage } \\
\text { and product } \\
\text { package } \\
\text { opened, take } \\
\text { package and } \\
\text { hide package } \\
\text { inside coat }\end{array}$ & Med-Low & 60 \\
\hline & & $\begin{array}{l}\text { General } \\
\text { observation after } \\
\text { covert entry }\end{array}$ & $\begin{array}{l}\text { Ope age and } \\
\text { prd } \\
\text { pac e with } \\
\text { han pols }\end{array}$ & Low & 30 \\
\hline & & $\begin{array}{l}\text { General observation } \\
\text { after overt entry }\end{array}$ & \begin{tabular}{|l|l|} 
Ope & age and \\
prod & t \\
pact & e with \\
han & pols
\end{tabular} & Low & 30 \\
\hline
\end{tabular}


Select Possible Method for Step 4 (Target is the bunker with intent to steal a $20 \mathrm{~kg}$ package)

\begin{tabular}{|c|c|c|c|c|c|}
\hline Step & Action & $\begin{array}{l}\text { Measures along } \\
\text { path }\end{array}$ & $\begin{array}{l}\text { Possible } \\
\text { Methods }\end{array}$ & $\begin{array}{l}\text { Likelihood of } \\
\text { Detection }\end{array}$ & $\begin{array}{l}\text { Time } \\
\text { (Sec) }\end{array}$ \\
\hline \multirow[t]{3}{*}{4} & \multirow[t]{3}{*}{$\begin{array}{l}\text { Covertly } \\
\text { remove a } \\
\text { container } \\
\text { from the } \\
\text { Bunker }\end{array}$} & $\begin{array}{l}\text { General } \\
\text { observation, MBA } \\
\text { custodian } \\
\text { oversight }\end{array}$ & $\begin{array}{l}\text { Normal exit } \\
\text { with package } \\
\text { hidden } \\
\text { under coat }\end{array}$ & High & 60 \\
\hline & & $\begin{array}{l}\text { General } \\
\text { observation after } \\
\text { covert entry and } \\
\text { removal }\end{array}$ & $\begin{array}{ll}\text { M } & \\
\text { ng ally out } \\
\text { dd and } \\
\text { ad }\end{array}$ & Medium & 60 \\
\hline & & $\begin{array}{l}\text { General } \\
\text { observation after } \\
\text { overt entry and } \\
\text { removal }\end{array}$ & $\begin{array}{ll}\text { M } & \text { as } \\
\text { qd } & \text { ly as } \\
\text { pd } \\
\text { dd }\end{array}$ & Medium & 30 \\
\hline
\end{tabular}




\section{How does step 4 change under emergency conditions?}

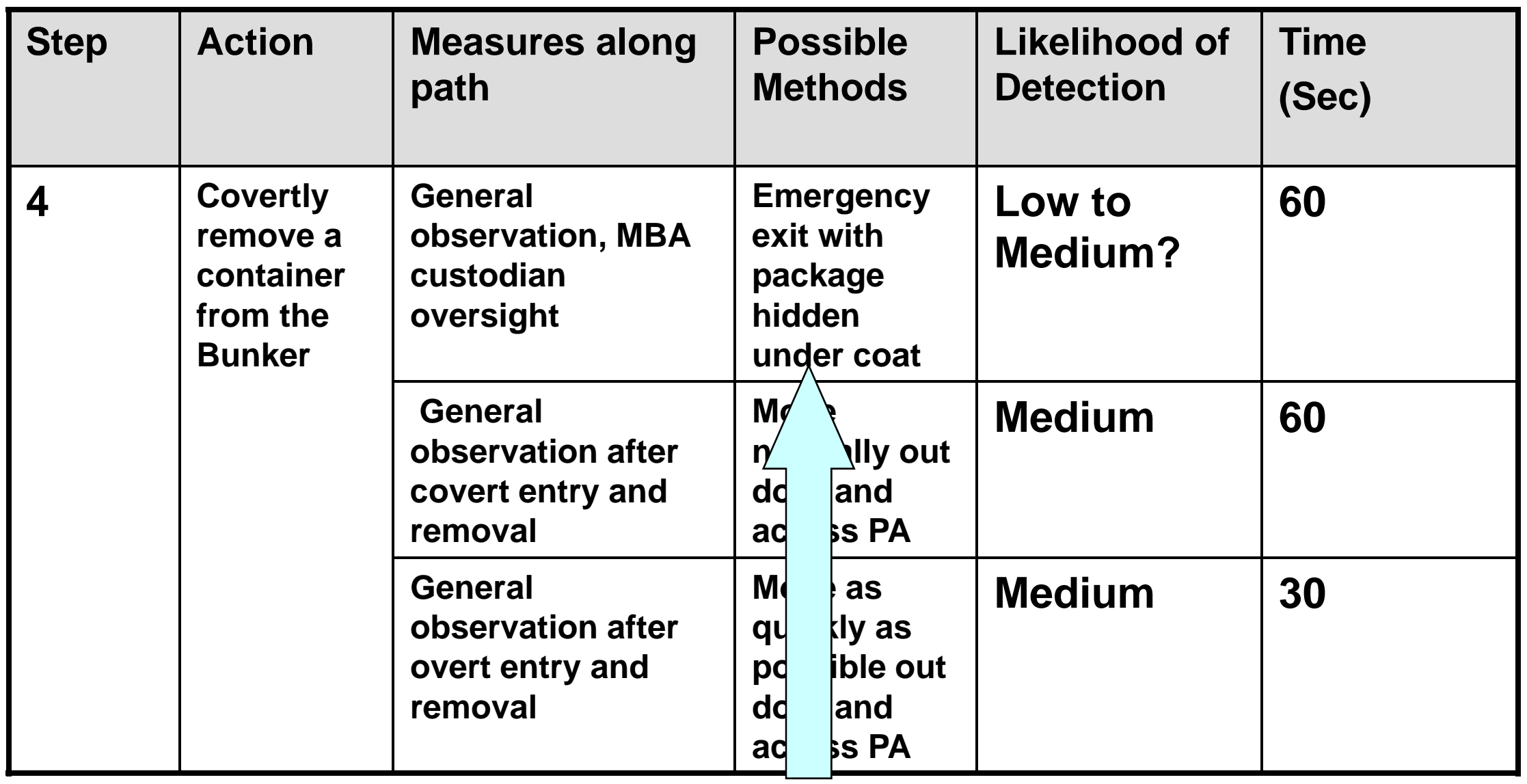

Were the insider's chances enhanced? 


\section{Select Possible Method for Step 5 (Target is}

\section{the bunker with intent to steal a $20 \mathrm{~kg}$ package)}

\begin{tabular}{|l|l|l|l|l|l|}
\hline Step & Action & $\begin{array}{l}\text { Measures along } \\
\text { path }\end{array}$ & $\begin{array}{l}\text { Possible } \\
\text { Methods }\end{array}$ & $\begin{array}{l}\text { Likelihood } \\
\text { of Detection }\end{array}$ & $\begin{array}{l}\text { Time } \\
\text { (Sec) }\end{array}$ \\
\hline 5 & $\begin{array}{l}\text { Covertly } \\
\text { remove a } \\
\text { container } \\
\text { from the PA }\end{array}$ & $\begin{array}{l}\text { General } \\
\text { observation, Carry } \\
20 \mathrm{Kg}, \text { Material } \\
\text { detectors }\end{array}$ & $\begin{array}{l}\text { Normal exit with } \\
\text { explanation that } \\
\text { he had gotten } \\
\text { contaminated }\end{array}$ & High & 90 \\
\cline { 2 - 5 } & $\begin{array}{l}\text { General } \\
\text { observation, Carry } \\
20 \text { Kg, Material } \\
\text { detectors }\end{array}$ & $\begin{array}{l}\text { Forceful exit after } \\
\text { material detector } \\
\text { alarms or is } \\
\text { observed with } \\
\text { package }\end{array}$ & High & 30 \\
\begin{tabular}{|l|l|l|l|} 
We will select this \\
One because the \\
detection is lower. \\
BUT will it produce \\
a credible scenario?
\end{tabular} & $\begin{array}{l}\text { Throw package } \\
\text { over the zone to } \\
\text { ne outside for } \\
\text { recovery later }\end{array}$ & Medium & $\begin{array}{l}30 \text { (but 20 } \\
\text { kg may be } \\
\text { difficult to } \\
\text { throw!) }\end{array}$ \\
\hline
\end{tabular}




\section{Or what if the HP takes advantage of their regular job duties for Step 5?}

\begin{tabular}{|c|c|c|c|c|c|}
\hline Step & Action & $\begin{array}{l}\text { Measures along } \\
\text { path }\end{array}$ & $\begin{array}{l}\text { Possible } \\
\text { Methods }\end{array}$ & $\begin{array}{l}\text { Likelihood } \\
\text { of Detection }\end{array}$ & $\begin{array}{l}\text { Time } \\
\text { (Sec) }\end{array}$ \\
\hline \multirow[t]{3}{*}{5} & \multirow[t]{3}{*}{\begin{tabular}{|l|} 
Covertly \\
remove a \\
container \\
from the PA
\end{tabular}} & $\begin{array}{l}\text { General } \\
\text { observation, Carry } \\
20 \mathrm{Kg} \text {, Material } \\
\text { detectors }\end{array}$ & $\begin{array}{l}\text { Normal exit with } \\
\text { explanation that } \\
\text { he is removing } \\
\text { the Americium } \\
\text { test source }\end{array}$ & Low & 90 \\
\hline & & $\begin{array}{l}\text { General } \\
\text { observation, Carry } \\
20 \mathrm{Kg} \text {, Material } \\
\text { detectors }\end{array}$ & $\begin{array}{l}\text { FG dl exit after } \\
\text { ma lal detector } \\
\text { ala } \text { s or is } \\
\text { obs ved with } \\
\text { pad ge }\end{array}$ & High & 30 \\
\hline & & \multirow{2}{*}{\multicolumn{3}{|c|}{$\begin{array}{l}\text { Per Will the persons at the PA } \\
\text { be able to tell an } \\
\text { americium test source from } \\
\text { uranium? Is this more } \\
\text { credible for this insider? }\end{array}$}} & $\begin{array}{l}30 \text { (but } 20 \\
\text { kg may be } \\
\text { difficult to } \\
\text { throw!) }\end{array}$ \\
\hline & & & & & Lecture 7-15 \\
\hline
\end{tabular}




\section{Example 1: Covert theft during routine bunker access}

Step 1. HP Tech enters protected area normally - no detection so time doesn't matter

Step 2. Enter bunker under normal operation - no detection so time doesn't matter

Step 3. Covertly take package and hide under coat

Step 4. Normal exit from bunker (or emergency exit)

Step 5. Normal walk across area to fence where the package is thrown over the PA boundary (or piggy back through PA on source transfer) 


\section{Example 1 - Possibly the Most Vulnerable Path For HP Tech/ Bunker}

\begin{tabular}{|c|l|l|l|}
\hline Step & Action & $\begin{array}{l}\text { Likelihood of } \\
\text { Detection }\end{array}$ & $\begin{array}{l}\text { Time } \\
\text { (Sec) }\end{array}$ \\
\hline 1 & $\begin{array}{l}\text { Enter protected area } \\
\text { normally }\end{array}$ & Very Low & N/A \\
\hline 2 & Enter bunker normally & Very Low & N/A \\
\hline 3 & $\begin{array}{l}\text { Take package and hide } \\
\text { under coat }\end{array}$ & High & 60 \\
\hline 4 & $\begin{array}{l}\text { Walk out of bunker } \\
\text { normally }\end{array}$ & High & 60 \\
\hline 5 & $\begin{array}{l}\text { Walk normally to fence and } \\
\text { throw package over }\end{array}$ & Medium & 30 \\
\hline
\end{tabular}




\section{Example 1 - Further enhanced by the introduction of an emergency situation}

\begin{tabular}{|c|l|l|l|}
\hline Step & Action & $\begin{array}{l}\text { Likelihood of } \\
\text { Detection }\end{array}$ & $\begin{array}{l}\text { Time } \\
\text { (Sec) }\end{array}$ \\
\hline 1 & $\begin{array}{l}\text { Enter protected area } \\
\text { normally }\end{array}$ & Very Low & N/A \\
\hline 2 & Enter bunker normally & Very Low & N/A \\
\hline 3 & $\begin{array}{l}\text { Take package and hide } \\
\text { under coat }\end{array}$ & Low & 60 \\
\hline 4 & $\begin{array}{l}\text { Emergency exit out of } \\
\text { bunker }\end{array}$ & Medium & 60 \\
\hline 5 & $\begin{array}{l}\text { Use normal source } \\
\text { transfer to remove from PA }\end{array}$ & Medium & 30 \\
\hline
\end{tabular}




\section{Logic Tree For Example 1}

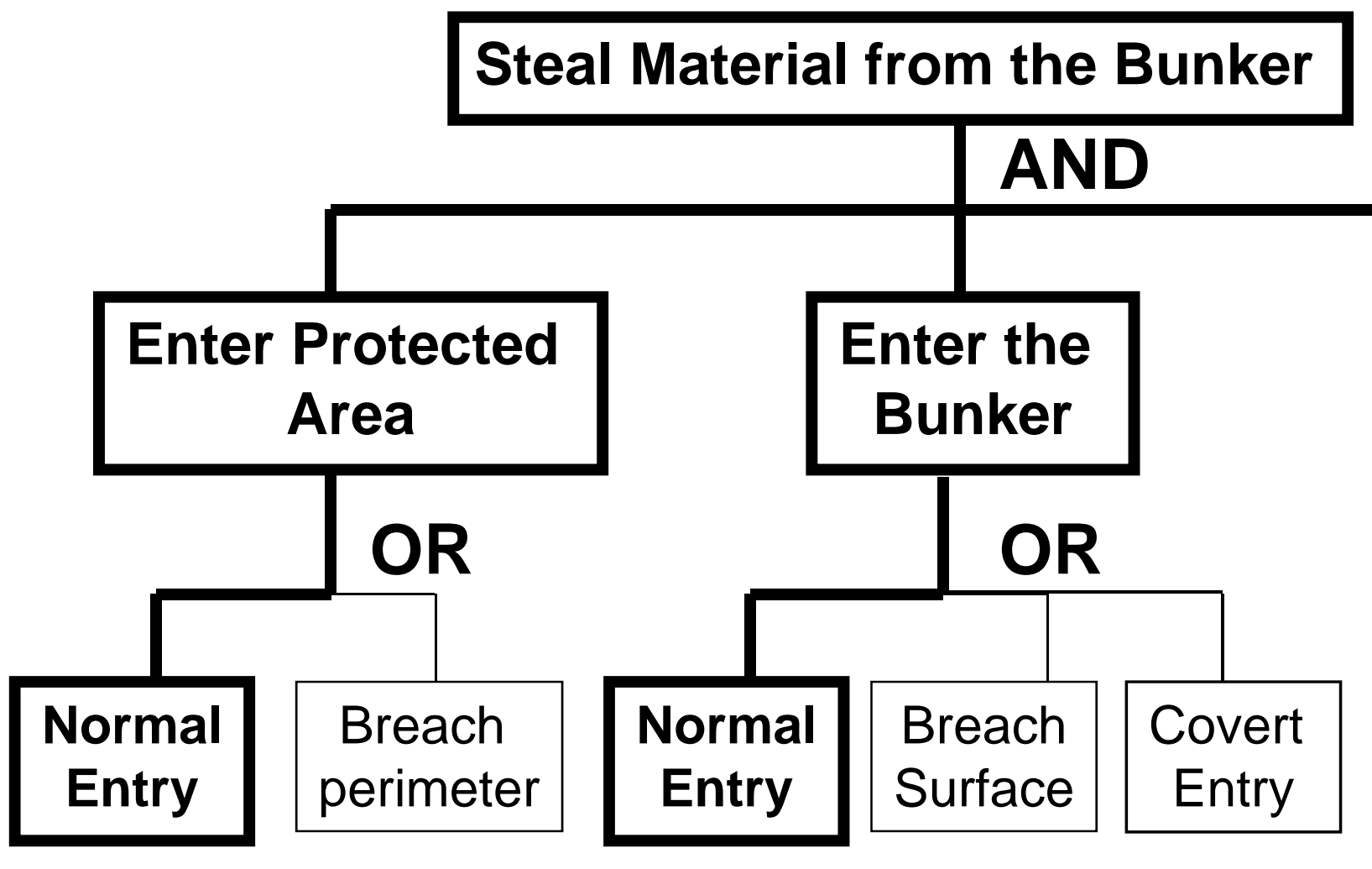

Tabular presentation of Example 1 (slide 15) only includes the heavily outlined actions

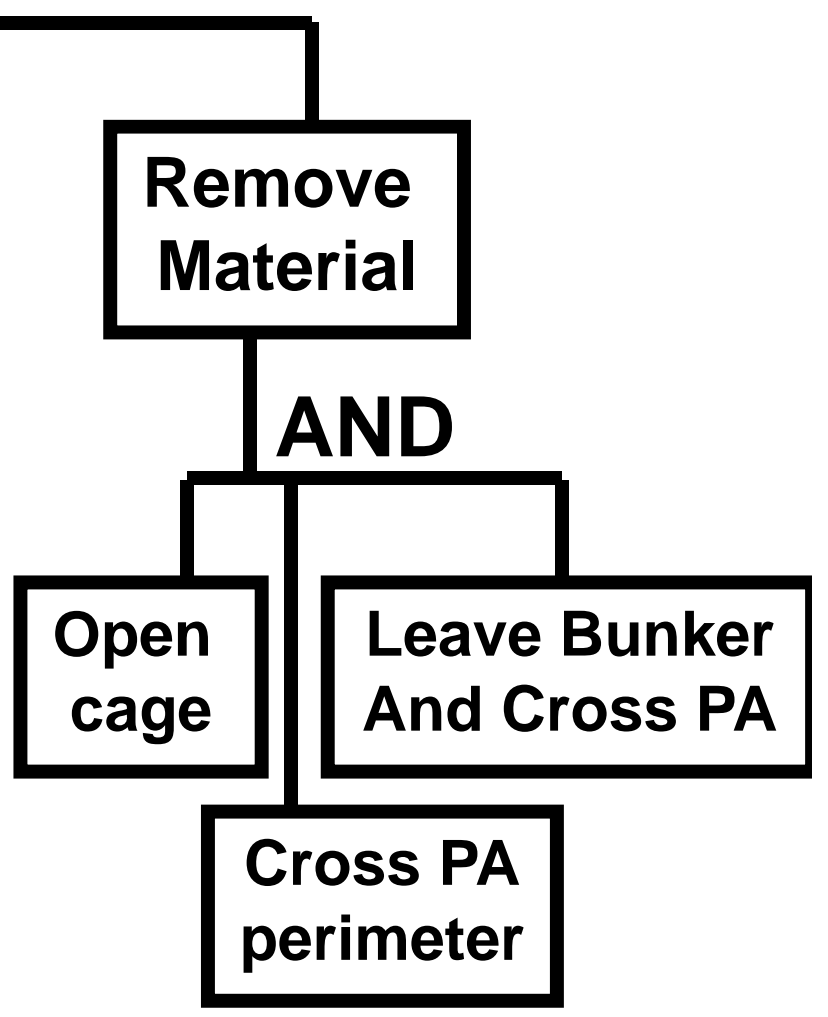

Lecture 7-19 


\section{Second Example for Developing Most Vulnerable Path}

- Example 1: covert theft during routine bunker access

- Example 2: covert theft by stealing the door combination 


\section{Select Measures along Path (Target is the}

\section{bunker with intent to steal a $20 \mathrm{~kg}$ package)}

\begin{tabular}{|l|l|l|l|l|l|}
\hline Step & Action & $\begin{array}{l}\text { Measures Along } \\
\text { Path }\end{array}$ & $\begin{array}{l}\text { Possible } \\
\text { methods }\end{array}$ & $\begin{array}{l}\text { Likelihood of } \\
\text { Detection }\end{array}$ & $\begin{array}{l}\text { Time } \\
(\mathrm{Sec})\end{array}$ \\
\hline 1 & $\begin{array}{l}\text { Enter and } \\
\text { traverse } \\
\text { PA }\end{array}$ & $\begin{array}{l}\text { Entry control and } \\
\text { General observation } \\
\text { OR }\end{array}$ & $\begin{array}{l}\text { Normal entry } \\
\text { No contraband }\end{array}$ & Very Low & 300 \\
\cline { 2 - 5 } & $\begin{array}{l}\text { Perimery } \\
\text { Genera }\end{array}$ & $\begin{array}{l}\text { Cut or climb } \\
\text { fences }\end{array}$ & $\begin{array}{l}\text { Medium } \\
(.36)\end{array}$ & 25 \\
\hline
\end{tabular}




\section{Select Possible Method for Step 2 (Target is}

\section{the bunker with intent to steal a $20 \mathrm{~kg}$ package)}

\begin{tabular}{|l|l|l|l|l|l|}
\hline Step & Action & $\begin{array}{l}\text { Measures } \\
\text { along path }\end{array}$ & $\begin{array}{l}\text { Possible } \\
\text { Methods }\end{array}$ & $\begin{array}{l}\text { Likelihood of } \\
\text { Detection }\end{array}$ & $\begin{array}{l}\text { Time } \\
\text { (Sec) }\end{array}$ \\
\hline 2 & $\begin{array}{l}\text { Enter } \\
\text { the } \\
\text { bunker }\end{array}$ & $\begin{array}{l}\text { Combination Lock, } \\
\text { General } \\
\text { observation, MBA } \\
\text { custodian } \\
\text { oversight }\end{array}$ & Normal entry & Very Low & 120 \\
\cline { 3 - 6 } & $\begin{array}{l}\text { Combination lock, } \\
\text { General } \\
\text { observation, BMs } \\
\text { sensor }\end{array}$ & $\begin{array}{l}\text { Covertly obtain } \\
\text { the combination }\end{array}$ & $\begin{array}{l}\text { Medium } \\
\text { High for BMS }\end{array}$ & 60 \\
\cline { 3 - 6 } & $\begin{array}{l}\text { Walls, Door } \\
\text { Bre } \\
\text { sur } \\
\text { too } \\
\text { wit }\end{array}$ & $\begin{array}{l}\text { hen using } \\
\text { fquired } \\
\text { facility }\end{array}$ & High & $\begin{array}{l}60 \text { for } \\
\text { door } \\
174 \text { for } \\
\text { walls }\end{array}$ \\
\hline
\end{tabular}




\section{Some Possible Methods for Getting the Combination}

- Some possible methods to be used by the health physics technician for getting the combination to steal a $20 \mathrm{~kg}$ package from the bunker

- Covertly look over the shoulder of the material custodian during normal openings

- Obtain the combination from the safe

- Others?

We will use this one. $P_{D}=$ Medium 


\section{Additional Step}

- The combination may be obtained but how does the insider try to defeat the BMS alarm?

- No defeat - just hurry

- Can he just cut the wires?

We will use this one for the example but these other questions need to be answered in a full

- Other technical defeats?

- Can he get to a signal box and analysis. Likelihood of detection $=$ High compromise the signal there?

- Can he use the procedures to get the alarm ignored

- Other?

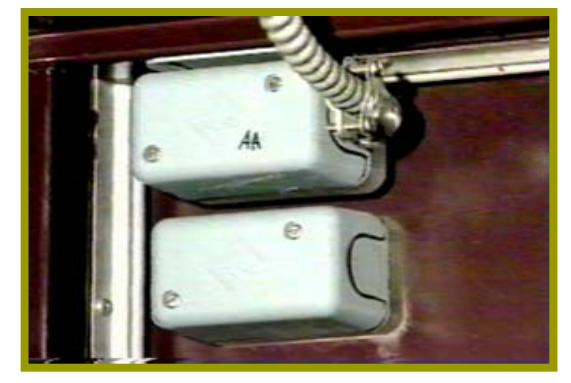




\section{Select Possible Method for Step 3 (Target is}

\section{the bunker with intent to steal a $20 \mathrm{~kg}$ package)}

\begin{tabular}{|c|c|c|c|c|c|}
\hline Step & Action & $\begin{array}{l}\text { Measures along } \\
\text { path }\end{array}$ & $\begin{array}{l}\text { Possible } \\
\text { Methods }\end{array}$ & $\begin{array}{l}\text { Likelihood } \\
\text { of Detection }\end{array}$ & $\begin{array}{l}\text { Time } \\
\text { (Sec) }\end{array}$ \\
\hline \multirow[t]{3}{*}{3} & \multirow[t]{3}{*}{$\begin{array}{l}\text { Covertly } \\
\text { remove a } \\
\text { container }\end{array}$} & $\begin{array}{l}\text { General observation, } \\
\text { MBA custodian } \\
\text { oversight, Cage for } \\
\text { product packages, } \\
\text { product package, } \\
\text { Remove } 20 \mathrm{Kg} \\
\text { package }\end{array}$ & $\begin{array}{l}\text { Wait until cage } \\
\text { and product } \\
\text { package opened, } \\
\text { take package and } \\
\text { hide package } \\
\text { inside coat }\end{array}$ & High & 60 \\
\hline & & $\begin{array}{l}\text { General observation } \\
\text { after covert entry }\end{array}$ & $\begin{array}{l}\text { Open cage and } \\
\text { product package } \\
\text { with hand tools }\end{array}$ & Low & 120 \\
\hline & & $\begin{array}{l}\text { General observation } \\
\text { after overt entry }\end{array}$ & $\begin{array}{l}\text { Op cage and } \\
\text { pro ct package } \\
\text { wit and tools }\end{array}$ & Low & 120 \\
\hline \multicolumn{6}{|c|}{$\begin{array}{l}\text { Our example uses this one. Any other ideas on how else the } \\
\text { insider could open the cage? Key to cage lock? }\end{array}$} \\
\hline
\end{tabular}




\section{Select Possible Method for Step 4 (Target is the bunker with intent to steal a $20 \mathrm{~kg}$ package)}

\begin{tabular}{|c|c|c|c|c|c|}
\hline Step & Action & $\begin{array}{l}\text { Measures along } \\
\text { path }\end{array}$ & $\begin{array}{l}\text { Possible } \\
\text { Methods }\end{array}$ & $\begin{array}{l}\text { Likelihood } \\
\text { of Detection }\end{array}$ & $\begin{array}{l}\text { Time } \\
\text { (Sec) }\end{array}$ \\
\hline \multirow[t]{3}{*}{4} & \multirow[t]{3}{*}{$\begin{array}{l}\text { Covertly } \\
\text { remove a } \\
\text { container } \\
\text { from the } \\
\text { Bunker }\end{array}$} & $\begin{array}{l}\text { General observation, } \\
\text { MBA custodian } \\
\text { oversight, Cage for } \\
\text { product packages }\end{array}$ & $\begin{array}{l}\text { Normal exit } \\
\text { with package } \\
\text { hidden under } \\
\text { coat }\end{array}$ & High & 60 \\
\hline & & $\begin{array}{l}\text { General observation } \\
\text { after covert entry and } \\
\text { removal }\end{array}$ & $\begin{array}{l}\text { Move normally } \\
\text { out door and } \\
\text { across PA }\end{array}$ & Medium & 60 \\
\hline & & $\begin{array}{l}\text { General observation } \\
\text { after overt entry and } \\
\text { removal }\end{array}$ & $\left.\begin{array}{l|l}\text { Move } \\
\text { quick } \\
\text { possi } \\
\text { door } \\
\text { acros }\end{array}\right]\left[\begin{array}{l}\text { s } \\
\text { out }\end{array}\right.$ & High & 30 \\
\hline & & \multicolumn{4}{|c|}{$\begin{array}{l}\text { We will use this one. Any other ideas on } \\
\text { what else the insider could do covertly? }\end{array}$} \\
\hline
\end{tabular}




\section{Select Possible Method for Step 5 (Target is}

\section{the bunker with intent to steal a $20 \mathrm{~kg}$ package)}

\begin{tabular}{|c|c|c|c|c|c|c|}
\hline Step & Action & $\begin{array}{l}\text { Measures along } \\
\text { path }\end{array}$ & $\begin{array}{l}\text { Possik } \\
\text { Metho }\end{array}$ & & $\begin{array}{l}\text { Likelihood } \\
\text { of Detection }\end{array}$ & $\begin{array}{l}\text { Time } \\
\text { (Sec) }\end{array}$ \\
\hline \multirow[t]{3}{*}{5} & \multirow[t]{3}{*}{$\begin{array}{l}\text { Covertly } \\
\text { remove a } \\
\text { container } \\
\text { from the } \\
\text { PA }\end{array}$} & $\begin{array}{l}\text { General } \\
\text { observation, Carry } \\
20 \mathrm{~kg} \text {, Material } \\
\text { detectors }\end{array}$ & \multicolumn{2}{|c|}{$\begin{array}{l}\text { Normal exit with } \\
\text { explanation that } \\
\text { he had gotten } \\
\text { contaminated }\end{array}$} & High & 90 \\
\hline & & $\begin{array}{l}\text { General } \\
\text { observation, Carry } \\
20 \mathrm{Kg} \text {, Material } \\
\text { detectors }\end{array}$ & $\begin{array}{l}\text { Force } \\
\text { mater } \\
\text { alarms } \\
\text { obser } \\
\text { packa }\end{array}$ & $\begin{array}{l}\text { exit after } \\
\text { detector } \\
r \text { is } \\
\text { with }\end{array}$ & High & 30 \\
\hline & & Perimeter zone & $\begin{array}{l}\text { Throw } \\
\text { over th } \\
\text { the ou } \\
\text { recove }\end{array}$ & $\begin{array}{l}\text { zckage } \\
\text { zone to } \\
\text { de for } \\
\text { later }\end{array}$ & Medium & $\begin{array}{l}30 \text { (but } 20 \\
\mathrm{~kg} \text { is } \\
\text { difficult to }\end{array}$ \\
\hline \multicolumn{7}{|c|}{ We will select this one to add variety to this example } \\
\hline
\end{tabular}




\section{Example 2: Covert Theft using stolen combination}

Step 1. HP Tech enters protected area normally - no detection so time doesn't matter

Step 2. Obtain stolen combination - If not detected time doesn't matter

Step 2a. Open bunker door using stolen combination Step 3. Cut into cage and open product package and take package

Step 4. Move normally out door and across PA

Step 5. Normal exit from PA with talking his way through the reason for the nuclear material alarm 


\section{Example 2 - Possibly the Most Vulnerable Path For HP Tech/ Bunker}

\begin{tabular}{|c|l|l|l|}
\hline Step & Action & $\begin{array}{l}\text { Likelihood of } \\
\text { Detection }\end{array}$ & $\begin{array}{l}\text { Time } \\
\text { (Sec) }\end{array}$ \\
\hline 1 & $\begin{array}{l}\text { Enter protected area } \\
\text { normally }\end{array}$ & Very Low & N/A \\
\hline 2 & Obtain combination & Medium & $?$ \\
\hline $2 \mathrm{a}$ & $\begin{array}{l}\text { Open bunker door using } \\
\text { combination }\end{array}$ & $\begin{array}{l}\text { Very Low until the door } \\
\text { is opened }-\mathrm{P}_{\mathrm{D}}=\text { High }\end{array}$ & 60 \\
\hline 3 & $\begin{array}{l}\text { Cut through cage and } \\
\text { product package and } \\
\text { take package }\end{array}$ & Low & 90 \\
\hline 4 & $\begin{array}{l}\text { Take package, hide under } \\
\text { coat and cross the PA }\end{array}$ & Medium & 60 \\
\hline 5 & $\begin{array}{l}\text { Pass through portal } \\
\text { High }\end{array}$ & 90 \\
\hline
\end{tabular}




\section{Comments for this Path Example}

- Obtaining the combination has some probability of detection but may not be in the same time sequence of the actual theft attempt

- The probability of detection at the portal may be much different if the adversary has significant authority at the facility or if they take advantage of their other job duties as with example 1 regarding the source transfer

- The adversary success could be enhanced by using force at the exit portal

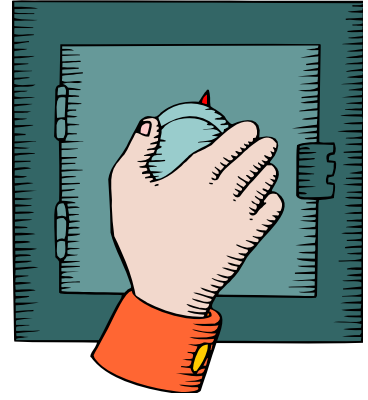




\section{Considerations when Developing Vulnerable Paths}

- Consistent tactics

- Using stealth or deceit after force may not be logical

- If tools are used, include the tool acquisition in the defeating the path measure

- If there have been serious questions about measure selection, do another path with the other most credible options

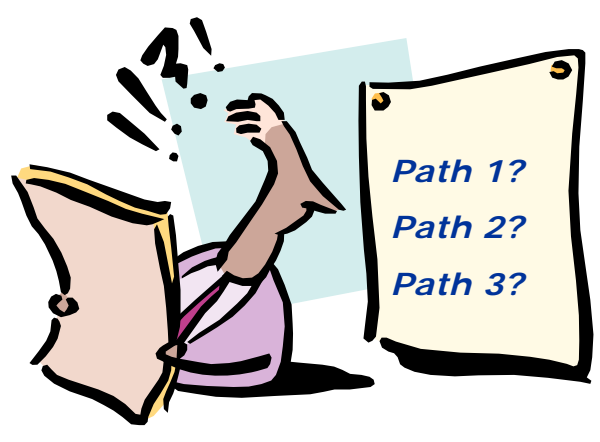




\section{Develop Most \\ Vulnerable Paths Summary}

- Develop most vulnerable paths by:

1. Selecting adversary path with least effective protection measures

2. Considering the time to defeat, the detection likelihood and the adversary capabilities

3. Selecting path measures based on logic and judgment

- Vulnerable paths are developed for each credible threat and target combination 


\section{Module Summary}

- Identify most vulnerable protection measures

- Develop most vulnerable paths for threat / target combination

- Estimate likelihood of detection and time for each path step

Questions or Comments?? 


\section{Exercise 7: Develop Most Vulnerable Paths}

- Utilize the worksheets completed in previous Exercise and develop:

- Three vulnerable paths

- Select the protection measures for the most advantage to the adversary, i.e., the measures with the lowest effectiveness

- Consider both the time to defeat and the detection likelihood and adversary capabilities, etc.

- Mark the measures selected on the tables

- Complete a path worksheet

- Present summary to the large group 


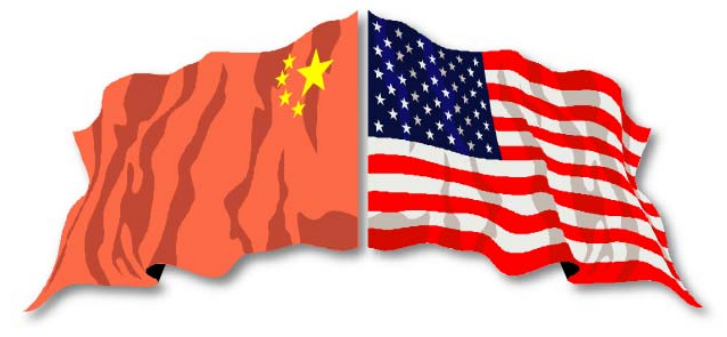

\section{Lecture 8}

\section{Evaluate Scenarios}

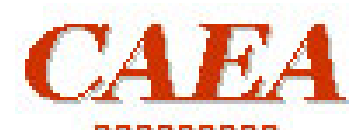

uadougado

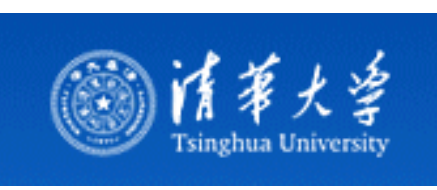

\begin{tabular}{|lll}
\hline & & $\begin{array}{l}\text { Sandia } \\
\text { National } \\
\text { Laboratories }\end{array}$
\end{tabular}
The

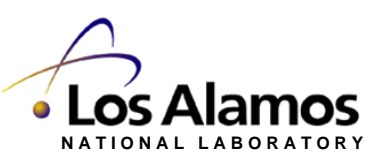




\section{Learning Objectives}

- Integrate response into the effectiveness analysis and derive $P_{1}$ and $P_{E}$

- Develop worst case scenarios

- Discriminate between continuous and discontinuous time sequences 


\section{Methodology for Evaluating the Protection System}

1. Develop a sequence of adversary actions for each target

2. Identify measures to protect against these actions

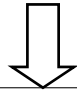

3. Characterize protection measures

4. Develop most vulnerable paths

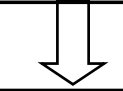

5. Develop worst case scenarios 


\section{Incorporate Response Measures}

- Using the most vulnerable path for each target and threat combination, determine the effectiveness of:

- The preventive I protective system

- The operational protective system

- The mitigating measures

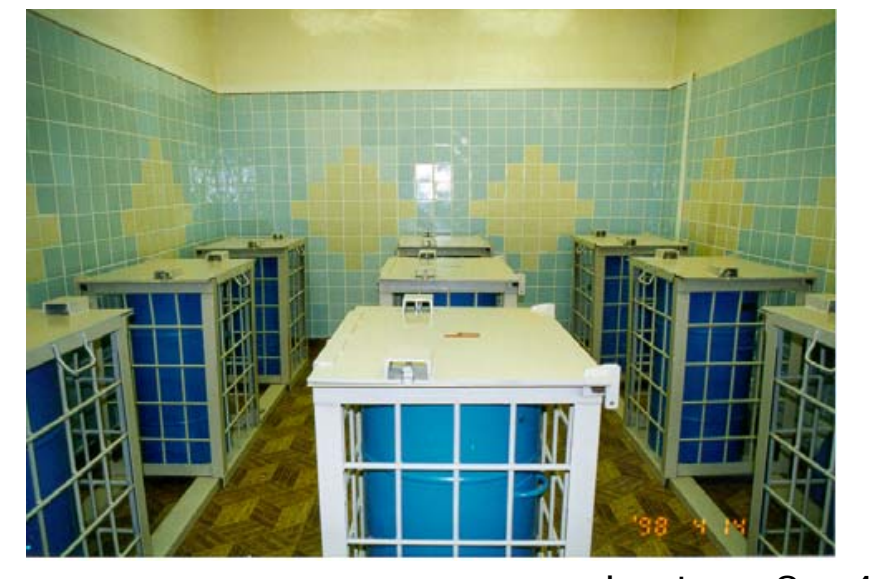




\section{Response}

- Depends on level and type of act

- Depends on where detection occurs in the sequence

- Response (prevent consequences):

- Security system

- Operations personnel and equipment

- Safety systems
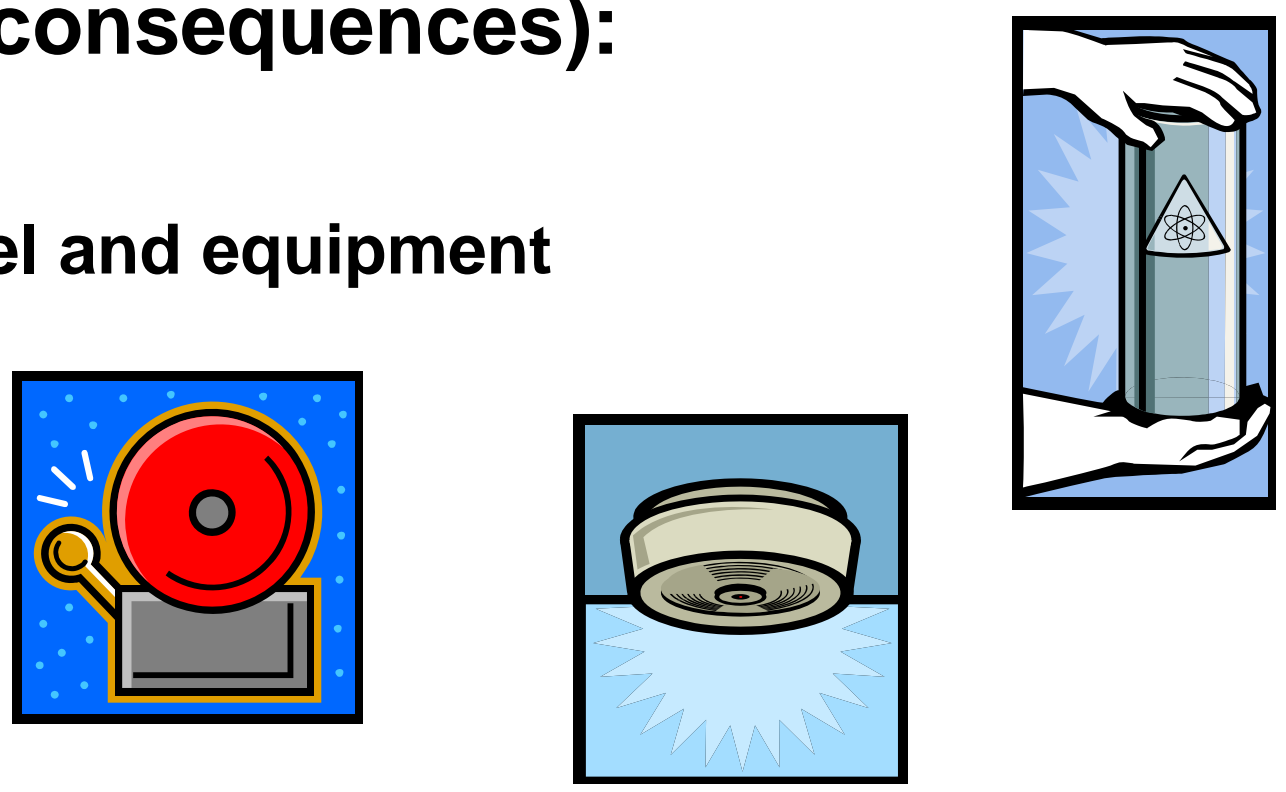


\section{Response (cont'd)}

- Mitigation (response when no timely detection occurs):

- Operational

- Emergency management system

- Safety systems

- Security forces assist in controlling situation

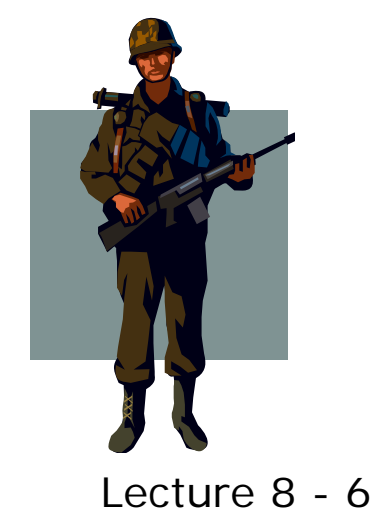




\section{Preventive/ Protective System Response}

- Determine the response type

- Employees and/or guards for non-violent insider

- Guards for violent insider

- Determine the time taken for the response

- Include all time elements

- Determine the ability of the response to stop the adversary

- Use testing results

- Data provided by studies and simulations

- Expert opinion 


\section{Large Group Discussion: Who will Respond?}

- Who will respond for the given situation:

- Procedural error (may be malevolent)?

- BMS alarm?

- Person seen taking material?

- Person discovered attempting to acquire combination?

- Person entering faulty data in MC\&A system?

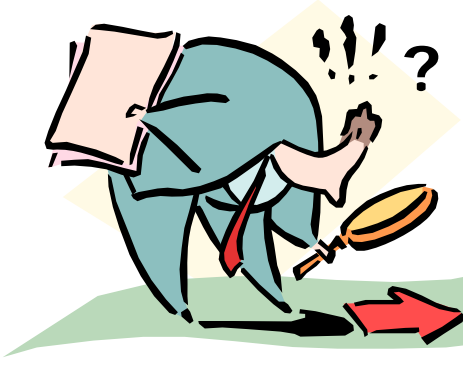




\section{URF Protective Force Response Table}

\begin{tabular}{|c|c|c|c|}
\hline Location & Number & $\begin{array}{l}\text { Number that } \\
\text { Respond }\end{array}$ & $\begin{array}{l}\text { Time to } \\
\text { Bunker }\end{array}$ \\
\hline CAS & 1 & 0 & N/A \\
\hline Quick response & 4 & 4 & \\
\hline PA Entry control & 2 & \multirow{2}{*}{\multicolumn{2}{|c|}{$\begin{array}{l}\text { How and why may the } \\
\text { times differ for insider } \\
\text { threats vs. outsider } \\
\text { threats? }\end{array}$}} \\
\hline Process ECP & 2 & & \\
\hline Inner patrol & 1 & 1 & \\
\hline Outer patrol & 1 & 1 & \\
\hline Towers & 4 & $4^{*}$ & N/A \\
\hline
\end{tabular}

*Remain in place but can engage from tower 


\section{Protective Force Response for I nsiders}

- Procedure may call for different deployments

- How does the response force know if it is an insider or outsider alarm?

- Outsider

- Respond to target location

- All responders available deploy

- Insider?

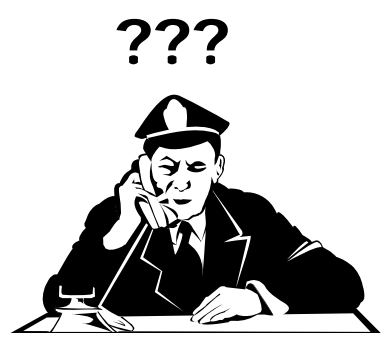

- Probably depends on insider action - if known

- Respond to exit points

- Respond to target location and perhaps miss the insider

- Only 1 to 2 responders needed to apprehend so full force can cover several points 


\section{Other Responders}

- Adjacent co-workers

- Response time is essentially zero

- Are they trained to respond in any way?

- Query each other about unusual activity?

- Physically restrain other workers?

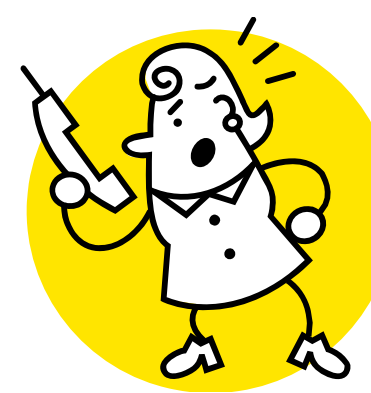

- If they are trained to contact the guards:

- How do they do this?

- How long does it take?

- Casual observers

- Probably only contact guards in exceptional cases

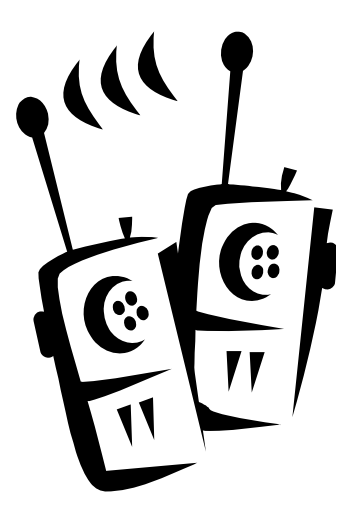




\section{Timeliness And Preventive Response}

- The initial response to a detected act is considered to be the same for both the continuous and discontinuous cases

- But in discontinuous cases where the person committing the act is not identified, the response is not considered to be effective 


\section{Time Dependence Of Measures}

- Continuous

- The classical physical protection "foot race"

- Time line analysis works well

- Discontinuous

- Time line is usually long but detection is often possible at multiple steps during the sequence

- If possible, the malevolent action detected can be repaired or undone

- Detection can be enhanced for steps after a detection that is attributed to malevolence but the perpetrator is not identified 


\section{Time Dependence Of Measures (cont'd)}

- Some actions are not related to time

- Authorized or undetected actions have no time line

- Examples will be given in the next several slides

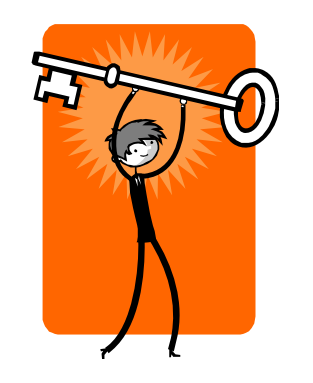




\section{Insider Continuous Sequence}

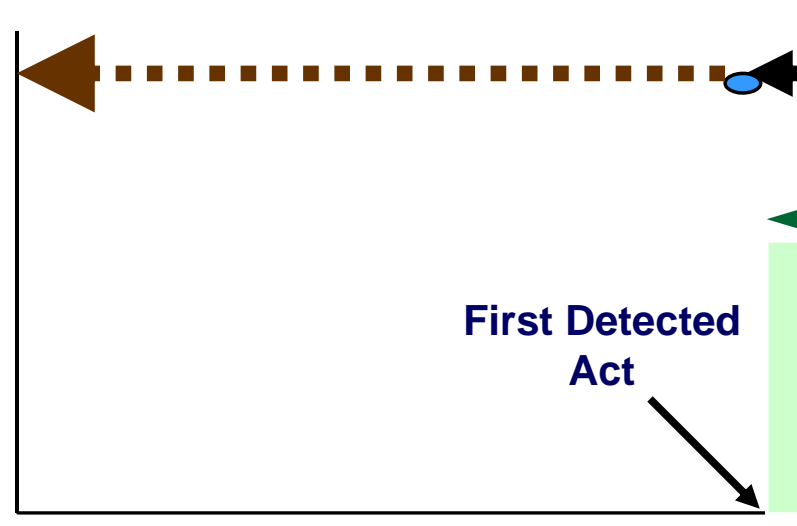

Insider Malevolent Task Time after detection

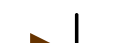

\section{System Time Required}

T1

Detect
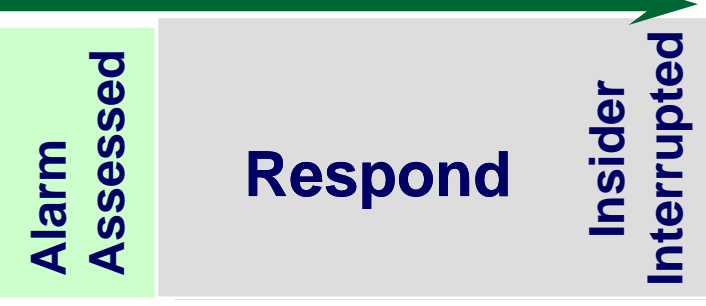

T3

T4

Time

System detection and response time must be less than insider malevolent task time after detection 


\section{Insider Discontinuous Sequence Example}

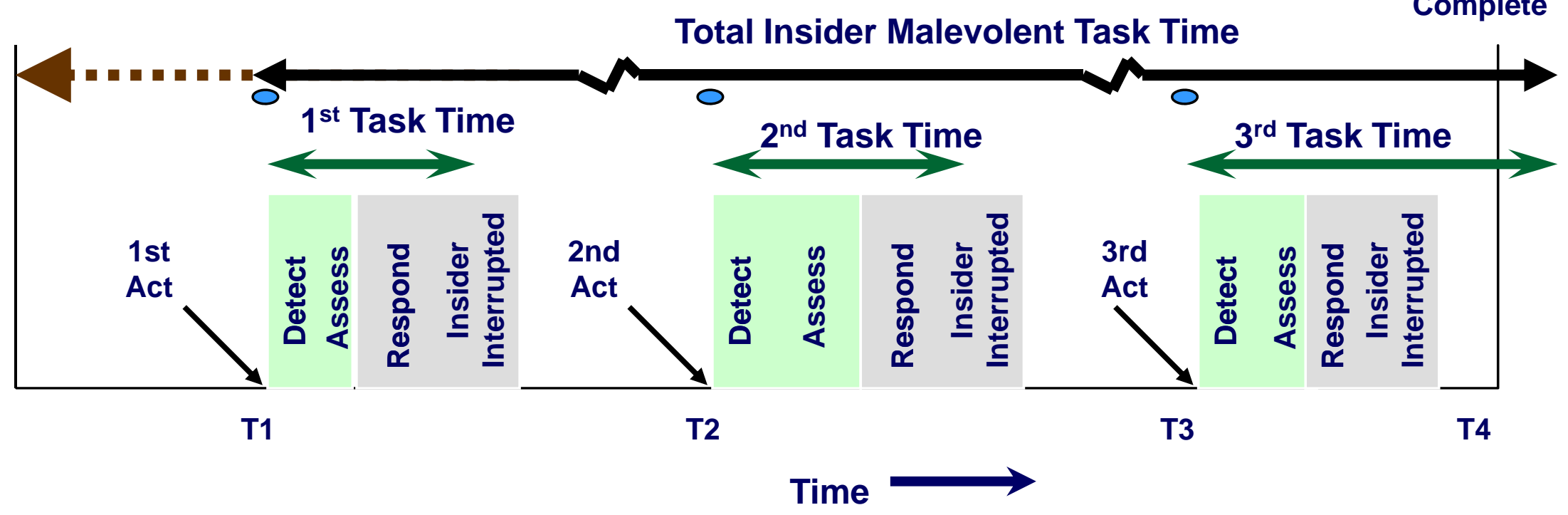

System detection and response time must be less than segmented insider malevolent task time after detection but detection possibilities at T1, T2, T3 may not be complementary as they are in the continuous sequence 


\section{Two Example Scenarios}

1. Theft from the bunker - The HP Tech example already started

- We will work example 1 as a continuous time sequence since there are only a few actions to detect

2. Theft from the bunker - The HP Tech example already started

- We will work example 2 as a discontinuous time sequence since the combination can be acquired at any time 


\section{Estimate Security System Effectiveness Process}

1. Derive cumulative detection likelihood

2. List cumulative task times

3. Use the total response time to calculate the point in time where response must start if the malevolent action is to be stopped

4. Ascertain the likelihood of detection at or before this point

- This is the measure of system effectiveness used 


\section{Example 1 - Possibly the Most Vulnerable Path For HP Tech/ Bunker}

\begin{tabular}{|c|l|l|l|}
\hline Step & Action & $\begin{array}{l}\text { Likelihood of } \\
\text { Detection }\end{array}$ & Time (Sec) \\
\hline 1 & Enter protected area normally & Very Low & $\begin{array}{l}\text { N/A } \\
\text { etections }\end{array}$ \\
\hline 2 & Enter bunker normally & $\begin{array}{l}\text { Very Lovese } \\
\text { of thes }\end{array}$ & N/A \\
\hline 3 & $\begin{array}{l}\text { Take package and hide unorea } \\
\text { coat }\end{array}$ & High & 60 \\
\hline 4 & $\begin{array}{l}\text { Walkonfof bunker normally } \\
\text { the }\end{array}$ & High & 60 \\
\hline 5 & $\begin{array}{l}\text { Walk normally to fence and throw } \\
\text { package over }\end{array}$ & Medium & 30 \\
\hline
\end{tabular}




\section{Questions about the Responder for these Detection Locations?}

- In the Bunker

- Other workers?

- What is the response time if they detect?

- Does the adversary stop if detected?

- Do they stop the action or call the guards?

- Crossing the PA

- Other workers? Response time?

- Guards in towers? Rapid response?

- Throwing package across the perimeter

- Other workers? Response time?

- Guards in towers? Rapid response?

OR

- Transferring package out as an americium test source

- Other workers? Where and how does the assessment occur that initiates the response? Or does it? 


\section{Example 1: Response Time Table for an Adjacent Co-worker/ Guards}

\begin{tabular}{|c|c|c|}
\hline Response Action & \multicolumn{2}{|c|}{$\begin{array}{l}\text { Time taken (seconds) } \\
\quad \operatorname{Min} \quad \operatorname{Max}\end{array}$} \\
\hline $\begin{array}{l}\text { Co-worker identify malevolent action - Sees } \\
\text { material removal - assume detection at this } \\
\text { point }\end{array}$ & 0 & 60 \\
\hline Communicate to guards & 60 & 180 \\
\hline Guard communication time & \multicolumn{2}{|c|}{30} \\
\hline Response prep time & \multicolumn{2}{|c|}{50} \\
\hline Travel & 0 to ECPs & 30 to Bunker \\
\hline Intervene & $\mathbf{0}$ & 60 \\
\hline Total & 140 & 380 \\
\hline
\end{tabular}

This example has several uncertainties - Who? Where? When? 


\section{Insider Continuous Timeline}

If Response Force Time is 140 to $380 \mathrm{sec}-\mathrm{P}_{\mathrm{I}}=$ zero BUT if we assume the Tower Guard could respond quickly $-P_{\mathbf{I}}=\mathbf{M}$

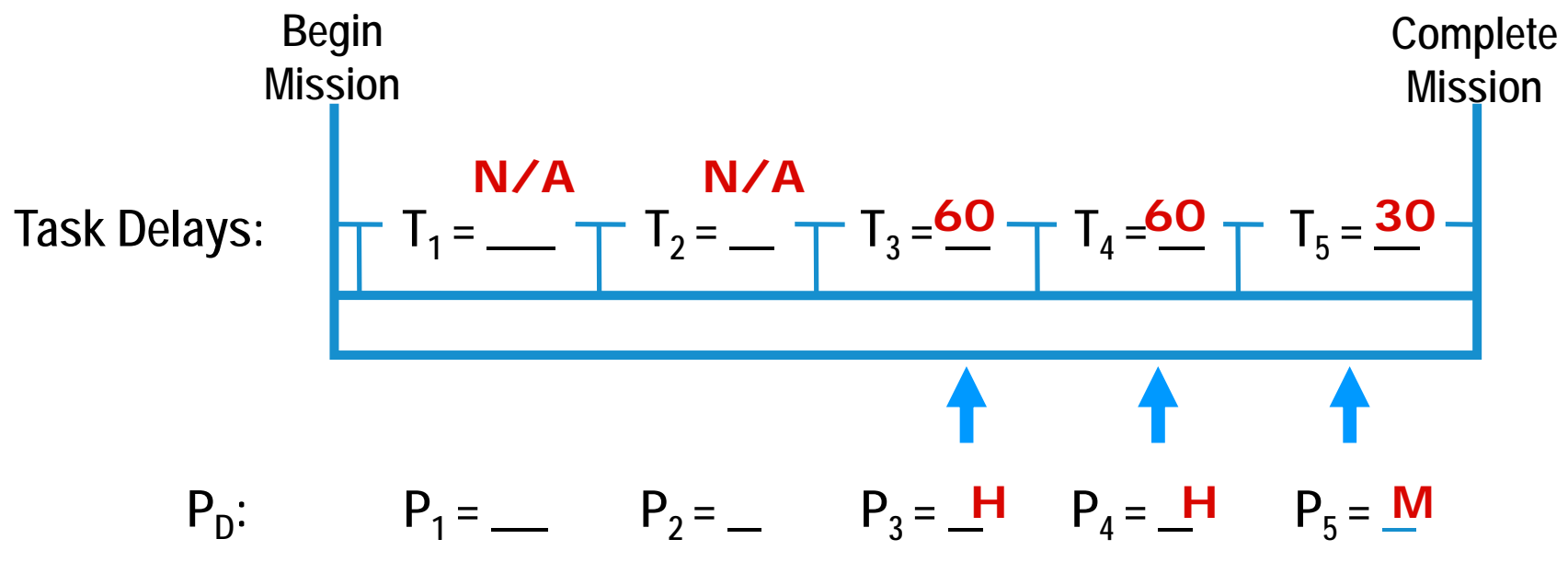

Time Remaining: $\quad \mathrm{TR}_{1}=\ldots \quad \mathrm{TR}_{2}=\ldots \quad \mathrm{TR}_{3}=\underline{120} \mathrm{TR}_{4}=\underline{60} \quad \mathrm{TR}_{5}=\underline{15}$

Timely Detection?

NO 


\section{Second Example Scenario}

1. Theft from the bunker - The HP Tech example already started

- We will work example 1 as a continuous time sequence since there are only a few actions to detect

2. Theft from the bunker - The HP Tech example already started

- We will work example 2 as a discontinuous time sequence since the combination can be acquired at any time 


\section{Example 2 - Possibly the Most Vulnerable Path For HP Tech/ Bunker}

\begin{tabular}{|c|c|c|c|}
\hline Step & Action & $\begin{array}{l}\text { Likelihood of } \\
\text { Detection }\end{array}$ & Time (sec) \\
\hline 1 & $\begin{array}{l}\text { Enter protected area } \\
\text { normally }\end{array}$ & Very Low & N/A detectio \\
\hline 2 & Obtain combination & Medium of the & $?$ \\
\hline $2 a$ & $\begin{array}{l}\text { Enter bunker using } \\
\text { combination }\end{array}$ & $\begin{array}{l}\text { Very Low until the door is } \\
\text { opened then } \mathrm{H}\end{array}$ & 60 \\
\hline $\begin{array}{c}3 \\
\text { Who }\end{array}$ & $\begin{array}{l}\text { pht though cage and } \\
\text { product package and take } \\
\text { package }\end{array}$ & Low & 90 \\
\hline 4 & $\begin{array}{l}\text { Take package, hide under } \\
\text { coat and cross the PA }\end{array}$ & Medium & 60 \\
\hline 5 & Pass through portal & High & 90 \\
\hline
\end{tabular}




\section{Questions about the Responder for these Detection Locations?}

- Getting the combination

- General observation

- What is the response time if they detect?

- Does the adversary stop if detected?

- Entering Bunker

- BMS alarm - guards

- General observation

- Leaving the Bunker

- General observation

- What is the response time if they detect?

- Does the adversary stop if detected?

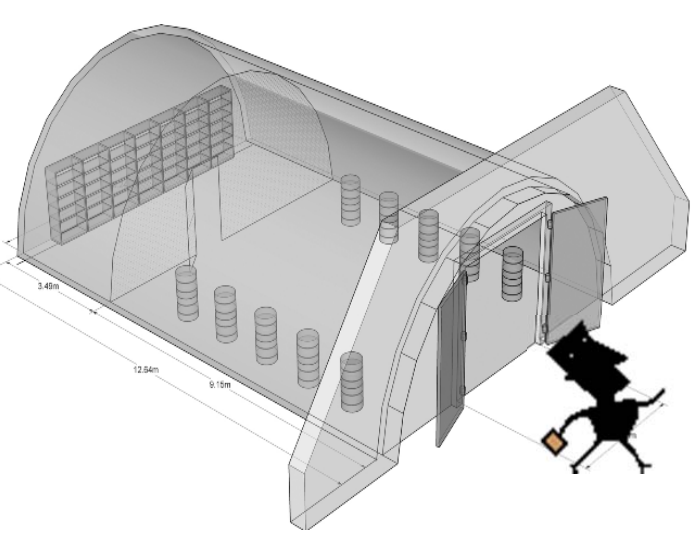

- Do they stop the action or call the guards? 


\section{Questions about the Responder for these Detection Locations? (cont'd)}

- Crossing the PA

- Other workers? Response time?

- Guards in towers? Rapid response?

- Throwing package across the perimeter

- Other workers? Response time?

- Guards in towers? Rapid response?

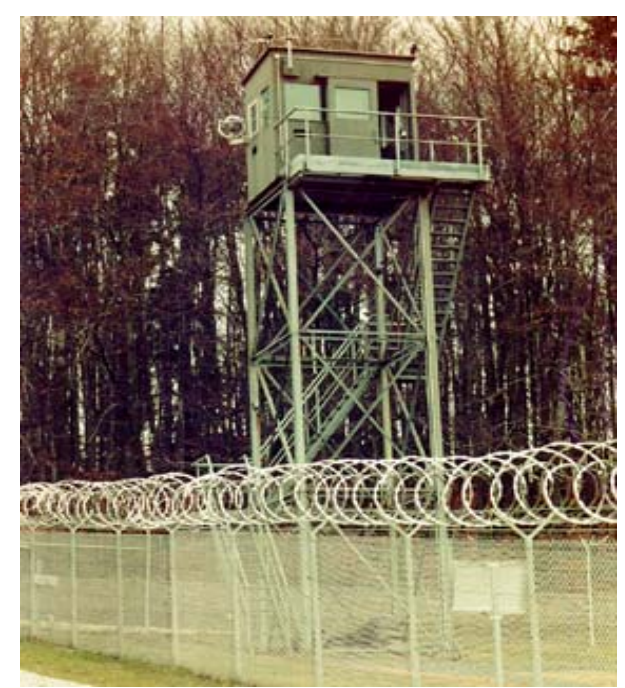




\section{Example Response Time Table for Guards - Bunker Example 2}

\begin{tabular}{|c|c|c|}
\hline Response Action & \multicolumn{2}{|c|}{$\begin{array}{l}\text { Time taken (seconds) } \\
\quad \text { Min } \quad \text { Max }\end{array}$} \\
\hline $\begin{array}{l}\text { Co-worker identify malevolent action - Sees } \\
\text { material removal }\end{array}$ & \multicolumn{2}{|c|}{ Not likely to be detected } \\
\hline Communicate to guards - BMS alarm & 0 & 10 \\
\hline Assessment time by inner patrol & 20 & 60 \\
\hline Guard communication time & \multicolumn{2}{|c|}{30} \\
\hline QRT prep time & \multicolumn{2}{|c|}{50} \\
\hline Travel & 0 to ECPs & 30 to Bunker \\
\hline Intervene & 0 & 60 \\
\hline Total & 100 & 240 \\
\hline
\end{tabular}

This example also has several uncertainties - Who? Where? When? 


\section{Bunker Example 2 Time Sequence}

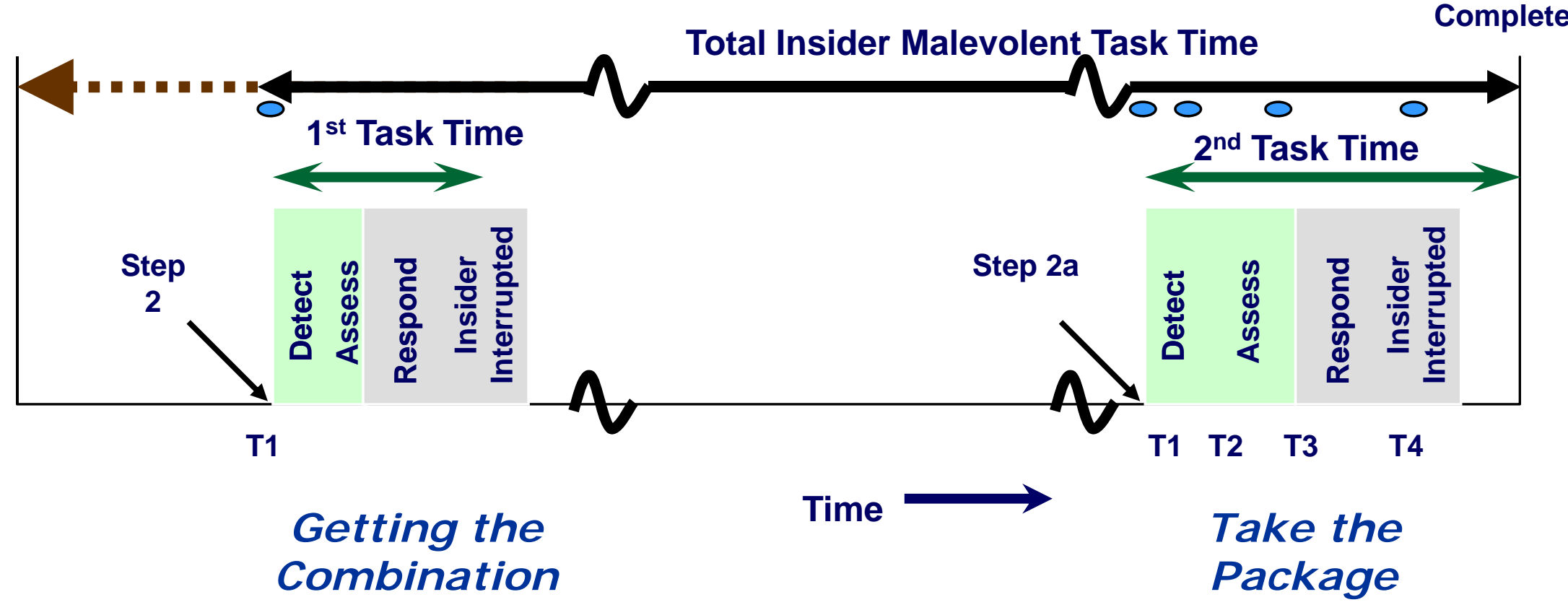

- Detection points 


\section{Bunker Example 2 Timeline}

Time is not relevant in this phase of the action $P_{1} \& P_{2}$ are NOT combined with the remaining events

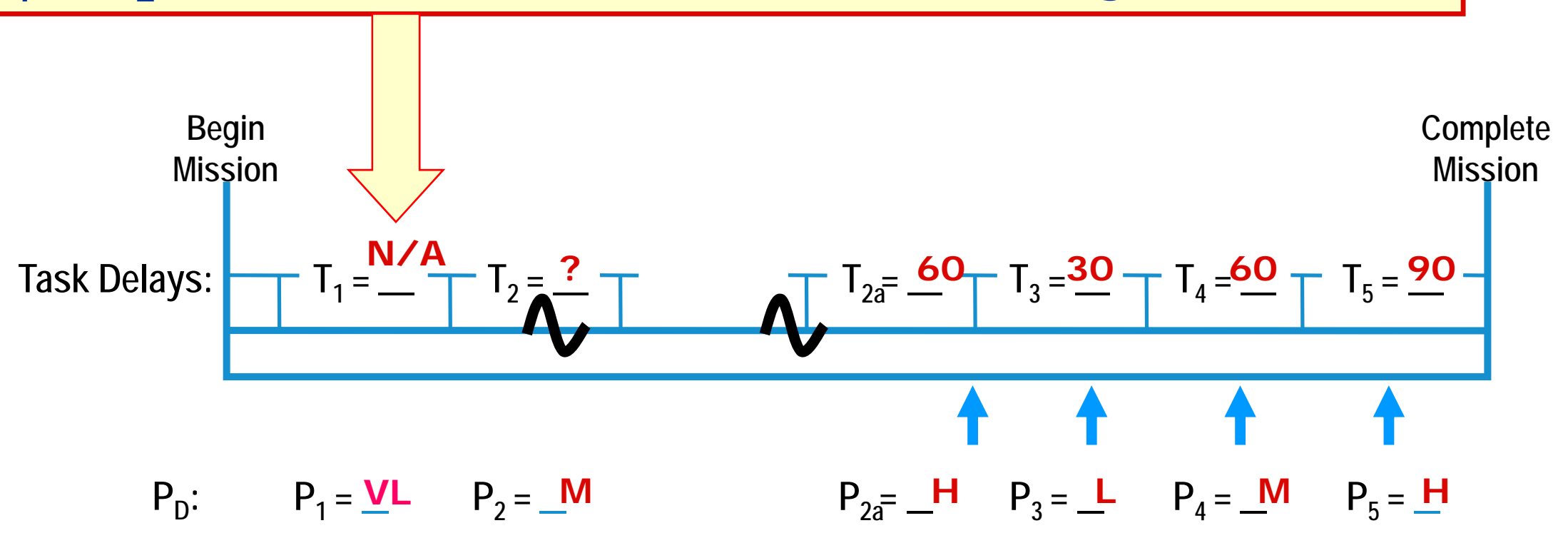

Time Remaining: $\quad \mathbf{T R}_{1}=$ $\mathbf{T R}_{2}=$ If the response time is $100 \mathrm{sec}$ Time Detection?

If the response time is $240 \mathrm{sec}$ November $200 /$

$$
\begin{aligned}
& \mathrm{TR}_{2 \mathrm{a}}=\underline{180} \mathrm{TR}_{3}=\underline{165} \mathrm{TR}_{4}=\underline{120} \mathrm{TR}_{5}=\underline{45}
\end{aligned}
$$

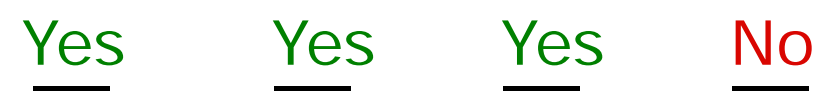

$$
\begin{aligned}
& \text { No }
\end{aligned}
$$




\section{Suggested Simple Rules For Deriving Cumulative Likelihood - Example Table}

\begin{tabular}{|c|c|}
\hline Measures in Sequence & Cumulative Likelihood \\
\hline $\mathrm{VL} \& \mathrm{VL}$ & $\mathrm{VL}$ \\
\hline VL \& VL \& VL & L \\
\hline VL\&L & L \\
\hline VL \& VL \& L & L \\
\hline L\& \& & M \\
\hline L\& \& \& L & M \\
\hline L\& M & M \\
\hline L\&L\&M & H \\
\hline$M \& M$ & H \\
\hline L\&H & $\mathrm{H}$ \\
\hline$M \& H$ & $\mathrm{H}$ \\
\hline$M \& M \& H$ & $\mathrm{VH}$ \\
\hline$H \& H$ & VH \\
\hline
\end{tabular}




\section{Bunker Example 2 Timeline}
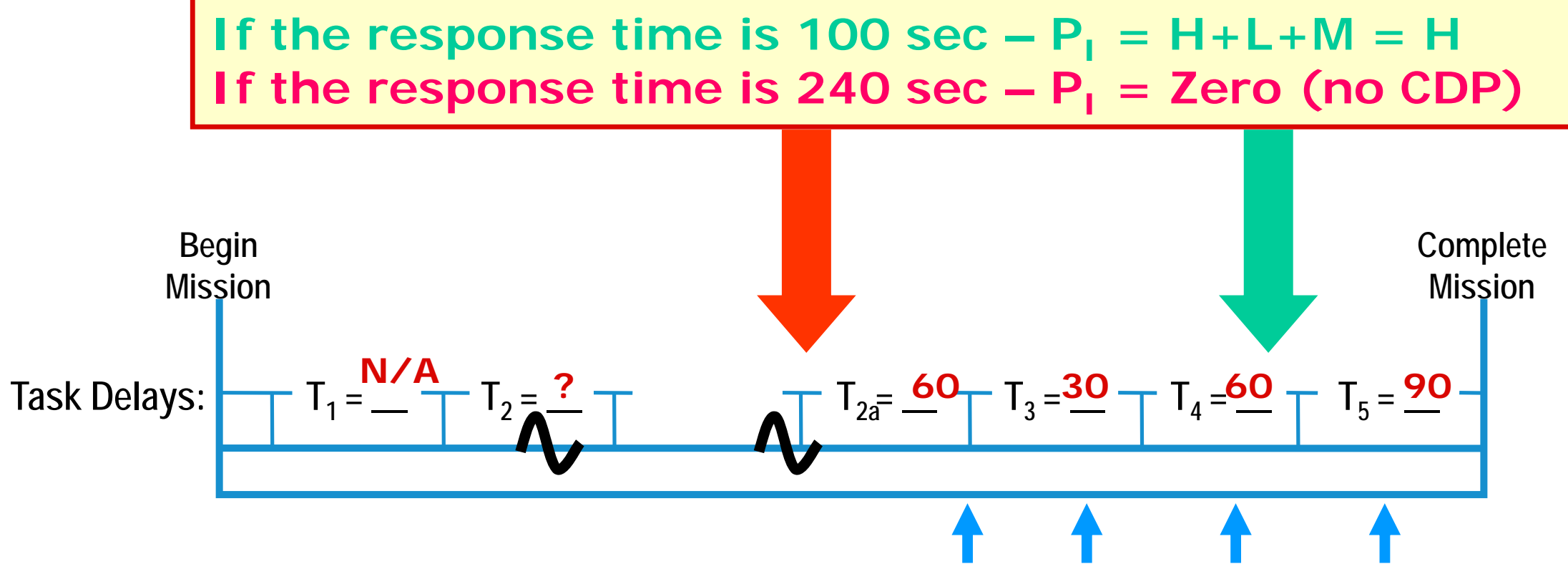

$$
\mathbf{P}_{\mathrm{D}^{\prime}} \quad \mathbf{P}_{1}=\mathbf{P}_{2}=\underline{M} \quad \mathbf{P}_{2 \mathrm{a}}=\mathrm{P}_{3}=\underline{\mathrm{L}} \quad \mathbf{P}_{4}=\underline{M} \quad \mathbf{P}_{5}=\underline{H}
$$

Time Remaining: $\quad \mathbf{T R}_{1}=$ $\mathbf{T R}_{\mathbf{2}}=$

If the response time is $100 \mathrm{sec}$

Time Detection?

If the response time is $240 \mathrm{sec}$ November 2001

$$
\begin{gathered}
\mathbf{T R}_{\mathbf{2 a}}=\frac{180}{\mathbf{R}_{\mathbf{3}}=}=\frac{165}{\mathbf{T R}_{\mathbf{4}}}=\underline{\underline{\mathbf{1 2 0}}} \mathbf{T R}_{\mathbf{5}}=\underline{\mathbf{4 5}} \\
\frac{\text { Yes }}{\text { No }} \quad \underline{\text { Yes }} \quad \underline{\text { Yes }} \quad \underline{\text { No }}
\end{gathered}
$$




\section{$\mathbf{P}_{\mathrm{N}}$ Recommendations for I nsiders}

- If an insider is not violent

- Assume $\mathrm{P}_{\mathrm{N}}=\mathbf{1 . 0}$

- If an insider is violent but does not have a weapon, use estimation curve and give the advantage to the guard

$$
\begin{aligned}
& \text { - } 1: 1 P_{N}=0.7 \\
& \text { - } 2: 1 P_{N}=1.0
\end{aligned}
$$

- If the insider has a weapon use estimation curve with adversary advantage
- $1: 1 \mathrm{P}_{\mathrm{N}}=0.15$
- $2: 1 \mathrm{P}_{\mathrm{N}}=0.85$

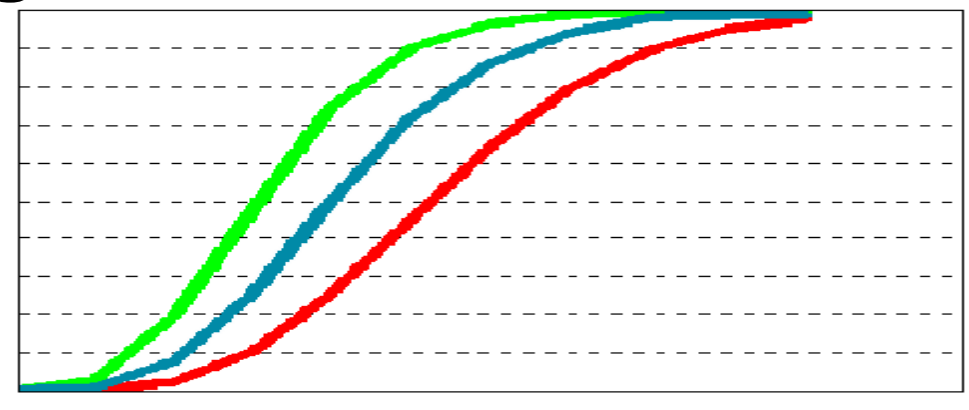




\section{Overall System Effectiveness $\left(\mathbf{P}_{\mathrm{E}}\right)$}

- Use same considerations as in outsider

- $P_{E}=P_{1}{ }^{*} P_{N}$

- Must consider Critical Detection Point

- Since the process combines $P_{1}{ }^{*} P_{N}$ we need to identify how to combine numbers and qualitative designators, for example:

- $\mathrm{VH}=0.9-1.0$

- $\mathrm{H}=0.7-0.9$

- $M=0.3-0.7$

- $L=0.1-0.3$

- $\mathrm{VL}=0.0-0.1$ 


\section{Bunker System Effectiveness $\left(P_{E}\right)$ - Example 1}

- Continuous time sequence

- $\mathrm{P}_{\mathrm{E}}=\mathrm{P}_{\mathrm{I}}{ }^{*} \mathrm{P}_{\mathrm{N}}=0.0$ * $\mathrm{P}_{\mathrm{N}}=$ Zero for RFT $>120 \mathrm{sec}$

- $P_{E}=P_{1} * P_{N}=\operatorname{Med}(.5) * 1.0=0.5(M e d)$ for tower guard 


\section{Bunker System Effectiveness $\left(P_{E}\right)$ - Example 2}

- Example 2 - without considering obtaining the combination

- $\mathrm{P}_{\mathrm{E}}=\mathrm{P}_{\mathrm{I}}{ }^{*} \mathrm{P}_{\mathrm{N}}=\operatorname{High}(.8) * 1.0=0.8(\mathrm{High})$ for RFT $=100$

- $P_{E}=P_{1} * P_{N}=0.0 * 1.0=$ Zero for $R F T=240$

- If the adversary is violent at the portal (1:1)

- $P_{E}=P_{1} * P_{N}=\operatorname{High}(.8) * 0.7=0.56(\mathrm{Med})$ for $R F T=100$ 


\section{Worst Case Considerations}

- We may have identified the most vulnerable paths but are these necessarily the paths for the worst cases after we add response considerations?

- Can the insider delay or eliminate the response?

- Can the insider prevent the alarms from being generated or communicated?

- Can the insider utilize authority to reduce assessment effectiveness of an action?

- Can diversionary actions be used to assist in successful scenario completion?

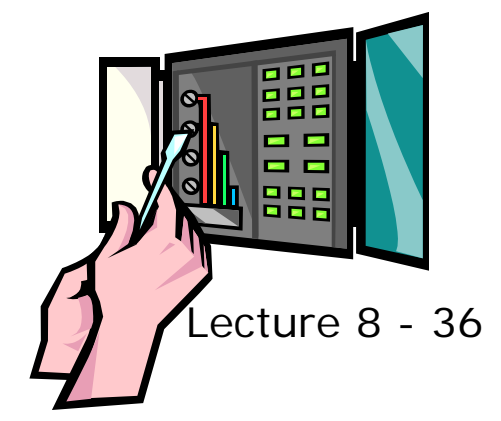




\section{Possible I mpacts on $\mathbf{P}_{\mathbf{N}}$}

- A non-violent insider won't actively interact forcefully with the guards BUT

- Can he divert them?

- Delay them?

- A violent insider has the advantage over the guards in the early stages of a confrontation - could eliminate at least one guard without generating an alarm

- This confrontation could be at the end of the path - as in example 2 at the portal 


\section{Developing Worst Case Scenarios Summary}

- Distinguish between continuous and discontinuous insider threat time sequences

- Use response time to calculate where response must start to stop a continuous malevolent event

- Use the standard timeline for continuous scenarios

- Use segmented analysis for discontinuous activities

- Review multiple scenarios and be ready to select more than one worst case

- It may be worth investing in upgrades and/or instituting procedures that address multiple scenarios (threats) 


\section{Module Summary}

- Integrate response into the effectiveness analysis and derive $P_{1}$ and $P_{E}$

- Develop worst case scenarios

- Discriminate between continuous and discontinuous time sequences

Questions or Comments?? 


\section{Exercise 8: Estimate System Effectiveness $\left(P_{E}\right)$}

- Complete the tables developed in previous Exercises describing the most vulnerable paths:

- Determine the response type

- Determine the time taken for the response

- Determine the ability of the response to stop the adversary

- Derive a $P_{E}$ for all three vulnerable paths giving three potential worst case scenarios

- Do you think these are the worst case scenarios?

- Present summary to the large group 


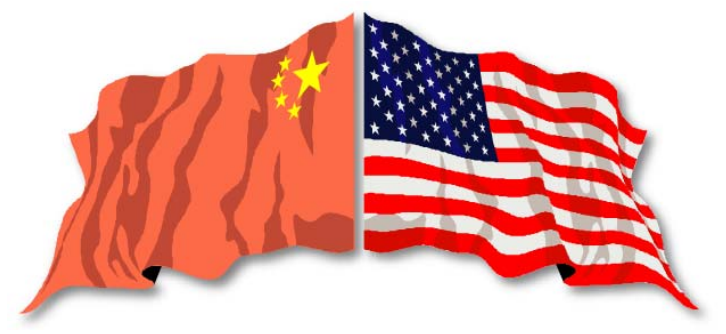

\section{Lecture 9}

\section{Upgrades Analysis}

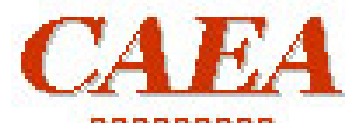

adougadou

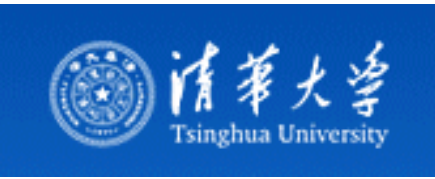

The 


\section{Student Learning Objectives}

- In this module we will:

- Discuss the importance of, and a process for, upgrade selection

- Discuss examples of effective system enhancements 


\section{I dentifying Effective Upgrades}

- What system strengths and weaknesses exist for the spectrum and threats

- Which safeguards upgrades could potentially enhance protection

- How to package the alternative for meaningful analysis of their benefits

- What are the costs and operational impacts of these upgrades packages

These should be considered for all threat/target combinations and facilities within the site 


\section{I dentifying Effective Upgrades, con't}

It I I mportant Not to Focus Exclusively on "Worst Case" Results

- Consider the entire adversary spectrum

- Examine strategies or scenarios that are tied with or close to the optimal scenario

- Perform defense-in-depth analysis to identify critical components 


\section{I dentifying Effective Upgrades - 2}

- What system strengths and weaknesses exist for the spectrum of threats

- Which safeguards upgrades could potentially enhance protection

- How to package the alternatives for meaningful analysis of their benefits

-What are the costs and operational impacts of these upgrades packages 


\section{Examining the Evaluation Results}

Facility layer

Weaknesses

Target

Vault-shelf

Take can/material

MAA

Emergency exit

PA

Evacuation

Bump and throw

Vehicle portal

Shield in vehicle

Piggyback

Disguise as sample / waste 


\section{Potential Upgrades}

Facility layer

Target

Vault -shelf

MAA

Emergency exit

PA

Vehicle portal
Weaknesses

Take can I material

Bump and throw

Evacuation

Shield in vehicle

Piggyback

Disguise as sample
Potential upgrades

Enhanced 2 person rule - Add cages

CCTV

Emergency Inventory

Better criticality

alarm

Vehicle search

Cart / carrier search

Verify transfer 


\section{Upgrades Will Vary in Their Benefits and Ease of I mplementation}

- Some vulnerabilities are easy to deal with via "quick fixes"

- Combinations of hardware and procedural upgrades are often needed

- Procedural upgrades are often less costly and easier to implement

- Hardware fixes can be expensive and difficult to implement

- An upgrade to deal with a given vulnerability may introduce a new one

Careful analysis should be performed prior to implementing any proposed upgrades 


\section{I dentifying Effective Upgrades - 3}

-What system strengths and weaknesses exist for the spectrum of threats

- Which safeguards upgrades could potentially enhance protection

- How to package the alternatives for meaningful analysis of their benefits

-What are the costs and operational impacts of these upgrades packages 


\section{I dentifying Effective Upgrades - 3, con't}

Upgrades can be organized by theft stage addressed and ease of implementation

Theft Stage

e.g., SNM Acquisition

MAA Removal

PA Removal

Ease of Implementation

e.g., Quick Fix

Moderately Expensive

Most Expensive 


\section{A Matrix Helps Package Potential Upgrades}

\begin{tabular}{|c|c|c|c|c|c|}
\hline Potential upgrades & $\begin{array}{c}1 \\
\text { Quick } \\
\text { Fixes }\end{array}$ & $\begin{array}{c}2 \\
\text { Vault } \\
\text { cages }\end{array}$ & $\begin{array}{c}3 \\
\text { Exit } \\
\text { CCTV }\end{array}$ & $\begin{array}{c}4 \\
\text { Package } \\
\text { monitoring }\end{array}$ & $\begin{array}{c}5 \\
\text { All } \\
\text { upgrades }\end{array}$ \\
\hline Add cages & & $x$ & & & $x$ \\
\hline Better 2-person rule & $x$ & $x$ & $\mathbf{x}$ & $x$ & $x$ \\
\hline $\begin{array}{l}\text { Escort maintenance in } \\
\text { vault }\end{array}$ & $x$ & $x$ & $x$ & $x$ & $x$ \\
\hline HP search of SNM & & & & $x$ & $x$ \\
\hline $\begin{array}{l}\text { Evacuation drill } \\
\text { observers }\end{array}$ & $x$ & $x$ & $x$ & $x$ & $x$ \\
\hline CCTV & & & $x$ & & $x$ \\
\hline Emergency inventory & $x$ & $x$ & $x$ & $x$ & $x$ \\
\hline $\begin{array}{l}\text { X-ray package search at } \\
\text { PA }\end{array}$ & & & & $x$ & $x$ \\
\hline Cargo search & & & & $x$ & $x$ \\
\hline Verify transfers at PA & $x$ & $x$ & $\mathbf{x}$ & $x$ & $x$ \\
\hline
\end{tabular}




\section{I dentifying Effective Upgrades - 3, con't}

- Identify Potential Upgrade Packages

- Repeat Analysis With Upgrades in Place

- If Upgrades Achieve Acceptable Risk, Conduct Cost-Benefit Analysis

- If Upgrades Do Not Achieve Acceptable Risk, Identify Additional Upgrades and Repeat

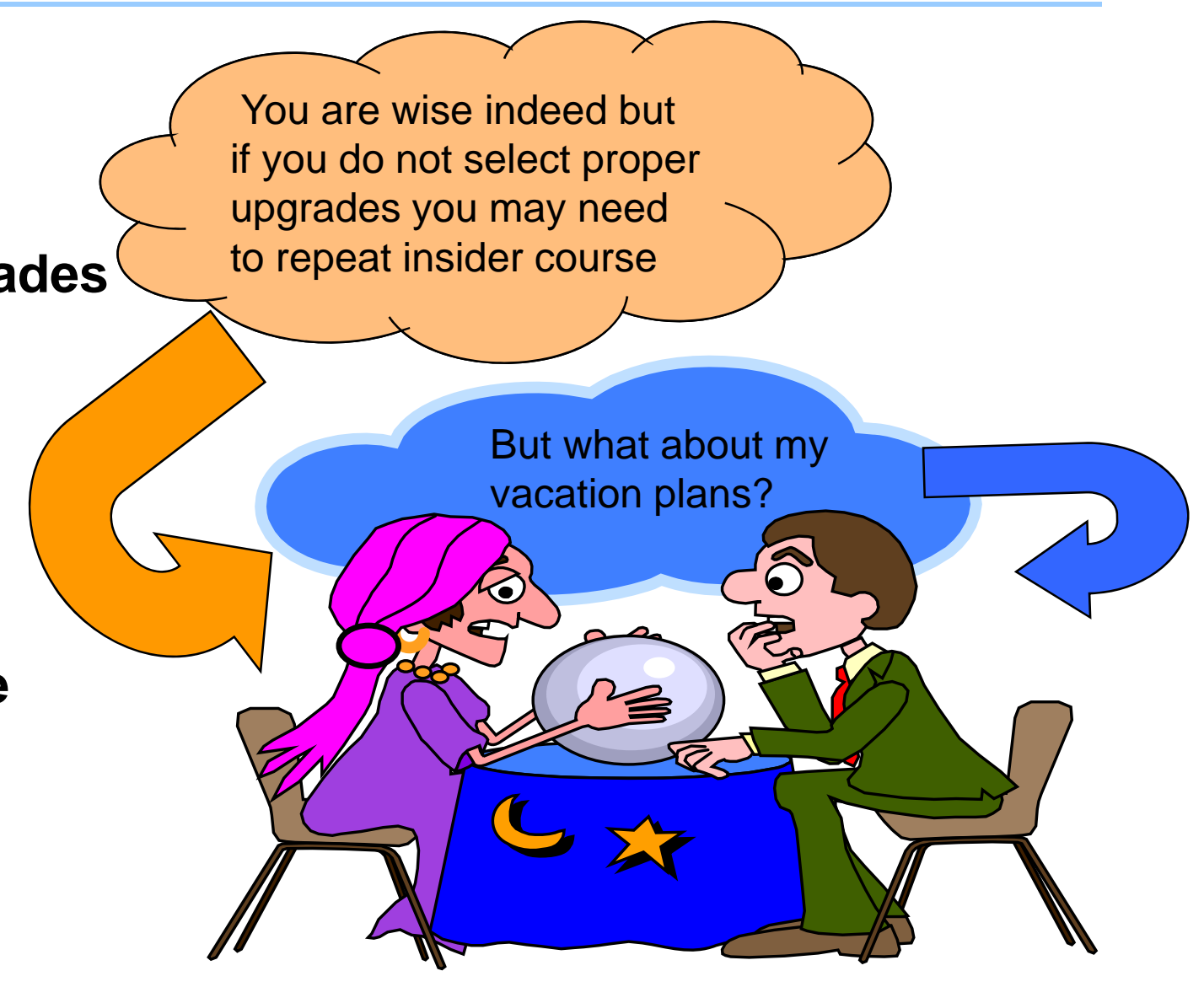




\section{I dentifying Effective Upgrades - 4}

-What system strengths and weaknesses exist for the spectrum of threats

- Which safeguards upgrades could potentially enhance protection

- How to package the alternatives for meaningful analysis of their benefits

- What are the costs and operational impacts of these upgrades packages 


\section{We Need to Consider the Full Range of "Costs"of Upgrades}

\begin{tabular}{|l|l|}
\hline Onetime costs & $\begin{array}{l}\text { Design } \\
\text { Equipment } \\
\text { Installation }\end{array}$ \\
\hline Recurring costs & Operation \\
& Maintenance \\
& Repair \\
& Replacement \\
\hline Non-monetary costs & Production impact \\
& Health and safety \\
& Employee morale \\
& Aesthetics \\
\hline
\end{tabular}




\section{Upgrade Examples}

\begin{tabular}{|l|l|l|}
\hline Tie-Downs & $\begin{array}{l}\text { Delay increasing adversary task } \\
\text { time }\end{array}$ \\
\hline Key Security & $\begin{array}{l}\text { Increases detection of unauthorized } \\
\text { access to keys }\end{array}$ \\
\hline Two-person rule & $\begin{array}{l}\text { Increases surveillance of material } \\
\text { and early detection } \\
\text { Devices }\end{array}$ & $\begin{array}{l}\text { Increases material control and can } \\
\text { aid in detection }\end{array}$ \\
\hline Portal monitoring & Increases detection and delay & \\
\hline
\end{tabular}




\section{Upgrade Examples}

\begin{tabular}{|l|l|l|}
\hline Data Accountability & $\begin{array}{l}\text { Increases detection of diversion } \\
\text { activity }\end{array}$ \\
\hline Inventory Control & $\begin{array}{l}\text { Increasing inventories and/or } \\
\text { adding bar coding devices } \\
\text { increases detection of theft and } \\
\text { diversion }\end{array}$ & $\begin{array}{l}\text { Increases accuracy of } \\
\text { increasements and accounting data, } \\
\text { increases detection of diversion }\end{array}$ \\
\hline $\begin{array}{l}\text { Daily administrative } \\
\text { checks }\end{array}$ & $\begin{array}{l}\text { Increases detection of theft or } \\
\text { diversion }\end{array}$ \\
\hline Process alarms & Increases detection of diversion & \\
\hline
\end{tabular}




\section{Upgrade Examples}

\begin{tabular}{|l|l|l|}
\hline $\begin{array}{l}\text { Assessments and } \\
\text { quality assurance }\end{array}$ & $\begin{array}{l}\text { Verifies accuracy of data and } \\
\text { increases detection of diversion and } \\
\text { protracted theft }\end{array}$ \\
\hline $\begin{array}{l}\text { Human Reliability } \\
\text { Program }\end{array}$ & $\begin{array}{l}\text { Increases detection of insider } \\
\text { adversaries }\end{array}$ \\
\hline $\begin{array}{l}\text { Balance Magnetic } \\
\text { Sensors }\end{array}$ & $\begin{array}{l}\text { Increases detection of adversary } \\
\text { malevolent actions }\end{array}$ \\
\hline $\begin{array}{l}\text { Electronic access } \\
\text { control }\end{array}$ & $\begin{array}{l}\text { Increases material control and } \\
\text { surveillance capabilities aids } \\
\text { detection }\end{array}$ \\
\hline Surveillance cameras & $\begin{array}{l}\text { Increases material control and } \\
\text { surveillance capabilities aids } \\
\text { detection }\end{array}$ & \\
\hline
\end{tabular}




\section{Summary}

- Questions and Answers

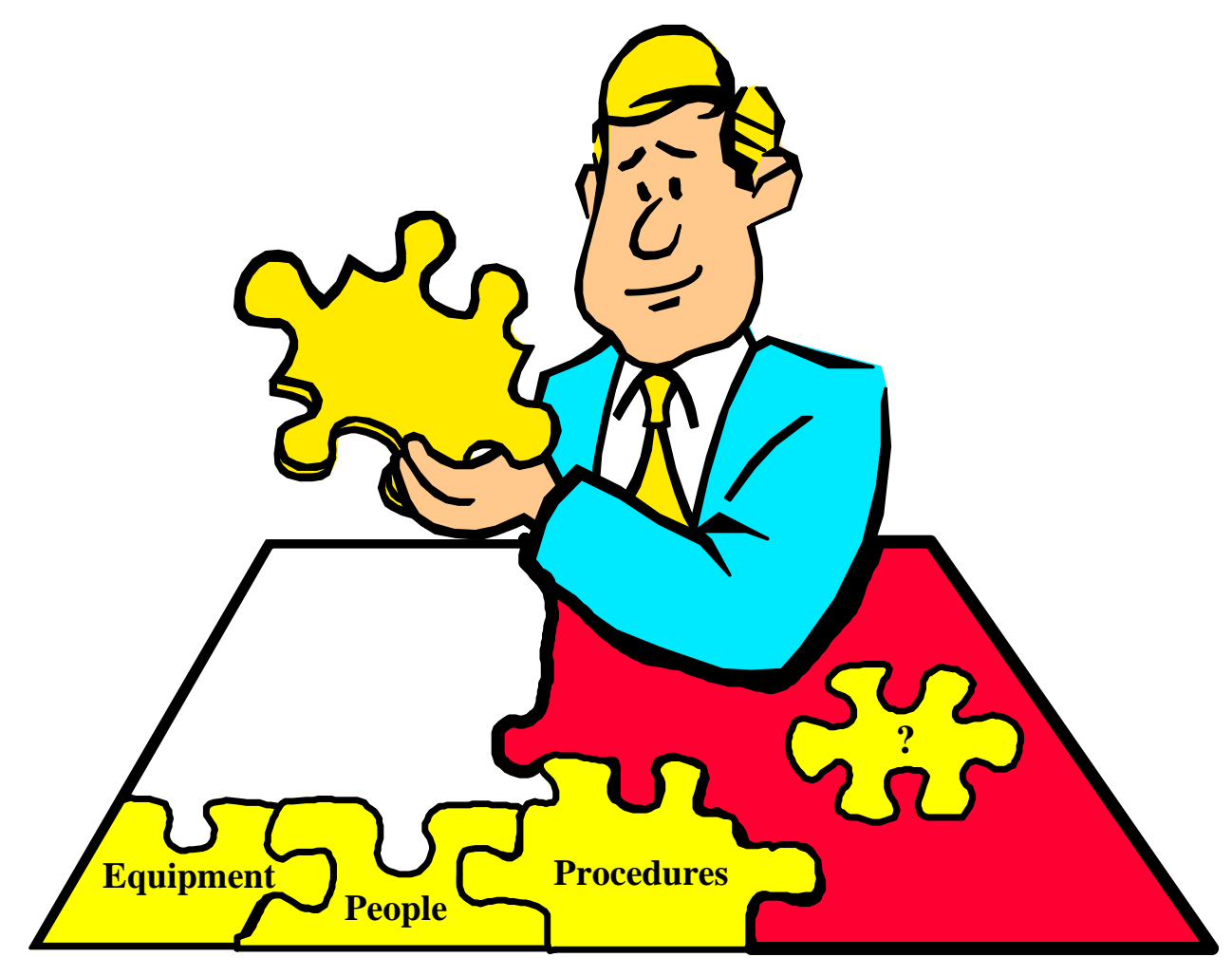




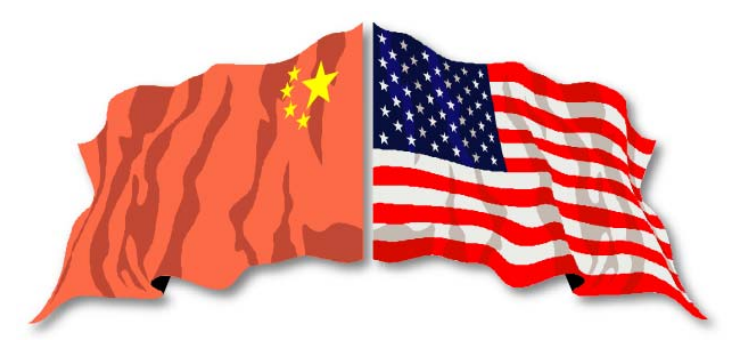

\section{Lecture 10}

\section{Upgrade Exercise}

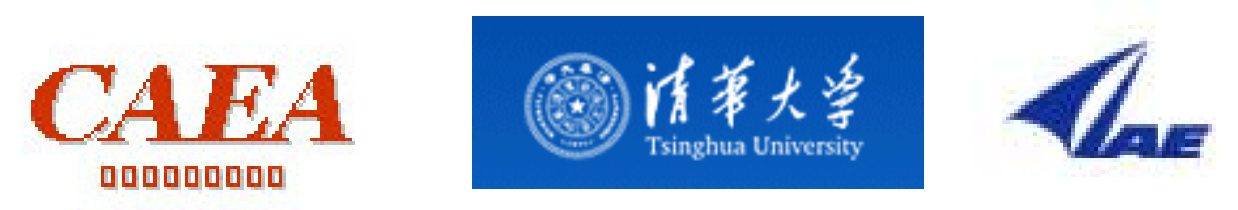




\section{Student Learning Objectives}

- In this module:

- Each team will discuss and determine the most effective upgrades for their assigned scenarios

- Each team will describe their selected upgrades and their effect toward risk reduction 


\section{Presentation of Upgrade Selections}

- Team 1

- Selection of upgrades and explanation for choices

- Team 2

- Selection of upgrades and explanation for choices

- Team 3

- Selection of upgrades and explanation for choices

- Team 4

- Selection of upgrades and explanation for choices 


\section{Summary}

- Questions and Answers

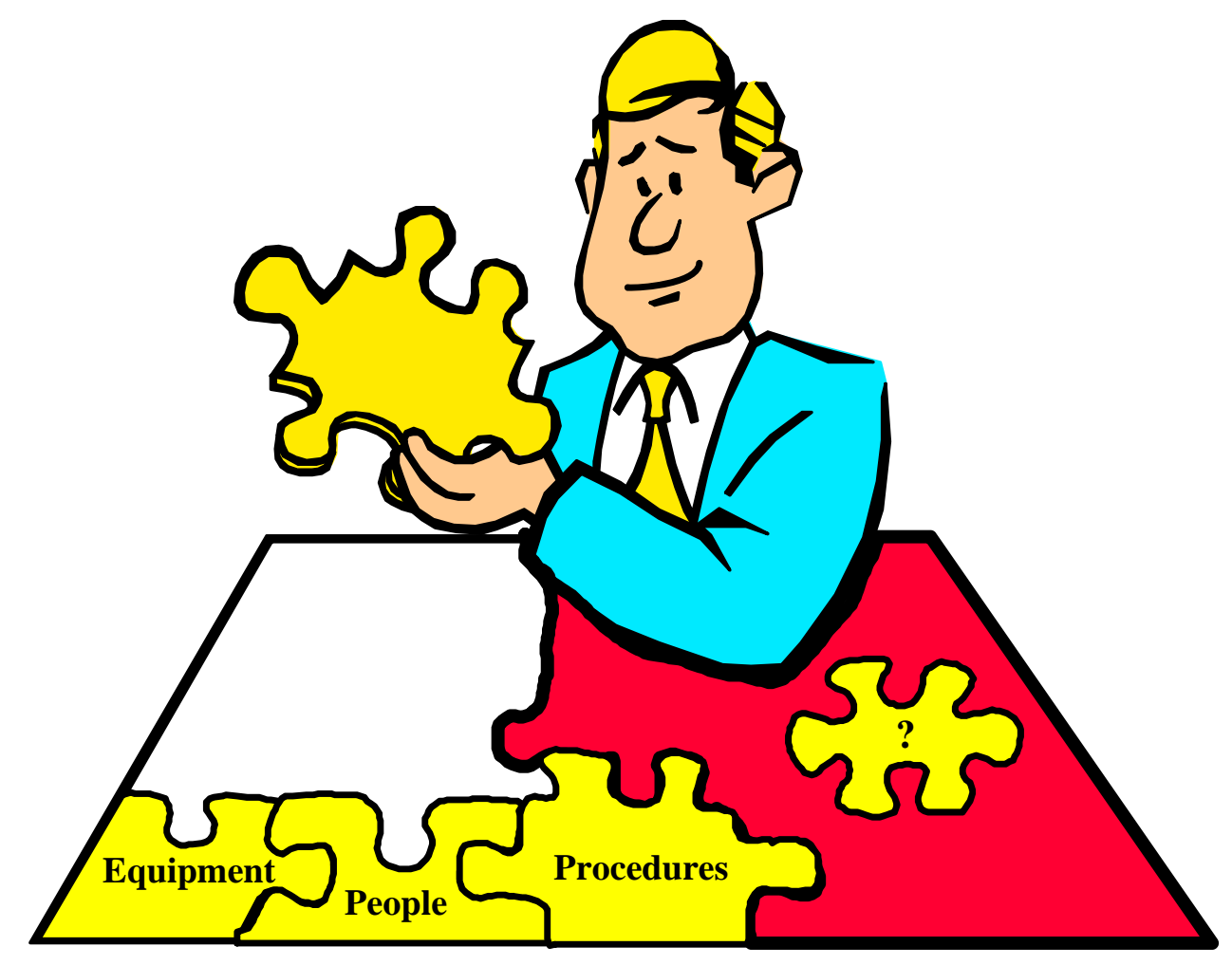




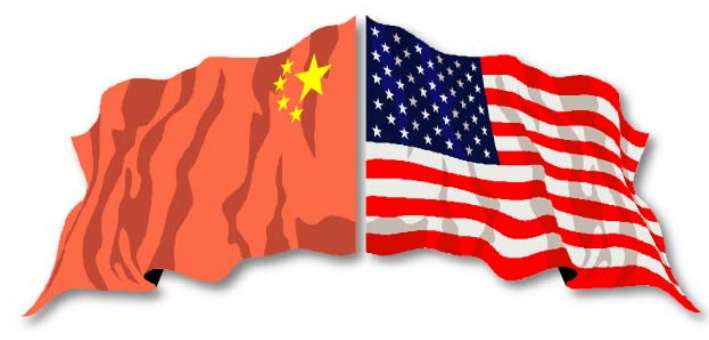

\section{Lecture 11}

\section{Maintaining System Effectiveness}

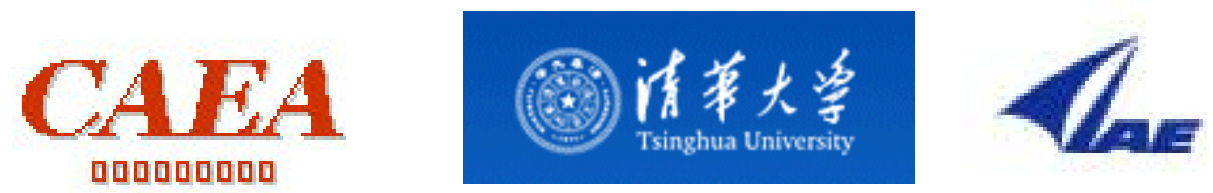




\section{Student Learning Objectives}

- In this module we will discuss:

- How insider threat mitigation strategies are assured through:

- Self-assessments,

- Performance testing of key systems,

- Oversight activities 


\section{Self-Assessment Programs}

- To maintain system effectiveness, each site should conduct self-assessments administered through a formal program.

- Best accomplished through an independent objective organization

- Assessment program plan and performance of the plan are subject to annual review

- Programs should assess MPC\&A functions deemed critical by a vulnerability assessment

- Without evaluating your system's effectiveness, you cannot have a high confidence that your facility is protected against insider (and outsider) threats. 


\section{Performance Testing}

- Performance testing is an integral part of selfassessments. Testing should focus on:

- Individual MPC\&A elements considered critical to detection and/or mitigation of theft or diversion scenarios, and

- Multiple MPC\&A elements (systems) based upon defined theft or diversion scenarios

- Personnel and systems are periodically tested according to an approved plan

Response Force functions are also included as part of PP testing 


\section{Benefits of a Testing Program}

- Determines the effectiveness of the safeguards and security program elements

- Determines effectiveness of individual critical protection elements

- Identifies system strengths and weaknesses

- Validates vulnerability analysis

- Validates procedures

- Validates training effectiveness 


\section{Benefits of a Testing Program}

- Promotes continuous improvement of protection systems

- Produces data for lifecycle management

- Provides data for financial analysis for continued support/upgrades

- Promotes quality by supporting improvement initiatives

- Integrates MC\&A and physical protection 


\section{Key MPC\&A Elements for Testing}

- Access control systems and procedures

- Surveillance systems and procedures

- Administrative procedures

- Detection sensors

- Process control systems and procedures
- Inventory systems and procedures

- Measurement systems and procedures

- Accounting systems and procedures

- Material Transfer procedures

- Health and safety systems and procedures

The Emergency Management System should also tested 


\section{Element Evaluation Approaches}

- Standard requirements

- Performance tests

- Functional tests

- Effectiveness tests

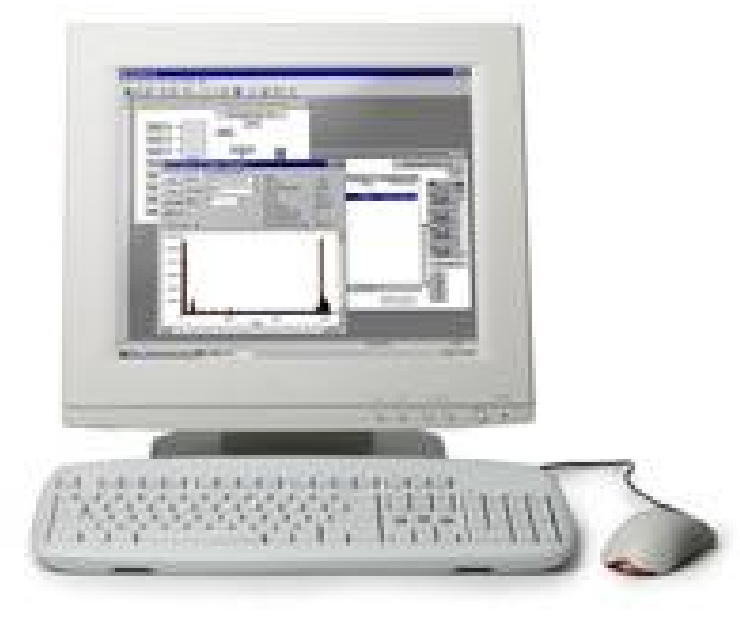

It is essential to analyze performance test data in order to: 1) support insider analyses; 2) validate effectiveness of protection programs; 3) validate the VA and it's assumptions; 4) validate training \& procedures 


\section{Standard Requirements}

For many system elements, standard requirements may already exist, or can be created.

They should assure that:

- The inherent capabilities of the protective system will be fully realized.

- Protective systems are working at their intended/required level of performance.

- The protective system functions consistently and reliably.

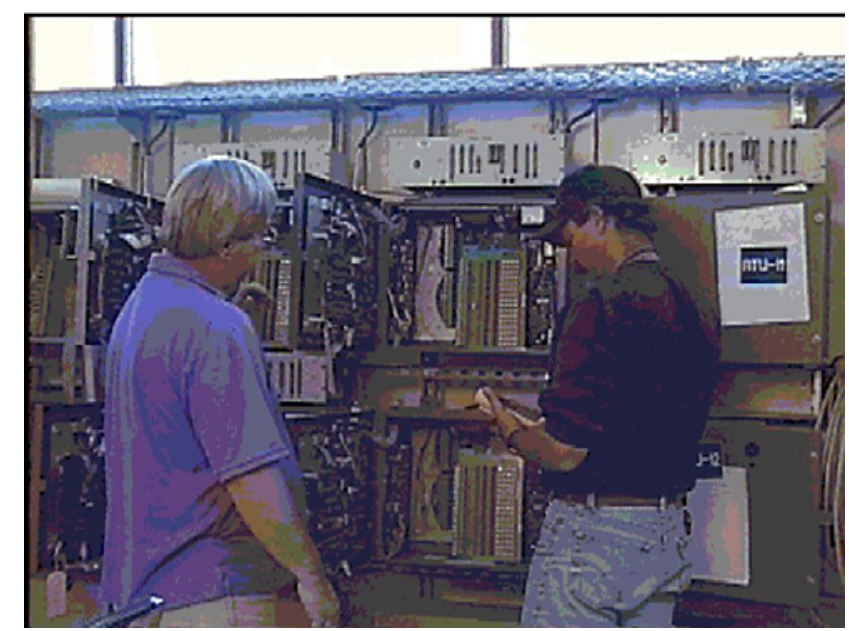

- Malfunctions and failures are detected and corrected in a timely manner. 


\section{Expert J udgment}

- The effectiveness of many detection elements, especially those relying on human factors, may be difficult to quantify by testing.

- Additionally, determining what elements to test and how often requires a lot of coordination between departments.

- Here the collective judgment of knowledgeable and experienced individuals will be of value.

- Sites often form Performance Test "Boards" to determine what to test and to set test parameters (desired effectiveness levels)

- The approach should be carefully structured

- It should draw on individuals from all relevant areas 


\section{Performance Tests}

The security manager typically wants to know two things about the protective system: Are the systems functioning and are they functioning at the required level of effectiveness.

- Functional tests: Determine that the element is operating

- "does it work or not"

- Effectiveness tests: Determine that element and/or system of elements are operating at intended level of effectiveness

- "how well does it work"

The selection, design, and execution of performance tests and the analysis of their results requires a carefully structured approach. 


\section{Limited Scope Testing}

- Prior to a full-scale exercise, certain system elements can be examined or evaluated with limited-scope performance tests

- Alarm systems

- Emergency situations

- Material control measures

- Waste streams

- Effectiveness of area searches

- Transfer procedures

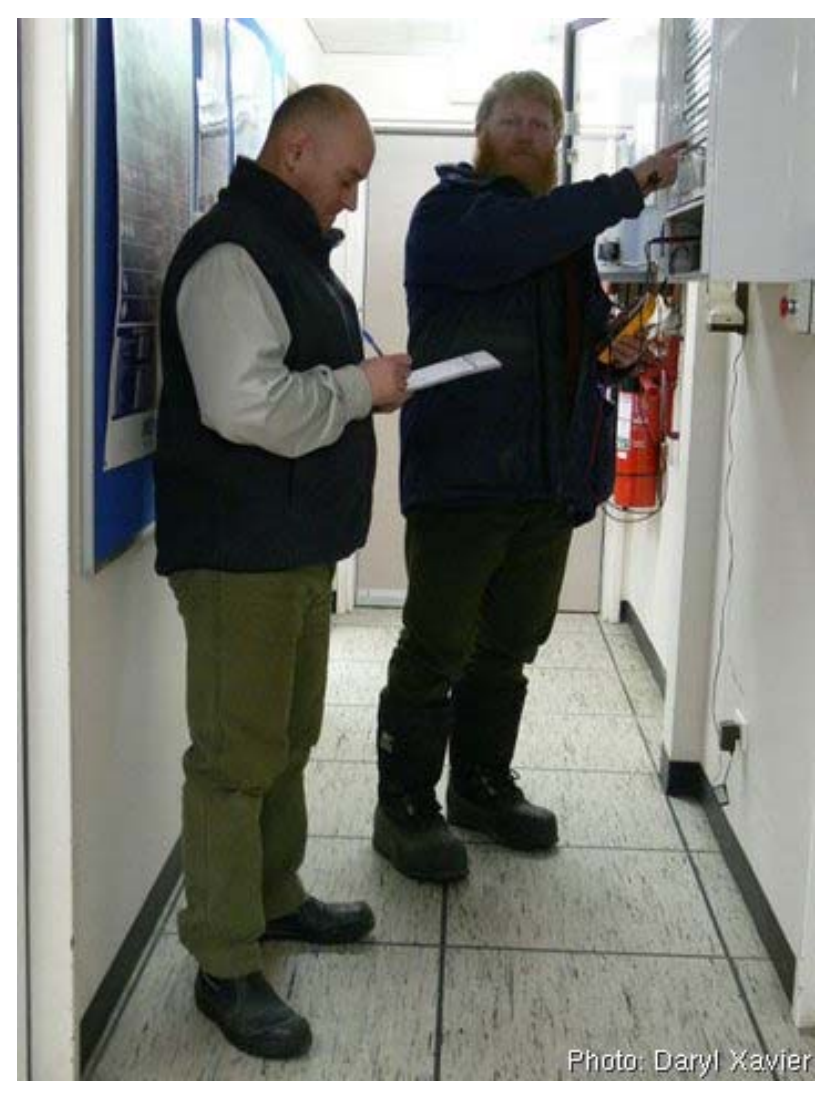




\section{System/ Subsystem Testing}

- Higher and more complex level of performance test

- Evaluates:

- Individual protection elements

- Elements within a critical path

- The interaction/integration of the individual elements

- Includes equipment and personnel

- Usually based on one of the scenarios identified in a vulnerability assessment such as an insider threat scenario

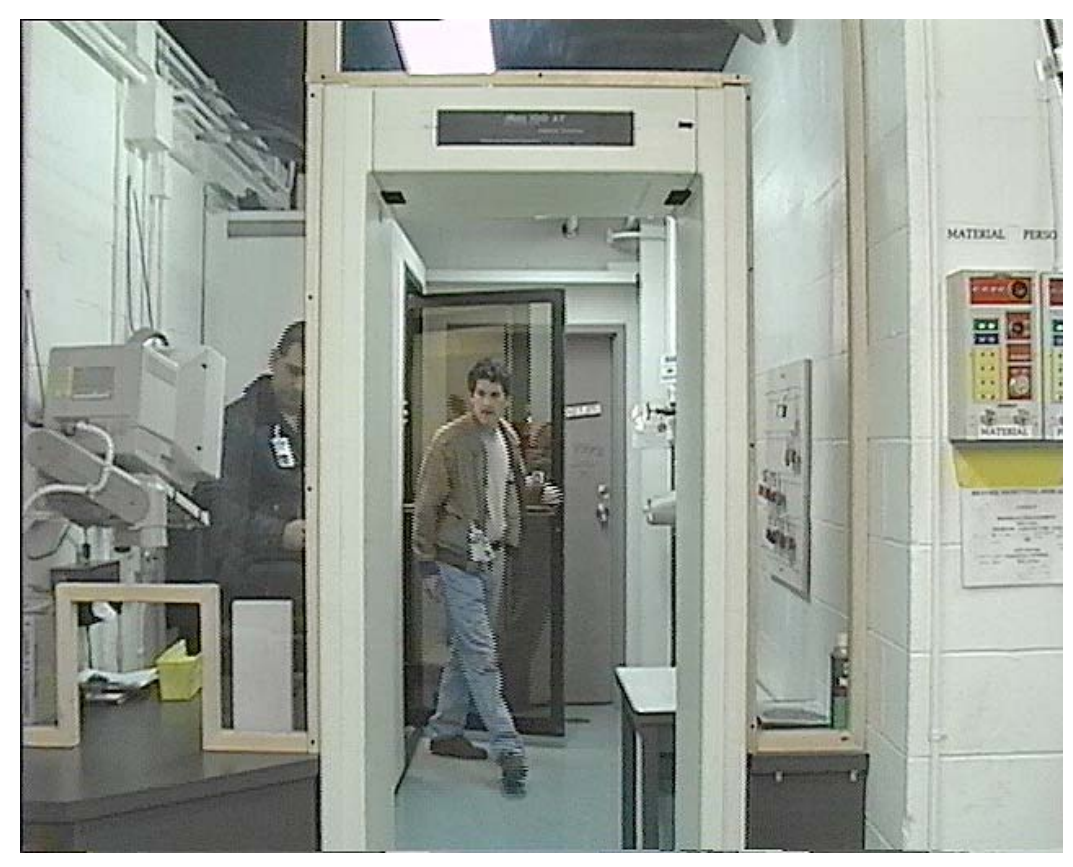




\section{Performance Tests - Selection}

Since resources are limited, tests should be selected which will provide the most useful information about critical protection elements. Important considerations include:

- Testing program should be organized to produce the greatest number of data points with the least impact on resources and operations

- Components and systems that have the greatest impact on

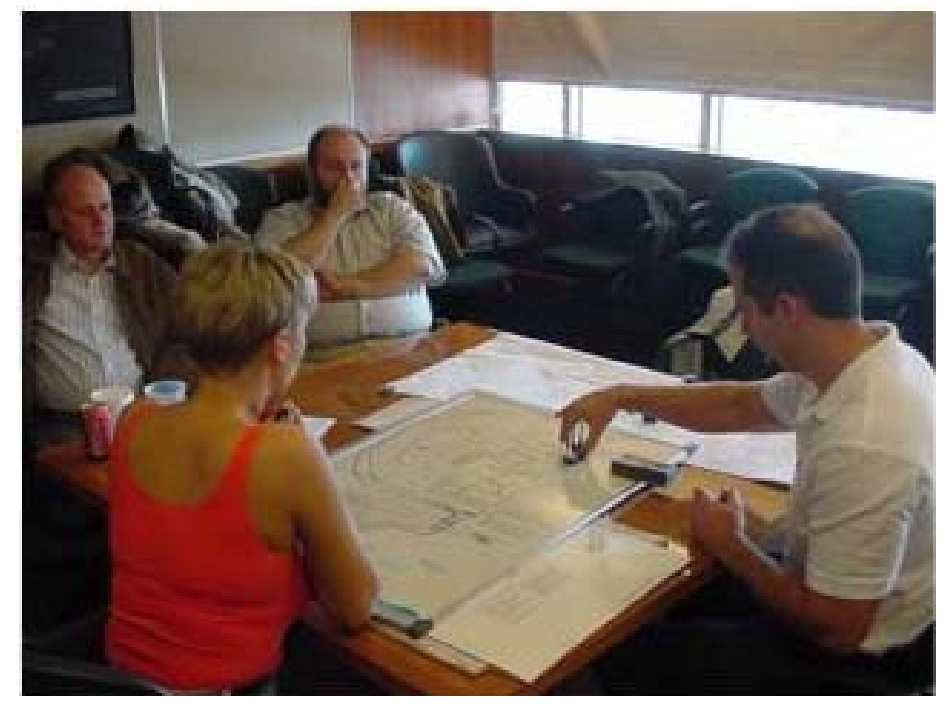
reducing risk should be tested more frequently 


\section{Performance Tests - Design}

The design of performance tests involves a number of important considerations:

- Scope

- Test conditions

- Test environment

- Test scenario

- Control of variables

- Test controls

- Facility area and personnel participation

- Notification plans

- Reporting Test results

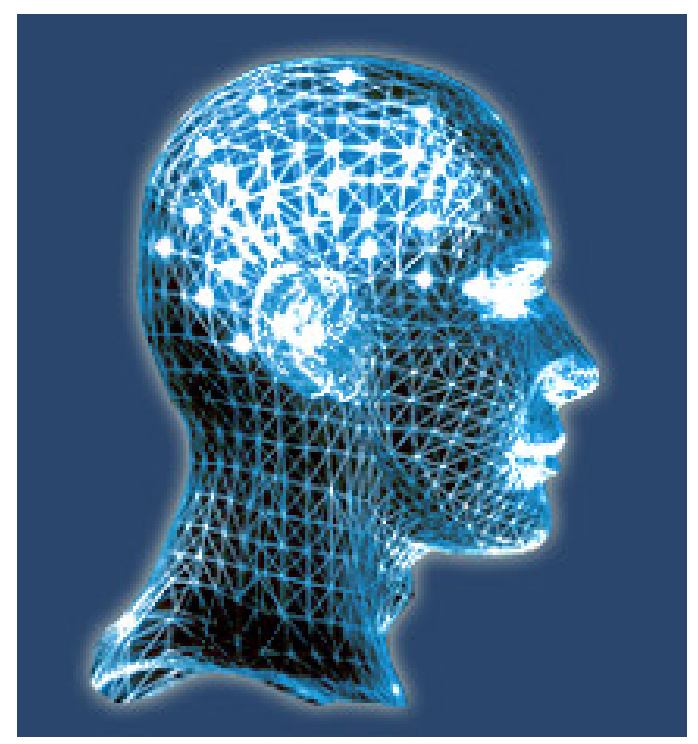

Plan carefully 


\section{Performance Tests - Constraints}

A number of

considerations may affect how tests are performed:

- Unacceptable impact on operations

- Personnel Health or safety issues

- Labor/management agreements and relations

- Unacceptable risk to materials or assets 


\section{Performance tests - Evaluation}

After the completion of a test, an evaluation must be carried out to reach certain conclusions:

- Achievement of test objectives

- Applicability of results

- Indications of deficiencies or vulnerabilities

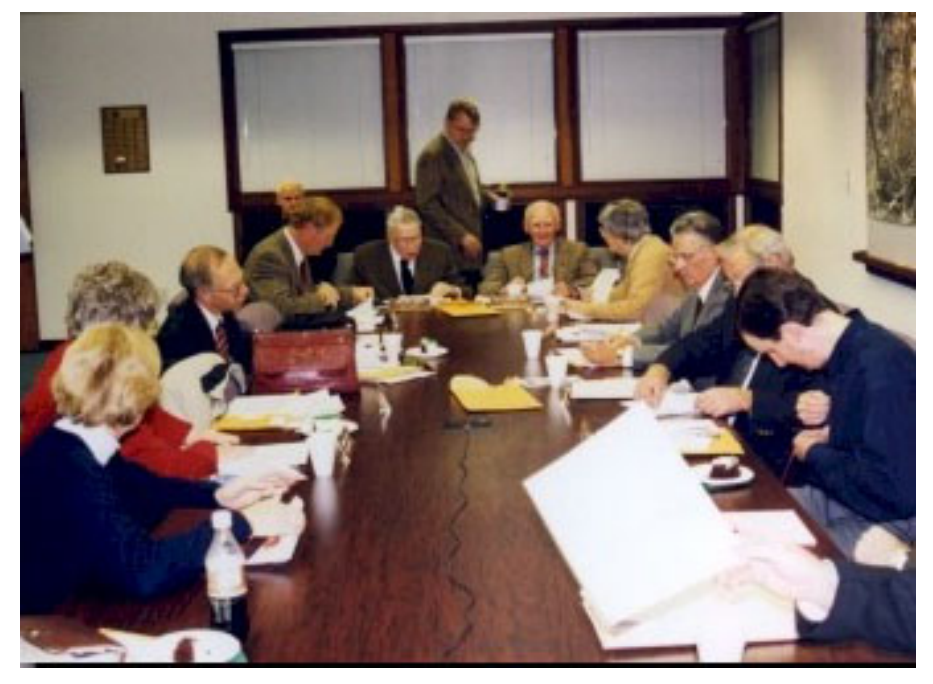




\section{Summary}

- A well designed Performance Testing Program serves as the vehicle to determine the health of the safeguards and security system.

- For each critical protection element, equipment, procedures, personnel and system integration must be considered.

- The performance testing program is a continuous process.

- Without performance testing, the effectiveness of insider threat mitigation strategies is not really known. 


\section{Summary}

- Questions and Answers

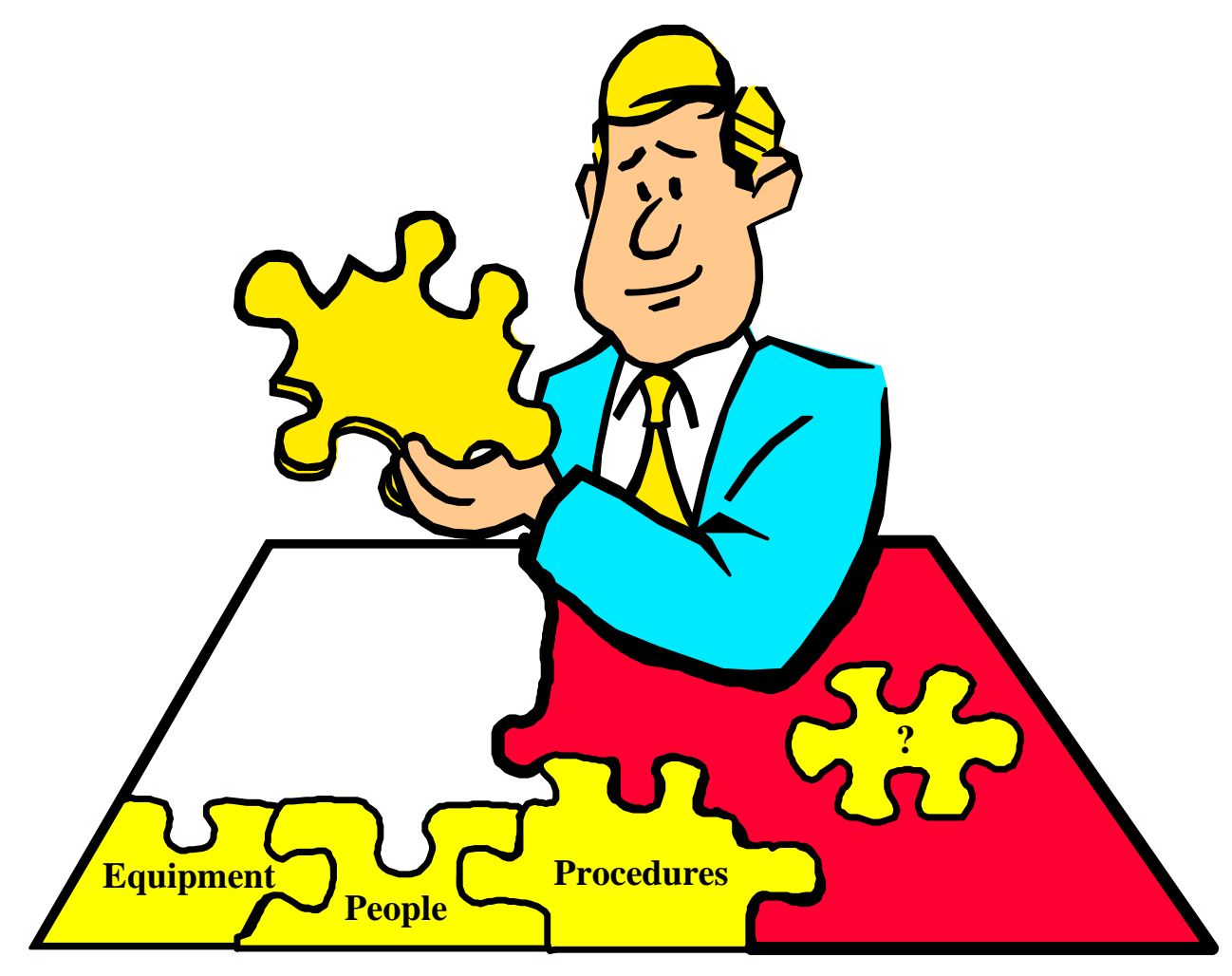




\section{Backup slides}




\section{Example: Tamper I ndicating Devices}

The basic objective of a tamper indicating device (TID) program is to detect unauthorized access to material

- Functional tests determine:

- Difficult to perform function tests on passive TIDs

- Active TIDs may be function tested similarly as other detection sensors.

- Effectiveness tests: test to determine the ability of a TID technology to detect unauthorized access to material

- Tests of personnel to properly apply TIDs tests the effectiveness of the training program.

- The intentional tampering of TIDs to determine whether or not it performs as designed is also an effectiveness test. 


\section{Example: Tamper I ndicating Devices}

- Statistical sampling should be used to verify:

- Records accurately reflect the location and identity of TIDs

- Proper application and integrity of TIDs

- Performance tests should be used to determine the effectiveness of

- Surveillance associated with TIDs

- TID inspections

- Control of TIDs and associated records
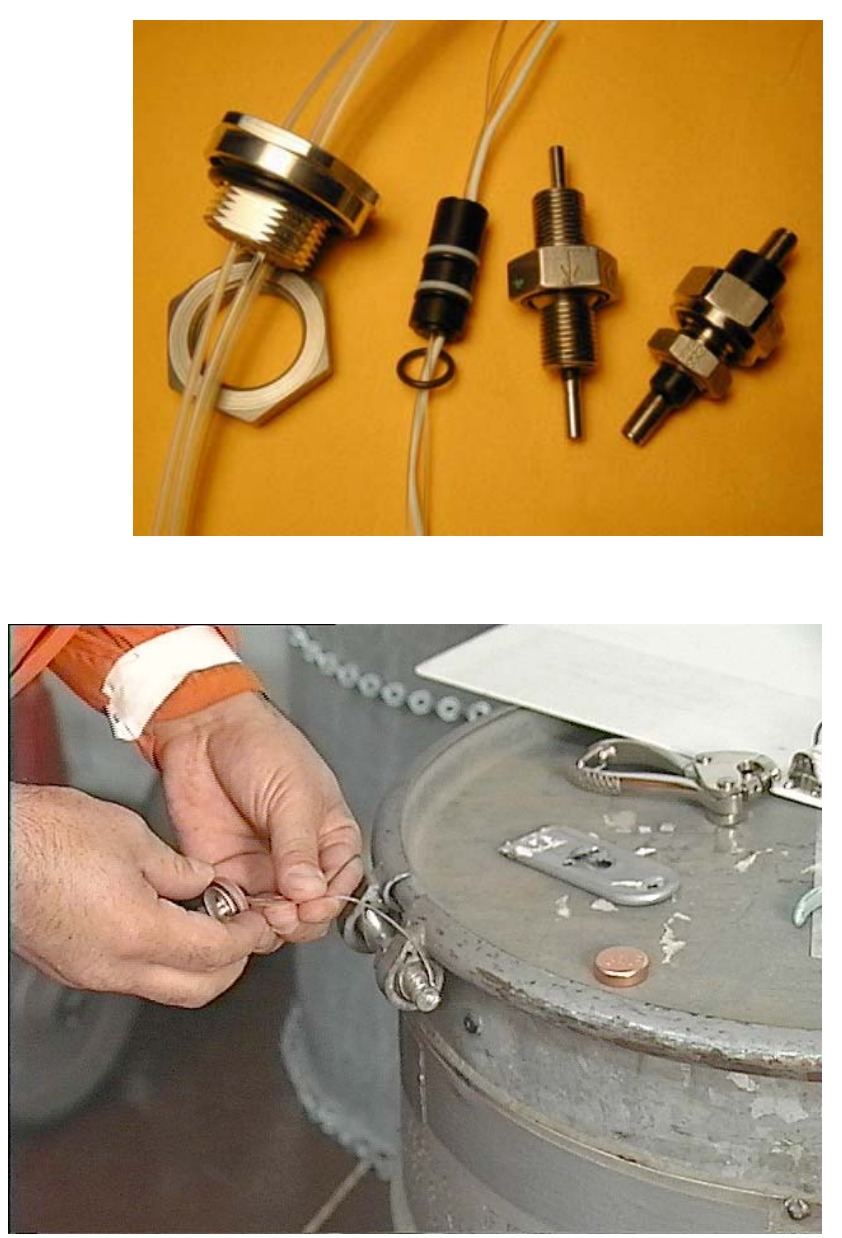


\section{Exercise 2a}

\section{Administrative Measures}

\section{Session Objectives:}

After the session the participants will be able to do the following:

1. Each group will be able to identify the strengths and weaknesses of four administrative measures.

2. Identify methods the adversary could use to covertly or overtly reduce the effectiveness of these measures.

3. Estimate the effectiveness of these measures.

\section{Estimated Time:}

30 minutes in subgroup

+10 minutes in large group discussion

40 Minutes total

\section{Exercises:}

1. Evaluate the following administrative measures:

a. Pre-employment process

b. Employment checks

c. Information compartmentalization

d. Equipment operations

Consider each method describing its strengths and weaknesses. Identify methods an adversary could use to covertly or overtly defeat each measure. Estimate each measures overall effectiveness.

\section{Report Your Results in Large Group Discussion:}

Each subgroup will present their to the class for input and discussion. 


\title{
1) Pre-employment Process: \\ Strengths:
}

Weaknesses:

Methods to defeat:

\author{
Effectiveness:
}

2) Employment Checks:

Strengths:

Weaknesses:

Methods to defeat:

Effectiveness: 
3) Information compartmentalization:

Strengths:

Weaknesses:

Methods to defeat:

\section{Effectiveness:}

4) Equipment Operations:

Strengths:

Weaknesses:

Methods to defeat:

\section{Effectiveness:}




\section{Exercise 2b \\ Technical Measures}

\section{Session Objectives:}

After the session the participants will be able to do the following:

1. Each group will be able to identify the strengths and weaknesses of listed PP and MC\&A technical measures.

2. Identify methods the adversary could use to covertly or overtly reduce the effectiveness of these measures.

3. Estimate the effectiveness of these measures.

\section{Estimated Time:}

30 minutes in subgroup

+10 minutes in large group discussion

40 Minutes total

\section{Exercises:}

1. Evaluate the following PP technical measures at the PA Portal:

a. Doors into the PA

b. Posted Guards

c. X-ray

d. Metal detector

e. SNM detector

f. Doors into the portal

2. Evaluate the following MC\&A System technical measures:
a. MBA Structure
b. TIDs
c. Measurement systems
d. Physical inventory procedures
e. Shipper/Receiver procedures
f. Manual documentation to computer system

Consider each method describing its strengths and weaknesses. Identify methods an adversary could use to covertly or overtly defeat each measure. Estimate each measures overall effectiveness.

\section{Report Your Results in Large Group Discussion:}

Each subgroup will present to the class for input and discussion. 


\begin{tabular}{|l|l|l|l|}
\hline Measures & Weaknesses of the Measure & Potential Defeat Methods & $\begin{array}{c}\text { Estimate } \\
\text { Effectiveness } \\
\text { (H,M,L) }\end{array}$ \\
\hline \hline Doors into PA & & & \\
\hline Posted guard & & & \\
\hline X-ray search & & & \\
\hline $\begin{array}{l}\text { Metal } \\
\text { detector }\end{array}$ & & & \\
\hline SNM detector & & & \\
\hline \hline $\begin{array}{l}\text { Doors into } \\
\text { portal }\end{array}$ & & & \\
\hline
\end{tabular}




\begin{tabular}{|l|l|l|l|}
\hline \multicolumn{1}{|c|}{ Measures } & Weaknesses of the Measure & Potential Defeat Methods & $\begin{array}{c}\text { Estimate } \\
\text { Effectiveness } \\
\text { (H,M,L) }\end{array}$ \\
\hline Four MBAs & & & \\
\hline $\begin{array}{l}\text { Unique TID } \\
\text { Identifier }\end{array}$ & & & \\
\hline Measurements & & & \\
\hline $\begin{array}{l}\text { Physical } \\
\text { Inventory }\end{array}$ & & & \\
\hline $\begin{array}{l}\text { Shipper / } \\
\text { Receiver }\end{array}$ & & & \\
\hline $\begin{array}{l}\text { Manual } \\
\text { documentation } \\
\text { to Computer } \\
\text { System }\end{array}$ & & & \\
\hline
\end{tabular}




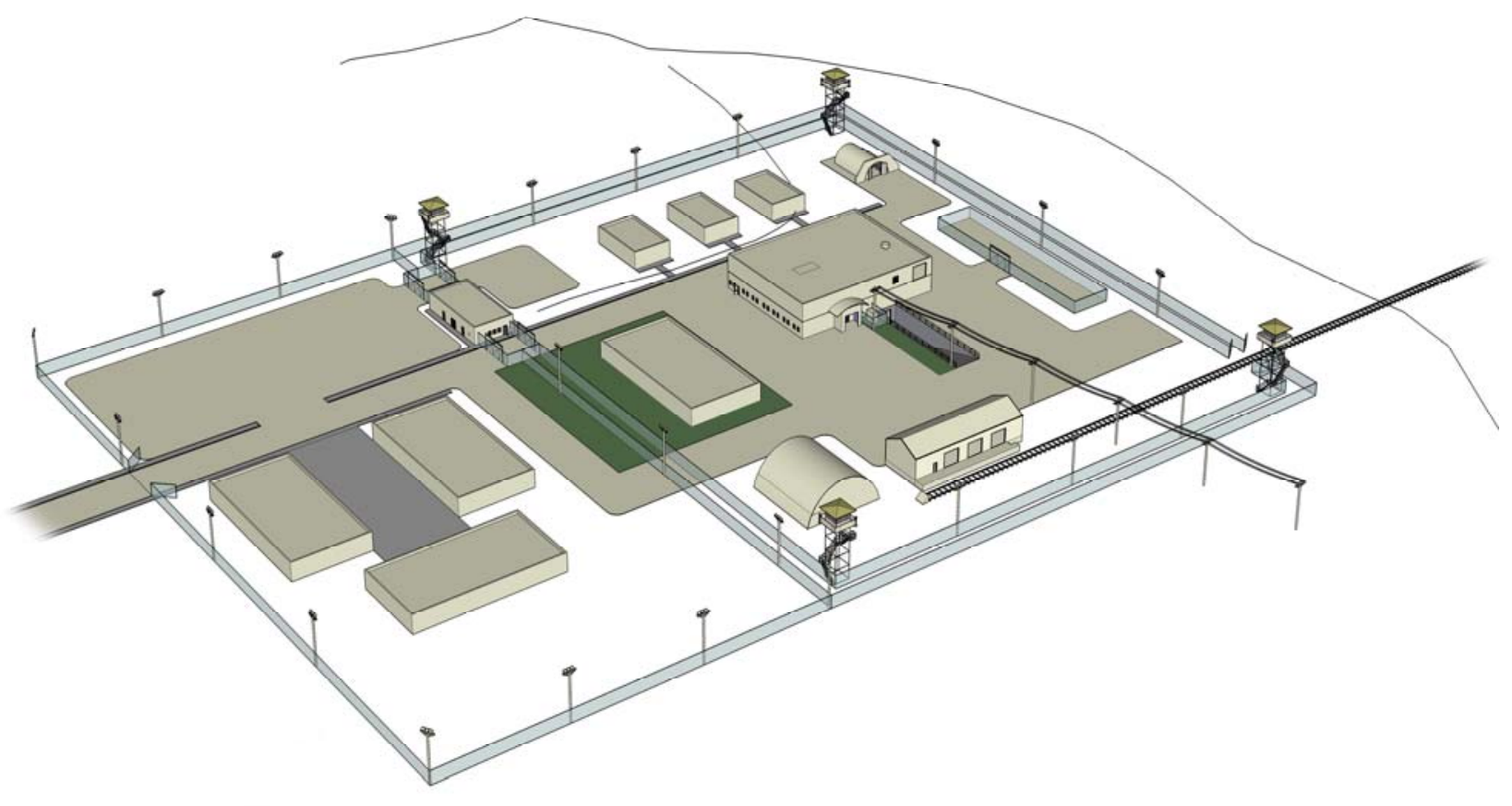

Plant Overview Exercise 
Plant Manager Overview: Good afternoon. I am the Plant Manager. I'll give you an overview of the plant operations. You can find more details in your handbook about the site. At the end I'll be happy to answer your questions. First let me tell you some things about our site:

The Uranium Research Facility (URF).is a national defense facility for the manufacture of uranium billets used in research. During normal operation, 250 full-time employees work at the site in plant operations, maintenance, engineering, technical support, management and administrative support positions. Of these, 182 employees require some access to the Protected Area (PA).

The site, which is located in a semi-arid high desert, is divided into two main areas. The first is the low security Administration Area, where much of the non-production activities take place. Approximately $30 \%$ of the staff works in this area. The second area is the PA. This very high-security area contains the main fabrication buildings, the production support buildings, storage vaults, road and rail transportation terminus, and the main cafeteria.

The main product of the URF is high-quality uranium billets that are used in nuclear material research. The input stream of this process begins with the delivery of uranium dioxide $\left(\mathrm{UO}_{2}\right)$ powder. This powder is processed into raw ingots through a casting process. The raw ingots are then further processed into standard billets of specific size, shape, and weight. The waste from these processes goes into a uranium recovery stream that reintroduces the scrap material into the input stream. The finished product undergoes quality assurance (QA) checks and is then stored at a bunker until it is transported by rail or truck to end users.

The northern two-fifths of the URF Site is the Administrative Area (AA). This area is surrounded by a fence along three sides—-known as the North Fence-and the PA fence along the southern side.

The buildings in the AA are unlocked except on weekends and holidays. Most senior management personnel have keys to the outer doors of these buildings. Personnel all have keys to their specific work areas All keys are controlled by the guard force and are stamped "Do not duplicate."

The buildings of the AA are not alarmed, except for the analytical lab on the first floor of the building nearest the PA. The guard force responds to any alarms that occur in this area. Members of the guard force have a master key that allows them to enter and investigate the analytical lab after an alarm occurs.

There are nine buildings inside the PA perimeter. The main production building is the Process Facility located near the center of the area. There is also an Entry Control Building (ECB) that straddles the northern perimeter and houses pedestrian and vehicular entry control points, the CAS, and the Response Force Ready Room. Material shipments are processed through the shipping and receiving building. This building can support both road and rail transports. A storage bunker, located in the southeast corner of the PA, is used to store finished products prior to shipping. A full service $\mathrm{x}$-ray diagnostic facility, located in northwest corner of the PA, is used for product quality control inspections. The PA also houses several small office buildings and the main cafeteria. 
All manufacturing processes are contained within the URF Processing Building. This building is a multi-story facility with a basement, ground, and mezzanine level. It has a total area of approximately 1700 square meters. The partial basement is the machine cooling fluid processing area, the ground floor is the processing area, and the mezzanine is the heating, ventilation, and air conditioning (HVAC) area. The production areas of the building are under negative pressure and all ventilation from these areas is passed through high efficiency particulate air (HEPA) and/or charcoal filters to minimize plant releases.

The URF Processing Building houses the following areas/operations:

- Casting Furnace Area-This area holds the two furnaces where $\mathrm{UO}_{2}$ power is cast into ingots.

- Billet Vault—Finished ingots are stored here until needed by machining process.

- Special Nuclear Material (SNM) Machining Area-This area holds nine milling machines that can be configured to work as three lines of a three-step milling process or as nine individual stations. The milling process converts raw ingots to finished billets.

- Product Vault-This vault stores finished billets before they are sent to QA or to the Storage Bunker.

- QA Vault-In-process billet samples and final products are measured and tested in this vault. Only a limited amount of material may be in this vault at any one time.

- AA-The Administrative Area is the general office area.

- Chip Vault-This vault stores return stream waste from the Casting Furnace and Machining areas before it is reintroduced into the input stream.

The Shipping and Receiving building (23 in Figure 1-2) is a one-story building with loading docks on both sides (one for rail shipments and one for trucks). Although several cubical office spaces are inside, it is basically an open warehouse.

The Bunker (20 in Figure 1-2) is used to store nuclear material that was shipped in for recycling, and finished products that are packed and ready to ship.

There are three single-story Support Buildings that house offices and light laboratory facilities. These Support Buildings, located east of the Processing Building $(17,18,19)$, store some classified material in safes. Nuclear material is not brought into these buildings.

Now, I'll be happy to answer your questions. 
MC\&A Manager Overview: Good afternoon. I am the Site MC\&A Manager. I'll give you an overview of the site MC\&A program. You can find more details in your handbook about the site. At the end I'll be happy to answer your questions. First let me tell you some things about our program.

By letter of designation, the plant manager has delegated the responsibilities and authorities of all safeguard positions. A single individual is assigned the responsibility for technical coordination of the overall MC\&A program. This position is referred to as the Material Control Manager. This is me. This position is separate from production and any other responsibilities that might give rise to a conflict of interest. In addition, there is a Measurement Control Coordinator, and, if needed, multiple Material Balance Area (MBA) Custodians assigned specific authorities, responsibilities, and locations reporting directly to the Material Control Manager.

Three MBAs have been established at the URF. These are the Production Floor, the XRay Facility, and the Final Products Bunker. All SNM at the URF is maintained in one of these three MBAs. The physical boundaries of the X-Ray Facility and the Final Products Bunker MBAs are the structural boundaries of the respective building. The physical boundaries of the Production Floor MBA are the walls and access control point for the production area.

The Measurements and Measurement Control program is under the control of the Measurement Control Coordinator. The measurement control program is expected to establish and verify inventory quantities and to ensure the quality and reliability of the measurement data. This facility would incorporate the following measurement control elements:

- various mass weighing stations

- destructive laboratory analysis and sampling

- non-destructive analysis (NDA) measurement systems

- weekly calibration or operability checks with reference standards

- a sampling program to ensure that portions of the bulk material taken for measurement are representative of the bulk material

- control programs associated with all measurement systems to assure the quality of data generated

The measurement Control Coordinator maintains the equipment and standards in a locked room in the non-nuclear material portion of the processing facility and is responsible for the proper use and calibration of the equipment.

In addition, the MC\&A organization would control and issue TIDs for use throughout the facility. MBA Custodians would be the only personnel trained to apply and remove TIDs.

A physical inventory is conducted every two months under normal conditions. This physical inventory consists of a $100 \%$ inventory of items or containers with TIDs, and measurement of a statistical sample of items. The measurements are NDA measurements and the attributes are compared to the book data. Discrepancies are tracked in the measurement control system. If a measurement is beyond the control limits for that 
measurement from the recorded value, the item in question is subjected to additional confirmatory measurements, including opening the container and, if required, conducting destructive measurements.

Data obtained during the physical inventory, data from measurements during the material reconciliation period, and control program data are used to calculate the Limit of Error of Inventory Difference (LEID). Special inventories are conducted when custodial responsibilities are changed, items are believed to be missing, inventory differences exceed established control limits, and other abnormal occurrences take place. These special inventories may be limited to a single vault or MBA, depending on the occurrence. However, the facility may be impacted, depending on the circumstances. Investigation of inventory differences between accounting records and physical inventory results will be performed to determine the cause.

Material measurements may take place at several points in an item's life in the processing area. Material is normally measured on the following occasions:

- A receipt measurement is taken within five days of receipt.

- Depending on whether the mass limit exceeds $2 \mathrm{kgs}$, an item may require a measurement for Internal Transfers between MBAs.

- Measurements are taken when modifications are made to materials in the machining or casting process.

- Measurements are taken as part of Item Monitoring along the process path.

- Final product measurements are taken before containerization and TID application.

- A final measurement is performed within five days before shipment.

Items received are booked on shipper's values for element and isotope content. When shipments are received, the item count and item identifiers are verified against the shipping documents. Items shipped are sent based upon the book values for the element and isotope content. Where shipper receiver differences are identified on shipped items, the shipper-receiver difference is resolved by adjusting the URF book values to the receiver's measured values, as long as the difference does not reflect a difference in the number and identity of the items shipped and received.

In addition to the fixed periodic physical inventories, the process area has further designated several Inventory Control Locations, which provide the capability to physically locate (or confirm the location of) items in a timely manner. This capability to localize losses (or thefts) of SNM allows for the identification of the mechanism/s for any such loss (or theft) in a more time-sensitive manner. Process boundaries are selected primarily on the basis of manufacturing control; however, this division also enables managerial assignment of specific material handling and control responsibilities, if required.

URF submits material balance reports for each MBA within 30 days of completion of a physical inventory. Nuclear material transaction reports for the MBA covering all transactions during the inventory period are submitted with the material balance report. URF provides a telephone report to the State regulator within four hours of determining that an item cannot be accounted for. This report is followed up by a written report within 24 hours of this determination. 
URF employs a computer-based accounting system that is managed and operated by personnel who are not authorized access to SNM. The computer on which the accounting system is run is a standalone machine. Entry of or access to accounting data or modification of the accounting software requires authorization via a password system. All data is input to the URF computer accounting system from paper records (e.g., inventory sheets and material transfer forms), which are uniquely numbered, accounted for, signed by the individuals completing them, and retained for the life of the plant. The URF accounting software is commercially procured and is not modified by plant staff.

Physical control of the material is established through several individual programs. Access controls limit personnel access to the processing area, and additional access controls further limit personnel access to the processing floor in the processing building. Once on the processing floor, procedural measures limit access to material to those with an established need for access. The MBA Custodians for the various process area locations authorize all material movements. Material access is further enforced through the use of the two-person rule. Any time a material location is accessed, two persons must be present. Two persons must also be present when material is on the machines on the process floor. The machine operator is one of the two persons and the machining supervisor or MC\&A representative acts as the second person for all material being worked on at any given time. Access to specific parts is controlled through the use of locks on the birdcages containing materials. The machine operator is only issued the keys for the work that is at his station for the day

Personnel entering the PA must process through the ECP. The ECP is open from 0700 to 1800 Monday through Friday. Authorized personnel enter the area through the middle double doors to the ECP and process through contraband portal detectors. All handcarried items are placed in plastic boxes and processed through the X-ray machine. Personnel then proceed through the portal metal detector. If they trigger an alarm, they may walk back through the portal, search themselves to determine what caused the alarm, place that material on the X-ray belt, and walk through the portal again. If they do not trigger another alarm, they may collect their materials and enter into the processing area. If they set off the portal alarm a second time, they must be searched by the guards with a hand-held unit. The guards also monitor the X-ray video for contraband. There are two guards at the portal area to process personnel.

Personnel exiting the PA enter the ECP through the double doors and pass through the nuclear material monitoring portal. If they do not set off the alarm, they continue through the exit doors (east and west). If there is an alarm, the guards will stop the person passing through the alarming portal and call the Health Physics personnel, who will respond to determine the cause of the alarm. If the portals alarm when personnel are passing through them to enter the area, the person is stopped and questioned regarding possible reasons the alarm might have gone off and Health Physics is called to check the equipment. That exit door will be locked until the monitor is certified to be in working order.

The ECP for the processing floor in the processing building is similar to the area ECP and contains the same equipment (although the metal detection threshold is lower).

Now, I'll be happy to answer your questions. 
Security Manager Overview: Good afternoon. I am the Site Security Manager. I'll give you an overview of the site security. You can find more details in your handbook about the site. At the end I'll be happy to answer your questions. First let me tell you some things about our response force:

\begin{tabular}{|c|c|}
\hline $\begin{array}{l}\text { Types of } \\
\text { Response Force } \\
\text { Personnel }\end{array}$ & $\begin{array}{l}\text { The response force consists of two types of onsite security personnel: } \\
\text { - Unarmed guards } \\
\text { - Armed guards, including tactical response teams }\end{array}$ \\
\hline $\begin{array}{l}\text { Responsibilities } \\
\text { of Response } \\
\text { Force }\end{array}$ & $\begin{array}{l}\text { These security personnel are responsible for: } \\
\text { - assessment of alarms } \\
\text { - administrative duties, such as access control and key service } \\
\text { - routine patrol and staffing of fixed posts } \\
\text { - response to all security alarms } \\
\text { All posts and patrols have defined policies and procedures with which the } \\
\text { guard force must comply. }\end{array}$ \\
\hline Supervisors & $\begin{array}{l}\text { For each shift, one supervisor is present to supervise the guards that } \\
\text { conduct administrative duties, patrols, and intrusion alarm response. }\end{array}$ \\
\hline $\begin{array}{l}\text { Equipment: } \\
\text { Unarmed } \\
\text { Guards }\end{array}$ & $\begin{array}{l}\text { All unarmed guards are equipped with: } \\
\text { - a straight baton } \\
\text { - one set of handcuffs } \\
\text { - a small flashlight } \\
\text { - a handheld radio }\end{array}$ \\
\hline $\begin{array}{l}\text { Equipment: } \\
\text { Armed Guards }\end{array}$ & $\begin{array}{l}\text { All armed guards are equipped with: } \\
\text { - an automatic pistol with a fully loaded magazine } \\
\text { - two spare magazines of ammunition } \\
\text { - a straight baton } \\
\text { - one set of handcuffs } \\
\text { - a small flashlight } \\
\text { - a handheld radio }\end{array}$ \\
\hline $\begin{array}{l}\text { Equipment: } \\
\text { Tactical } \\
\text { Response Team }\end{array}$ & $\begin{array}{l}\text { The tactical response team members are equipped with: } \\
\text { - an automatic pistol with a fully loaded magazine } \\
\text { - an automatic assault rifle with a fully loaded magazine } \\
\text { - two spare magazines of ammunition for each weapon } \\
\text { - a straight baton } \\
\text { - handcuffs } \\
\text { - flashlight } \\
\text { - handheld radio } \\
\text { - body armor is readily available in the response force vehicles }\end{array}$ \\
\hline $\begin{array}{l}\text { Alarm Stations } \\
\text { and } \\
\text { Communication }\end{array}$ & $\begin{array}{l}\text { The Central Alarm Station (CAS) is located in P-1 and is staffed by a } \\
\text { minimum of one guard at all times. This guard is responsible for the } \\
\text { assessment of alarms and communication to the response force. The } \\
\text { security force supervisor is routinely at the CAS. } \\
\text { The CAS is equipped with: } \\
\text { - } 100 \text {-watt radios that can communicate to all posts and patrols within } \\
\text { the boundaries of the Institute } \\
\text { - } 2 \text { telephone lines-one is linked to each fixed post via a buried } \\
\text { telephone cable and the second is a direct link to the offsite response } \\
\text { force located in the city }\end{array}$ \\
\hline
\end{tabular}


All hand-held radios and fixed posts are equipped with a duress switch to allow sending the CAS a covert signal of unauthorized activity. When the CAS receives a duress alarm, the response force is contacted.

We also have a complete site access control system. The site uses a new badge printing process that prints directly on plastic badge stock. The entire system has changed to this new type of badge, and a background has been designed and a tamper-resistant overlay has been provided for all national sites to use. Although each site has a special alphanumeric identifier that shows where the particular badge was issued, the badges are designed to allow access at all affiliated sites. The badge office (in the Administrative Building outside of the PA) prints all employee and visitor badges for this site. Badge stock is locked up in a safe in the badge office when it is not occupied. Different colors around the border of the badge signify different access authorizations. A legend of these designators is posted in access control points to quickly resolve any questions about access.

Personnel are permitted access through an access control point after verification that they have a current site badge. The guard controlling access is required to verify that the picture matches the badge holder and that the badge has not expired or been revoked. There is an access control office in the Administration Building that issues permanent and temporary badges for access to the plant. There is no check on exiting personnel.

Vehicles authorized routine entry to the site are provided with decals. The security officer(s) on duty permit vehicles to enter upon verifying the vehicle decal and the badges of all vehicle occupants. Temporary vehicle passes may be obtained at the Administration Building with appropriate authorization from site management.

When a delivery vehicle arrives, the guards review the manifest and shipping documents to verify that the truck has a delivery for the institute. The guards then contact the recipient of the delivery to verify that it is expected. Once this is done, the guards inspect the truck for contraband. If the delivery vehicle passes inspection, it is permitted entry to the site. There are no checks on exiting vehicles.

These gates are normally closed and locked with high-security padlocks. When a vehicle arrives, an ECP guard verifies that the driver either has a URF badge permitting access to the URF PA, or has the required escorts. Once the guard has verified that the vehicle is expected, the guard inspects it for contraband. If the vehicle passes inspection, the guards contact the CAS to request that the PA intrusion detection system zone at the gates be placed in the access mode. The guards then unlock the vehicle gates to permit the vehicle entry to the URF PA. After the vehicle has entered the PA, the gates are locked and the PA intrusion detection system zone at the gates is returned to the secure mode.

On exit, vehicles are scanned with a radiation monitor to ensure that there is no contamination and are searched for SNM. Once guards verify that the vehicles are not contaminated and do not have unauthorized SNM, the vehicles are permitted to exit. The contamination scan and SNM search are performed inside the PA with the vehicle gates locked. 
Personnel entering the PA undergo a search for contraband by passing through metal and explosive detectors. Hand-carried items are X-rayed and passed through metal detectors. Suspicious items are physically searched. Individuals who fail the metal detector search are either searched again with a hand-held metal detector or subjected to a pat-down search. The personnel then enter the URF PA via a key-card-accessed door. The guards who perform the badge checks have a "panic" button that will override the key card reader, freezing the doors and precluding any entry to the PA. In a Site Emergency, the doors can also be reconfigured to permit egress from the PA to facilitate evacuation. The layout of the entry control section of the URF PA Access Control point is shown in Figure 5.1.

Personnel exiting the PA undergo a search for SNM by passing through metal and SNM detectors. Hand-carried items are X-rayed. Suspicious items are physically searched.

Individuals who fail the metal detector search are either searched again with hand-held metal detectors and SNM detectors or are subjected to a pat-down search. After verification that individuals are not carrying SNM, they undergo a badge exchange, turning in their URF picture badges and key cards and picking up their Site picture badges. The personnel then exit the URF PA via unlocked doors.

The technical unit is also charged with installing locks, making keys, and changing combinations. One master locksmith and several clerks assist with key control. The office for the lock unit is in Administrative Annex 1. All combinations and key blanks are stored in a safe. Records of keys and work requests and completions are kept on a computer in the office. Only the master locksmith and the clerical staff have the password to the system. Keys for office doors, building doors, and padlocks are cut on a special key blank registered to the site. There are not supposed to be any master keys. Once a certain number of keys have been lost (greater then 5\%), all locks are re-cored with a new keyway. All combination locks have the combinations changed at least annually. However, if a change in personnel occurs, the combination will be changed immediately.

The URF Site is surrounded by an unalarmed 2.5-meter-high chain-link fence to delineate the legal boundary and keep out trespassers. The URF PA is surrounded by two 2.5meter-high chain-link fences with an alarmed isolation zone between the two fences. The vital areas within the URF are enclosed by 20-cm-thick reinforced concrete walls with access through 0.75 -cm steel-plate water tight doors. Access is controlled by an electronic key card system that releases a door latch. In Personnel entering the PA undergo a search for contraband by passing through metal and explosive detectors. Hand-carried items are X-rayed and passed through metal detectors. Suspicious items are physically searched. Individuals who fail the metal detector search are either searched again with a hand-held metal detector or subjected to a pat-down search. The personnel then enter the URF PA via a key-card-accessed door. The guards who perform the badge checks have a "panic" button that will override the key card reader, freezing the doors and precluding any entry to the PA. In a Site Emergency, the doors can also be reconfigured to permit egress from the PA to facilitate evacuation.

In closing, let me add that we have a complete intrusion detection system. The details of this system are identified in your facility handout. Now, do you have any questions? 


\section{Subgroup Exercise 4}

\section{Target Analysis}

\section{Session Objectives:}

After the session the participants will be able to do the following:

1. Describe the URF targets in detail

2. Characterize specific targets with more detail

3. Prioritize targets based on DOE guidance documents

\section{Estimated Time:}

75 minutes

\section{Exercises:}

1. Read the detailed URF site information on targets and target locations

2. Fill out Target Characterization Worksheet for your subgroup's assigned target

\section{Attachment: DOE Graded Safeguards Table}




\section{Exercise 1: Read the URF Detailed Information on Targets and Target Locations}

\section{Materials in Bunker}

The uranium in the bunker consists of materials received for recycling or finished products packed and ready to ship. The material for recycling is on open shelves inside the bunker. Received material is in approved shipping containers. The received containers weigh $100 \mathrm{~kg}$. The containers consist of a heavy gauge steel drum with a bolt on lid. The lid is held by six bolts and after being tightened down to a specified bolt tension, each bolt has a TID run through it to indicate if any tampering has occurred. Inside the steel shipping container is the material container. A packing sleeve is placed in the shipping container to secure the material container. Then the material container is placed in the shipping container and another packing sleeve is placed in the shipping container to secure the material container. The material container is a heavy gauge steel container with a lid secured by six bolts. This container is also sealed with a TID on one bolt. The shipping container weighs $65 \mathrm{~kg}$, the packing material weighs $7 \mathrm{~kg}$, the material container weighs $25 \mathrm{~kg}$ and the material weight is between 2 and $3 \mathrm{~kg}$.

The product containers are inside an expanded metal locked enclosure and weigh 50 to $100 \mathrm{~kg}$ (depending on the type). The $100 \mathrm{~kg}$ product containers are essentially the same as the containers for received material. The $50 \mathrm{~kg}$ containers are designed to fit inside a larger shipping overpack container and are not as robust as the $100 \mathrm{~kg}$ container. They are about one half as tall and the lids snap on with three quick release levers. The same type of inner container is used for all items (there will be some variations in shape/size).

\section{Materials in Processing Building Vaults}

The material in the processing building vaults is in various forms and quantities:

- The chip vault has material in all sizes, shapes and enrichments. When parts to be recycled come to the facility, they are crushed into small chips (between 200 and 500 grams each normally). These chips are classified by enrichment and stored in 2 liter stainless steel cans. The amount of material in each can may vary, but nuclear safety has established a limit of $1 \mathrm{~kg}$ of material in each can regardless of the enrichment. These cans are stored on open shelves in the vault.

- The billet vault contains 5 kg billets. When new parts are to be manufactured, chips are consolidated in a lot and brought to the casting line, here they are melted and poured into a mold for a billet. The billets (after a cooling period) are collected and stored in plastic bags inside metal cans. These metal cans are an integral part of the birdcages (see figure 1). The birdcages ensure correct separation distances and add some delay to the material. Each birdcage weighs $20 \mathrm{~kg}$ and is stored on the floor or on open shelves. 
- The product vault contains the finished parts before they are shipped. These parts are stored in a special birdcage insider an inert gas package. The birdcage is essentially the same as the billet birdcage with a different container integrated into it. The finished products normally weigh between 2 and $3 \mathrm{~kg}$ (depending on the particular product being manufactured). The birdcage weighs $20 \mathrm{~kg}$ and is stored inside an expanded metal enclosure within the vault.

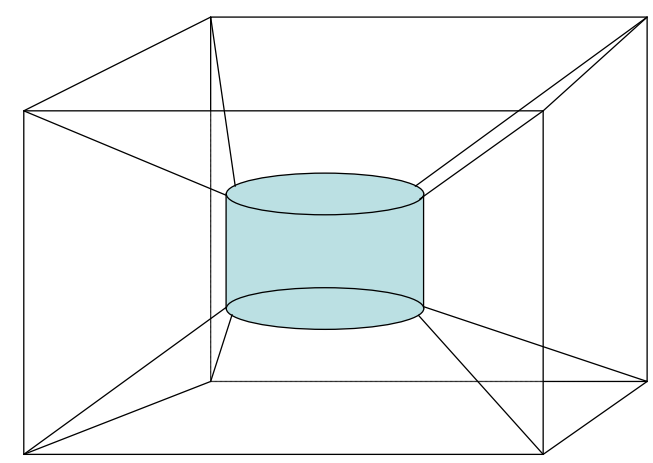

Figure 1. Birdcage

\section{Materials in Processing Area}

The amount of material exposed in the processing area at any one time in the material process can range from 6 to $50 \mathrm{~kg}$ but is only present during the normal five day work period. The bird cages with the material for specific machine input and output are moved by cart to the machine area at the start of each shift and are locked in place to a ring set in the floor. The material handlers have the key to lock the birdcage to the floor. The machinist has the key to open the cage to mount the material in the machine. Mounting the material can take 30 minutes, but dismounting can be done in 15 seconds. Since mounting takes so long on some machines, during breaks the material is left in the machine. When the machining is done, the product is put back in the birdcage and stored until it is picked up on pickup rounds. The material custodian has a schedule of work and picks up the product soon after it is completed. If there is a problem in the process and the product will not be ready for pickup on schedule, the machinist notifies his supervisor who notifies the Material Custodian. Material at various stages of machining is stored in the billet vault during the non-working hours.

\section{Materials moved from the Processing Area}

When a product is complete it is moved to the quality control area where it is inspected. This area is set up as a vault since some materials may stay here for extended periods of time. Products will also be sent via inter-site convoy to the x-ray facility as part of quality control. Once material has passed quality control, it is packed in the material container and stored in the product vault. In preparation for off-site shipment, products 
are packaged in shipping containers and moved to the bunker for storage pending shipment. Material is shipped out on schedule set by the military.

\section{Materials in Basement Recovery Area}

Material is also accumulated in the recovery area in the basement. The turnings from the machines that are taken up in the cooling fluid are stored in the recovery area until a significant amount has accumulated. When weight differences indicate that greater than $2 \mathrm{~kg}$ of material is in the recovery area, recovery operations are undertaken, the fluid is filtered away from the material in a settling tank. When the fluid has been drawn away, the filter material is washed to recover the Uranium. The recovered uranium is weighed, put in a can and sent back up to the chip vault for later re-use. A sample of the material will be taken and sent to the analytical lab to determine the isotopic content of the material (since many different enrichments may be machined in one batch)

\section{$\underline{\text { X-ray Facility }}$}

Parts are in the X-ray for about 6 hours during a normal test. When things are not normal (e.g. when there are potential problems that need more investigation), parts can be left there overnight (to preserve the diagnostic setup). When materials are in the X-ray facility overnight, patrols put a seal on the door and check the seal every 30 minutes. The $\mathrm{X}$-ray facility is constructed like a vault. When material is left there it is left in a positioning unit that it can be removed from in 60 seconds.

\section{Shipping and Receiving Warehouse}

Shipments are put into the vault the same day they are received, but are often left in the shipping and receiving warehouse for 2 to 3 hours while the receiving paperwork is completed and all the weights and serial numbers are verified. While in the shipping and receiving warehouse, material is constantly attended and Patrols check on them every 30 minutes. Material in these locations will be in the $100 \mathrm{~kg}$ shipping containers that they will be stored in until put into the recycling process. 


\section{Exercise 2: Complete Target Characterization Worksheet}

Based on the detailed target information you have been provided and your assigned target, complete the Target Characterization Worksheet below with as much information as possible (your team may have to make some assumptions). Any incomplete areas will help to identify what additional information still needs to be collected.

\begin{tabular}{|l|l|l|}
\hline \multicolumn{3}{|c|}{ Target Characterization Worksheet } \\
\hline Target: & \multicolumn{1}{|c|}{ Tescription } & \multicolumn{1}{|c|}{ Comments } \\
\hline Material Form & & \\
\hline $\begin{array}{l}\text { Attractiveness } \\
\text { Level }\end{array}$ & & \\
\hline Category & & \\
\hline $\begin{array}{l}\text { Container } \\
\text { Characteristics }\end{array}$ & & \\
\hline Restraints & & \\
\hline Weight & & \\
\hline Portability & & \\
\hline $\begin{array}{l}\text { Radiation } \\
\text { Level }\end{array}$ & & \\
\hline $\begin{array}{l}\text { Discrete or } \\
\text { Roll-up }\end{array}$ & & \\
\hline Other: & & \\
\hline
\end{tabular}




\section{Exercise 5b}

\section{Insider Threat Group Table for Targets}

\section{Session Objectives:}

After the session the participants will be able to do the following:

1. Gather information on potential insiders based on job functions.

2. Generate threat group tables for targets

3. Prioritize insider threat groups

\section{Estimated Time:}

20 minutes in subgroups

+30 minutes for large group discussion

50 minutes total

\section{Exercises:}

1. Develop a Threat Group Table that defines qualitatively (high, medium, and low) the level of access, authority, and knowledge that each insider has for your assigned area. Each group will be assigned one insider group.

2. Prioritize the five positions for the assigned area.

\section{Report Your Results in Large Group Discussion:}

1. Each subgroup will present their qualitative designations for access, authority, and knowledge for their assigned insider group. Each group will explain the rationale of their designations for group discussion.

2. Each subgroup will present their ranking for group discussion. 
Exercise 1: Develop a Threat Group Table

Instructions: Using the Threat Group Table for your assigned area, assign a designation (high, medium, or low) for the level of access, authority, and knowledge for your assigned insider group.

Example:

\section{Example of $H, M, L$ Applied to Threat Group Table for the Bunker}

\begin{tabular}{|c|c|c|c|}
\hline Position (Number) & Routine Access & $\begin{array}{l}\text { Routine Authority I } \\
\text { Responsibility }\end{array}$ & Knowledge \\
\hline $\begin{array}{l}\text { Plant Manager (1) } \\
\text { (Plant Manager Org.) }\end{array}$ & $\begin{array}{l}\text { Protected Area, All Inner } \\
\text { Areas (usually escortec) }\end{array}$ & $\begin{array}{l}\text { Overall direction. Not } \\
\text { authorized to direct detail :.1 } \\
\text { facility operations }\end{array}$ & $\begin{array}{l}\text { General knowedge of } \\
\text { plant operations, lacks M// } \\
\text { detailed understanding of } \\
\text { facility }\end{array}$ \\
\hline $\begin{array}{l}\text { Shift Supervisor (3 total with } 1 \\
\text { per shift) } \\
\text { (Shift Supervisor Org.) }\end{array}$ & $\begin{array}{l}\text { Protected Area, All InnE r } \\
\text { Areas }\end{array}$ & $\begin{array}{l}\text { Detailed direction of all } \\
\text { facility activities. Directiof } \\
\text { obeyed without question in } \\
\text { most situations }\end{array}$ & $\begin{array}{l}\text { Extensive, detailed } \\
\text { knowedge about all } \\
\text { aspects of facility design, } \\
\text { layout, and operation. }\end{array}$ \\
\hline $\begin{array}{l}\text { Machining operator (6 total } \\
\text { with nominal } 4 \text { per day shift) } \\
\text { (Operations Support Org.) }\end{array}$ & $\begin{array}{l}\text { Protected Area, All InחE L } \\
\text { Areas }\end{array}$ & $\begin{array}{l}\text { Detailed direction of all } \\
\text { machining activities. Undel- } \\
\text { direction of shift } \\
\text { supervisor. }\end{array}$ & $\begin{array}{l}\text { Extensive, detailed } \\
\text { knowledge about all } \mathrm{M} / \\
\text { activities in the } \\
\text { machining area. }\end{array}$ \\
\hline $\begin{array}{l}\text { Health Physics Technicians (4 } \\
\text { total with nominal } 3 \text { per day } \\
\text { shift) } \\
\text { (Health Physics Org.) }\end{array}$ & $\begin{array}{l}\text { Protected Area, all Inner } \\
\text { Areas and occasional I// } \\
\text { escorted acoess to } \\
\text { Storage }\end{array}$ & $\begin{array}{l}\text { Monitor radiological } \\
\text { conditions. Not permitted } \\
\text { to work on plant equipment. }\end{array}$ & $\begin{array}{l}\text { Specialized knowedge } \\
\text { related to their duties. } \\
\text { Narrow knowledge of } \\
\text { facility systems. }\end{array}$ \\
\hline $\begin{array}{l}\text { Operations Support (6 total } \\
\text { with nominal } 4 \text { per day shift) } \\
\text { (Operations Support Org.) }\end{array}$ & $\begin{array}{l}\text { Protected Area, All Inner } \\
\text { Areas and occasional } \\
\text { escorted acoess to } \\
\text { Storage }\end{array}$ & $\begin{array}{l}\text { Perform specific operations } \\
\text { tasks under direction of } \\
\text { machining and casting } \\
\text { operators }\end{array}$ & $\begin{array}{l}\text { Specialized knowledge } \\
\text { related to their duties. } \\
\text { Narrow knowledge of } \\
\text { complete facility } \\
\text { systems. }\end{array}$ \\
\hline
\end{tabular}




\section{Exercise 1}

\section{Threat Group Table}

\begin{tabular}{|l|l|l|l|}
\hline \multicolumn{1}{|c|}{ Position (Number) } & \multicolumn{1}{|c|}{ Routine Access } & $\begin{array}{l}\text { Routine Authority / } \\
\text { Responsibility }\end{array}$ & \multicolumn{1}{|c|}{ Knowledge } \\
\hline $\begin{array}{l}\text { Plant Manager (1) } \\
\text { (Plant Manager Org.) }\end{array}$ & $\begin{array}{l}\text { Protected Area, All } \\
\text { Inner Areas (usually } \\
\text { escorted) }\end{array}$ & $\begin{array}{l}\text { Overall direction. Not } \\
\text { authorized to direct detailed } \\
\text { facility operations }\end{array}$ & $\begin{array}{l}\text { General knowledge of plant } \\
\text { operations, lacks detailed } \\
\text { understanding of facility }\end{array}$ \\
\hline $\begin{array}{l}\text { Shift Supervisor (3 total } \\
\text { with 1 per shift) } \\
\text { (Shift Supervisor Org.) }\end{array}$ & $\begin{array}{l}\text { Protected Area, All } \\
\text { Inner Areas }\end{array}$ & $\begin{array}{l}\text { Detailed direction of all } \\
\text { facility activities. Direction } \\
\text { obeyed without question in } \\
\text { most situations }\end{array}$ & $\begin{array}{l}\text { Extensive, detailed } \\
\text { knowledge about all aspects } \\
\text { of facility design, layout, } \\
\text { and operation. }\end{array}$ \\
\hline $\begin{array}{l}\text { Machining operator (6 } \\
\text { total with nominal 4 per } \\
\text { day shift) } \\
\text { (Operations Support Org.) }\end{array}$ & $\begin{array}{l}\text { Protected Area, All } \\
\text { Inner Areas }\end{array}$ & $\begin{array}{l}\text { Detailed direction of all } \\
\text { machining activities. Under } \\
\text { direction of shift supervisor. }\end{array}$ & $\begin{array}{l}\text { Extensive, detailed } \\
\text { knowledge about all } \\
\text { activities in the machining } \\
\text { area. }\end{array}$ \\
\hline $\begin{array}{l}\text { Health Physics } \\
\text { Technicians (4 total with } \\
\text { nominal 3 per day shift) } \\
\text { (Health Physics Org.) }\end{array}$ & $\begin{array}{l}\text { Protected Area, all Inner } \\
\text { Areas and occasional } \\
\text { escorted access to } \\
\text { Storage }\end{array}$ & $\begin{array}{l}\text { Monitor radiological } \\
\text { conditions. Not permitted to } \\
\text { work on plant equipment. }\end{array}$ & $\begin{array}{l}\text { lpecialized knowledge } \\
\text { related to their duties. } \\
\text { Narrow knowledge of } \\
\text { facility systems. }\end{array}$ \\
\hline $\begin{array}{l}\text { Operations Support (6 } \\
\text { total with nominal 4 per } \\
\text { day shift) } \\
\text { (Operations Support Org.) }\end{array}$ & $\begin{array}{l}\text { Protected Area, All } \\
\text { Inner Areas and } \\
\text { occasional escorted } \\
\text { access to Storage }\end{array}$ & $\begin{array}{l}\text { Perform specific operations } \\
\text { tasks under direction of } \\
\text { machining and casting } \\
\text { operators }\end{array}$ & $\begin{array}{l}\text { lpecialized knowledge } \\
\text { related to their duties. } \\
\text { Narrow knowledge of } \\
\text { complete facility systems. }\end{array}$ \\
\hline
\end{tabular}


Exercise 2: Rank the Five Positions for your assigned area

Instructions: Using the completed Threat Group Table for your assigned area, rank the five positions from highest degree of access to lowest degree of access

Example: Degree of Access

\begin{tabular}{|c|l|c|c|c|}
\hline Ranking & Position & $\begin{array}{l}\text { Routine } \\
\text { Access }\end{array}$ & $\begin{array}{l}\text { Routine } \\
\text { Authority/Responsibility }\end{array}$ & Knowledge \\
\hline $\mathbf{1}$ & $\begin{array}{l}\text { Health Physics } \\
\text { Technician }\end{array}$ & $\mathrm{M}$ & $\mathrm{L}$ & $\mathrm{M}$ \\
\hline $\mathbf{2}$ & $\begin{array}{l}\text { Operations } \\
\text { Support }\end{array}$ & $\mathrm{M}$ & $\mathrm{L}$ & $\mathrm{M}$ \\
\hline $\mathbf{3}$ & $\begin{array}{l}\text { Shift } \\
\text { Supervisor }\end{array}$ & $\mathrm{L}$ & $\mathrm{H}$ & $\mathrm{M}$ \\
\hline $\mathbf{4}$ & Plant Manager & $\mathrm{L}$ & $\mathrm{M}$ & $\mathrm{M}$ \\
\hline $\mathbf{5}$ & $\begin{array}{l}\text { Machining } \\
\text { Operator }\end{array}$ & $\mathrm{L}$ & $\mathrm{L}$ & $\mathrm{M}$ \\
\hline
\end{tabular}

Degree of Access

\begin{tabular}{|c|l|l|l|l|}
\hline Ranking & Position & Routing Access & $\begin{array}{l}\text { Routing } \\
\text { Authority/Responsibility }\end{array}$ & Knowledge \\
\hline 1 & & & & \\
\hline 2 & & & & \\
\hline 3 & & & & \\
\hline 4 & & & & \\
\hline 5 & & & & \\
\hline
\end{tabular}




\section{Exercise 6a}

\section{Path Analysis - Sequence of Actions}

\section{Session Objectives:}

After the session the participants will be able to do the following:

1. Develop an insider adversary sequence of actions (path) that could be used to steal nuclear material.

2. Identify areas the adversary would have to cross to accomplish his objective.

3. List protection measures along the path that protects the target and might detect or delay the adversary actions.

\section{Estimated Time:}

50 minutes in subgroup

+10 minutes in large group discussion

60 Minutes total

\section{Exercises:}

1. Develop one path for each threat group to your assigned target. Describe the areas to be crossed and the adversary actions in the sequence. List all the existing protection measures (both technical and administrative) in place at each step in the sequence.

\section{Report Your Results in Large Group Discussion:}

Each subgroup will present their results for both paths to the class for input and discussion. 


\section{Exercise 1: Sequence of Actions and Measures to Protect Target}

Refer back to the prioritized target list (Subgroup Exercise 4) and insider threat group tables you created in the Advanced VA Overview course (Subgroup Exercise 9). Use your assigned target group for this exercise.

Instructions: For your assigned target -

- Task 1: Select two of the insider threat groups from your tables (Subgroup Exercise 9 from the VA Overview) and develop one path for each group to the target as explained below. Use the same target.

- Task 2: Develop each path by creating the sequence of actions and measures. To do this, list the areas to be crossed and the insider actions (how the areas are crossed), and record this information in Columns 2 and 3 of the Insider Path Analysis Worksheet.

- Task 3: Identify and list all the existing protection measures (both technical and administrative) in place at each step in the sequence. These are the measures the insider adversary must defeat to be successful. Record these measures in column 4 of the worksheet.

- Task 4: Repeat the above for your $2^{\text {nd }}$ insider threat group. Do not write in the other columns of the worksheet - these will be completed in the remaining subgroup exercises.

- Task 5: Choose one of the paths to present to the rest of the group during the class discussion on the exercise. Include the assigned target, threat group, path description, adversary actions, and protection measures in place when reporting your results to the class.

\section{Important Notes / hints:}

1. Continue on the backside of the paper if your paths have more steps than the 10 rows listed in the tables below.

2. It might be easier to fill out the tables below using a spreadsheet or word-processing program on your laptop computer. 


\begin{tabular}{|c|c|c|c|c|c|c|}
\hline \multicolumn{7}{|c|}{ Insider Path Analysis Worksheet: Path 1} \\
\hline \multicolumn{4}{|c|}{ Target: } & \multicolumn{3}{|l|}{ Insider Threat Group: } \\
\hline 蓄 & $\begin{array}{c}\text { Area } \\
\text { Crossed }\end{array}$ & Insider Actions & $\begin{array}{l}\text { Existing Protection Measures } \\
\text { (admin \& technical) }\end{array}$ & Possible Defeat Methods & \begin{tabular}{|c|} 
Likelihood \\
of Detection \\
(L, M, H)
\end{tabular} & $\begin{array}{c}\text { Time } \\
\text { Taken } \\
\text { (sec) }\end{array}$ \\
\hline \multirow[b]{2}{*}{1} & & & & & & \\
\hline & & & & & & \\
\hline & & & & & & \\
\hline & & & & & & \\
\hline \multirow[t]{2}{*}{2} & & & & & & \\
\hline & & & & & & \\
\hline & & & & & & \\
\hline \multirow{3}{*}{3} & & & & & & \\
\hline & & & & & & \\
\hline & & & & & & \\
\hline & & & & & & \\
\hline \multicolumn{7}{|l|}{4} \\
\hline & & & & & & \\
\hline & & & & & & \\
\hline \multirow{3}{*}{5} & & & & & & \\
\hline & & & & & & \\
\hline & & & & & & \\
\hline
\end{tabular}




\begin{tabular}{|c|c|c|c|c|c|c|}
\hline \multicolumn{7}{|c|}{ Insider Path Analysis Worksheet: Path 1} \\
\hline \multicolumn{4}{|c|}{ Target: } & \multicolumn{3}{|l|}{ Insider Threat Group: } \\
\hline 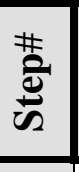 & $\begin{array}{c}\text { Area } \\
\text { Crossed } \\
\end{array}$ & Insider Actions & $\begin{array}{c}\text { Existing Protection Measures } \\
\text { (admin \& \& technical) }\end{array}$ & Possible Defeat Methods & \begin{tabular}{|c|}
$\begin{array}{l}\text { Likelihood } \\
\text { of Detection } \\
(\mathrm{L}, \mathrm{M}, \mathrm{H})\end{array}$ \\
\end{tabular} & $\begin{array}{l}\text { Time } \\
\text { Tiken } \\
\text { (sec) }\end{array}$ \\
\hline \multirow{2}{*}{6} & & & & & & \\
\hline & & & & & & \\
\hline & & & & & & \\
\hline \multirow{2}{*}{7} & & & & & 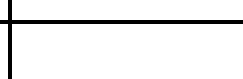 & \\
\hline & & & & & & \\
\hline & & & & & & \\
\hline \multirow{2}{*}{8} & & & & & & \\
\hline & & & & & & \\
\hline & & & & & & \\
\hline \multicolumn{7}{|l|}{9} \\
\hline & & & & & & \\
\hline & & & & & & \\
\hline 10 & & & & & & \\
\hline
\end{tabular}




\begin{tabular}{|c|c|c|c|c|c|c|}
\hline \multicolumn{7}{|c|}{ Insider Path Analysis Worksheet: Path 2} \\
\hline \multicolumn{4}{|c|}{ Target: } & \multicolumn{3}{|l|}{ Insider Threat Group: } \\
\hline 蓄 & $\begin{array}{c}\text { Area } \\
\text { Crossed }\end{array}$ & Insider Actions & $\begin{array}{l}\text { Existing Protection Measures } \\
\text { (admin \& technical) }\end{array}$ & Possible Defeat Methods & \begin{tabular}{|c|} 
Likelihood \\
of Detection \\
(L, M, H)
\end{tabular} & $\begin{array}{c}\text { Time } \\
\text { Taken } \\
\text { (sec) }\end{array}$ \\
\hline \multirow[b]{2}{*}{1} & & & & & & \\
\hline & & & & & & \\
\hline & & & & & & \\
\hline & & & & & & \\
\hline \multirow[t]{2}{*}{2} & & & & & & \\
\hline & & & & & & \\
\hline & & & & & & \\
\hline \multirow{3}{*}{3} & & & & & & \\
\hline & & & & & & \\
\hline & & & & & & \\
\hline & & & & & & \\
\hline \multicolumn{7}{|l|}{4} \\
\hline & & & & & & \\
\hline & & & & & & \\
\hline \multirow{3}{*}{5} & & & & & & \\
\hline & & & & & & \\
\hline & & & & & & \\
\hline
\end{tabular}




\begin{tabular}{|c|c|c|c|c|c|c|}
\hline \multicolumn{7}{|c|}{ Insider Path Analysis Worksheet: Path 2} \\
\hline \multicolumn{4}{|c|}{ Target: } & \multicolumn{3}{|l|}{ Insider Threat Group: } \\
\hline 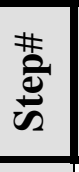 & $\begin{array}{c}\text { Area } \\
\text { Crossed } \\
\end{array}$ & Insider Actions & $\begin{array}{c}\text { Existing Protection Measures } \\
\text { (admin \& \& technical) }\end{array}$ & Possible Defeat Methods & \begin{tabular}{|c|}
$\begin{array}{l}\text { Likelihood } \\
\text { of Detection } \\
(\mathrm{L}, \mathrm{M}, \mathrm{H})\end{array}$ \\
\end{tabular} & $\begin{array}{l}\text { Time } \\
\text { Tiken } \\
\text { (sec) }\end{array}$ \\
\hline \multirow{2}{*}{6} & & & & & & \\
\hline & & & & & & \\
\hline & & & & & & \\
\hline \multirow{2}{*}{7} & & & & & & \\
\hline & & & & & & \\
\hline & & & & & & \\
\hline \multirow{2}{*}{8} & & & & & & \\
\hline & & & & & & \\
\hline & & & & & & \\
\hline \multicolumn{7}{|l|}{9} \\
\hline & & & & & & \\
\hline & & & & & & \\
\hline 10 & & & & & & \\
\hline
\end{tabular}




\section{Subgroup Exercise 6b}

\section{Path Analysis - Characterize Protection Measures}

\section{Session Objectives}

After the session the participants will be able to do the following:

1. List potential defeat methods for various measures along an adversary action sequence.

2. Estimate the detection likelihood for each protection measure in the sequence.

3. Estimate the time it would take an adversary to defeat each protection measure

\section{Estimated Time:}

50 minutes in subgroup

+10 minutes in large group discussion

60 Minutes total

\section{Exercises:}

1. Continue to evaluate your paths from the previous exercise for each threat group and your assigned target. List potential defeat methods, likelihood of detection, and time taken at each step in the action sequence.

\section{Report Your Results in Large Group Discussion:}

Each subgroup will present their results for one of their paths to the class for input and discussion. 


\section{Exercise 1: Characterize Protection Measures}

Note: In this exercise the protection measures are characterized using your professional judgment to estimate the likelihood of detection and time taken to defeat each protection measure in each step of the action sequence.

Instructions: For your target and insider threat groups, return to the Insider Path Analysis Worksheet from previous Subgroup Exercise and continue to evaluate the sequence of actions and measures for both insider threat groups. Consider credible defeat methods, likelihood of detection, and time taken at each step in the sequence.

- Task 1: Discuss and list possible defeat methods for each protection measure, and record them in column 5 of the worksheet. You might be able to think of more than one defeat method per protection measure. List all that you think are credible.

- Task 2: Estimate the likelihood of detection for each defeat method you listed in Task 1, for the selected insider group. Use your best judgment to come to agreement on the likelihood of detection. Record it in column 6.

- Task 3: Estimate the time taken at each step for the adversary to complete the action (crossing the area and defeating the protection measure, for each defeat method), and record this in column 7 .

- $\quad$ Task 4: Repeat the above tasks for your $2^{\text {nd }}$ insider group.

- Task 5: Be prepared to present your results for one of the insider groups during the class discussion on the exercise. This time, focus on the defeat methods, likelihood of detection, and time taken (delay) at each step when presenting your results.

Note: Slides from the lecture show an example of how to complete the tables. Continue on the backside of the paper if your paths have more steps than the 10 listed in the worksheet.

Note: It might be easier to fill out the tables using a spreadsheet or word-processing program on your laptop computer. 


\section{Exercise 7}

\section{Scenario Development}

\section{Session Objectives:}

After the session the participants will be able to do the following:

1. Review an adversary sequence of actions (including methods, likelihood of detection, and time) to determine the most vulnerable paths.

2. Select protection measures in the sequence that are most advantageous to the insider

3. Develop vulnerable paths that are credible, use consistent tactics, and take advantage of protection measure weaknesses.

\section{Estimated Time:}

50 minutes in subgroups

+10 minutes for large group discussion

60 minutes total

\section{Exercises:}

1. Choose three most vulnerable paths from each action sequence, by choosing protection measures most advantageous to the adversary as discussed in the lecture.

\section{Report Your Results in Large Group Discussion:}

Each subgroup will briefly ( $\approx 4$ minutes) present one of their most vulnerable paths to the large group for input and discussion. 


\section{Exercise 1: Develop Three Most Vulnerable Paths (MVPs)}

Instructions: Return to the Insider Path Analysis Worksheet from the previous exercise (you created one worksheet for each of your insider threat groups). Develop the three most vulnerable paths by doing the following:

- Task 1: In each step of the action sequence, and for each protection measure that must be defeated, select the defeat method with the most advantage to the adversary. Consider the adversary's capabilities, the detection likelihood, and the time it takes to defeat the protection measure(s).

o Mark the measures and defeat methods you selected on the tables perhaps with a star, or by circling the measure.

o It is recommended that you use a different color for each path, when selecting protection measures to defeat.

- Task 2: Repeat Task 1 until you have what you consider to be the three most vulnerable paths. Record each of these three most vulnerable paths on the "Most Vulnerable Path" tables provided on the following pages. An example from the lecture has been repeated here for you.

\begin{tabular}{|c|l|l|l|}
\hline \multicolumn{4}{|c|}{ Sample Path Worksheet (Example 2 from the Lecture) } \\
\hline Step & \multicolumn{1}{|c|}{ Insider Action } & \multicolumn{1}{|c|}{$\begin{array}{c}\text { Detection } \\
\text { (L, M, H) }\end{array}$} & $\begin{array}{c}\text { Delay (time } \\
\text { taken) }\end{array}$ \\
\hline 1 & Enter protected area normally & Zero & N/A \\
\hline 2 & Enter bunker normally & Zero & N/A \\
\hline 3 & Take package and hide under coat & High & 60 \\
\hline 4 & Walk out of bunker normally & High & 60 \\
\hline 5 & $\begin{array}{l}\text { Walk normally to fence and throw } \\
\text { package over }\end{array}$ & Medium & 30 \\
\hline
\end{tabular}

- Task 3: Repeat Tasks 1 and 2 for your second insider group (or second Path Analysis Worksheet). You should end up with a total of 6 most vulnerable paths; three paths for each of two insider threat groups.

- Task 4: Present one of your most vulnerable paths to the class for discussion. 


\begin{tabular}{|c|c|c|c|}
\hline \multirow[t]{2}{*}{ Target } & \multicolumn{3}{|c|}{ Threat Group: } \\
\hline & \multicolumn{3}{|c|}{ Most Vulnerable Path 1} \\
\hline Step & Insider Actions (Measures defeated and how) & $\begin{array}{c}\text { Likelihood of } \\
\text { Detection }\end{array}$ & $\begin{array}{c}\text { Delay or time } \\
\text { taken (Sec) }\end{array}$ \\
\hline 1. & & & \\
\hline 2. & & & \\
\hline 3. & & & \\
\hline 4. & & & \\
\hline 5. & & & \\
\hline 6. & & & \\
\hline 7. & & & \\
\hline 8. & & & \\
\hline 9. & & & \\
\hline
\end{tabular}

\begin{tabular}{|c|c|c|c|}
\hline \multirow[t]{2}{*}{ Target: } & \multicolumn{3}{|c|}{ Threat Group: } \\
\hline & \multicolumn{3}{|l|}{ Most Vulnerable Path 2} \\
\hline Step & Insider Actions (Measures defeated and how) & \begin{tabular}{|c} 
Likelihood of \\
Detection
\end{tabular} & \begin{tabular}{|c|}
$\begin{array}{c}\text { Delay or time } \\
\text { taken (Sec) }\end{array}$ \\
\end{tabular} \\
\hline 1. & & & \\
\hline 2. & & & \\
\hline 3. & & & \\
\hline 4. & & & \\
\hline 5. & & & \\
\hline 6. & & & \\
\hline 7. & & & \\
\hline 8. & & & \\
\hline 9. & & & \\
\hline
\end{tabular}




\begin{tabular}{|c|c|c|c|}
\hline \multirow[t]{2}{*}{ Target } & \multicolumn{3}{|c|}{ Threat Group: } \\
\hline & \multicolumn{3}{|c|}{ Most Vulnerable Path 3} \\
\hline Step & Insider Actions (Measures defeated and how) & $\begin{array}{c}\text { Likelihood of } \\
\text { Detection }\end{array}$ & $\begin{array}{c}\text { Delay or time } \\
\text { taken (Sec) }\end{array}$ \\
\hline 1. & & & \\
\hline 2. & & & \\
\hline 3. & & & \\
\hline 4. & & & \\
\hline 5. & & & \\
\hline 6. & & & \\
\hline 7. & & & \\
\hline 8. & & & \\
\hline 9. & & & \\
\hline
\end{tabular}




\begin{tabular}{|c|c|c|c|}
\hline \multirow[t]{2}{*}{ Target } & \multicolumn{3}{|c|}{ Threat Group: } \\
\hline & \multicolumn{3}{|c|}{ Most Vulnerable Path 1} \\
\hline Step & Insider Actions (Measures defeated and how) & $\begin{array}{c}\text { Likelihood of } \\
\text { Detection }\end{array}$ & $\begin{array}{l}\text { Delay or time } \\
\text { taken (Sec) }\end{array}$ \\
\hline 1. & & & \\
\hline 2. & & & \\
\hline 3. & & & \\
\hline 4. & & & \\
\hline 5. & & & \\
\hline 6. & & & \\
\hline 7. & & & \\
\hline 8. & & & \\
\hline 9. & & & \\
\hline
\end{tabular}

\begin{tabular}{|c|c|c|c|}
\hline \multirow[t]{2}{*}{ Target: } & \multicolumn{3}{|c|}{ Threat Group: } \\
\hline & \multicolumn{3}{|l|}{ Most Vulnerable Path 2} \\
\hline Step & Insider Actions (Measures defeated and how) & \begin{tabular}{|c} 
Likelihood of \\
Detection
\end{tabular} & \begin{tabular}{|c|}
$\begin{array}{c}\text { Delay or time } \\
\text { taken (Sec) }\end{array}$ \\
\end{tabular} \\
\hline 1. & & & \\
\hline 2. & & & \\
\hline 3. & & & \\
\hline 4. & & & \\
\hline 5. & & & \\
\hline 6. & & & \\
\hline 7. & & & \\
\hline 8. & & & \\
\hline 9. & & & \\
\hline
\end{tabular}




\begin{tabular}{|c|c|c|c|}
\hline \multirow[t]{2}{*}{ Target } & \multicolumn{3}{|c|}{ Threat Group: } \\
\hline & \multicolumn{3}{|c|}{ Most Vulnerable Path 3} \\
\hline Step & Insider Actions (Measures defeated and how) & $\begin{array}{c}\text { Likelihood of } \\
\text { Detection }\end{array}$ & $\begin{array}{l}\text { Delay or time } \\
\text { taken (Sec) }\end{array}$ \\
\hline 1. & & & \\
\hline 2. & & & \\
\hline 3. & & & \\
\hline 4. & & & \\
\hline 5. & & & \\
\hline 6. & & & \\
\hline 7. & & & \\
\hline 8. & & & \\
\hline 9. & & & \\
\hline
\end{tabular}




\section{Exercise 8}

\section{Evaluate Scenarios}

\section{Session Objectives:}

After the session the participants will be able to do the following:

1. Analyze the response to the insider threat and determine its characteristics and effectiveness

2. Develop and analyze a Path Event Timeline for the most vulnerable paths

3. Determine the critical detection point and likelihood of interrupting the insider for these paths

4. Derive $P_{E}$ for the most vulnerable paths

5. Consider credible scenarios in which an active non-violent insider could degrade the system $\left(\mathrm{P}_{\mathrm{I}}\right.$ or $\left.\mathrm{P}_{\mathrm{N}}\right)$ even further

6. Calculate values for $\mathrm{P}_{\mathrm{E}}$ based on these worst case scenarios.

\section{Estimated Time:}

50 minutes in Subgroup

+10 minutes in discussion

60 minutes

\section{Exercises:}

1. Select any three 3 of your most vulnerable paths from the previous exercise. Determine the response type, time taken for the response, and ability of that response to stop the adversary.

2. Complete a path event timeline for each of these three most vulnerable paths.

3. Derive $P_{E}$ for all three most vulnerable paths, yielding 3 potential worst case scenarios.

\section{Report Your Results in Large Group Discussion:}

Note: Each subgroup will briefly present one of their most vulnerable paths to the class for input and discussion. 


\section{Exercise 1: Determining Effectiveness of the Response}

Instructions: Select 3 of your most vulnerable paths (MVPs) from the previous exercise (it may be easier if you select all 3 from one insider threat group and target combination) to work with for this exercise. Review the hypothetical facility description for the types of response groups located in the URF.

- Task 1: Determine in your subgroup the type of response you will use in your analysis for these most vulnerable paths, and the characteristics of that response (who, what, where, how, training and capabilities, etc). Record this in formation in Table 1: Response Characteristics. Record any assumptions you make about your response group.

- Task 2: Determine how long it will take to respond and the ability of the response to stop the adversary. Again, base this off of the information contained in the URF about your responders. If you need to make any assumptions, do so and record them in Table 1.

\section{Table 1: Response Characteristics}

\begin{tabular}{|l|l|l|}
\hline Response Type: & Insider Threat Group: \\
\hline
\end{tabular}

Response Characteristics (describe your responders in terms of training, capabilities, response strategy, deployment locations, etc):

\section{Assumptions:}

\section{Response Time:}

Ability to Stop Adversary: 


\section{Exercise 2: Complete a Path Event Timeline for the Three Most Vulnerable Paths}

- Task 1: Complete Table 3: Path Event Timeline for all three most vulnerable paths. See lecture slides for an example of how this is done. Completing the timeline will allow you to determine the

1. Critical detection point (CDP) for the path

2. Time remaining after interruption at each stage in the timeline

3. Cumulative "qualitative" probability of detection (assuming a CDP exists on your path)

When determining the time remaining after detection, start at the end of the timeline and work backwards to the beginning of the action sequence. Continue using qualitative values for likelihood of detection, and determine where the detection will most likely occur (beginning, middle, or end) within each step.

Note: In this exercise we rearranged the vertical action sequence/path to a horizontal timeline structure, but the actions steps remain the same. You may have more or less than the number of steps shown in the table.

- Task 2: Answer the questions listed on the page after each path event timeline. Table 2 below may help you determine cumulative likelihoods of detection.

\begin{tabular}{|c|c|}
\hline \multicolumn{2}{|c|}{$\begin{array}{c}\text { Table 2: Suggested Simple Rules For } \\
\text { Deriving Cumulative Likelihood }\end{array}$} \\
\hline Measures in Sequence & Cumulative Likelihood \\
\hline VL \& VL & VL \\
\hline VL \& VL \& VL & L \\
\hline VL \& L & L \\
\hline VL \& VL \& L & L \\
\hline L \& L & M \\
\hline L \& L \& L & M \\
\hline L \& M & M \\
\hline L \& L \& M & H \\
\hline M \& M & H \\
\hline L \& H & H \\
\hline M \& H & H \\
\hline M \& M \& H & VH \\
\hline H \& H & VH \\
\hline
\end{tabular}




\begin{tabular}{|c|c|c|c|c|c|c|c|c|c|c|}
\hline \multirow{2}{*}{ Begin Action } & \multicolumn{9}{|c|}{ Table 3: Path Event Timeline - Most Vulnerable Path 3} & \multirow{2}{*}{ End Action } \\
\hline & Target: & & & & Insider & Gro & & & & \\
\hline Action or Step & 1. & 2. & 3. & 4. & 5. & 6. & 7. & 8. & 9. & 10. \\
\hline Task Delay & & & & & & & & & & \\
\hline $\begin{array}{l}\text { Point of } \\
\text { Detection } \\
\text { (B, M, E) }\end{array}$ & & & & & & & & & & \\
\hline $\begin{array}{l}\text { Likelihood of } \\
\text { Detection } \\
\text { (L, M, H) }\end{array}$ & & & & & & & & & & \\
\hline $\begin{array}{c}\text { Time } \\
\text { remaining after } \\
\text { detection, at } \\
\text { this step? }\end{array}$ & & & & & & & & & & \\
\hline $\begin{array}{l}\text { Timely } \\
\text { Detection? } \\
\text { (Y or N) }\end{array}$ & & & & & & & & & & \\
\hline
\end{tabular}

1. CDP: Where is the critical detection point in this path? Indicate it on the timeline above.

2. Accumulate the qualitative likelihoods of detection (up to and including the CDP) using Table 2.

3. Translate your qualitative $P_{I}$ value into a quantitative value (by using the suggested scale in Table 2 above): 


\begin{tabular}{|c|c|c|c|c|c|c|c|c|c|c|}
\hline \multirow{2}{*}{ Begin Action } & \multicolumn{9}{|c|}{ Table 3: Path Event Timeline - Most Vulnerable Path 3} & \multirow{2}{*}{ End Action } \\
\hline & Target: & & & & Insider & irc & & & & \\
\hline \begin{tabular}{|l|} 
Action or Step \\
\end{tabular} & 1. & 2. & 3. & 4. & 5. & 6. & 7. & 8. & 9. & 10. \\
\hline Task Delay & & & & & & & & & & \\
\hline $\begin{array}{l}\text { Point of } \\
\text { Detection } \\
(B, M, E)\end{array}$ & & & & & & & & & & \\
\hline $\begin{array}{l}\text { Likelihood of } \\
\text { Detection } \\
\text { (L, M, H) }\end{array}$ & & & & & & & & & & \\
\hline $\begin{array}{l}\text { Time } \\
\text { remaining after } \\
\text { detection, at } \\
\text { this step? }\end{array}$ & & & & & & & & & & \\
\hline $\begin{array}{l}\text { Timely } \\
\text { Detection? } \\
\text { (Y or N) }\end{array}$ & & & & & & & & & & \\
\hline
\end{tabular}

1. CDP: Where is the critical detection point in this path? Indicate it on the timeline above.

2. Accumulate the qualitative likelihoods of detection (up to and including the CDP) using Table 2 .

3. Translate your qualitative $P_{I}$ value into a quantitative value (by using the suggested scale in Table 2 above): 


\begin{tabular}{|c|c|c|c|c|c|c|c|c|c|c|}
\hline \multirow{2}{*}{ Begin Action } & \multicolumn{9}{|c|}{ Table 3: Path Event Timeline - Most Vulnerable Path 3} & \multirow{2}{*}{ End Action } \\
\hline & Target: & & & & Insider & irc & & & & \\
\hline \begin{tabular}{|l|} 
Action or Step \\
\end{tabular} & 1. & 2. & 3. & 4. & 5. & 6. & 7. & 8. & 9. & 10. \\
\hline Task Delay & & & & & & & & & & \\
\hline $\begin{array}{l}\text { Point of } \\
\text { Detection } \\
\text { (B, M, E) }\end{array}$ & & & & & & & & & & \\
\hline $\begin{array}{l}\text { Likelihood of } \\
\text { Detection } \\
\text { (L, M, H) }\end{array}$ & & & & & & & & & & \\
\hline $\begin{array}{l}\text { Time } \\
\text { remaining after } \\
\text { detection, at } \\
\text { this step? }\end{array}$ & & & & & & & & & & \\
\hline $\begin{array}{l}\text { Timely } \\
\text { Detection? } \\
\text { (Y or N) }\end{array}$ & & & & & & & & & & \\
\hline
\end{tabular}

1. CDP: Where is the critical detection point in this path? Indicate it on the timeline above.

2. Accumulate the qualitative likelihoods of detection (up to and including the CDP) using Table 2 .

3. Translate your qualitative $P_{I}$ value into a quantitative value (by using the suggested scale in Table 2 above): 


\section{Exercise 3: Derive $P_{E}$ for 3 Most Vulnerable Paths}

Task 1: Calculate $P_{E}$ for each path. Assume that $P_{N}$ is 1.0, as we are assuming that our insider threat group is active, but "non-violent". (If your insider threat group is violent, use a $\mathrm{P}_{\mathrm{N}}$ value that is less than 1.0). Remember, $\mathrm{P}_{\mathrm{E}}=\mathrm{P}_{\mathrm{I}} \times \mathrm{P}_{\mathrm{N}}$.

\begin{tabular}{|c|c|c|c|}
\hline $\begin{array}{c}\text { Most Vulnerable } \\
\text { Path \# }\end{array}$ & $\begin{array}{c}\text { Probability of } \\
\text { Interruption (P) }\end{array}$ & $\begin{array}{c}\text { Probability of } \\
\text { Neutralization }\left(\mathbf{P}_{\mathbf{N}}\right)\end{array}$ & $\begin{array}{c}\text { System } \\
\text { Effectiveness }\left(\mathbf{P}_{\mathbf{E}}\right)\end{array}$ \\
\hline 1. & & 1.0 & \\
\hline 2. & & 1.0 & \\
\hline 3. & & 1.0 & \\
\hline
\end{tabular}

Task 2: These paths might not be the worst case scenarios. Discuss in your group how the adversary can make the situation along the path even worse for our hypothetical facility (by reducing $\mathrm{P}_{\mathrm{I}}$ or $\mathrm{P}_{\mathrm{N}}$ ), by answering the questions below.

\begin{tabular}{|c|c|c|}
\hline Question: & Sub Group Answer: & $\begin{array}{l}\text { Path \#'s where } \\
\text { this is credible }\end{array}$ \\
\hline $\begin{array}{l}\text { 1. Can the insider take } \\
\text { advantage of an } \\
\text { emergency situation } \\
\text { (fire alarm, criticality } \\
\text { alarm, etc)? How? }\end{array}$ & & \\
\hline $\begin{array}{l}\text { 2. Can the insider } \\
\text { prevent alarms from } \\
\text { being generated or } \\
\text { communicated? } \\
\text { How? }\end{array}$ & & \\
\hline $\begin{array}{l}\text { 3. Can the insider divert } \\
\text { your response force? } \\
\text { How? }\end{array}$ & & \\
\hline $\begin{array}{l}\text { 4. Can the insider delay } \\
\text { the response in } \\
\text { anyway? How? }\end{array}$ & & \\
\hline $\begin{array}{l}\text { 5. What else might an } \\
\text { active, non-violent } \\
\text { insider do to reduce } \\
\mathrm{P}_{\mathrm{I}} \text { or } \mathrm{P}_{\mathrm{N}} \text { ? }\end{array}$ & & \\
\hline
\end{tabular}


Task 3: Using your responses from Task 2 above, estimate new quantitative values of $\mathrm{P}_{\mathrm{I}}$ and/or $\mathrm{P}_{\mathrm{N}}$ (that is, how much can the insider degrade $\mathrm{P}_{\mathrm{I}}$ or $\mathrm{P}_{\mathrm{N}}$ ?) for those paths where the adversary can credibly do so, as you discussed in your group. Recalculate $\mathrm{P}_{\mathrm{E}}$. These are the worst case paths.

\begin{tabular}{|c|c|c|c|}
\hline $\begin{array}{c}\text { Most Vulnerable } \\
\text { Path \# }\end{array}$ & $\begin{array}{c}\text { Probability of } \\
\text { Interruption }\left(\mathbf{P}_{\mathbf{I}}\right)\end{array}$ & $\begin{array}{c}\text { Probability of } \\
\text { Neutralization }\left(\mathbf{P}_{\mathbf{N}}\right)\end{array}$ & $\begin{array}{c}\text { Worst Case System } \\
\text { Effectiveness }\left(\mathbf{P}_{\mathbf{E}}\right)\end{array}$ \\
\hline 1. & & & \\
\hline 2. & & & \\
\hline 3. & & & \\
\hline
\end{tabular}




\section{Exercise 10}

\section{Upgrades Analysis}

\section{Session Objectives:}

After the session the participants will be able to do the following:

1. Analyze the response to the insider threat and determine its characteristics and effectiveness after upgrades have been applied

2. Revise and analyze a Path Event Timeline for one of the previous 3 identified most vulnerable paths

3. Determine the new critical detection point and likelihood of interrupting the insider for the path

4. Derive $\mathrm{P}_{\mathrm{E}}$ for the selected path

5. Use the previously developed base-line credible scenarios in which an active non-violent insider could degrade the system $\left(\mathrm{P}_{\mathrm{I}}\right.$ or $\left.\mathrm{P}_{\mathrm{N}}\right)$ even further

6. Calculate values for $\mathrm{P}_{\mathrm{E}}$ based on these worst case scenarios.

\section{Estimated Time:}

50 minutes in Subgroup

+10 minutes in discussion

60 minutes

\section{Exercises:}

1. Select one (1) of the three 3 (1) most vulnerable paths from the previous exercise.

2. Apply selected upgrades along the path.

3. Determine the new response type, time taken for the response, and ability of that response to stop the adversary.

4. Complete a revised path event timeline for the selected path.

5. Derive $\mathrm{P}_{\mathrm{E}}$ for the path, yielding a new scenario and time-line.

[Note: As we are only revising one of the initial three worst case path, the one chosen for revision may not be the worst case]

\section{Report Your Results in Large Group Discussion:}

Each subgroup will briefly present the upgrades selected, the reason for selecting the upgrades and the result the upgrades had on overall risk to the class for input and discussion. 


\section{Exercise 1: Determining Effectiveness of the Response}

Instructions: Select 1 most vulnerable path (MVPs) from the previous exercise to work with for this exercise. Review the hypothetical facility description for the types of response groups located in the URF.

- Task 1: Determine in your subgroup the type of response you will use in your analysis for the selected path, and the characteristics of that response (who, what, where, how, training and capabilities, etc). Record this in formation in Table 1: Response Characteristics. Record any assumptions you make about your response group.

- Task 2: Determine how long it will take to respond and the ability of the response to stop the adversary. Again, base this off of the information contained in the URF about your responders. If you need to make any assumptions, do so and record them in Table 1.

\section{Table 1: Response Characteristics}

\begin{tabular}{|l|l|l|}
\hline Response Type: & Insider Threat Group: \\
\hline
\end{tabular}

Response Characteristics (describe your responders in terms of training, capabilities, response strategy, deployment locations, etc):

\section{Assumptions:}

\section{Response Time:}

Ability to Stop Adversary: 


\section{Exercise 2: Revise Path Event Timeline for the Selected Path}

- Task 1: Complete Table 3: Path Event Timeline for the selected path. See lecture slides for an example of how this is done. Completing the timeline will allow you to determine the

1. Critical detection point (CDP) for the path

2. Time remaining after interruption at each stage in the timeline

3. Cumulative "qualitative" probability of detection (assuming a CDP exists on your path)

When determining the time remaining after detection, start at the end of the timeline and work backwards to the beginning of the action sequence. Continue using qualitative values for likelihood of detection, and determine where the detection will most likely occur (beginning, middle, or end) within each step.

Note: In this exercise we rearranged the vertical action sequence/path to a horizontal timeline structure, but the actions steps remain the same. You may have more or less than the number of steps shown in the table.

- Task 2: Answer the questions listed on the page after each path event timeline. Table 2 below may help you determine cumulative likelihoods of detection.

\begin{tabular}{|c|c|}
\hline \multicolumn{2}{|c|}{$\begin{array}{c}\text { Table 2: Suggested Simple Rules For } \\
\text { Deriving Cumulative Likelihood }\end{array}$} \\
\hline Measures in Sequence & Cumulative Likelihood \\
\hline VL \& VL & VL \\
\hline VL \& VL \& VL & L \\
\hline VL \& L & L \\
\hline VL \& VL \& L & L \\
\hline L \& L & M \\
\hline L \& L \& L & M \\
\hline L \& M & H \\
\hline L \& L \& M & H \\
\hline M \& M & H \\
\hline L \& H & H \\
\hline M \& H & VH \\
\hline M \& M \& H & VH \\
\hline H \& H & \\
\hline \hline
\end{tabular}




\begin{tabular}{|c|c|c|c|c|c|c|c|c|c|c|}
\hline \multirow{3}{*}{\begin{tabular}{|c|} 
Begin Action \\
Action or Step \\
\end{tabular}} & \multicolumn{9}{|c|}{ Table 3: Path Event Timeline - Most Vulnerable Path } & \multirow{2}{*}{ End Action } \\
\hline & Target: & & & & Insider & Gro & & & & \\
\hline & 1. & 2. & 3. & 4. & 5. & 6. & 7. & 8. & 9. & 10. \\
\hline Task Delay & & & & & & & & & & \\
\hline $\begin{array}{l}\text { Point of } \\
\text { Detection } \\
\text { (B, M, E) }\end{array}$ & & & & & & & & & & \\
\hline $\begin{array}{l}\text { Likelihood of } \\
\text { Detection } \\
\text { (L, M, H) }\end{array}$ & & & & & & & & & & \\
\hline $\begin{array}{c}\text { Time } \\
\text { remaining after } \\
\text { detection, at } \\
\text { this step? }\end{array}$ & & & & & & & & & & \\
\hline $\begin{array}{l}\text { Timely } \\
\text { Detection? } \\
\text { (Y or N) }\end{array}$ & & & & & & & & & & \\
\hline
\end{tabular}

1. CDP: Where is the critical detection point in this path? Indicate it on the timeline above.

2. Accumulate the qualitative likelihoods of detection (up to and including the CDP) using Table 2.

3. Translate your qualitative $P_{I}$ value into a quantitative value (by using the suggested scale in Table 2 above): 


\section{Exercise 3: Derive $\mathbf{P}_{\mathrm{E}}$ for The selected Most Vulnerable Path}

Task 1: Calculate $P_{E}$ for the path. Assume that $P_{N}$ is 1.0, as we are assuming that our insider threat group is active, but "non-violent". (If your insider threat group is violent, use a $\mathrm{P}_{\mathrm{N}}$ value that is less than 1.0). Remember, $\mathrm{P}_{\mathrm{E}}=\mathrm{P}_{\mathrm{I}} \times \mathrm{P}_{\mathrm{N}}$.

\begin{tabular}{|c|c|c|c|}
\hline $\begin{array}{c}\text { Most Vulnerable } \\
\text { Path \# }\end{array}$ & $\begin{array}{c}\text { Probability of } \\
\text { Interruption (P) }\end{array}$ & $\begin{array}{c}\text { Probability of } \\
\text { Neutralization }\left(\mathbf{P}_{\mathbf{N}}\right)\end{array}$ & $\begin{array}{c}\text { System } \\
\text { Effectiveness }\left(\mathbf{P}_{\mathbf{E}}\right)\end{array}$ \\
\hline 1. & & 1.0 & \\
\hline 2. & & 1.0 & \\
\hline 3. & & 1.0 & \\
\hline
\end{tabular}

Task 2: This path might not be the worst case scenario. Discuss in your group how the adversary can make the situation along the path even worse for our hypothetical facility (by reducing $\mathrm{P}_{\mathrm{I}}$ or $\mathrm{P}_{\mathrm{N}}$ ), by answering the questions below.

\begin{tabular}{|c|c|c|}
\hline Question: & Sub Group Answer: & $\begin{array}{l}\text { Path \#'s where } \\
\text { this is credible }\end{array}$ \\
\hline $\begin{array}{l}\text { 1. Can the insider take } \\
\text { advantage of an } \\
\text { emergency situation } \\
\text { (fire alarm, criticality } \\
\text { alarm, etc)? How? }\end{array}$ & & \\
\hline $\begin{array}{l}\text { 2. Can the insider } \\
\text { prevent alarms from } \\
\text { being generated or } \\
\text { communicated? } \\
\text { How? }\end{array}$ & & \\
\hline $\begin{array}{l}\text { 3. Can the insider divert } \\
\text { your response force? } \\
\text { How? }\end{array}$ & & \\
\hline $\begin{array}{l}\text { 4. Can the insider delay } \\
\text { the response in } \\
\text { anyway? How? }\end{array}$ & & \\
\hline $\begin{array}{l}\text { 5. What else might an } \\
\text { active, non-violent } \\
\text { insider do to reduce } \\
\mathrm{P}_{\mathrm{I}} \text { or } \mathrm{P}_{\mathrm{N}} \text { ? }\end{array}$ & & \\
\hline
\end{tabular}


Task 3: Using your responses from Task 2 above, estimate new quantitative values of $\mathrm{P}_{\mathrm{I}}$ and/or $\mathrm{P}_{\mathrm{N}}$ (that is, how much can the insider degrade $\mathrm{P}_{\mathrm{I}}$ or $\mathrm{P}_{\mathrm{N}}$ ?) for those paths where the adversary can credibly do so, as you discussed in your group. Recalculate $\mathrm{P}_{\mathrm{E}}$. This is the upgraded path. Compare the results with your base-line case.

\section{Upgrade Results}

\begin{tabular}{|c|c|c|c|}
\hline $\begin{array}{c}\text { Most Vulnerable } \\
\text { Path \# }\end{array}$ & $\begin{array}{c}\text { Probability of } \\
\text { Interruption }\left(\mathbf{P}_{\mathrm{I}}\right)\end{array}$ & $\begin{array}{c}\text { Probability of } \\
\text { Neutralization }\left(\mathbf{P}_{\mathrm{N}}\right)\end{array}$ & $\begin{array}{c}\text { Worst Case System } \\
\text { Effectiveness }\left(\mathbf{P}_{\mathrm{E}}\right)\end{array}$ \\
\hline 1. & & & \\
\hline
\end{tabular}

Base-line Results

\begin{tabular}{|c|c|c|c|}
\hline $\begin{array}{c}\text { Most Vulnerable } \\
\text { Path \# }\end{array}$ & $\begin{array}{c}\text { Probability of } \\
\text { Interruption (P) }\end{array}$ & $\begin{array}{c}\text { Probability of } \\
\text { Neutralization }\left(\mathbf{P}_{\mathbf{N}}\right)\end{array}$ & $\begin{array}{c}\text { Worst Case System } \\
\text { Effectiveness }\left(\mathbf{P}_{\mathbf{E}}\right)\end{array}$ \\
\hline 1. & & & \\
\hline
\end{tabular}

Task 4: Present results to large group.

\begin{tabular}{|l|l|l|l|}
\hline Upgrade Selected & Reason for Selection & Effect & Overall Result \\
\hline & & & \\
\hline & & & \\
\hline
\end{tabular}

